\title{
Sustainability, environmental economics, welfare
}

SÁNDOR KEREKES - ZSUZSANNA MARJAINÉ SZERÉNYI - TAMÁS KOCSIS
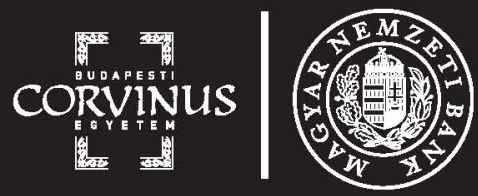


\section{Sustainability, environmental economics, welfare}




\title{
$\overline{\text { GEO }}$
}

\section{Corvinus Geographia, Geopolitica, Geooeconomia}

\author{
Book series of
}

Institute of Economic Geography, Geoeconomy and Sustainable Development CUB

Series editors: László Jeney - Márton Péti - Géza Salamin

ISSN 2560-1784 
Sándor Kerekes

Zsuzsanna Marjainé Szerényi

Tamás Kocsis

\section{Sustainability, environmental economics, welfare}

Foreword by John Morelli, professor emeritus,

Rochester Institute of Technology

Corvinus University of Budapest 
Translated by Attila Kovács and Gábor Csizmadia

Professional proof-reader: John Morelli

English language proof-reader: Simon Milton

Publishing coordinator:

Krisztina Székely

Chapters 4, 5, 6 were supported by the

National Research, Development and Innovation Office-NKFIH(\#120183)

ISBN 978-963-503-707-0

ISBN 978-963-503-711-7 (e-book)

"This book was published according to the cooperation agreement between Corvinus University of Budapest and The Magyar Nemzeti Bank."
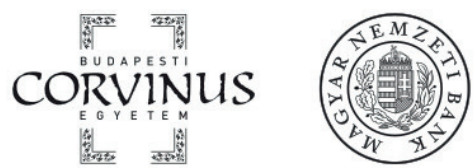

\section{Publisher: Corvinus University of Budapest}

Printed: Komáromi Printing and Publishing LTD

Leader in charge: Ferenc János Kovács executive director 


\section{CONTENTS}

Foreword by John Morelli ...........................................................................

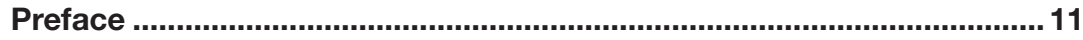

From Rachel Carson to the Club of Rome ………................................ 11

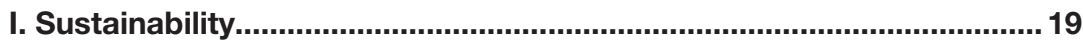

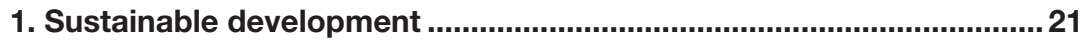

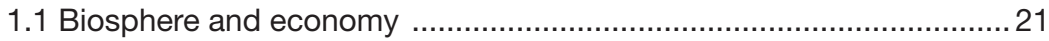

1.2 The concept of sustainable development........................................26

1.3 The principles of sustainable development .......................................29

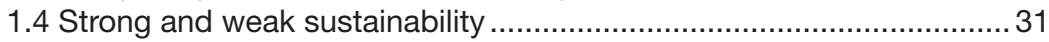

2. The background to environmental problems from the perspective of natural sciences ...............................................36

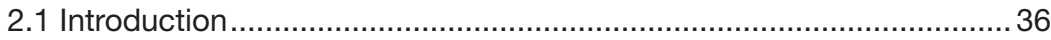

2.2 Problems concerning the atmosphere............................................... 36

2.2.1 Global warming (climate change) .............................................. 37

2.2.2 Ozone depletion................................................................ 38

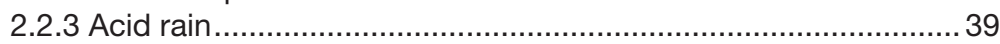

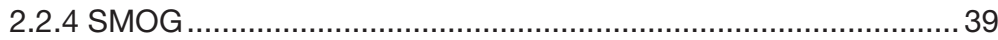

2.3 Problems affecting water ................................................................ 40

2.4 Problems affecting soil................................................................. 42

3. Our planet's limits: tipping points ......................................................... 45

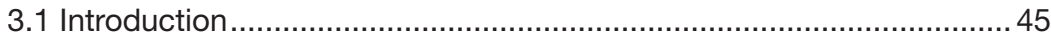

3.2 Main dimensions and their tipping points........................................ 45

3.3 Carrying capacity and meadows' models ........................................ 48

3.4 Natural and social resilience .......................................................... 51

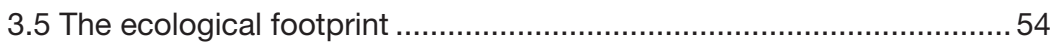

3.6 Calculating the ecological footprint ....................................................5

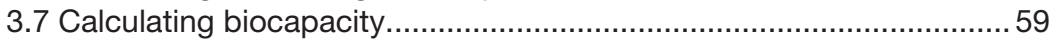

3.7.1 Ecological deficit and overshoot ...........................................59

3.8 Reliability of the calculation of ecological footprint ..............................63

3.9 Economic macro indicators (GDP, GNP) and their flaws.......................6 63

3.10 The effect of economic growth on environment pollution ...................66 66

3.11 The theory of environmental kuznets curves ....................................69

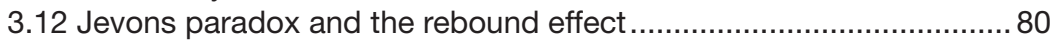

3.13 The sustainability of public deficits...................................................... 83 


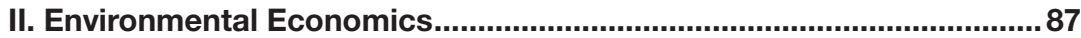

4. The economics of natural resources.................................................... 89

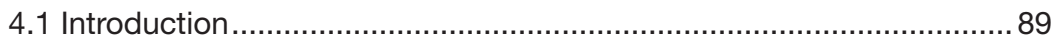

4.2 The concept and significance of biodiversity ................................... 89

4.3 The concept of natural resources .................................................... 93

4.4 Overuse of public goods: 'The Tragedy of the Commons' .................. 94

4.5 Non-renewable (exhaustible) natural resources..................................97

4.5.1 Stocks of non-renewable (exhaustible) natural resources.......... 97

4.5.2 The optimal use of exhaustible natural resources .................... 100

4.6 Renewable resources and their optimal use ...................................... 101

4.7 The theory of public and collective goods ..................................... 108

4.8 The trap of present value calculation............................................... 110

4.9 The economic valuation of environmental changes -

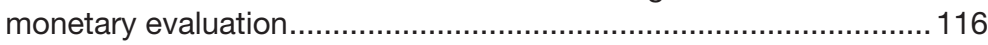

4.9.1 The relationship between total economic value and
ecosystem services ............................................................116

4.10 Monetary evaluation methods ……………................................... 121

4.10.1 Classification of methods of evaluation ...............................121

4.10.2 Methods involving estimates based on conventional

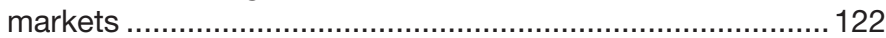

4.10.3 Valuation methods based on implicit markets ...................... 124

4.10.4 Valuation methods based on constructed markets ............... 126

4.10.5 The benefit transfer method...............................................129

4.11 Beyond monetary evaluation.................................................... 130

5. The economics of environmental pollution.......................................... 133

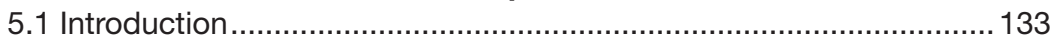

5.2 The theory of economic externalities............................................ 133

5.3 Types of external influences.......................................................... 134

5.4 Two basic types of environment pollution: flow and stock pollution. 137

5.5 The economic consequences of externalities ................................. 138

5.6 The economically optimal level of environmental pollution ................ 139

5.7 The optimal size of externalities..................................................... 140

5.8 Handling externalities in economic theory -

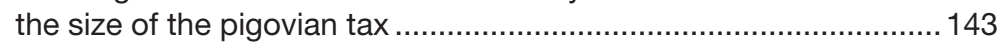

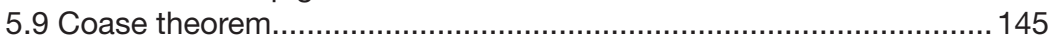

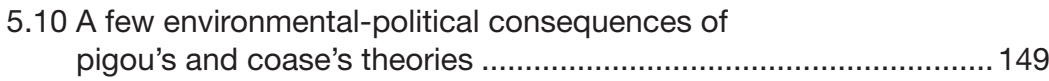

5.11 Two methods of reducing pollution in the case of one polluter ....... 150

5.12 Cost-effective sharing of abatement obligations among several polluters, or abatement options .............................151

5.13 The regulatory matrix of environmental load ................................. 152 
5.14 Choosing environmental policy tools

(taxes and normative regulation).

5.15 Does normative regulation spur innovation? ................................. 160

5.16 The effect of externalities on a monopolistic market ........................162

5.17 The case of joint application of direct and indirect tools .................. 163

5.18 Environment regulation in the case of non-stationary pollution........ 165

5.19 The issue of inflation and price elasticity regarding green taxes ..... 167

5.20 Accumulating externalities............................................................. 168

5.21 Towards strong sustainability:

Expanding the notion of negative environmental externalities .......170

6. The economics of environmental risks .............................................174

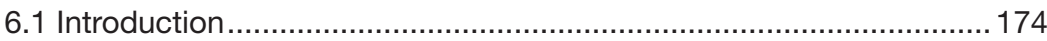

6.2 Risk theory and its relevance to environmental disasters.................. 174

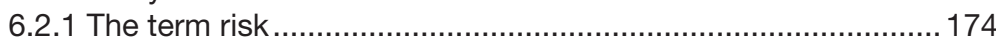

6.2.2 The acceptability of risk,
the importance of technical and cultural rationality.................. 175

6.3 Natural and environmental disasters,

unlimited business for insurance .................................................... 177

6.4 Managing risk: the business approach ............................................ 183

6.4.1 Risk assessment and its consequences.................................. 183

6.4.2 The appropriate environmental management strategy .............. 185

6.4.3 Endogenous and exogenous elements of environmental risk... 186

6.4.4 Environmental management as

a function of environmental risk ............................................... 188

6.4.5 Comparing reactive and strategic environmental

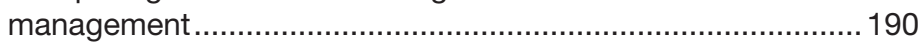

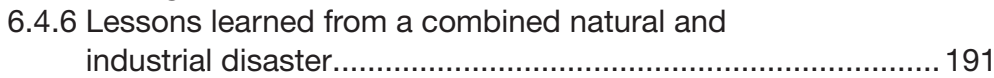

6.4.7 Industrial disasters, and how they are treated.......................... 195

III. Welfare

7. The welfare effects of environmental regulation and

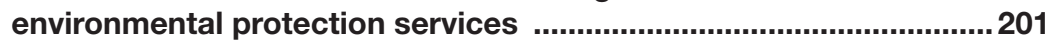

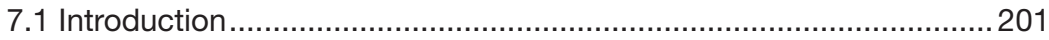

7.2 The unfavourable consequences of the polluter pays principle ........201

7.3 Excessive self-criticism, inaccurate situation assessment,

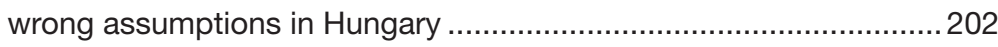

7.4 Socio-economic problems concerning the establishment and operation of environmental protection infrastructure.......................205

7.5 The decline of utilities and villages ...............................................206

7.6 Rising utility tariffs, falling capacity utilisation...................................209 
7.7 Wastewater treatment in the Által-ér catchment area -

The case of a small town's wastewater treatment plant....................213

7.8 General trends in utility development in Hungary .............................215

8. The characterisation of welfare, welfare indicators............................220

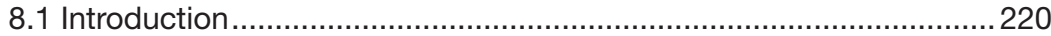

8.2 The characterisation of inequality in the distribution of income ........220

8.3 The measurement of human development .......................................222

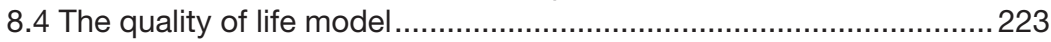

8.4.1 The Scandinavian model - prioritising objective elements

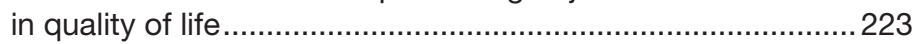

8.4.2 The American 'personal satisfaction' model ...........................223

8.4.3 The quality of society model.................................................224

8.5 The UNDP Human Development Index ...........................................225

8.6 Sustainable consumption and The Easterlin paradox ........................229

8.7 To what end environmental pressure?

A simplified model of human satisfaction .........................................236

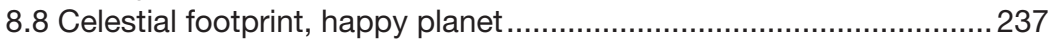

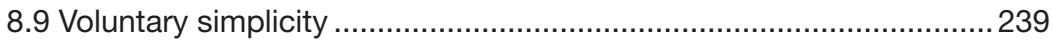

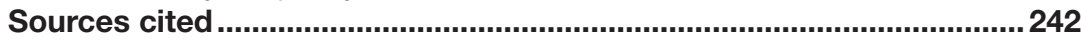




\section{FOREWORD BY JOHN MORELLI}

If in 1970, an environmentally minded individual walked into an industrial manufacturing facility and asked the operations staff to reduce the company's waste emissions to zero percent, there probably would have been a slight speechless pause followed by some muted laughter and then the company security officer would have been called to escort the individual to the exit. The request would have appeared ludicrous to the operations staff because a zero emissions outcome was well beyond their conceptual horizon. Today however, some companies have in fact set zero-emission targets; but it is not an easy goal to achieve. No one company stands alone. Each is a part of a larger network of suppliers and consumers that eventually reach beyond the control of any single element of the economy.

The decisions that we, as elements of a society, make and the consequential actions that we take are, in part, a result of the meanings and understandings that we hold in common. These understandings evolve with time, owing to a variety of inputs, and are seen to manifest themselves in the preparation and practice of our professions. Movement toward a more sustainable future is evidenced by the development over the last half century of new sub-professions including 'environmental' economist, 'environmental' engineer, 'environmental' scientist, etc. While these evolutionary developments are necessary and laudable, they are inadequate to meet the challenges we face. Each addresses issues inherent within their existing framework, but a broader horizon is necessary to reach toward a truly sustainable future. A more 'ecological' world view is warranted; a view that holds our societies and economies to be subsystems of the ecosystems that support them.

In Sustainability, environmental economics, welfare the distinguished authors reach toward this broader horizon. It is an advanced, thought-provoking and comprehensive treatise on sustainability, environmental science, environmental economics, and environmental management, visiting and revisiting historical, present and developing theories, policies, practices and understandings regarding natural capital, agriculture, human welfare, population, environment, pollution, wealth, life, happiness, competition, consumption, cooperation, carrying capacity, ecology, ecosystem services, economic valuation, environmental externalities, risk, ecological footprint, economic growth, GDP and voluntary simplicity.

This is an encyclopaedic resource that identifies and examines the environmental aspects of sustainability, the problems with our current measures, the inappropriateness of our assumptions regarding the appropriateness of pollution, the 'sin' of dominant paradigms, and continues on to examine key socio-economic models of quality of life and human development, considering many 'if' statements regarding the extent and pace of development. It presents 
visions for possible (sustainable) paths forward, suggesting alternative assessments and principles to follow to keep the economy within the limits of Earth's carrying capacity. It includes an excellent discussion on resilience, limits and ecological footprint and an outstanding description of total economic valuation.

In the discussion of environmental problems, the authors claim that the 'basic context will be defined from the perspective of natural sciences in a highly concise manner, primarily for readers trained in social sciences'. Yet, in presenting it in this way and including discussions regarding our responses to these problems, it identifies key concerns that even environmental scientists and engineers may have overlooked, owing to the narrow focus of their respective specialities. I believe that no matter what a reader's area of expertise may be, there will be something additional to be learned by reading this book.

This book reveals the enormous complexities of the problems we face and yet, I believe, is undergirded by the strength of the human spirit, including phrases like, 'inexhaustible human creativity', 'human technological ingenuity', and 'the omnipotence of human knowledge'. It will serve as an indispensable resource for all concerned about our future on this planet.

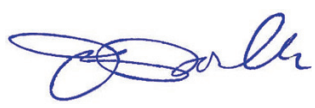

John Morelli, PhD, PE

Professor Emeritus,

Environmental Management \& Technology

Rochester Institute of Technology 


\section{PREFACE}

Since humans have been on Earth we have used ecosystem services, without which we would have found it impossible to survive; however, we initially paid no heed to the limitations of using those services. We have considered natural 'assets' to be inexhaustible, and become accustomed to using them for our own purposes, caring little that the living creatures that inhabit the Earth comprise an extremely complex ecosystem, and senseless destruction risks the lives of all. In the beginning, the number of humans on Earth was so small and our tools so primitive that our impact on the biosphere was eclipsed by the latter's ability to regenerate. Soon, our ancestors began to 'play with fire', burning up natural ecosystems either on purpose or by accident. In some cases, we sought to dominate territories that were suitable for agricultural cultivation, while at other times we were led to destroy forests 'simply' because we needed timber to build vessels. The first defensive measures against such harmful effects were only taken when humankind had already populated the globe and had tools at its disposal with which the destruction of nature had become highly effective. Seeking to protect nature, or rather our own property, wise sovereigns introduced regulations about the use of forests, making it mandatory to replace felled trees. They imposed restrictions on hunting, while fishing was also curbed and limits were set on mining. Once the concept of land ownership had emerged, the protection of property soon followed. This has not saved nature from being destroyed by humans. 'Utilisation' has become the privilege of the wealthy, destruction continues, and is now being wrought on a disastrous scale.

\section{From Rachel Carson to the Club of Rome}

Our profession, environmental protection, dates back approximately half a century. For a citizen of Central Europe, this half-century has been different from any other fifty-year period because it has largely passed in peace, and was at most disturbed by local wars. On the other hand, over these fifty years humankind has used more natural resources than in the entire preceding millennium. Radical changes have taken place in the biosphere: we are again at war - only this time it is not with one another, but with nature. All this has happened since we became heavily involved in protecting the environment. It is intriguing to see with our own eyes what humankind has done in its efforts to save the Earth from destruction. Rachel Carson's book, Silent Spring, was 
published more than fifty years ago. In 1962, Carson shocked the world by arguing that the build-up of DDT in the food chain would leave humankind without birds. Many of us were touched by that book, but it was taken with a pinch of salt by perhaps an even greater number of readers, including also those who have since been going on at length about the benefits of scientific advancement. Obviously, there is a lot to go on about. The insecticidal effect of DDT was discovered in 1934 by Paul Hermann Müller, who in 1948 was awarded the Nobel Prize in Medicine for his discovery. Since then, plenty of information has emerged about DDT, which is nevertheless still used in a number of countries given the difficulty of choosing between malaria and DDT. As 'replacement' compounds decompose rapidly, especially at higher temperatures, they are not effective enough. Early warnings about environmental problems were also issued in Hungary. In 1971, the Hungarian publisher, KJK published Suicidal Civilisation, a book by Lajos Jócsik. It was a highly 'balanced' piece of work, but essentially pessimistic. Citations began with the Bible and concluded with a quote from a speech by the General Secretary of the Central Committee of the Communist Party. Brezhnev knew the solution to everything; how could he not identify the solution to environmental issues? A few years later, relying on reports to the Club of Rome, the latter also addressed the problem more comprehensively (In Defence of Our Environment. KJK, 1976).

In 1972, the Club of Rome published The Limits to Growth, a report whose attempt to promote the concept of 'zero growth' met with extremely strong reactions. Warnings were given, but were taken rather lightly by political and economic actors. Nevertheless, a group of researchers was formed which started to address the problem in a systematic manner, and sought to provide increasingly accurate forecasts about the future using global models. Arguing for 'organic growth', in 1974 Mersarovic and Pestel published Mankind at the Turning Point, the second report to the Club of Rome. The second report was already available in Hungarian as well, but only to the lucky few, given that the Hungarian translation of the book was 'published' in the form of numbered copies. The models in the book had become somewhat more refined, but the point remained the same, and the Mersarovic-Pestel model also presented a rather pessimistic view of the future.

Meanwhile, in the UK in 1973 Schumacher published his book, Small Is Beautiful, the success of which is demonstrated by the short time it took to become a bestseller. Schumacher did not propose a model, but he did question the values inherent in the prevailing economic order. These were disquieting thoughts, and it was not by coincidence that the book remained untranslated in Hungary for a long time. 
Even the third report to the Club of Rome was no longer concerned with models. And this was despite the fact that its head of research, Jan Tinbergen, had earned worldwide renown through his achievements in the field of dynamic modelling. The work published under his name represented a real breakthrough in terms of research on global issues. The findings of the team headed by Jan Tinbergen were released in 1976 under the title Reshaping the International Order (RIO). In Hungary, the book was published with a threeyear lag (1979), but was legally made available to everyone. As Jan Tinbergen had already been awarded the Nobel Prize in 1969, the RIO Report that was completed in 1976 was awarded to a Nobel Prize laureate. Tinbergen and his team argued for the need to establish a new order for the world economy, and earned scientific renown for how he addressed environmental problems.

The sinister reports of the Club of Rome were followed by publications that brought relief. It may not be erroneous to claim that a more optimistic position concerning environmental issues was heralded by the Brundtland Report. Published in 1987, the Brundtland Report introduced the concept of sustainable development, which was brought into focus at the Rio Conference of 1992, together with eco-efficiency.

Conversely, the definition offered in the Brundtland Report concerns meeting the needs of present and future generations; i.e., the welfare of present and future generations, which depends on both the stock of accumulated capital and the size of the population to be sustained. If it is assumed that the stock of natural capital does not diminish over time, welfare may also increase as population grows. Population growth may be offset by advances in technology, which may be instrumental in ensuring that a unit of natural capital yields greater welfare. Published by the World Bank in 1992, the World Development Report demonstrates that at a certain level of economic growth, growth and pollution diverge. Above a per capita GDP of USD 10,000, clear improvements occur in environmental indicators such as $\mathrm{SO}_{2}$ emissions, the volume of untreated wastewater, the concentration of lead and other heavy metals in air, etc. In environmental economics, the curves describing such relationships are referred to as Kuznets curves. As Kuznets collected the Nobel Prize, the first report to the Club of Rome, Limits to Growth, was already being drafted by Meadows et al. and was published in 1972, questioning the sustainability of growth in the long term, and the proposition that the impact of growth is positive. A closer look at the above propositions reveals that the theory of growth of the former economist, who is now considered a ground-breaking thinker, has been the subject of criticism by numerous researchers over the past thirtyfive years. Namely, while considering technological and social innovation to be 
the drivers of development - and also recognising the importance of social and cultural dimensions - in his Nobel Prize Lecture, Kuznets argued that 'modern technology with its emphasis on labour-saving inventions may not be suited to countries with a plethora of labour but a scarcity of other factors, such as land and water; and modern institutions, with their emphasis on personal responsibility and pursuit of economic interest, may not be suited to the more traditional life patterns of the agricultural communities that predominate in many less developed countries.' For Kuznets GDP obviously did not represent an indicator of welfare; indeed, in the same lecture he clearly states that 'the conventional measures of national product and its components do not reflect many costs of adjustment in the economic and social structures [...] This shortcoming of the theory $[\ldots]$ has led $[. .$.$] to attempts to expand the national accounting frame-$ work to encompass the so far hidden but clearly important costs, for example, in education as capital investment, in the shift to urban life, or in the pollution and other negative results of mass production. These efforts will also uncover some so far unmeasured positive returns - in the way of greater health and longevity, greater mobility, more leisure, less income inequality, and the like.' The reader is reminded that the Human Development Index (HDI) and Cobb and Daly's Index of Sustainable Economic Welfare (ISEW) only attracted general interest much later, in the 1990s.

Initially published in 1995 in German, Factor 4 was perhaps the first wholly enthusiastic report to the Club of Rome. The report was also subsequently published in English in 1997, proving that there was hope. Ernst von Weizsäcker, Amory B. Lovins and L. Hunter Lovins described the opportunities offered by science and technology (Weizsäcker, 1997). They found that a radical improvement in eco-efficiency would enable humankind to double its welfare while halving the environmental load it had previously generated per unit of growth. It was around this time that UNIDO's Cleaner Production Centres were established, the US set up pollution prevention centres, and the end of the defensive era for environmental protection could happily be acknowledged. Prominent figures in the world of business joined the 'club', such as Michael Porter, with his efforts to make the 'business case' for environmental protection, and also more recently (2006) corporate social responsibility an integral part of corporate strategy. Additionally, new Factor books such as Factor 5 and Factor 10 have been and continue to be released almost on an annual basis, all calling for inexhaustible human creativity. Generally, they claim no less than the possibility of generating much greater welfare than humankind has ever achieved at the expense of much more limited consumption of materials and energy, and a much smaller environmental load; that is, that the Earth is 
capable of supporting up to nine billion people, if ... But yes, that 'if' at the end of the sentence reminds us that we cannot go on the way we have been doing so far. That 'if' reminds us that we must change our ideas and expectations about welfare, comfort, consumption, production and virtually everything we have grown accustomed to. A stock society must be transformed into a flow society. We can no longer possess goods; we must be content to use the services they provide. The cheapness and comfort of fossil fuels should be replaced by renewable energy sources that are more expensive and are of lower energy density.

The so-called hydrogen economy might solve energy issues, but even then access to raw materials will remain limited, and their price will certainly increase. If... if there were a way for wages to converge to the EU level more slowly than with quality of life, and quality of life could be given an institutional definition other than the one given to it by EU citizens. If policy did not promise rapid improvements in living conditions, and immediate existential betterment to each individual, and did not adopt measures driven (or coerced?) by such promises, but aimed for more moderate growth and slower convergence. If countries could be set on a path of development other than what the average European citizen expects in terms of quality, this would certainly generate returns in the future. Unfortunately, for the time being improvements in ecoefficiency are being offset by increasing consumption. Due to the lower consumption of materials and energy, products have become cheaper so individuals can buy more of them, leading to an overall increase in the use of natural resources as measured in non-financial terms such as kilograms and joules. There is in fact a need for more 'economy' (i.e., thrift) and recycling; nothing should be thrown away or dumped in a landfill, and so on and so forth. There is hardly anything we can go on doing in the old way.

We have gradually forgotten about the models, although in their 2004 book, Limits to Growth: The 30-Year Update, Dennis and Donella Meadows and Jørgen Randers reminded us of the work they published in 1972, proving that the forecasts they had made were accurate for the most part. It seemed that in 2004 we were already past caring.

Obviously, there are still pessimists who are not convinced of the omnipotence of human knowledge. New theories have emerged; they tend to reiterate the first reports to the Club of Rome. To promote his theory of degrowth, the outstanding French professor Serge Latouche is touring the world and has written a book under the title Little Treatise on Serene Degrowth, and is giving lectures - mostly to 'believers', it must be admitted.

For an overview of the history of the problem, we should choose an earlier 
point of reference. Revisiting the roots of the issue, the 'father' of theories about global issues is most probably Malthus. Malthus wrote his famous essay in 1798, proposing that the supply of food to a growing population could not be guaranteed because growth in food supply followed a mathematical progression, while that of population a geometric progression. In Malthus' time, the Earth was populated by less than a billion people. The population stood at two billion in 1930, and had reached seven billion by 2010. Almost immediately, Malthus' opponents declared his theory to be flawed, partly on the grounds of its failure to take into account the development of science and technology. Published in 1803 and creating a much greater stir than his first essay, a following book (Effects on Human Happiness) features a concept that is being rediscovered today. Malthus was not concerned with the ability of humans to defeat each other, but with the happiness of humankind as a whole. Deceased in 1900, the outstanding English scholar Ruskin discusses the same point: 'There is no wealth but life. Life, including all its powers of love, of joy, and of admiration. That country is the richest which nourishes the greatest numbers of noble and happy human beings; that man is richest, who, having perfected the functions of his own life to the utmost, has also the widest helpful influence [...] over the lives of others.' Humankind should at long last understand that more happiness can be created through cooperation than competition. This can also be demonstrated on the basis of game theory, relying on the logic of the prisoner's dilemma. Despite this, the theorem tends to be forgotten, even by those who have respect for what Neumann and Morgenstern found. John von Neumann and his compatriots 70 years ago, Ruskin 120 years ago, and indeed Malthus still understood what purpose humans serve on Earth.

The dichotomy between optimism and pessimism is not easy to abandon, but it is equally difficult to move on. Revisiting the roots, one may argue that the ultimate purpose of all human activity, including economic activity, is to make people happy. Kahneman, also a Nobel Prize laureate, cites Easterlin (1974), who, after examining the relationship between economic growth and happiness, found that even a major improvement in the standard of living had no demonstrable effect on human satisfaction or happiness. Easterlin (1995) also found that in Japan the reported level of individual happiness failed to increase between 1958 and 1987, despite a five-fold multiplication in real incomes over the same period. To some degree, this appears to contradict our own intuition and, more strongly, the fundamental doctrines of economics. Yet, as Kahneman points out, in the long term welfare is not closely associated with individual circumstances or opportunities. One possible explanation for this proposed by Kahneman is that people regularly adjust their aspirations 
to the utility that is achieved, thereby preventing them from reporting a higher level of satisfaction, even when the welfare they experience has significantly improved. The highest levels of satisfaction were recorded for the citizens of Northern European countries, no correlation was found between GDP and happiness in relatively wealthy countries, while inhabitants of the former Soviet bloc are highly dissatisfied (a historical trend, of course), and, surprisingly, citizens of South America are satisfied.

In an article from 2000, Csíkszentmihályi questions the general theory put forward by Maslow that consumers make rational decisions concerning the satisfaction of their basic needs (Maslow's hierarchy of needs). Csíkszentmihályi finds that in a welfare economy, consumers are less concerned with 'existence' itself, and are more focused on 'experiential' needs. That is, they need activities which serve to promote the enjoyment of real-life experiences. Curiously, consumers in the 'developed world' are no longer interested in what they buy, but more in the experience of buying. In terms of sustainable consumption, this change may have both positive and negative consequences. Researchers of happiness (Ng, 2008) find that 'Public policy should put more emphasis (than suggested by existing economic analysis) on factors more important for happiness than economic production and consumption, including employment, environmental quality, equality, health and safety.' The Korean author adds, interestingly, that 'scientific advance in general and in brain stimulation and genetic engineering in particular may offer the real breakthroughs against the biological or psychological limitations on happiness'.

Happiness researchers report that 'despite a huge increase (several times instead of just several percentage points) in real income or consumption levels, the average happiness level of a country has typically remained largely unchanged.' (Easterlin, 1974, 2002; cited in Ng, 2008). 'Cross-country comparison of average happiness levels shows lower happiness levels for low-income countries and high happiness levels for high-income countries but the positive correlation between income and happiness is not significant after the income level of about US $\$ 7,500$ per capita per annum.' (Inglehart-Klingemann, 2000; cited in $\mathrm{Ng}, 2008$ ). 'Other social-economic factors like being married have higher correlation with happiness than income or consumption; interpersonal relationships are essential for happiness.' (Bruni, 2006, cited in Ng, 2008).

$\mathrm{Ng}$ suggests that if these results are valid, a revolution in economic thinking is needed, as proposed by Layard (2005). At the social and global level, the pursuit of economic growth may be illusory as it does not really increase the value of the ultimate objective: happiness. In fact, 'if account is taken of the environmental disruption effects, economic growth may well be welfare-reduc- 
ing, if not survival-threatening' $(\mathrm{Ng}-\mathrm{Ng}, 2001)$. Sustainability means the ability to ensure the existence of 'something' continuous. The meaning of development is more intricate, given the possibility to interpret growth in quantitative and qualitative terms; e.g., as a steady increase in welfare or in terms of wellbeing. Obviously, interpretation makes a difference. For example, GDP growth does not necessarily bring about an increase in welfare, and particularly not in well-being (Harangozó et al., 2018). Increased well-being comes from the development of education, an increase in the number of healthy lived years, improvements in life and social security, as well as in factors such as personal freedom, which are all components of quality of life. Without underestimating the unfavourable effects of perceivable economic development trends on the natural environment, we must objectively admit that dangerous effects are predominantly being felt in the social dimension. Income inequality is increasing, while some channels of social mobility, such as education, are becoming blocked. Certain segments of society face multiple disadvantages and discrimination. Owing to these problems, while still underlining the need to award priority to promoting the sufficient quality of natural and built environments in terms of both quality of human life and functioning of the economy, sustainable development strategy should not exclusively prioritise the sustainability of nature.

On these grounds, our book is subdivided into three main parts. Part I addresses the issue of environmental sustainability itself, including a chapter that throws light on the background to the problem from the perspective of natural sciences. Part II describes the analytical methods and language for interpreting sustainability in terms of environmental economics, while also giving an account of tried and tested public policy recommendations that have been implemented extensively. Finally, Part III, in the spirit of the question 'to what end the environmental load', addresses the welfare issues involved in sustainability, discussing subjects such as whether it is rational to install a sewage system in every village, and how to measure happiness.

As it should be clear from this Introduction, welfare is used and defined in this book as 'the health, happiness, and fortunes of a person or group' (Oxford English Dictionary). However, this term refers mainly to the material and financial means needed to achieve a broader fulfilment of human being, namely the well-being of it. In Chapter 8, within the concept of the 'quality of life', the differences of these concepts will be more thoroughly elaborated. 
I. SUSTAINABILITY 



\section{Sustainable development}

Sustainable development is the twenty-first century's great challenge to the human race. The term first appeared in the Brundtland report in 1987. Twenty years have since passed, and professionals are still arguing about the meaning of this term: why we are supposed to differentiate between development and growth, and should we show solidarity towards future generations while we still have problems providing a living for generations presently co-existing? This chapter examines whether the relationship between the economy and the environment can be harmonious, and suggests what principles we ought to follow to keep the economy within the limits of Earth's carrying capacity.

\subsection{Biosphere and economy}

The relationship of economy and nature has become controversial, a fact well recognisable in the schematic figure (Figure 1-1.) that illustrates the correlation between the biosphere, the social system and the economic system. The circles indicate the embeddedness of these systems within each other; the largest system, the biosphere, is located outside with the social system within; next, the even-smaller economic system with the industrial subsystem inside (Tyteca, 2001). Some dispute whether the biosphere can indeed 'contain' the social-economic system with its present - and even less with its future - size.

The most problematic issue from the conservation perspective is that, according to conventional economic logic, the ecological system supplies free assets (according to the demand for raw materials and energy) which are then returned to the ecological system in the form of waste (throughput economy).

Throughput economy: the operation of traditional economies from an ecological economic perspective. This says that the traditional economy resembles a system (such as a digestive tract) that is fed with useful (low-entropy) energy, raw materials, and natural resources. At the output end (and even during the process) are produced useless (high entropy) by-products and pollutants. In reality, useful end-products fit for human consumption also become waste after use. One of the main efforts of ecological economics is to 'stop' energy and matter throughput, and turn economic activity into - or come as close as possible to - a 'circular' process, as seen in nature. As a result, energy and material economies of scale will be realised, and the efficiency of the use of energy and other resources will significantly increase. 
The 'value creation' performed by the economic system is waste production from the ecological perspective, or expressed in scientific terms, involves the transformation of low-entropy natural resources into high entropy waste. However, the economic system satisfies human needs with products and services produced through the industrial subsystem. 'Value creation', however, involves loss of value, involving a deterioration from nature's perspective. The speed at which this loss of value occurs is certainly not irrelevant; neither is it indifferent at what level the economic system satisfies human needs during the process. These controversial issues are illustrated in Figure 1-1.

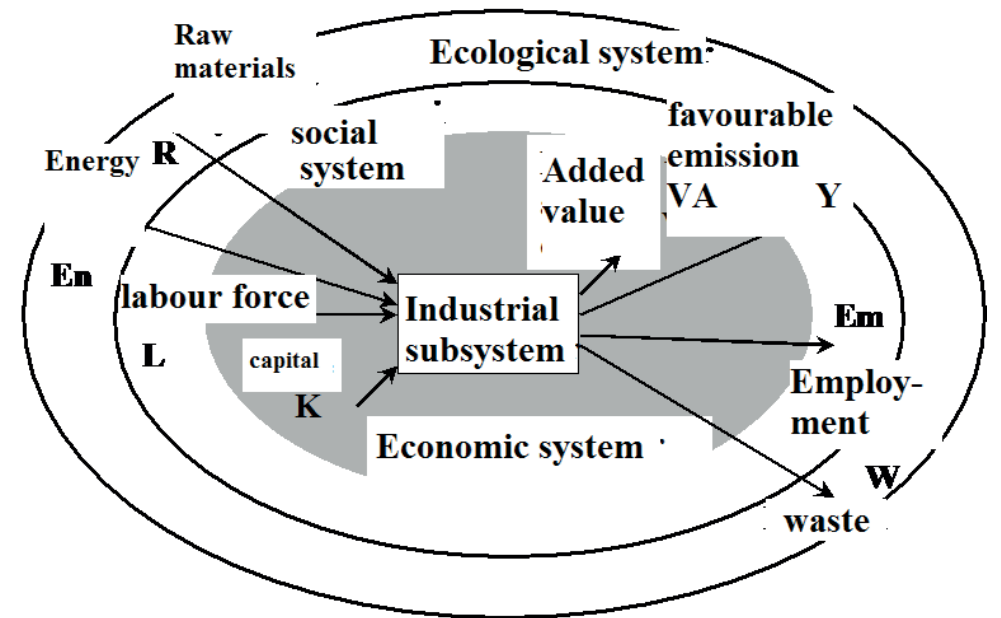

Figure 1-1. The mutual embeddedness of economic, social and ecological systems (Daniel Tyteca CEMS block semenarium presentation, August 2002, Tata, Hungary).

A company that satisfies human needs with only minor growth in entropy creates more value than one that causes major growth of entropy, the satisfaction of needs being equal. The former company may be considered to be value creating, while the latter wastes nature's assets. Methods recently developed in the environmental sciences such as life cycle analysis, or on a macro-scale the calculation of ecological footprints, largely attempt to answer the question to what extent a given product or service (or the economy of a given country) can be considered environmentally friendly.

Figure 1-1. also demonstrates another controversy that is elementary from the perspective of the functioning of society: the economic system strives to minimise the use of labour force as input, while on the output side maximum employment is desirable. The contradiction is irreconcilable, and the proffered solutions are none too convincing. 
The contradiction could be resolved by reducing average working hours or lowering retirement age. However, in developed countries policymakers pursue the very opposite solution, and, unfortunately, individuals also tend to prefer a higher income over more leisure time. Shorter working hours would expose companies to challenges concerning the organisation of work, and reductions (or only maintenance) of incomes for employees. The rapidly growing population of the Earth in itself provides adequate justification for reducing per capita weekly working hours, for example by making extensive use of 35-hour or even shorter working weeks. A cut in standard working hours would also be justified by the rapid spread of automation/robotisation, but such initiatives are rare in practice.

For the most part, social scientists are at odds in terms of the numbers. With reference to labour productivity, economists use value added at factor cost divided by the number of employees (Labour productivity in EU-27 by sector and company size [2004-2005], n.d.). As regards the heart of the matter, this macrodefinition makes little sense because for the same work USD 50 is paid to a worker in Norway, USD 8 to one in Hungary, and barely USD 2 to one in India. Examining the case of Bethlehem Steel, where he was responsible for handling pig iron, Taylor found that when workers used the right tools and methods they could handle 47.5 tons per day, whereas typical per capita performance was 12.5 tons a day. According to Taylor's calculations, with a precisely regulated loading procedure 140 workers would have sufficed instead of the regular headcount of 500. Taylor developed a financial incentive system to compensate workers who were able to meet the new standard. Taylor's methods of organising work led to a sharp increase in labour productivity at the factory, and the power of Taylorian organisation has since become phenomenal. Rather than making workers work more, Taylor's objective was for them to work more reasonably, and earn more as a result (Frederick Taylor and Management, n.d.).

Data concerning the increase in the productivity of agricultural work are available to the public. In the past one hundred years, while the amount of cereal grown per hectare has increased 6-10 fold, the number of working hours and thus the number of employees per hectare has dropped to a 15-20th of earlier amounts. It is common knowledge that in developed countries $2-5 \%$ of the total workforce are capable of providing the whole population with food, and before long the proportion of industrial employees will drop below 5-7\%. According to optimistic analysts, employment issues will be dealt with by the uptake in the service or tertiary sector. Others predict growth in free time because the same amount of work will be distributed among more people, which will result in a double benefit: more free time favours the development of the service sector and creates demand for services.

The situation appears to be more complex in the light of statistical data. In certain regions - e.g. South America - a third generation is growing up in which 
no-one in the family has had a permanent job; this generates huge social tension and there is not much hope that children socialised in such families will become employed as adults.

The other no less surprising fact is that employees' free time is not increasing, even in developed countries; what is rather typical is that people work more than eight hours a day and cannot even take their vacations. Examination of the labour market shows that there are very few jobs involving 4-6 hours' employment, which would be indispensable for the healthy functioning of families. That is to say, changes in the labour market do not attest to the more optimistic predictions; a developed economy can only cope with a well-qualified labour force that is prepared to compete, and those who want nothing 'but' to make a living are useless in the current economy. Social services in welfare states attempt to handle these issues, which are usually easily manageable in an economic sense. The productive economy is capable of taking care of the physical needs of the unemployed. Maintaining the quality of life of the millions excluded from the economy, however, is a more complex problem than satisfying their physical needs.

The issue of unemployment is not merely concerned with livelihoods, but the stability of society as a whole. It is worthwhile citing at some length the work of the outstanding Hungarian-born scientist Tibor Scitovsky: 'I completely ignored the idle poor, the long-term unemployed and the unemployables whose inadequate upbringing made them unfit for work; in short all those who have more leisure than they know what to do with and suffer from uninterrupted chronic boredom, a deprivation as serious as starvation, with equally fatal consequences. As hunger makes one look for food, so boredom makes one seek excitement; and just as people with no money for buying food stoop to thieving to avoid starvation, so those who lack the skills that can relieve boredom is a harmless way, will relieve it with violence or vandalism-the most exciting and so most enjoyable activities, and the only ones that require no skill, only strength or a weapon. Think of the mischief small children engage in when bored. Violence and vandalism are the adult equivalent. Education therefore not only adds interest and variety to people's lives, it is also an essential and necessary condition of civilized society and the peaceful coexistence of its members' (Bianchi, 2012).

The 'second shift' that is done in households creates economies that are used for accumulation, even in the middle class. If instead of accumulating the income saved by this second shift we paid employees to do most of the 'housework' and provide a quality service, we would have more free time and the quality of our lives would improve. Social differences would be reduced with very beneficial social-environmental effects. Finally, we would live in a world capable of remaining in harmony with Earth's limited carrying capacity. The economy could finally use the resources that are available without limits: 
the human labour force. One of the main obstacles to this is man's possessiveness. If individuals did not desire to possess but rather satisfy their needs, they would not strive to accumulate assets but to maximise happiness.

Disregarding housework is a frequently noted error with GDP calculations. Providing that such activities are turned into paid services in the future, this would result in the growth of GDP and reduce environmental impact.

Greater division of labour could produce several positive effects. The degree to which the world is prepared for this is questionable, but interestingly, positive examples are found in two directions. In retrospect, a primitive communal society represented a world that exploited the opportunities and benefits offered by shared activities. From there, we have moved towards an individualistic society that places excessive emphasis on private property and makes consumption prestigious. We have now reached a point at which some part of developed society has had enough of the proliferation of private property, and the capitalism that it has created. In the spirit of voluntary simplicity, an increasing number of people are making attempts at switching to a model that questions the conventional values of consumer society (Chapter 8$)$. The scarcity of Earth's resources (Chapter 4), problems resulting from pollution (Chapter 2), and population growth in developing countries vs. population decline in developed countries across the world are problems that are so well known that they almost sound trivial. Not only has the demand for consumption been increasing in developed countries, it is also being driven by the new middle class emerging in developing countries, particularly India and China. This will lead to severe sustainability problems in both the long and short term.

Ehrlich's model illustrates what components define total environmental impact. It hypothesises that:

$$
\begin{array}{ll}
I=P * A * T \text {, where } \\
I- & \text { Environmental Impact } \\
P- & \text { Population } \\
A- & \text { GDP per capita } \\
T- & \text { Impact per Unit of GDP (technology). }
\end{array}
$$

Total environmental impact is thus created by the product of population, per capita affluence and impact per unit of the economy.

The role of the population in the model needs no special explanation; the environmental impact is primarily defined by the number of Earth's inhabitants. The model takes all goods that an individual consumes as aggregate consumption per capita. Such units of consumption may include kilometres driven by car, kilograms of beef that are eaten, or units of beer consumed as expressed in litres. Each service or product consumed by the population 
creates some impact on the environment through the raw material used for production and the pollution emitted to the environment, but mainly through a combination of both. This fact is incorporated into the model as the size of environmental impact per unit of service - for example,the impact caused by one $\mathrm{km}$ that is driven (Meijkamp, 1998).

In a study published in 2000 (Mont, 2000), the Swedish Environmental Protection Agency drafted the following three optional solutions for addressing the ever more urgent issue of sustainability:

- reduce population

- reduce the level of consumption

- make consumption sustainable.

The first option is obviously impracticable in the short run, since all the indications are that even if the growth rate of the population does not accelerate but is maintained, global population could reach 8-10 billion by 2100 (Walker H. C.).

Sustaining such a huge population clearly makes the second option (cutting down on consumption) impossible. The situation is made even graver by the fact that most of the population growth will happen in developing regions where living standards lag far behind those of the developed part of the world. In terms of improving economic performance, however, even the citizens of poor regions will want to have consumption patterns similar to those of the 'developed' world. Moreover, inhabitants of countries emerging from poverty are liable to be much less be sensitive to the conservationist perspective and be inclined to exploit environmental resources disproportionately to enjoy marginal improvements in their living standards. Efforts aimed at reducing the rate of consumption could also evoke a major public uproar in countries where inhabitants already consume at a rate in excess of their needs. No national government would be ready to support such programmes.

As mentioned, one of the commonly observed flaws with the way GDP is calculated is that it fails to take into account work carried out in households (Chapter 3). If in the future such activities were to be converted into services rendered for money, this would both drive GDP growth and lead to reduced environmental loads.

\subsection{The concept of sustainable development}

In response to the environmental crisis that is endangering the Earth, the General Assembly of the UN invited Mrs Gro Harlem Brundtland, then Prime Minister of Norway, to develop a comprehensive programme and make suggestions 
about the necessary changes. The World Commission on Environment and Development ${ }^{1}$, led by Mrs Brundtland, prepared a report called Our Common Future in 1987 which laid down the principles and requirements through which the Earth may be preserved for future generations. These principles became globally known as the principles of sustainable development (Szlávik, 2013).

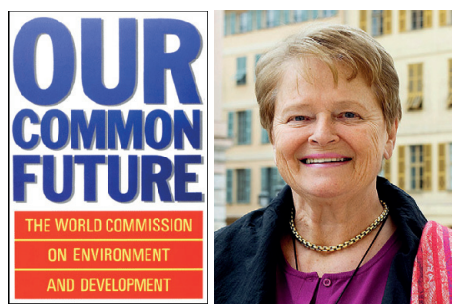

Fig. 1-2. The front cover of the book Our Common Future, published in 1987 with a portrait of the head of the committee Gro Harlem Brundtland.

The Brundtland Committee's Our Common Future became the bible of conservationists for a number of years. The primary message of the committee's report was that the pursuit of growth will lead to the collapse of the global biosphere; consequently, economic development must not be carried on as before. Many believe the way out is to pursue sustainable development. Conservationists found out relatively quickly that the concept of sustainable development does not in fact require a change of paradigms since it fits into traditional economic philosophy very well. Sustainable development does not demand that we limit our needs, but it only encourages us to satisfy them using less resources and energy, and to minimise the polluting effects of production-related activity. It is no wonder that this proposal quickly found support in developed societies; partly because it moderates the bad conscience of individuals about their high per capita consumption, and in contrast, by making comparisons involving specific levels of consumption it supports the idea that the real threat to environment is posed by developing countries. Implementation of the concept involves a war over statistics and data. A common language is hard to identify, since researchers from developing countries argue on the basis of the principle of justice (such countries typically have low per capita energy and raw material consumption), while the developed world, pointing out the high level of consumption they obtain from one unit of GDP (i.e., a higher level of efficiency), accuses underdeveloped countries of wasting natural assets. Both parties are right, of course, as far as the authenticity of the statistics goes; moreover, it would be harmful if the inhabitants of developing countries wanted to reach the standard of consumption of developed coun-

1 Of the 22 members of the commission there was one Hungarian: István Láng. 
tries or a consumption structure that exists in any part of the world we consider developed. Examining the matter from the other side, we can of course immediately see that the developed world should probably not be satisfied with achievements in saving energy and raw materials, or increasing emissions. If the developing world is not able to follow the path of development already pursued by more developed countries, they may justly be expected to make more effort to address per capita consumption rather than promote efficiency. This relatively simple 'human right' seems to be rather difficult to modify or force others to accept in practice (so much so that, despite the fact that the governments of advanced bourgeois democracies have developed numerous conservation-related programmes, none of them take into consideration that the level of satisfaction of needs must be decreased in their rather wasteful societies), and that it is thus not enough to rethink the rationale for consumption. It is clearly not coincidental that societies built on the free market refuse to hold an inquiry into whether all human needs are of similar value and whether their satisfaction is justifiable.

A significant number of alternative thinkers claim that environmental issues may only be rendered manageable using a new paradigm. There is no mature concept about this yet, but practical experiments are ongoing in small communities. These small communities usually strive to create an economy in which people produce and exchange products and services without the intermediary use of money. The use of money is limited to their connection with the real economy, while money practically takes no place in exchange relationships among each other. The point of this community philosophy is that by excluding money that generates real interest - thereby removing a major driver of economic growth - we can create an economy which creates full employment, and also a way of life significantly more economical and simple, not driven by material wealth and money.

This model has special significance from the perspective of conservationists so long as mutual exchange systems are always limited to subregions, which are also the units used in so-called bio-regional economic models. Long-distance transport induced by globalisation, the fetishisation of comparative advantage are among the major accelerators of the destruction of the environment. The bioregional model is not a 'back to basics' type of concept but an economic philosophy in which economic participants focus on using local resources and satisfying local needs in a non-hierarchical society. In a society built on regions there is space for the development of multicultural communities that accept the existence of a variety of values, and whose members of society are interdependent. This approach strongly counters the model prompted by the middle and top-level managers of today's large and medium-sized companies (multinational firms) who accept that their mission to increase the value of shares at any cost is an unquestionable truth. Milton 
Friedman, the so-called spiritual father of economic liberalism, goes as far as to state that the socially responsible executive (one who spends more on environmental protection than prescribed by law) is unilaterally imposing costs on shareholders.

While Richard Welford's bioregional model (Welford-Gouldson, 1992) confronts globalisation and considers it a drawback rather than a blessing, the liberal approach believes in the 'quasi' omnipotence of market operations, and would prefer the existence of an economy without the intervention of the government or any kind of community.

The development of the economy in the past one hundred years indicates that it is capable of developing more efficiently if not hindered by government or other regulations. It has also been proved that the market is unable to resolve issues like poverty or social inequality. The market generates irresolvable contradictions by attempting to minimise the use of labour as a production factor when a state of maximum employment is more desirable from the perspective of society. Rates of economic growth or consumption are defined by the size of the human population, the complexity of ecosystems, as well as how much, what, and in what way an individual consumes.

The concept of sustainable development has undoubtedly had a major influence on the economy, for example by supporting the spread of environment friendly consumption habits, clean technologies, and an appreciation for the significance of renewable resources and defining development as qualitative rather than quantitative growth.

\subsection{The principles of sustainable development}

The main message of the World Bank's 1992 report entitled Development and the Environment (World Bank, 1992) according to the authors is that protecting the environment is a part of development. Development is impossible without this, and without development the investment necessary for environment protection cannot be made.

The concept of sustainable development in the broader sense also includes sustainable economic, ecological and social development, but there is a narrower interpretation that limits the content of the term to the environmental realm (i.e., to the optimal use of resources and environmental management).

According to this latter, narrower interpretation, to foster sustainable development the services of natural resources (Chapter 4) and their quality must be preserved. 
From the perspective of sustainable development, natural resources are usually divided into three groups:

- renewable natural resources (water, biomass, etc.),

- non-renewable ones (e.g. minerals),

- semi-renewable ones (e.g. soil fertility, waste assimilation capacity).

The requirements for sustainable development can be summarised as follows:

- the consumption rate of renewable natural resources should be less than or equal to the rate of their natural or managed regeneration;

- the production of waste should be less than or equal to the environment's capacity for assimilation;

- a reasonable pace of exploitation of now depleting resources should be encouraged, which is partly defined by substituting depleting resources with renewable ones, and partly by technological progress.

Violation of the principles described above will lead to a paucity of resources, if:

- environmental services and assets are elementary to and indispensable for the existence and operation of the economic system;

- the opportunities for substituting reproducible capital and environmental functions are not satisfactory;

- environmental health is not increased by technological progress.

The three criteria above suggest a certain amount of caution. Economists have been wrong a number of times because they did not take the new opportunities created by technological progress into consideration.

Human technological ingenuity, one of the two components of economic development, seems inexhaustible in terms of the exploitation of energy and other resources. The other component, the stocks of these resources which this ingenuity can make profitable, seems, however, very much limited. Stocks are dwindling and their quality is becoming poorer. The situation is not disastrous, but the warning signs are clear.

The concept and principles of sustainable development offer an alternative pathway, and may halt these unfavourable effects. However, sustainable development as a concept and a possible alternative is disputed by many. Everybody agrees on one point though: adhering to the basic principles of 
sustainable development is useful for mankind. The nine basic principles are as follows (IUCN, 1991):

1. Attention and care for communities

2. Improvements in human quality of life

3. Conservation of Earth's viability and diversity

- conservation of life-supporting systems

- conservation of biodiversity

- guaranteeing the continuous usability of renewable resources

4. Minimisation of the use of non-renewable resources

5. Keeping the development of economy and society within the limits defined by Earth's carrying capacity

6. Changing people's attitudes and behaviour

7. Enabling communities to take care of their own environments

8. Creating national frameworks for integrated development and environment protection

9. Establishing global cooperation

Between 2000 and 2030 the world's population will grow by 2.5 billion, the demand for food will nearly double, industrial production and energy consumption will triple, and in relation to this, the rate of developing countries is expected to quintuple. This growth suggests the risk of environmental disaster, but also the opportunity to create a better environment and conditions for providing mankind with basic goods, clean air, and healthy water. Which of the alternatives will happen basically depends on political decisions and politics.

\subsection{Strong and weak sustainability}

The roots of sustainability (Hicks, 1939) are found in Hicks' idea that 'a man's income is the maximum value which he can consume during a week and still expect to be as well off at the end of the week as he was at the beginning'. In 1970, when the outlines of the environmental crisis were already visible, the same John Hicks claimed that a few grains of sand in the wheels of international finance would do the job of slowing down development. The so-called Tobin tax (which is basically a currency transaction tax) is just being re-invented by the EU bureaucracy and domestic politics for a similar purpose. It may seem strange that what was then expected to slow down development is now hopefully going to intensify the growth of the economy.

Ecological economics builds its concepts about sustainable development partly on Hicks' Theory of Wages (Marshall-Toffel, 2005). The need for equality between generations that appears in the Brundtland definition of SD is also 
rooted in the history of a theory known as the Solow-Hartwick sustainability rule (Marshall-Toffel, 2005). This rule states that consumption is sustainable and may grow even if the rate of non-renewable resources drops, provided that the benefit generated by the use of these resources is invested into reproducible capital. In 1920 Marshall wrote: 'When capital ceases to increase, income likewise will stop growing. Hence seeking to keep capital intact should be seen as fundamental to income generation.' (Marshall, 1947). Environmental economists keep repeating this when referring to natural capital, but their words fall on deaf ears. Natural capital is decreasing because hardly any effort is being made to replace what has been consumed.

The discipline of economics has attempted to create a quantitative description of the concept of sustainable development. Pearce and Atkinson (1992) differentiate three types of capital:

- $\mathrm{K}_{\mathrm{M}}$ - man-made (or reproducible) capital (roads, factories, residential buildings, etc.),

- $\mathrm{K}_{\mathrm{H}}$ - human capital (compiled knowledge and experience), and

- $\mathrm{K}_{\mathrm{N}}$ - natural capital, which is interpreted rather broadly, and includes natural resources (minerals, soil), but all other natural goods crucial for maintaining life like biodiversity, pollution assimilation capacity, etc. (see Chapter 4)

Considering these three capitals, Pearce and Atkinson (1992) establish the Hicks-Page-Hartwick-Solow rule, which is a formulaic description of the concept of sustainability. The authors differentiate between so-called 'weak' and 'strong' sustainability. According to Pearce and Atkinson (1992) 'weak sustainability' can be expressed using the following formula:

$$
\frac{d K}{d t}=\frac{d\left(K_{M}+K_{H}+K_{N}\right)}{d t} \geq 0
$$

The formula is based on the assumption that capital goods are interchangeable without limit. In the economic sense, a state of weak sustainability exists if the value of capital goods available to society does not decrease over time. The 'weak' sustainability criterion, according to Pearce and Atkinson, can be written using the following formula:

$$
Z=\frac{S}{Y}-\frac{\delta_{M}{ }^{*} K_{M}}{Y}-\frac{\delta_{N}{ }^{*} K_{N}}{Y}
$$

where S - savings, $Y$ - Gross Domestic Product, and $\delta_{M}$ and $\delta_{N}$ are the amortisation rates of man-made and natural capital, respectively. 
Pearce-Atkinson also defines criteria for strong sustainability. The condition of realising a state of strong sustainability is that, with positive $Z$, natural capital should not devaluate over time. In this case, interchangeability among capital elements is not allowed:

$$
\frac{\delta_{N}{ }^{*} K_{N}}{Y} \geq 0
$$

Ecologists (and scientists in general) for obvious reasons reject the idea that capitals are interchangeable and thus the concept of weak sustainability; moreover, they also have problems with strong sustainability since the latter also allows for compensation and interchangeability within the realm of natural capital. In terms of strong sustainability, most ecological economists claim that no irreversible changes (e.g. extinction of species) should be allowed to occur in nature. This condition is of course impractical and leaves ecological economists with a concept which barely allows for the development of practical ecological policy.

According to the reference literature on economics, there is a sustainable course of development which makes sure that 'average (per capita) wealth' does not decrease. The initial approach is for economists not to 'bother' to apply a clear-cut definition of wealth, supposing that more (i.e., a growing) GDP is equivalent to higher quality of life.

The graph below illustrates possible paths of economic development (Figure 1-3).

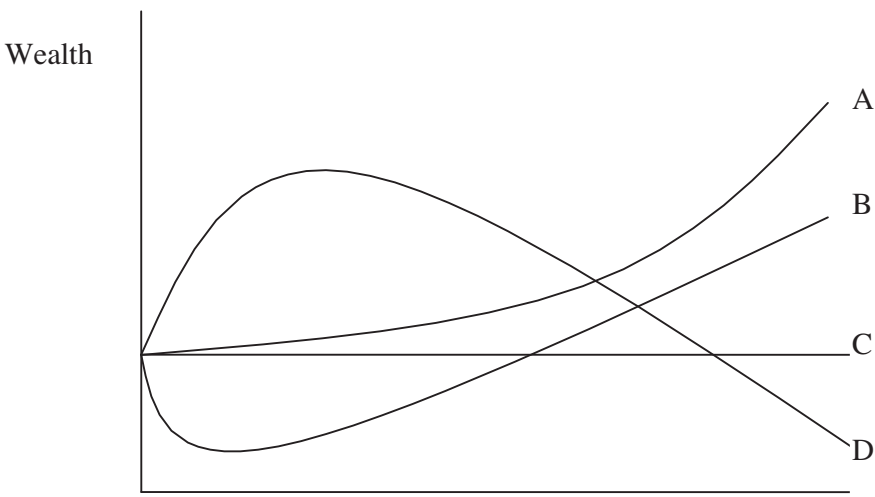

Time

Figure 1-3. Sustainable (A,B,C) and non-sustainable (D) development paths ${ }^{2}$

2 Based on Meadows-Meadows-Randers (1992) where the autors are listing the possibilities of the population growth (pp. 27-28). The B path is the author's supplement. 
Path $A$ in Figure 1-3. illustrates continuous growth in wealth. Path $\mathrm{C}$, according to the definition, is sustainable, although it is questionable whether it involves 'development' at all. Path D is non-sustainable in the long term, while it may be temporarily sustainable. Path B seems to be non-sustainable in the short term and sustainable in the long run. As the figure indicates, there is already enough trouble with interpreting sustainability without theoretical debates about the interpretation of the difference between wealth and well-being, or trying to interpret the difference between weak and strong sustainability.

Let us progress from the simple to the complex, and use the figure to examine the four possible paths and any problems that they raise.

With Curve A we can characterise, for example, the incessant growth of manmade capital on Earth. Road networks, accumulated scientific knowledge, or technologies that we bequeath to future generations suggest our responsibility to future generations. Optimists say that future generations will not need as many natural resources, because they will be able to use the infrastructure created by present generations.

Infrastructure: This refers to society's facilities and structural elements which create the basis of economic and social development. The development of infrastructure has a direct influence on standard of living and the performance of the economy. Elements include traffic facilities (roads, railways, seaports and airports), public utilities (water, gas, oil pipes, sewage systems, waste management and treatment facilities), residential and public buildings, commercial and media networks, educational, health, sports and social facilities. Their effect on the environment may be positive or negative. We must consider the removal, controlled management and elimination of sewage and waste as positive, while the harmful effects brought about by the occupation of land and use of infrastructure (e.g. motorways) are clearly negative, with costs frequently borne by the immediate environment as well as the whole of society (Láng, 2002).

Line $C$ supposes that wealth is constant in time. This is conceivable if we suppose that the economy grows only at a rate equal to population. The parallel line then only signifies constancy.

Curve D characterises a 'non-sustainable' path of development which is lamentably typical of developed countries and recently also developing countries. The excessive use of natural resources and a cheap labour force temporarily support growth in wealth. Later, however, a heavy price will be paid for environmental degradation and impoverishment, which decreases wealth in the long run.

The literature usually disregards the viability of the typical development path represented by curve $B$ (due to its lack of compliance with even weak sustainabil- 
ity criteria). This approach results in a temporary decrease in wealth before generating growth in the long run. Such a path results from investment into natural capital. Afforestation, for example, involves significant initial expenditure, and most of the economic benefits of this will be realised only $50-80$ years after planting.

Sustainable development can obviously be interpreted in a number of ways. It is worth, however, differentiating between three basic types:

1. Sustainability may be interpreted as constant consumption. This interpretation fits the criteria for weak sustainability, whereby natural and man-made capital are considered interchangeable. Levels of production and per capita consumption are sustainable as long as the profit generated by the use of natural resources is not consumed, but invested into material capital.

2. Sustainability may be interpreted as a stock of natural resources that is constant in time. This interpretation matches ideas about strong sustainability, which supposes that natural and man-made capital may supplement but not substitute each other in production.

3. Finally, sustainability may be interpreted as equality between generations. This approach differs from the previous two in that it makes no provision regarding the interchangeability of natural and man-made capital, but has a focus on a none-too-well defined requirement of creating, some kind of equality among generations' instead.

As we have seen, the first two types of sustainability are clearly amenable to economic approaches. Furthermore, weak sustainability would be economically possible even within the framework of the dominant paradigm. Most of the EU's environmental directives only help fulfil weak sustainability criteria. The IPPC directive, for example, in terms of preferring 'Best Available Technology' (BAT) requires cost-benefit analysis so that the selected 'best' technology is also cost effective.

The second definition, strong sustainability, is a category interpretable in economic terms, but the existing economy does not meet these criteria, and at most attempts can be made to approach them using a 'safe minimum standard'. The building of a motorway or a power station, for example, is sure to decrease biodiversity no matter what, and cause an irreparable loss of natural capital.

The third definition is not interpretable in an economic sense at all; this suggests that the approach may provide grounds for argument but it is as yet impossible to build a practical environmental policy on it. It may not be a coincidence that this least of all palpable concepts is also least well known to the public. 


\section{The background to environmental problems from the perspective of natural sciences}

\subsection{Introduction}

In the following section, various environmental problems will be classified and discussed in terms of environmental elements, thus we address issues involving the atmosphere, water and soil. In the discussion, the background to environmental problems and their basic context will be defined from the perspective of natural sciences in a highly concise manner, primarily for readers trained in social sciences. In an effort to define basic contexts that are able to stand the test of time, this chapter dispenses with dealing with trends and charts that are subject to rapid change, and which therefore become rapidly obsolete.

\subsection{Problems concerning the atmosphere}

Normally (i.e., in the case of ,clean' air), the atmosphere consists of a number of components; the $85 \mathrm{~km}$ stratum adjacent to the surface of the planet thus contains $78 \%$ nitrogen, $21 \%$ oxygen, and $0.9 \%$ argon. These are constant percentages, and oddly enough, the much-talked-about major air pollution problems are restricted to the remaining $0.1 \%$ of atmospheric components. This also indicates how sensitive a system we are dealing with when we address problems affecting the Earth's biosphere.

Yet, owing to the presence of a variety of material components, it is not that easy to tell at a glance what should be defined as pollution. For instance, does pollution include atmospheric nitrogen, or the carbon dioxide emitted by humans and other living creatures that are not photosynthetic? To help resolve such problems, the following definition is proposed by environmental economics: pollution is considered to include any emission that is introduced into the environment at a rate faster than the environment is capable of processing and assimilating it. That is, the natural environment has a certain waste processing capacity for most of our discharges which is a valuable renewable resource, although it may become overloaded. Obviously, this approach is also readily applicable to water and soil.

Air pollutants may be classified according to various criteria; for the purpose of this chapter, we mention only one of the most important of these: atmospheric residence time. Based on this approach, a distinction is made between long-term air pollutants, which reside in the atmosphere for more than one year, and short-term air pollutants.

It appears logical that long-term pollutants remain in the atmosphere for several decades, or even centuries, because they are stable (i.e., non-reactive). Such materials are not toxic, and work their harmful effects primarily by upset- 
ting the radiation balance of the atmosphere. These stable gases have time to spread all over the globe, leading to global problems. The two most widely known and most significant problems related to long-term pollutants are global warming (climate change) and ozone depletion.

\subsubsection{Global warming (climate change)}

The essence of global warming lies in the greenhouse effect, which is a useful process in itself, because in its absence the annual average temperature of the Earth would be $33^{\circ} \mathrm{C}$ less than it is today. The problem arises when this effect is intensified. The phenomenon is attributable to molecules that consist of three or more atoms - water vapour $\left(\mathrm{H}_{2} \mathrm{O}\right)$, carbon dioxide $\left(\mathrm{CO}_{2}\right)$ and methane $\left(\mathrm{CH}_{4}\right)$ - which comprise the most important greenhouse gases. These gases, trap' heat in earth's atmosphere that would normally escape into space, thus producing a ,greenhouse' effect. Given the fact that water vapour also has a cooling effect on the atmosphere, we limit our discussion to the latter two.

$\mathrm{CO}_{2}$ emissions are part of the carbon cycle of living nature (e.g. respiration), and as the quantity of $\mathrm{CO}_{2}$ emitted is absorbed by the natural environment, the atmospheric concentration of $\mathrm{CO}_{2}$ has been stable over the past millennia. However, since the industrial revolution, and in the aftermath of the discovery and industrial combustion of fossil fuels (carbon, mineral oil, and natural gas), $\mathrm{CO}_{2}$ has been released in quantities that have led to an unprecedented buildup of this gas in the atmosphere. The build-up of methane is attributable to ruminants (cattle, sheep, etc.) farmed by humans in the millions, as well as to emissions from landfills and rice paddies. The concentration of atmospheric methane has doubled since the industrial revolution.

The combined result of these two main effects (and a number of others) is that the greenhouse effect appears to be intensifying. This claim has been corroborated by a recent series of record-high temperatures, accompanied by melting glaciers and changing precipitation patterns. Importantly, the observed phenomenon should preferably be referred to as 'climate change' rather than, global warming' because although the global average temperature is indeed rising, this could in fact lead to the cooling of certain areas of the Earth.

Preventing the process would require humankind to make extremely costly sacrifices, involving placing our entire energy management system on new foundations. The most obvious solution would be to curb consumption in the 'developed' countries which have primary responsibility for the phenomenon; however, they have not shown even the slightest willingness to do this. Technological development suggests either the production of atomic energy (another serious threat to life), or the production of renewable energy (wind, hydro-electric, solar, etc.). However, the latter has not yet reached (and it is questionable whether it ever will reach) the level at which it can produce the volume of energy required to meet demands. A chance 
to switch to renewables only exists within a dispersed, less centralised economic structure that relies on local resources. Due to the high expense involved and the selfishness of developed nations we have not been able, or only with great difficulty, to even hammer out agreements that require only negligible reductions in $\mathrm{CO}_{2}$ emissions. See, for example, the Kyoto Protocol of 1997, compliance with which would only slightly mitigate the rate of warming by 2100 . More radical changes are needed, but for the time being there is little hope of their implementation.

\subsubsection{Ozone depletion}

The ozone layer filters out radiation that is harmful to life, and thus prevents it from reaching the surface of the Earth. The first observations of ozone depletion were made in the early 1980s above the Antarctic; since then the impact of the phenomenon has been felt across the globe. Should the process intensify, the rays of the Sun could easily reduce all land-borne life to ashes.

Investigation of the cause of ozone depletion have found that halogens (fluorine, bromine, and in particular chlorine) have been introduced to the stratosphere (i.e., atmospheric stratum at altitudes of $18-50 \mathrm{~km}$ ) where the ozone layer also exists. The situation may appear contradictory at first: given that these elements are extremely aggressive and reactive (which would make them short-term air pollutants at most), they might be expected to transform and leave the atmosphere before leaving the stratosphere. The contradiction is resolved by knowledge of halogenated hydrocarbons (CFCs).

These compounds are entirely artificial and thus are not found in nature. They were developed in the 1930s and, owing to their extreme stability, were subsequently used in a variety of industrial applications in vast quantities. They are specifically suitable as coolants, plastic foaming agents, propellants, siliconchip cleaning agents, etc. Some types are so stable that they can reside in the atmosphere for centuries, which explains their extensive build-up in recent decades. When reaching a high (stratospheric) altitude and hit by high-energy sunrays, they become unstable, and the halogens contained in them are released. These elements (in particular, chlorine) are responsible for ozone depletion.

In view of the extremely long atmospheric residence times of these halogenated hydrocarbons, the complete restoration of the ozone layer will take decades, even if prompt action is taken. That said, international conventions have made major achievements, whereby the artificial gases causing the problems will be completely phased out in a few decades (first in 'developed' and then in 'developing' countries). Of course, the ban is rather due to the fact that the materials can now be replaced profitably than by the responsible and unselfish thinking of humankind. Using that rationale, today the ban on halogenated hydrocarbons is being championed by the very companies that originally developed them, since they already have replacements ready to be marketed, and 
will gain a competitive advantage from the ban. While this sheds a negative light on international conventions from an ethical perspective, the existence of a ban or even a curb on the use of these chemicals is definitely welcome.

The rest of this chapter addresses the problems caused by short-term air pollutants which exit the atmosphere within a year and are toxic due to their reactivity.

\subsubsection{Acid rain}

Even in a normal case (i.e., when air is clean), precipitation is slightly acidic because of a large number of air pollutants of natural origin (e.g. volcanic eruptions). That acidity, however, does not cause any particular trouble to life on Earth, because life has become accustomed to it over millions of years. If, however, the concentration of such air pollutants increases as a result of human activity, acidification may reach harmful proportions.

The phenomenon of acid rain is in fact associated with the self-cleaning of the atmosphere, which is a highly beneficial process. Namely, air pollutants gradually exit the atmosphere; obviously, more reactive materials (short-term air pollutants) do so more quickly. Cleaning may take place either mechanically, or in the form of chemical reactions. The most basic chemical reaction involving such 'self-cleaning' is oxidation, the primary products of which are acids. For example, the nitrogen oxides emitted by motor vehicles produce nitric acid, the sulphur dioxide emitted in the course of burning coal produces sulphurous acid, and burning PVC produces hydrochloric acid. These acids are then precipitated to the surface of the Earth through rainfall.

As the materials concerned are short-term pollutants, it appears logical that the problems caused by them should at most be local or regional in scale, and not global. For example, carbon incinerated on an industrial scale in Great Britain has caused severe damage to Scandinavian pine woods, but has little worldwide impact. Damage from acid rain can be seen in both the built environment (e.g. in the rapid crumbling of historical monuments made from limestone) as well as in the natural environment. Due to higher levels of acidity, (1) nutrients are dissolved at evergreater depths; (2) heavy metals, which are hazardous toxins, become dissolved in water (mobilised) and are thereby introduced into the food chain; and (3) disruptions occur to the functioning of plant stomata, especially those of conifers. The most effective safeguard against acid rains is to decrease the emissions of short-term air pollutants, which may partly be done by means of technological development, and partly by reducing consumption (e.g. car use and energy generation).

\subsubsection{SMOG}

The term smog was coined from the words smoke and fog. The word adequately captures the essence of the phenomenon it describes, characteri- 
sed by the permanent accumulation of solid and fluid pollutants (lasting up to several days), mostly in cities and their surroundings. Interestingly, however, the concentrated emission of a significant volume of pollutants is an essential but in itself insufficient prerequisite of the phenomenon. Smog also requires a completely natural meteorological phenomenon: thermal inversion.

Normally, in the lowest 10,000 metres of the atmosphere (the troposphere), air cools from the bottom up (i.e., the sun first warms up the surface of the Earth, which subsequently transfers its heat to the lowest atmospheric layer. When this warms up, it simultaneously also expands and rises (convection), carrying with it the air pollutants emitted at surface level). It is owing to this phenomenon that rising warm air is constantly replaced by an inflow of fresh (clean) cool air, making life bearable even in large cities, as far as air pollution is concerned.

At times, however, sudden warming starts at altitudes of 800 to $1,500 \mathrm{~m}$, creating a vertically stable layer that is cold at the bottom and warm at the top. Ultimately, this thermal inversion acts like an invisible lid placed on top of a surface, under which pollutants rapidly accumulate if emitted in significant volumes (e.g. in large cities). This peculiar meteorological phenomenon can occur both in winter (a London-type smog, caused primarily by coal heating) and in summer (a Los Angeles-type smog, primarily a result of motor vehicles). When it does occur, the best hope is that wind will soon freshen and disperse the inversion layer, sweeping out the polluted air that has accumulated underneath. Calling a smog alert involves the highly expensive ex-post treatment of a symptom which does not improve the critical situation that has already arisen, but only reduces the chance of it worsening.

\subsection{Problems affecting water}

Most of the water on Earth is saline, which is unsuitable for direct human consumption but an important part of ecosystems. Also, most freshwater is locked up in snow and ice, leaving an extremely small fraction in the form of easy accessible fresh surface water and groundwater. The latter are becoming increasingly scarce resources, and as they are rather unevenly distributed on Earth, numerous future conflicts are expected to arise over drinking water. For the time being, the desalination of saline water is an extremely costly process, which only a few 'oil countries' in the Middle East can afford.

The initial approach to the pollution of water is similar to the approach to air pollution described in Chapter 2.1. That said, as regards water it should be pointed out that aquatic ecosystems can suffer damage from both pollution (a qualitative problem) and drainage, irrigation and overuse (a quantitative problem involving the destruction of wetlands). 
One particular type of 'water pollution' involves the introduction (intentional or unintentional) of alien species, as exemplified by the eel introduced into Lake Balaton, or the Nile perch into Lake Victoria in Equatorial Africa. The latter fish had no natural enemy in the lake, and as a result of its extreme voracity virtually devoured $60 \%$ of the wildlife in the lake after which the remaining $40 \%$ were declared endangered.

Water pollution is defined as any effect that changes the quality of surface water or groundwater by making such water less suitable or unsuitable for human use, or respectively, for the maintenance of the life processes accommodated within it. While this regrettable outcome may have a number of causes, the essence of almost all types of pollution is captured adequately by addressing one of the most important issues: oxygen balance.

Aquatic life depends on oxygen, which is found in water in dissolved form. One source is the atmosphere itself (the oxygen which is dissolved through the airsurface interface), and the other is photosynthesis, a process involving the release of oxygen. However, the organic matter in the water (e.g. the remains of dead animals and plants) must decompose in one way or another, which requires the presence of oxygen (aerobic decomposition). If the oxygen dissolved in the water is sufficient to provide the oxygen required for decomposition, no problems will arise; however, an excessive quantity of organic matter that decomposes can easily lead to a shortage of oxygen. This will trigger rotting (anaerobic decomposition), first leading to the destruction of higher-order species (fish), and accelerating eutrophication. For that very reason, the quantity of organic matter introduced into living waters makes a difference because that matter will ultimately decompose.

Biological Oxygen Demand, BOD: the volume of oxygen needed for the microbiological decomposition of organic substances dissolved, colloidal and suspended in a volume of water, capable of decomposing. Regarding the diversity, quality and availability of the substances and a number of external factors (temperature, light, the food and oxygen demand of the actual environment, the presence of toxic substances, etc.), the circumstances of decomposition are extremely variable. The measurements needed for the establishment of BOD are usually carried out at $20^{\circ} \mathrm{C}$, in total darkness, over a 5 or 20 day period of time. The establishment of the BOD of the water sample provides basic guidance regarding whether which technology is suitable for treating the polluted water.

Chemical oxygen demand, $C O D$, oxygen consumption: a measurement of the reduction capacity of substances in water in the presence of an oxidant (e.g. acidic potassium-dichromate, acidic potassium-permanganate, free chloride, iodide, iodine, etc.). The result is given in the equivalent of oxygen consumed by a volume of water. COD is proportionate to the volume of organic substances found in the water. (Láng, 2002) 
Using this proxy, the main types of water pollution can be clearly defined. For example, when introduced into water, excessive quantities of (1) phosphorus (from detergents and excrement) or (2) nitrogen (from over-fertilisation) act as nutrients and stimulate the growth of plants, which will subsequently consume oxygen when decomposing after their death. (3) Detergents foam on the surface of water, where they inhibit the dissolution of atmospheric oxygen into water while also filtering sunlight, which decelerates the process of photosynthesis and the release of oxygen. (4) Pollution from oil spills causes similar problems, and water birds may become exhausted if their plumage becomes oily. (5) Thermal pollution occurs with industrial processes that require vast amounts of cooling water (e.g. nuclear power plants). Water returned at a higher temperature can contain a smaller quantity of dissolved gases (including oxygen), while metabolic processes are also accelerated in warmer water, producing more dead organic matter. When due care is not exercised, thermal pollution may also accelerate eutrophication. Finally, (6) toxic materials (such as heavy metals and pesticides) do not inflict damage by disrupting the oxygen balance, but are poisonous in themselves.

To prevent the above types of pollution, wastewater should be treated before its discharge into receiving waters. Wastewater treatment comprises the following stages: (1) Mechanical treatment, involving the removal of solid pollutants prone to sedimentation, and the treatment of the sludge that is produced; (2) biological treatment, involving the use of decomposers (protozoa) to decompose the organic matter in wastewater through an aerobic process (in the presence of oxygen) or an anaerobic process (in the absence of oxygen), thereby preserving living waters; (3) chemical treatment, involving the use of chemicals for the removal of nutrients, phosphorus and nitrogen. Importantly, in the presence of toxic materials chemical treatment must precede biological treatment, otherwise the decomposers would be poisoned and thus prevented from being effective.

\subsection{Problems affecting soil}

Soil is the uppermost layer of the solid lithosphere, reaching approximately 5 metres in depth, which, by virtue of its accommodation of living organisms, also constitutes a part of the biosphere. The life processes and physical phenomena (e.g. weathering) that occur here collectively form soil, the fertility of which (within that $5 \mathrm{~m}$ layer) is progressively reduced with depth. Consequently, the most fertile layer is the uppermost one, which is the most exposed to destructive erosion by environmental elements (wind and water). This is exactly why one of the key tasks of environmental protection with regard to soil is conserving its original composition and structure. Similarly to the quantitative problems that affect water, this problem is also of a quantitative nature.

In the context of soil pollution the effects of industry, transport and urbanisation, although not negligible in themselves, will not be discussed for reasons 
of space, so only the problems caused by agriculture will be highlighted. Disregarding secondary salinization due to irrigation, the main cause of problems is the use of chemicals. Chemical use has become widespread for two main reasons: the need for (1) soil management, and (2) plant protection.

It has long been known that the fertility of soil becomes depleted over time, and that land must be left fallow and/or the nutrients lost in the course of harvesting must be replaced. Previously (and in some places even today, on a small scale) nutrient replacement involved spreading farmyard manure, which practice has largely been superseded by the use of fertilisers. The latter provides for the replacement of nitrogen, phosphorus and potassium, which typically become scarce but are essential for plant growth. Fertilisation can easily be mechanised and will almost immediately produce higher crop yields. On the other hand, notable drawbacks of fertilisation include the depletion of microelements that are also essential for the development of plants, and the 'migration' of misused fertilisers which stimulate growth in living water in exactly the same way as they do on land. The harmful effect of this is discussed in Chapter 2.3 in the context of water pollution. Moreover, when fertilisers are used, farmyard manure mostly remains unutilised, and will in the case of largescale animal farming pollute the environment in the form of slurry, creating a new task for environmental protection.

Chemical plant protection is also a product of modern large-scale agriculture. In the beginning (the 1950s), the chemicals that were used (e.g. DDT) had permanent toxic and generally destructive effects, but the former were soon found to accumulate in the food chain and disrupt ecosystems by causing severe poisoning, and ultimately returning to humans via food. Drawing a lesson from these findings, today's chemicals must be selective (destroy in a targeted manner), and decompose rapidly. This will obviously not eliminate all problems related to chemical use: the agents employed today may potentially cause a number of known and currently unknown forms of harm. A meaningful goal would be to eliminate the use of chemicals completely.

Integrated plant protection aims to do just this in an effort by reducing the presence of pests to a reasonable level rather than by causing wholesale destruction. That end may be met by means of (1) relying on the natural hierarchical links within the food chain (e.g. aphids should be fed to ladybirds rather than sprayed); and (2) cultivating more resistant plant varieties. The latter deserves more detailed discussion.

The need to alter the properties of plants (and animals) has long existed, and can only be fulfilled by improvements: desired properties can be produced by crossing two related species as a result of a long series of experiments, usually plagued by failure. Among other achievements, this is how crab apples the size of peanuts were improved into ,huge', red, durable tasty apples. At the same time, the hardiness of the improved plant is considerably reduced: while 
a forest produces wild fruits each year with no help, a fruit orchard requires constant attention (weeding, pruning, spraying, etc.).

Today, new opportunities are created by genetic engineering (biotechnology), allowing the genes responsible for the features of a species to be replaced with genes that transmit features that we consider to be more advantageous. Of course, these other genes can be transferred from any other species, allowing tomatoes to be crossed with flatfish (for example, if there is a need for a frost-tolerant tomato). By doing this we may be shorting out nature's internal defence system (which we rely on for improvements), gradually shaping the entire flora and fauna to our own demands. On the one hand, such technology is very alluring: it allows humankind to increase the vitamin content of fruit and to improve crop yields and hardiness, and even for certain bacterial strains to be, programmed' to produce specific medicines.

On the other hand, the technology grants particularly dangerous powers to humankind. (1) The features of humans are determined in the DNA in exactly the same way as those of other animals and all plants, making it possible for humans to become the means (this has already happened) or the ends of any utilitarian genetic interventions, (2) Gene transfers may also transfer features which are unknown at the time, and are only discovered subsequently. For instance, a new plant could become carcinogenic or allergenic, and this might be realised only decades later, (3) When the pollen of such plants are released, it might cross with that of wild (non-manipulated) species, allowing the modified features to be transferred. From that point on the process is effectively irreversible as released pollen can never be 'recalled'. Although humankind has indeed made plenty of errors to date (see also DDT accumulation in the food chain, and the emission of the halogenated hydrocarbons that cause ozone depletion, etc.), a timely response still leaves room for the reversal of the processes. By contrast, gene manipulation is irreversible, which is why various green movements have protested against it, and notwithstanding all its benefits, Christians also reject it on the grounds that it involves humans aspiring to assume a divine role.

What is more urgently needed in agriculture is the transposition of old practices into contemporary circumstances: the restoration of closed material cycles, and the production of healthy, residue-free food from local ingredients that relies on local resources. Indeed, a complex approach to agricultural production is needed, whereby the essence of agriculture is not limited to the production of food but also incorporates social and environmental considerations (multifunctional agriculture). This objective may be achieved by organic farming (not to be equated with biotechnology) which prohibits the use of any chemicals or genetically modified inputs, is much more labour-intensive than industrial agriculture, and as such is much more liable to sustain rural populations, foster cultural landscapes and help maintain biodiversity. 


\section{Our planet's limits: tipping points}

\subsection{Introduction}

In 2009, Rockström et. al published a very important article about 'planetary boundaries'. This report was as influential on public thinking as the first report by the Club of Rome, 'The Limits to Growth'. The new ideas were again linked to the Swedish capital of Stockholm. Scientists defined important planetary tipping points in ten dimensions, eight of which were defined in 2009. Continuing the research in 2015, the boundaries were redefined and the authors broadened the zone of uncertainty. The very important category 'resilience' was introduced and has been widely discussed by experts in all fields of science. In this chapter we discuss the ecological footprint, which is a single-indicator system, but which employs the so-called 'global hectare', a dimension of measure with a significant relative value and absolute volume. The ecological footprint is not an indicator of welfare but of sustainability, which certainly also indicates the state of our welfare. Generally, if we have a large ecological footprint, we obviously feel that our needs are being satisfied at a higher level. However, the indicator clearly warns us that a high standard of living is 'enjoyed' at other people's cost. A large ecological footprint is not sustainable. GDP is a macro-indicator which, despite its many flaws, is commonly used and accepted, because in spite of all its errors it is relatively easy to calculate and gives a fair preliminary overview of the state of the economy.

\subsection{Main dimensions and their tipping points}

Following the climate conference held in Copenhagen, the scientific team organised by the Stockholm Resilience Centre in Sweden published a study in Nature magazine which affected professionals' thinking at least as much as The Limits to Growth did when published in 1972. The authors claim that in three out of $8+2$ dimensions ${ }^{3}$ humanity has already overstepped the limits of a safe existence. The main limits that have been crossed involve the emissions of the greenhouse gases that cause climate change, increases in nitrogen flows due to fertilisation and concentrated animal farming, and the radical decrease in biodiversity.

3 1. climatic change, acidification of the oceans, 3. the thinning of stratospheric ozone, 4. the nitrogen cycle, 5. the phosphorus cycle, 6. global fresh water consumption, 7. changes in land use, 8 . changes in biodiversity, 9. changes in the aerosol content of the atmosphere, 10. chemical pollution 


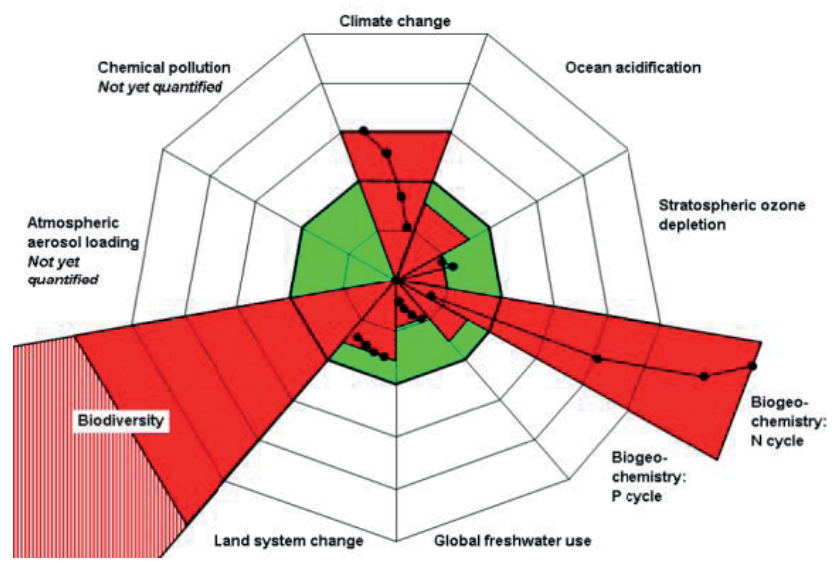

Figure 3-1. Planetary Boundaries (Rockström, 2009)

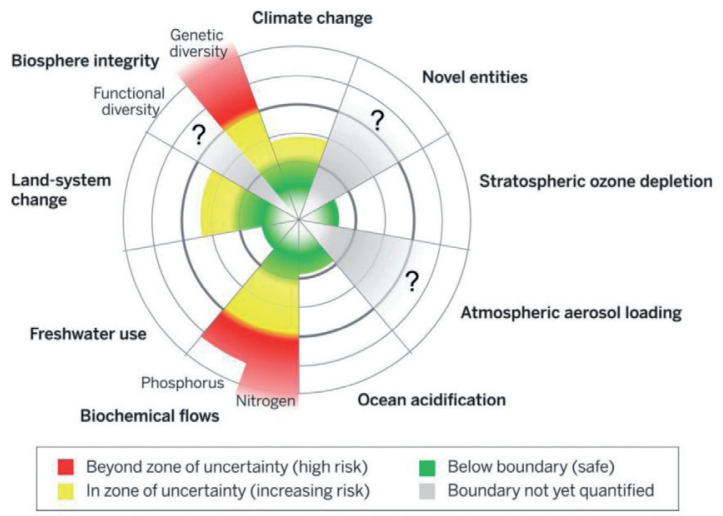

Fig. 3-2. Planetary Boundaries II (Steffen et al., 2015)

The authors of the study felt certain enough in eight areas to be able to define critical limits and state how far mankind is from the so-called tipping points. Regarding chemicals and atmospheric particles, the analysis was postponed.

As far as the climate goes, we know that the carbon dioxide concentration in the air was 280 ppm in the Holocene, which created ideal conditions for human evolution over the past fourteen thousand years. The 'critical concentration' is somewhat higher than this; some professionals suggest it lies around 
$400 \mathrm{ppm}$. As indicated by the figure below, scientists think that until the critical point is reached, changes can be prevented, and Earth will be capable of compensating by flexibly adapting. Beyond the limits, effects are irreversible.

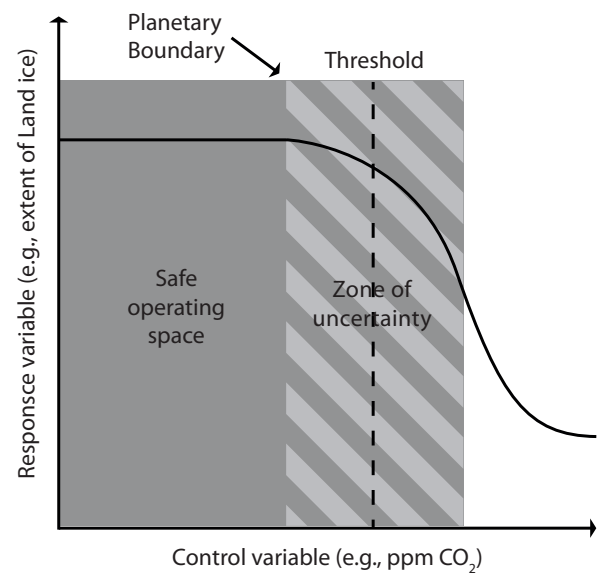

Figure 3-3. Planetary boundaries III (Rockström, 2009)

GEO-5, the latest global assessment report of the UN's Environmental Programme, also mentions the limits of planet Earth. Of course, scientists only agree that such limits exist, but opinions as to where these limits are tend to be very diverse. Our knowledge is insufficient, the context is extremely complex, and thresholds will probably only allow more precise definitions to be created later on. Some limits have been overstepped with no spectacular results, while changes at the global scale may occur without ever overstepping a single threshold. Spectacular changes like the melting of the polar ice caps or the retreat of glaciers can occur, while there are less spectacular ones like decreases in biodiversity. Overstepping the thresholds occasionally results in global effects such as damage to the ozone layer; other cases only have local effects such as pollution caused by nitrogen compounds. However, sudden changes ('tipping over') are well known in ecology. Conditions that cause rapid fish mortality may arise overnight, or even on a shorter timescale as the combined impact of a number of ecological factors. This can be true of larger systems, which is what is really dangerous. The mixing of local and global dimensions of issues may also cause problems. Nitrogen overdoses may cause local problems in China, while Africa may welcome the increased use of fertilisers for fighting famine. Many scientists claim that human interventions into the functioning of Earth have by now become so significant that the Holocene is already over and has been replaced by the so-called Anthropocene - a time when the future of the planet is fundamentally influenced by human activity. 
'The history of life on Earth - as Rachel Carson says - has been a history of interaction between living things and their surroundings. To a large extent, the physical form and the habits of earth's vegetation and animal life has been molded by the environment. Considering the whole span of earthly time, the opposite effect, in which life actually modifies its surroundings, has been relatively slight. Only within the moment of time represented by the present century has one species - man - acquired significant power to alter the nature of his world.' (Carson, 1962, Chapter 2)

In ecology, the 'carrying capacity' of a given territory is considered to be the largest possible population with a long-term survival ability that does not cause harm to the given territory. We may raise the theoretical question how many people the Earth can accommodate at an acceptable or preferred level.

The calculation is complex because we have no knowledge about:

- the resources future generations will use, or,

- the course of development developing countries will take.

The best possible and the worst possible scenario may be very different. Historical experience proves that optimists may have grounds for their beliefs: they claim that individuals make discoveries, so if enough individuals think about the solution to a problem they will be able to find one (Julian Simon). The recent change in the dimensions of the problems, however, counters the more optimistic perspectives. So far the economy has been dwarfed by the size of the biosphere, but it is now becoming dominant.

Supporters of the optimistic approach claim that today's generation may leave less natural resources for generations to come, but that our successors will have a higher standard of technology and a larger amount of capital (Vorosmarty, 1991) .

Regarding the future of the Earth, it is crucial how limited the planet's carrying capacity is, and how much the limits of carrying capacity are resistant to erosion.

Carrying capacity, of a landscape, of environment: 1. The possible rate of complex exploitation (living, production, recreation) of the landscape in a given territory that expresses the largest possible number of population it is able to accommodate for the purpose of living and manifold social activity. The $\sim$ of a landscape may be examined separately by the basic forms of activities with the consideration of how $\sim$ is limited or intensified by the rest of the activities. - 2. Ecological strategies. - 3. A central category of ecological economy. Its meaning is identical to sustainability, only it refers directly to ecosystems (unlike the previous term which is an indicator of human activity. (Láng, 2002) 


\subsection{Carrying capacity and Meadows' models}

Possible interactions between Earth's carrying capacity and economy are summarised in the following models by Meadows and colleagues (1992):

1.) According to one model, the physical limits of certain resources may increase together with the economy, as illustrated in the models presented in Figures 3-4. Such resources include the fertility of the land, which can be intensified by bringing unproductive lands into productive use, amelioration of existing land through use of chemicals and irrigation, active selection of seeds, and the improvement of agro-technology in general.

The pollution assimilation capacity of the Earth can also be increased through technological intervention. The self-purifying ability of surface waters or soils can be improved through a process of aeration, the decomposition of waste can be accelerated by increasing its surface area, etc. There are a number of well-known examples of technologies that reduce the exhaustion of raw materials; it enough to think of the results of solid-state physics or energy-saving lights or the uptake of the use of fibre optic cables in micro-electronics, etc.

Although there is a long list of arguments that support the aforementioned model, it is obvious that there are areas where expanding such limits has not been successful yet. Think of the development of the ozone hole, the dangers of global warming, etc.

a)

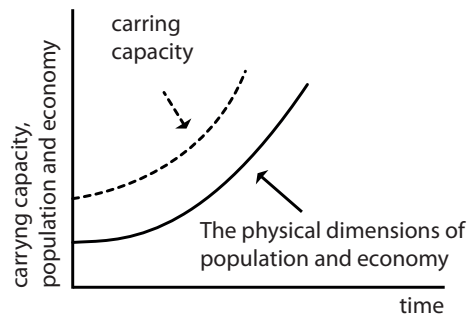

c)

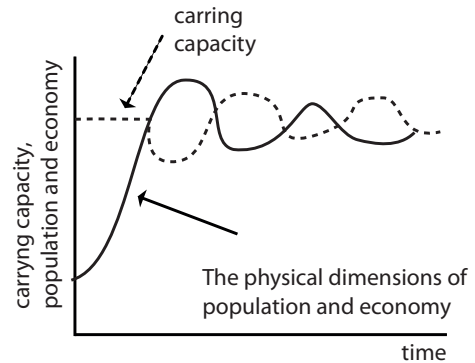

b)

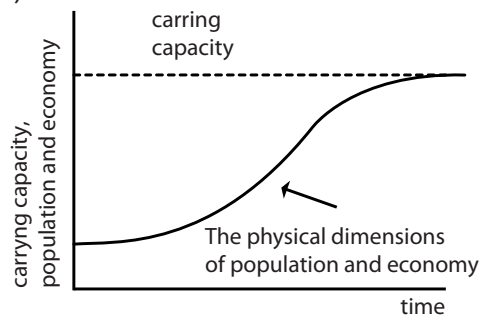

d)

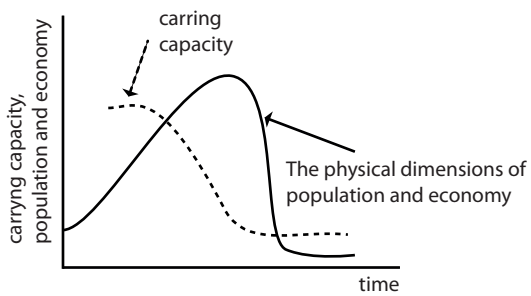

Figure 3-4. Models of the potential interrelations between carrying capacity and the economy (Meadows et al., 1992) 
2.) Model b. in Figure 3-4. provides an example of logarithmic expansion; it suggests that the economy and population exponentially grow for some time, then growth stops and a state of permanency is established. This model supposes that feedback communicated by the physical limits of the carrying capacity of the environment will trigger an immediate economic response, or that the population size and economic growth are self-controlling and do not require external intervention. This growth model is supported by a lot of practical experience. Think of the observation that at over a certain level of development, the size of population, specific raw material and energy consumption, etc. explicitly decrease, thereby stopping total consumption from growing, even with rising GDP.

3.) According to Model c. in Figure 3-4., the physical dimension of the economy exceed carrying capacity because feedback and interventions are delayed, yet limits are not eroded, or quickly regenerate. In this case, economy and carrying capacity reach a state of balance with fluctuations of shortening amplitude. Examples include when fish stocks decline due to overfishing, but restrictions help stocks recover within a few years or decades. A similar situation can occur in the case of oil pollution or excessive detergent load in a river After pollution ceases, the wildlife in the river will regenerate sooner or later. Luckily, this is what we observed in the years following the cyanide pollution of the River Tisza.

4.) Model d. in Figure 3-4. is the ,disaster model'. Here, due to delays in feedback and interventions, processes cause such damage to carrying capacity that it cannot regenerate through natural processes; the system degrades and carrying capacity also decreases. A local example is drought, which may be the result of overgrazing. Other disasters like Chernobyl with century-long consequences can be mentioned. Disasters involve irreversible changes in the biosphere involving the extinction of specific animal or plant species, etc.

Civilisation disaster: the possibility of the partial or total collapse of civilisation as a result of environmental changes wrought by man. Mankind is capable of destroying its own civilisation in several ways: 1. technology and knowledge, the purposeful or accidental use of which (e.g. nuclear stocks and equipment) may bring about the total destruction of humanity. 2. Over-pollution of the environment may change ecological conditions even on a global level, which may lead to (e.g. global climate change, desertification etc.). 3. The use of natural resources above carrying capacity, unless any substitute resource is found in time, may lead to the collapse of human civilisation. (Láng, 2002) 


\subsection{Natural and social resilience}

Scientists consider a system that is operating within the safe zone of operation to be flexibly adaptive. The phenomenon of resilience ('elastic deflection') is well known in mechanics, but is also applicable to the biosphere and social phenomena. Related research commenced in English-speaking countries when C. S. Holling established in the 1970s that resilience includes a system's load-bearing capacity, performance, and adaptivity-that is, its efficient operation, as well as its permanence, conservation capacity, and persistence.

Resilience, generally speaking, means flexible capacity for resistance; i.e., a system's creative ability (the system being either an individual, an organisation, an ecosystem or a type of material) to successfully adapt to powerful, renewing, or even shock-like external effects.

Resilience in psychological terms means the quality, or rather ability, to regain one's original healthy state after physical or mental suffering or after having lived through critical life situations.

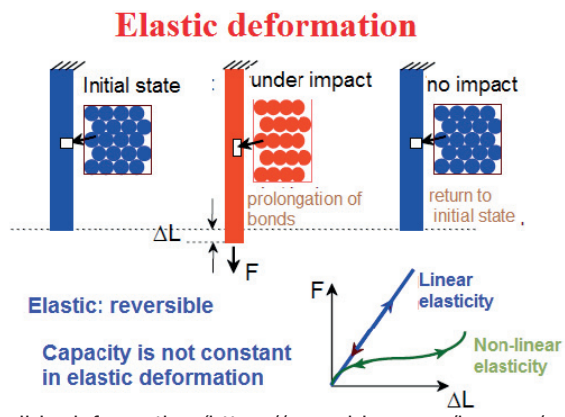

3-5. Figure Elastic / reversible deformation (https://www.bing.com/images/search?view=detailV2\&c cid=WT3IVHd9\&id=9BB9A88C0672C6D0C8A99DEC81FABB84E8491066\&thid=OIP.WT3IVHd9VPL qnKqi7Ca86wEgDY\&q=elastic+deformation\&simid=608009552505078228\&selectedindex=3\&mode $=$ overlay\&first $=1$ - accessed on 16/04/2018)

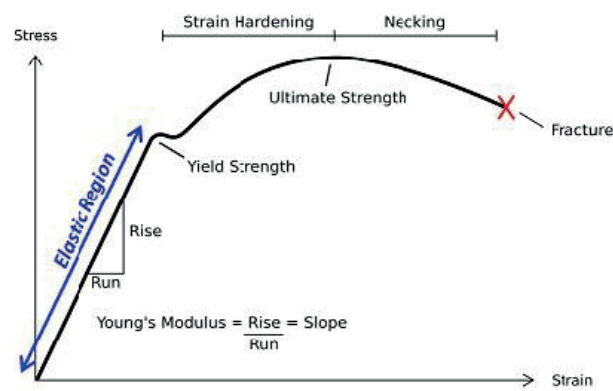

Figure 3-6. Tensile strength diagram, resilience of metals

(http://pediaa.com/wp-content/uploads/2015/09/Difference-Between-Stress-and-Strain-Stress_vs_ Strain_Curve_for_a_ductile_material.jpg - accessed on 16/04/2018) 
Resilience: External force causes deflection in bodies. If, once the effect has ceased, the body fully regains its original form, the deflection is called elastic. The difference between elastic and permanent deflection appears in reversibility: in the stage of elastic deflection a body will regain its initial size and form once the strain has ended, while in the permanent deflection stage it will not; this means plastic deformation is typically irreversible.

A nice example of resilience is described in the following way by the outstanding Hungarian ecologist Juhász-Nagy Pál: 'Well, let us take Lake Balaton as a sort of 'reactive person' who says things like: 'So you've taken away the Little Balaton and the forest groves? No problem, I'll build myself my 'New Little Balaton' in Keszthely harbour. You've stolen my natural lakesides? Trouble's trouble, but I'll build myself a more or less unbroken stripe of reeds to take care of my cleaning needs-better than nothing... You make me swallow all kinds of poison, faeces, and slurry? Rather unpleasant; what is more, disgusting. But I'll try to compensate for all this by re-organising the coenological relations, the trophic network, I mean for as long as I can' (Juhász-Nagy, 1984).

Resilience suggests a decentralised or regionalised 'planned economy' as opposed to the type of centrally planned economy that we experienced in this region before the political changes, and one which we may rediscover thanks to an EU bureaucracy plagued by management difficulties. But what does resilience mean for the social sciences and ecology? Obviously something different than for a mechanical engineer. Walker, Holling, Carpenter and Kinzig (Walker, 2004) discuss the three concepts of 'Resilience, adaptability and transformability' together, the interactions between which they think determine the resistance capability and stability of systems against external shock. 'While the technological flexibility approach focuses on the steady state and defines the amount of disturbances needed to move the system from one stability domain to another, 'ecological flexibility' is characterised by the amount of changing circumstances, which the system is able to absorb before its structure transforms due to the modification of variables, processes and the nature of management' (Walker, 2005).

The sustainable relationship between nature and man requires that attention is directed to ecological flexibility because its central concern is the space between stabilisation and destabilisation: present-day development, global environmental change, the decrease in biodiversity, the degradation of ecosystems, and sustainable development. The term technological flexibility, however, gives the dangerous impression that natural systems may be efficiently managed, that consequences are predictable, and that sustainability goals are achievable (Walker, 2005).

A flexible, adaptable and thus sustainable social-ecological system is characterised by the following characteristics:

- maintenance of diversity and support for its preservation (biological, landscape, economic and social), 
- limitation of ,human control' of ecological diversity,

- respect for modularity (combined systems withstand shock better),

- recognition and emphasis of the importance of education, social networks and locally developed rules.

For sustaining the operability of a flexible and adaptable social-ecological system it is necessary to:

- ensure prompt feedback (e.g. in the case of a drought, immediate irrigation is needed, with no time to wait for EU support policy to change). If there is no demand for selectively collected waste paper, its energy content must be exploited by burning it before it is otherwise destroyed. There may be no time for month- or year-long discussions;

- direct the attention of politics to slow variables and accumulations, despite the fact that politicians are disinterested in them: they are not newsworthy. In the case of a flood or a fire, funds are always made available for making good the damage, while nobody really cares about the slow demolition of dams. A slow increase in nitrogen or the accumulation of heavy metals in the soil is a graver problem than the occasional foaming of the River Rába. The latter, luckily, attracts attention, while the former does not;

- appropriately divide private and public property, and overlapping rights of access. The state appears to be a bad proprietor, which is why proponents of a liberal economy want to privatise everything. The state may be a bad proprietor in an economic sense, but it is good in the ecological sense, such as in the case of public assets (e.g. drinking water). Moreover, it may also be good with non-public assets (energy supplies) where private owners may be able to cut prices but are unable to ensure safe supply;

- strictly punish and increase social disdain for fraud. The health of the environment and society will only be ensured through an appropriate system of moral values;

- create an overlapping institutional system (that functions at different levels of decision-making). The principle of subsidiarity not only means that decisions should be taken at levels where the information is available, but also that higher (hierarchical) levels should support lower levels with problem handling. Expertise, material resources and perhaps coercive measures are required if, for example, a local government driven by economic interests destroys the living conditions of local inhabitants. Some settlements in the metropolitan agglomeration have engaged in such conduct;

- incorporate non-priced ecosystem services into development proposals. The construction of a motorway, a wind farm, a landfill or a sewage system involves environmental destruction, the rate of which may be decreased only if impact assessments are prepared and alternative proposals are also examined; 
- maintain openness to change: an atmosphere supportive of innovation and experiments presupposes trust in the institutional system. It is worth trying everything at a small scale before scaling it up. Smaller shocks are best met through the flexible reactions of ecosystems and society;

- strongly commit to avoiding major shocks and quick responses

- feedbacks to large volume effects.

\subsection{The ecological footprint}

The past two decades since 2000 have witnessed a number of initiatives aimed at the quantification of the effects of the economy on the environment. The most comprehensive and most successful attempt of all has definitely been the measurement of ecological footprints. The ecological footprint is not a welfare but a sustainability indicator, and it is due to the method of calculation involved that it is discussed in this chapter.

The ecological footprint expresses the annual renewability of the biosphere in hectares, either in terms of land or sea surface (i.e., what size of area is necessary for reproducing a given population's resource needs in a given year, considering widespread technologies and resource management practices). The use of area as a measure of life-supporting natural capital is based on the fact that the part of our planet's surface where photosynthesis takes place is the fundamental 'unit' of services provided by ecosystems.

The total national ecological footprint measures the biologically productive area which provides the full range of resources consumed by a population and absorbs/assimilates all the waste produced by a population, considering existing technologies and management systems. The present methodology that is considered to be up-to-date uses four thousand pieces of data per country per year to calculate the ecological footprint (Wackernagel et al., 2005).

The measurement of the ecological footprint dates back around fifteen years. Two basic methodological approaches are recognised.

1. The original approach constructs the ecological footprint from the elements (components) of the population's resource consumption and waste production. To do this, the consumption element first has to be defined (i.e., how much and what the population consumes). Then, lifecycle analysis is applied to explore using a ,cradle-to-grave' approach the environmental consequences of this consumption, considering both resource use and the effects on the environment's pollution assimilation capability. The reliability of the method depends on the level of detail the components of consumption are explored with. Considering the effects of environmental impact, how the boundaries of the lifecycle analysis are defined may result in inaccuracy/variability.

Results are significantly influenced by how complex supply chains are. In the case of more complex supply chains, double-counting often occurs. The 
differences between production technologies may also significantly affect the ecological footprint, of course, provided the same product or service can be produced at different levels of eco-efficiency.

The economic footprint, built up from a number of elements, in spite of its doubtless advantages is associated with a number of flaws. The most serious of all is the immense complexity and quantify of information that is required, which makes it rather expensive to calculate, while for most uses per-itemlevel detail is superfluous. Environmental policies work with aggregate data in any case, and detailed information is often wasted.

2. Considering these flaws, the new methodology calculates the ecological footprint using aggregate data provided by national statistics. The prerequisite is that the environmental impacts of the components/elements of consumption are known, allowing the calibration of the footprint from the aggregate data. The calculation of national footprints does not take into account the impact caused by, for example, different kinds of paper (wrapping paper, newspaper, printing paper, etc.); it is enough to examine the 'aggregate' environmental consequences of the production or consumption of a kilogram of 'statistical paper' (Wackernagel et al., 2005).

Dr. William Rees is a bioecologist by training, and former Director of the University of British Columbia's School of Community and Regional Planning (1994-1999), Dr. Rees is best known for his work on the 'ecological footprint' - an analytical tool for measuring how many hectares of land are capable of providing a community with energy and raw material at a specified given level.

'Throughout university I was constantly in search of what I thought should have been obvious, something called human ecology: the study of human beings as species of organism. I couldn't find it an-

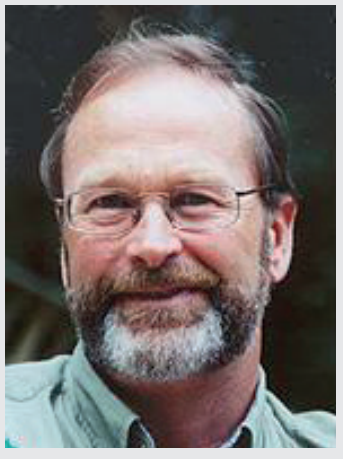
ywhere. It astonished me that academic ecologists and professional ecology had no focus at all on humans; it was all oriented to non-human species. I failed miserably to find any course that treated human beings as species. We were just beginning to think of environmental studies and that sort of thing, but that's not human ecology, that's really impact ecology.

In the seventies I began to develop at the planning school this notion of ecological footprint analysis. It's grown since, and we've now got the book out for the last five years. It's in six languages and selling all over the world and it's having, I am gratified to say, quite an impact on the way people think about sustainability, human carrying capacity, and so on'.

Gismondi, M. (2000). Dr. William Rees interviewed By Dr. Michael Gismondi. (aurora.icaap.org). 
The calculation of the ecological footprint is based on the following six presuppositions (Wackernagel et al., 2005):

1. National resource consumption and waste production is recorded by national and international organisations. Annual values are measured in physical units (tonnes, joules, cubic metres, etc.).

2. The volume of biological resources suitable for human consumption is directly correlated to the biologically productive area needed for regeneration and the assimilation of waste.

3. Provided the size of individual areas is evaluated in terms of their usable biomass productivity, different types of land can be expressed as standard, average bioproductive areas. These standard values are called global hectares, the fertility of which is equal to the expected annual average value of one hectare (averaged across the whole planet). This standard calculation is valid both for the ecological footprint and existing biocapacity.

4. All lands are expressible in global hectares, and their size is calculable by summing up the area needed for resource supply and waste assimilation. This means that no pieces of land are accounted for twice; one separate piece is needed for the production of resources, and another for the assimilation of waste. This certainly does not mean that a piece of land cannot perform two functions at a time. A forest, while providing timber, is also capable of protecting against floods. When calculating the ecological footprint, however, land units are counted only once according to their primary function.

5. Aggregate human needs and the supply of services provided by nature can be directly compared since both are measured in hectare equivalents.

6. The area of demand may exceed the area of supply. If the ecological footprint is larger than ecological capacity, it means the renewal capacity needed for subsistence exceeds the capacity of the natural capital. Overuse is considered to be 'ecological deficit', and can be compensated for in two ways. One option is through imports that take place through foreign trade involving the use of another country's natural capital. The other option - only temporarily, of course - is to overuse natural resources, although this involves the devaluation of natural capital.

\subsection{Calculating the ecological footprint}

Calculation of the ecological footprint occurs in two phases. The first involves the definition of the ecological supply (or bioproductive area). Next comes the calculation of the demand for nature (the ecological footprint). A total 11.2 billion hectares of biologically productive area is incorporated into the calcula- 
tion; this is the area that can be taken into account from the perspective of resources that can renew. The distribution of the presently existing area can be seen in the table below (Table 3-1.).

\begin{tabular}{|l|l|l|}
\hline \multicolumn{3}{|c|}{ Distribution of biologically productive area } \\
\hline Sea and lake & & 2.3 billion hectares \\
\hline Land & & 8.8 billion hectares \\
\hline - cropland & 1.5 billion hectares & \\
\hline - grazing land & 3.5 billion hectares & \\
\hline - forest & 3.6 billion hectares & \\
\hline - built-up area & 0.2 billion hectares & \\
\hline
\end{tabular}

Table 3-1. Distribution of biologically productive area on Earth (Global Footprint Network)

The area defined above can be considered determinant from the perspective of the planet's carrying capacity. It is very likely that at least $80-90 \%$ of total global biomass is produced in this area.

To calculate the ecological footprint, we need to know the average productivity of the 11.2 billion hectares (i.e., average productivity per global hectare). Productivity in this case does not refer to actual biomass production but the maximum 'yield potential' with the current agricultural input. A biologically productive area with favourable circumstances may substitute for several hectares of lower fertility. To take the different potential of areas into account, two types of conversion factors are employed. One is the equivalence factor, which applies to every country in the given year; the other is the yield factor, which is specific to every country and given year. The latter helps convert every biologically productive area into global hectares.

An example of the equivalence factors used in practice are shown in Table $3-2$., which indicates that 1 ha of biologically productive land was equal to 4.56 ha of grazing land in $2001(2.19 / 0.48=4.56)$.

While the equivalence factor facilitates the conversion between different methods of utilisation, the 'yield factor' helps when considering the differences between individual countries and the global average. The yield factor is different for each country each year. The yield factor takes into account not only differences in natural fertility, but also the dominant technological and organisational arrangements in the given location. In 2001, the biocapacity and ecological footprint of Peru was calculated using an equivalence factor (globally valid data) and a yield factor (data reflecting specific Peruvian potential) as illustrated in Table 3-2. The marginal biologically productive land yield factor is extremely high, due to the outstanding Peruvian olive plantations. 


\begin{tabular}{|c|c|c|}
\hline Bioproductive land & $\begin{array}{c}\text { Equivalence Factor } \\
\text { [gha/ha] }\end{array}$ & $\begin{array}{c}\text { Yield factor } \\
{[-]}\end{array}$ \\
\hline Primary cropland & 2.19 & 0.98 \\
\hline Marginal cropland & 1.80 & 2.57 \\
\hline Forest land & 1.37 & 0.82 \\
\hline Grazing land & 0.48 & 1.81 \\
\hline Sea & 0.36 & 3.39 \\
\hline Lake, river & 0.36 & 2.96 \\
\hline Built-up area & 2.19 & 0.98 \\
\hline
\end{tabular}

Table 3-2. Equivalence factor and yield factor (2001, Peru) (Wackernagel et al., 2005)

The major components of the ecological footprint are shown graphically in Fig. 3-7:

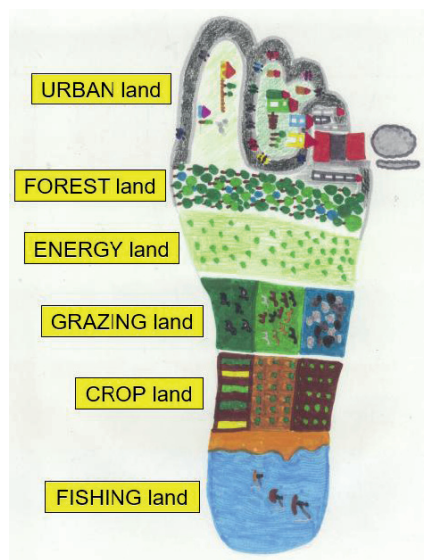

Figure 3-7. Major components of the ecological footprint (graphic by Imola Kocsis, (C2018)

The ecological footprint works by multiplying the size of areas (in ha) used for different purposes - cropland, grazing land, etc. - by the equivalence factor:

Ecological footprint (global hectare) $=$ Area $(\text { ha })^{\star}$ equivalence factor $(g h a / h a)$

Since the ecological footprint is intended to illustrate the consumption of the given country, its calculation should also take international trade (import-export) into account. Imports obviously increase the footprint, while exports decrease it. The issue of tourism poses an interesting problem. Tourist consumption is recorded where it takes place, and so is the fuelling of airplanes, not the location where 
airlines are established. This clearly influences the ecological footprint of some 'touring nations' and makes the footprint of, for example, Mediterranean countries, larger than would be suggested by the demands of the inhabitants alone.

The contribution to footprint caused by the use of fossil fuels and nuclear power cannot be measured as directly as in the case of consumed food of animal or plant origin. There are two options for the indirect calculation of the former. In the first case, the starting point is the area needed for the assimilation of the emitted waste (e.g. carbon dioxide). The other method focuses on the size of the area needed to produce the firewood equivalent of the fossil or nuclear power in terms of energy. The calculations arrive at different results, which fact must be taken into account during their interpretation.

\subsection{Calculating biocapacity}

The ecological footprint characterises the demand for the services of nature in a given country, while biocapacity captures the other side of the equation: suply of environmental services. The total biocapacity of a country is expressed in the volume of biologically productive area measured in global hectares. All of the bio-productive lands of different types are converted into hectares with the help of an equivalence factor and a nation-specific yield factor, which permit the calculation of the biocapacity of the given country for the given year.

Biocapacity $(\mathrm{gha})=$ Area $(\mathrm{ha})$ * Equivalence factor $(\mathrm{gha} / \mathrm{ha})$ * Yield factor $(-)$

Biocapacity expresses the theoretically available maximum resource supply of a given country which can be produced sustainably with widespread technologies and management systems. Biocapacity is a theoretical value which may not be maximised at any given time. For example, a country may have hard-to-access or protected areas which cannot be involved in the production of resource supply. This is why some calculations take the biocapacity of only accessible areas into account.

\subsubsection{Ecological deficit and overshoot}

Based on a comparison between ecological footprint and biocapacity we can decide if a country's natural capital is enough to sustain its consumption and production. If the ecological footprint calculated for consumption (gha) exceeds biocapacity (gha), we talk about an 'ecological deficit'.

Ecological deficit (gha) $=$ Ecological footprint ${ }_{\text {consumption }}$ (gha) - Biocapacity (gha)

In some countries, the ecological deficit is covered by imports; i.e., other countries' natural capital is used to satisfy needs. This category typically includes coun- 
tries with high population density like The Netherlands, or ones with unfavourable natural conditions like Ethiopia. Other countries such as Canada or Brazil have a biocapacity surplus, part of which they export. If the ecological deficit is impossible to cover through imports, which is usually the case in poor and geographically unfavourably situated countries, this will result in the overuse and depletion of natural resources. A typical example of the overuse of natural resources is the emission of greenhouse gases. The aggregate carbon dioxide emissions of the countries of the world are higher than the biosphere is able to absorb, leading to climate change.

The extent of 'overshoot' can be calculated for an individual country by comparing the ecological footprint caused by production with biocapacity.

$$
\text { Ecological overshoot }(\text { gha })=\text { Ecological footprint }_{\text {production }} \text { (gha) }- \text { Biocapacity }(\text { gha) }
$$

It is theoretically conceivable and common in practice that a country exports part of its biocapacity even when in a state of overshoot, thus using up its natural capital to promote the survival of its export activities. This often happens to countries that become caught in a debt trap.

The whole of the Earth has been in a state of overshoot since 1987. In 1987 the day when mankind had used up its resource supply for the given year fell on 19 December (World Overshoot Day). By 1995 this day had shifted to a month earlier (21 November), and by 2006 to 9 October. This suggests that mankind is consuming $30 \%$ more resources than the biosphere is able to produce in a year. The ecological deficit that we are leaving behind for future generations is thus accumulating in the form of climate change, decreases in biodiversity, decreases in the security of energy supply, water shortages, and other threats.

As shown in Figure 3-8., since 1967 Earth has been 'too small' for humankind, which is thus putting its own future at huge risk by overusing resources. The growth in the footprint is decisively caused by an increase in carbon dioxide emissions.

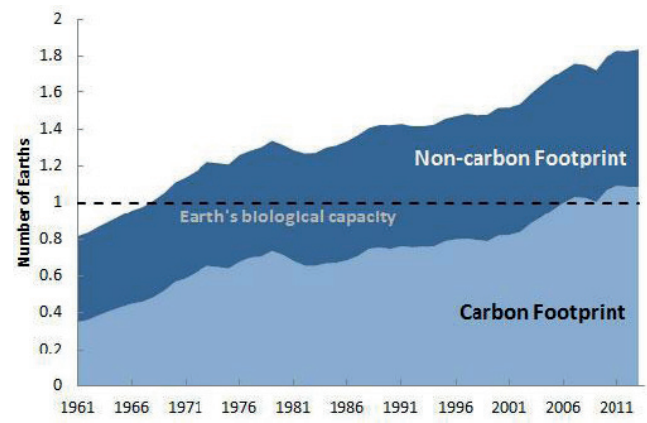

Figure 3-8. Change in the ecological footprint of humankind (https://www.footprintnetwork.org/our-work/climate-change - accessed on 16/04/2018) 
Calculation of the ecological footprint not only highlights the fact that the consumption of the whole of humankind has exceeded the carrying capacity of the Earth's biosphere, but also indicates the disparity that exists between so-called developed and developing regions in terms of resource consumption.

\section{Footprint by region}

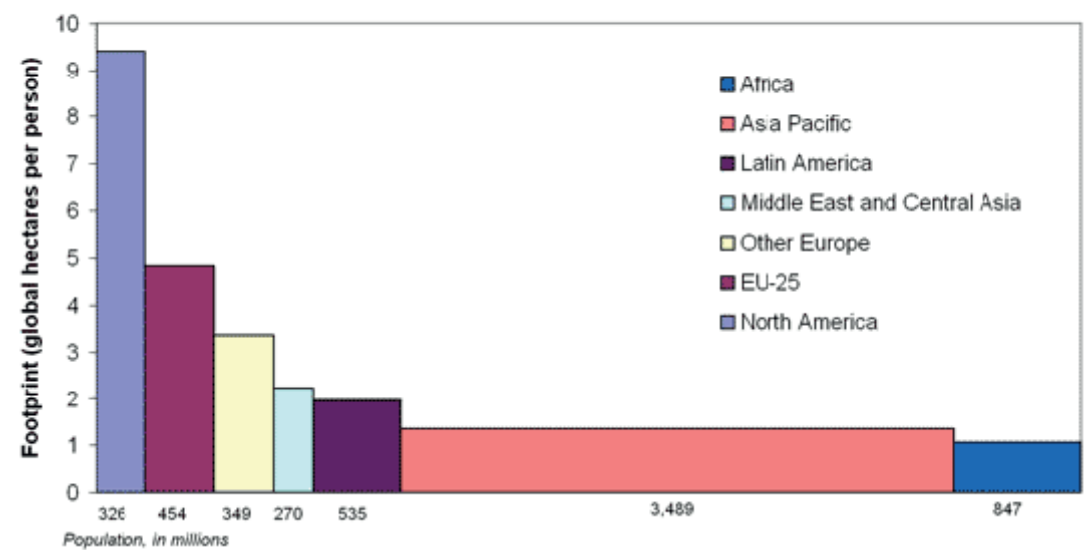

Figure 3-9. Population and the ecological footprint of individual regions of the world in 2006. (WWF)

As Figure 3-9. shows, one third of all the inhabitants of the Earth have a larger ecological footprint than they would be entitled to in the case that biocapacity were equally shared. Theoretically speaking, the footprint should be reduced to below 1.5 ha. Differences are sizeable even among OECD countries. The per capita ecological footprint of North America is nearly twice the of that of the average of the twenty-five European countries. ${ }^{4}$ Although Hungary improves (i.e., decreases) the EU average, the Hungarian footprint still exceeds existing biocapacity, which means that we are also suffering from a chronic deficit of resources (Figure 3-10.).

Growth in forest land in Hungary has favourably influenced the development of the footprint in the past two decades, but this has been compensated for by carbon dioxide emissions related to passenger transport (Figure 3-11.).

$4 \quad$ For a comprehensive analysis of ecological footprint and population density using the Intenscope analytical tool, see Kocsis (2014). For a historical perspective see Tóth-Szigeti (2016) 


\section{Footprint and Biocapacity}

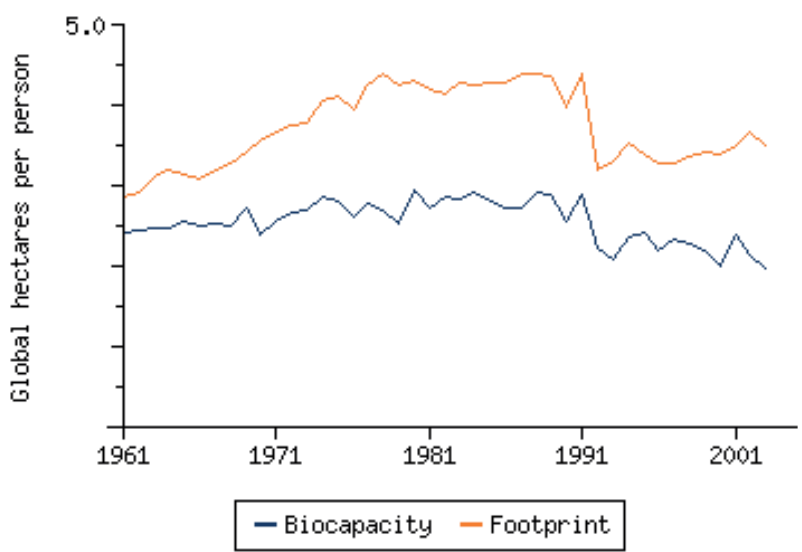

Figure 3-10. Development of average demand for resources (ecological footprint) and resource supply (biocapacity) in Hungary since 1961. Biocapacity changes annually, depending on the method of calculation applied, use of chemicals, weather, etc (based on Global Footprint Network data).

\section{Footprint by Component}

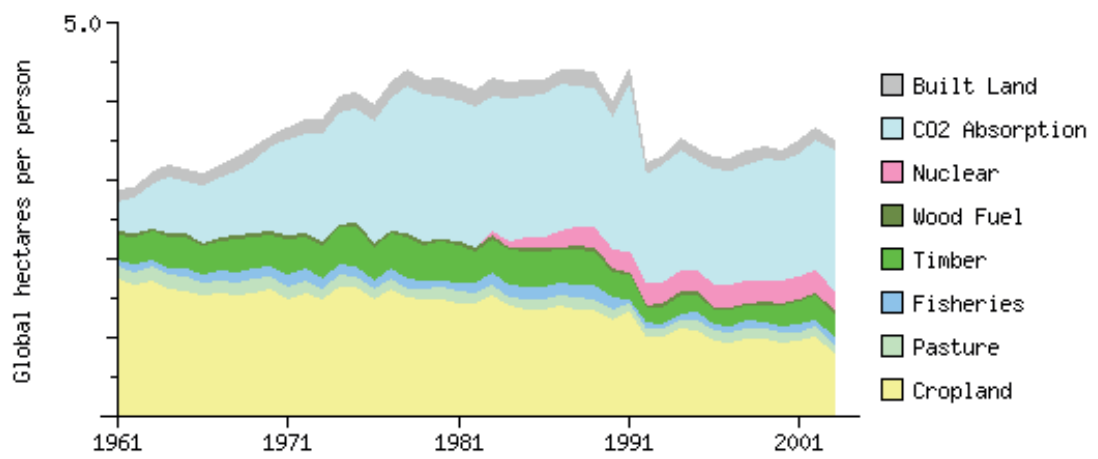

Figure 3-11. Change in Hungary's ecological footprint by components over forty-three years (based on Global Footprint Network data).

On the whole, Hungary's ecological footprint has not decreased to the extent that it could have as a result of structural changes in the economy. 


\subsection{Reliability of the calculation of ecological footprint}

There are a number of methods of calculating the ecological footprint, but the results vary over a relatively broad range. This arouses distrust in the method itself, while it is a fact that the past few years have witnessed remarkable improvement in the methods and the reliability of the data. The literature distinguishes six major types of potential methodological errors (Wackernagel et al., 2005):

1. Some theoretical and methodological errors originate from the fact that certain needs such as drinking water, soil erosion and the emission of certain toxic substances are not included in the footprint, which leads to underestimation of the deficit. The other group of errors are allocation errors which inaccurately distribute the environmental impacts caused by tourism and commerce between the supplying countries and the consuming countries. The latter, however, do not influence the validity of calculations on a whole-Earth basis.

2. Structural and data input errors. Techniques that test for the consistency of the data filter out major errors, but do not pick up smaller data errors which, taken together, may be significant.

3. The errors involved in estimates that replace missing data.

4. Statistical data for individual years are sometimes erratic. Attempts are made to filter these out using trend analyses, but they do not always work.

5. In United Nations statistics, some countries falsify data. A typical example is planned economies which, often supplying inflated production data, reduce actual logging rates, and inaccurately present the activities of the black and grey economy, making precise calculation impossible. Although inaccuracies in the data may be detectable, there is no way to correct them.

6. Certain data are lacking from UN statistics (concerning, for example, water shortages, or the biological effects of pollution, or the impact of waste on bio-productivity). If such data existed, they would increase the ecological footprint.

\subsection{Economic macro indicators (GDP, GNP) and their flaws}

Simon Kuznets, who invented the Gross Domestic Product (GDP) indicator, called attention to the fact that GDP is not a welfare indicator, and is flawed in a number of ways: 'The welfare of a nation can scarcely be inferred from a measure of national income ... Goals for more growth should specify more growth of what and for what' (Kuznets 1934). Since then, many individualspoliticians, first of all-have forgotten about the scholar's warning. The reason for this is that GDP proved to be easy to calculate and interpret, and although it is burdened with a number of problems as far as absolute figures are con- 
cerned, relative changes can be monitored with its help-with the necessary caution.

Gross Domestic Product: The total of goods produced domestically by home and foreign-owned companies. On the production side, this equals the sum of gross added value (i.e., the difference between outputs and intermediate consumption) created by economic units. On the consumption side, the gross domestic product equals the sum of products and services processed for final consumption, stock and export, having subtracted the value of products and services originating from imports (according to Hungarian Central Statistical Office).

International organisations such as the UN Human Development Programme have defined five exceedingly harmful types of GDP growth, adding that such growth 'is not sustainable or worth sustaining':

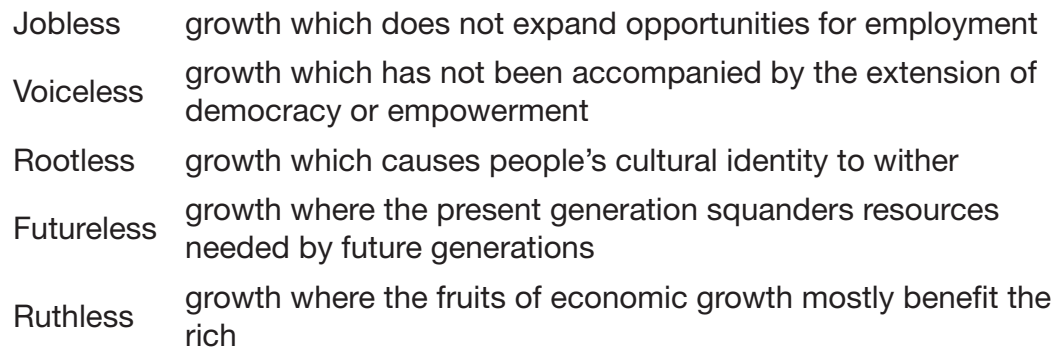

As reported earlier, growth in GDP in itself does not necessarily mean growth in welfare. Current alternative economic literature deals a lot with the flaws with GDP and GNP, describing the arguments against their use; however, these barely differ from those known about by researchers during the early period of the expansion of the use of the indicators. The most significant and commonly referenced counter-arguments are identified in Stiglitz, et al. (2010). This includes the following claims:

1. GDP does not incorporate the value of non-market activities of households and society-while this is where a significant share of products and services are created. The level of households and communities is where the activity most important for society takes place (raising children, cooking, cleaning, washing clothes, house maintenance and voluntary community jobs). These activities do not increase GDP because they do not involve cash flow. 
2. GDP does not measure or indicate how incomes are distributed among members of society. Growth in GDP does not necessarily mean that everybody's income grows; the income of the poor may not increase even when GDP does. The GPI (Genuine Progress Indicator) on the other hand, increases when the poor partake more of domestic product and decreases when their share falls.

3. GDP does not fully capture changes in the value of stocks in terms of built or natural capital. Sustenance of an adequate level of consumption requires the maintenance of the productivity of capital goods (capital stocks can be divided into several groups; two of which are built and natural capital. GDP conflates the value obtained by major technology acquisitions, investments into buildings and infrastructure - built capital - with the amount of money spent on them). GDP does not incorporate elements of natural capital such as minerals, fossil fuels and soil.

4. The use of GDP results in incorrect evaluations of preventative expenditures. The cost of equipment used to prevent environmental pollution (such as water filters) is incorporated in GDP as 'growth' (i.e., as being beneficial), while GPI considers such items as expenditure.

5. GDP ignores other components of the standard of life - like personal safety, the quality of the physical environment, and national identity.

6. GDP incorporates spending on crime, divorce and natural disasters as if they contributed to the economy. Any decay in society (in the form of legal costs, medical costs, and damages related to property) represent significant economic cost to individuals and society alike, but GDP incorporates these costs which are then perceived of as positive 'growth'.

In addition, the most significant problem may be the one ex-World Bank president Barber Conable bemoaned back in 1989; namely, that 'Unfortunately, GDP figures are generally used without the caveat that they represent an income that cannot be sustained. Current calculations ignore the degradation of the natural resource base and view the sale of non-renewable resources entirely as income. A better way must be found to measure the prosperity and progress of mankind.'

Despite all these well-known flaws, or perhaps exactly because of them, GDP and GNP are commonly used today. Present generations are loath to face the fact that the level of consumption reached in OECD countries is not sustainable. Moreover, politicians are expected to promise further growth in consumption. GDP is helpful for this purpose because it hides the fact that such growth is only possible at the cost of nature and future generations.

There is, of course, a pragmatic methodological explanation for using GDP. Efforts that have thus far been made to create alternative development indicators to replace GDP/GNP have had limited success mostly because the 
calculation of such indices - including GPI (Genuine Progress Indicator, 1995; Clifford Cobb, Ted Halstead and Jonathan Rowe) ISEW (Cobb and Daly), and HDI (UNDP), to mention only the most important ones - is laborious and often encumbered with subjective (weighting) considerations.

The issues with using GDP have long been known, and statistics offers us a number of solutions that present more realistic pictures about development and welfare, but not in the form of a single indicator. Although GDP increases in consequence of, for example, flood prevention activities (but national assets decrease), this is also indicated in annual surveys, and of course statistics also help us keep track of any decreases in cultivation areas, or changes in the state of forests. The problem is that obtaining this information requires combining a huge set of data. Accordingly, GDP is a single figure that should only be used as a 'thermometer'. Fever is only a sign of illness, and additional tests must be performed to determine the type of illness. GDP should similarly be treated as a warning indicator, and what it signals should be decided on the basis of detailed analyses. GDP does not express inequalities in income distribution, but this problem is easy to solve by using, for example, the Gini index, as illustrated below.

\subsection{The effect of economic growth on environment pollution}

Simon Kuznets, considered to be the pope of growth theory, was awarded the Nobel Prize in 1971. It may be natural that Kuznets viewed growth in an optimistic way. In a speech given at the former award ceremony, while acknowledging the negative effects of growth, he affirmed quite clearly that 'Two points are relevant here. First, the negative effects of growth have never been viewed as so far outweighing its positive contribution as to lead to its renunciation - no matter how crude the underlying calculus may have been. Second, one may assume that once an unexpected negative result of growth emerges, the potential of material and social technology is aimed at its reduction or removal. In many cases these negative results were allowed to accumulate and to become serious technological or social problems because it was so difficult to foresee them early enough in the process to take effective preventive or ameliorative action. Even when such action was initiated, there may have been delay in the effective technological or policy solution. Still, one may justifiably argue, in the light of the history of economic growth, in which a succession of such unexpected negative results has been overcome, that any specific problem so generated will be temporary - although we shall never be free of them, no matter what economic development is attained' (Kuznets, 1971). 
According to Grossman (1995), economic growth affects the quality of environment in three ways.

1. The so-called scale-effect, according to which larger (larger-scale) economic growth naturally generates larger-scale environmental degradation by raising demand for inputs including natural resources, thus necessarily leading to increased outputs in the form of waste.

2. The so-called structural effect, which may be favourable in the future. The first structural effects that hit economic activity - urbanisation, the shift from agricultural production to industrial production, etc. - had environmentally harmful effects. The present structural changes such as increases in energy efficiency, higher added value sectors and the spread of services can help reduce environmental impact per unit of GDP.

3. The technical-technological component of growth: this is a favourable effect because richer countries spend more on research and development, enabling them to replace polluting technologies with cleaner ones, thus decreasing environmental impact.

Back in 1979, Kuznets claimed that no-one had questioned the proposition that growth results in more good than bad, and that growth offers a means of offsetting the negative effects of technologies. After careful deliberation, Kuznets mentions six basic characteristics of modern economic growth:

1. Significantly faster growth of national product per capita and population in developed countries compared to earlier periods,

2. Significantly greater increase in work productivity compared to earlier periods,

3. High speed structural changes in the economy, agriculture taking a back seat and the developing dominance of industry first, and the service sector later. Companies take the lead from private enterprises, which changes employment circumstances,

4. Rapid changes in social structure and associated ideologies,

5. Transport and telecommunication technologies enable developed countries to easily access the rest of the world, leading to global convergence,

6. Despite economic growth, three-quarters of the world's population lives far below the standards which could be supported through the application of modern technology (Kuznets, 1971).

Kuznets's ideas significantly predate the emergence of the theory of sustainable development. While Kuznets was awarded the Nobel Prize, the writing of the first report of the Club of Rome entitled The Limits to Growth was already underway. Meadows's book was published in 1972, and expressed doubts 
about the long-term sustainability of growth as it considered the effects of growth to be rather positive than negative.

The Club of Rome: international group founded in Rome on the initiative of A. Peccei and A. King in 1968 with the goal of revealing to the world the dangers threatening mankind, so-called global issues. The is an independent organisation created from funds contributed to by researchers, scientists, scholars, outstanding personalities from every kind of cultural circle from around the world. Its primary mission is to discuss issues important for our planet and publish reports about them. Its general principles: 1. Take a global view, knowing that independent nations are unable to solve global problems; 2 . holistic thinking and getting to know the complexity of (political, social, economic, technological, environmental, psychological and cultural) problems; and 3. an interdisciplinary and long-term perspective on policies and decisions determining the destinies of future generations. The body published its first report entitled The Limits to Growth in 1972. There are 12 topics in the focus of the 's reports and discussions: economic development, employment, public education, food, health, water supply, environment, raw materials, energy, population, homes, urban life circumstances. The $\sim$ selected two Hungarian scientists as members; first, József Bognár, then János Szentágothai. From among Hungarian scientists living abroad, Ervin László and Dénes Gábor were authors of one report each. After A. Peccei's death, A. King, next Ricardo Diez Hochleitner, and later Prince El Hassan bin Talal became the 's new president. (Láng, 2002)

The authors of the Club of Rome certainly did not argue with Kuznets. Taking a close look at Kuznets's statements (above), it is obvious that the theory of growth of this economist, now considered a classic, encompasses all that researchers have criticised over the past thirty-five years. Kuznets views technological and social innovations as the basis of development, but also deems natural, social and cultural dimensions to be important by saying 'Thus, modern technology with its emphasis on labor-saving inventions may not be suited to countries with a plethora of labor but a scarcity of other factors, such as land and water; and modern institutions, with their emphasis on personal responsibility and pursuit of economic interest, may not be suited to the more traditional life patterns of the agricultural communities that predominate in many less developed countries' (Kuznets, 1971).

Kuznets certainly does not interpret GDP as an indicator of welfare; moreover, in the earlier-referenced paper he clearly states that 'the conventional measures of national product and its components do not reflect many costs of adjustment in the economic and social structures to the channeling of ma- 
jor technological innovations; and, indeed, also omit some positive returns. ... This shortcoming of the theory in confrontation with the new findings, has led to a lively discussion in the field in recent years, and to attempts to expand the national accounting framework to encompass the so far hidden but clearly important costs, for example, in education as capital investment, in the shift to urban life, or in the pollution and other negative results of mass production. These efforts will also uncover some so far unmeasured positive returns - in the way of greater health and longevity, greater mobility, more leisure, less income inequality, and the like..'

\subsection{The Theory of Environmental Kuznets curves}

A publication by the World Bank in 1992 (World Bank, 1992) claims that at a certain level of economic growth, growth and environment pollution decouple. This correlation is illustrated in Figure 3-12., which clearly shows that, after a certain point, while the number of cars, energy consumption, the population, etc. increase, pollution decreases on the whole. Economic growth and environment pollution thus become decoupled.

Dematerialisation, decoupling from material use: absolute or relative decreases in the volume of material used for and/or emitted waste per unit of economic output. According to the approach of $\sim$, the key to solving most ecological issues is provided by the quality and quantity of the material and energy flow between the technosphere and the biosphere. In compliance with the principle theorem of thermodynamics, all resources acquired from nature (inputs) sooner or later return to the same place in the form of polluting emissions or waste. Consequently, according to the strategy of $\sim$, reductions in the inputs of the technosphere (material use) will lead to reductions in harmful impacts on the biosphere. Different indicators of the $\sim$ are known: these include Total Material Requirement - TMR, Material Intensity per Service Unit - MIPS, etc. (Láng, 2002)

At more than ten thousand dollars per capita of GDP, environmental indicators such as sulphur dioxide emissions, the volume of untreated waste water, the lead and other heavy metal content of the air etc. clearly improve. Curves demonstrating such correlations are called Kuznets curves in environmental economics (Figure 3-13.). 


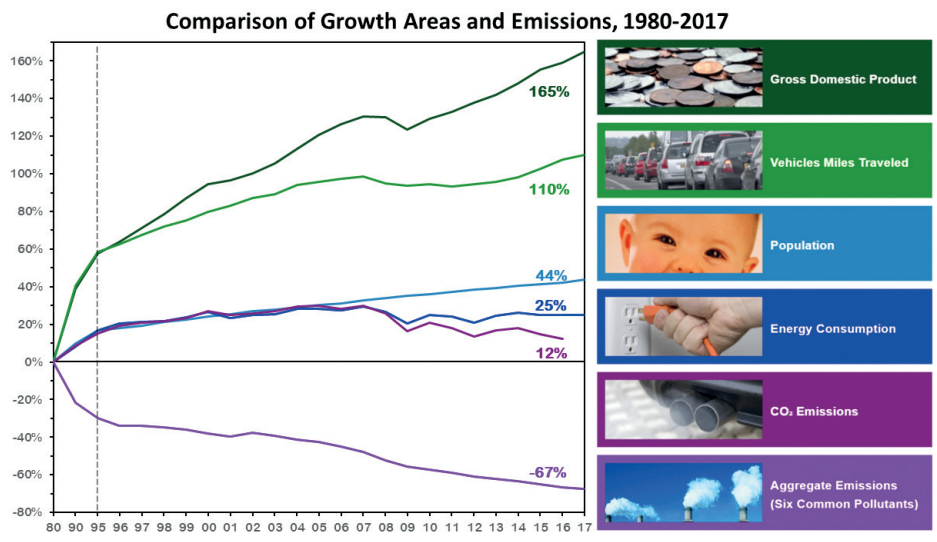

Figure 3-12. Comparison of measures of growth and emissions (1980-2006) (USA) Source: Latest finding on national air quality (http://www.epa.gov/air/airtrends/2007/report/sixprincipalpollutants.pdf)

environmental impact

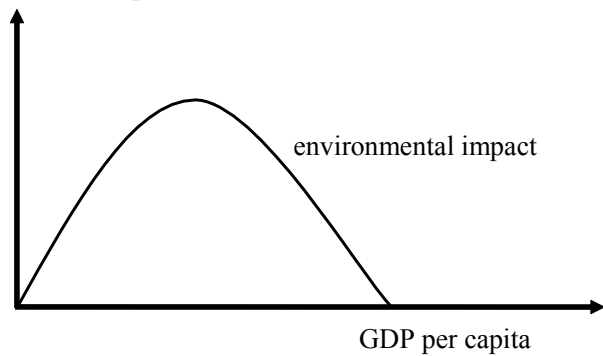

Figure 3-13. The inverted-parabola-shaped environmental Kuznets curve (quadratic approximation) (Borghesi, 1999)

It is not easy to verify this neat theory of environmental Kuznets curves using empirical data. This is partly because there are no appropriate data series at hand about environmental impact, and especially not for use in within-country analyses. Making international comparisons, however, is not convincing due to the different natural and social conditions and different environmental regulations of respective countries. The empirical evidence is convincing enough for certain air pollutants such as sulphur dioxide, carbon monoxide, nitrogen oxides and dust, especially in terms of urban or local air quality. In other cases, like carbon dioxide emissions, the data do not support the existence of an inverted U-shaped curve (for example, carbon dioxide emissions increase with 
GDP, meaning the effect of the increase in the volume of the economy outweighs any favourable effects of structure or technology). It poses a problem that the points at which various pollutants start to decrease differ according to differing levels of GDP. For example, the emission of nitrogen oxides starts to fall at a far higher GDP than the emission of sulphur dioxide or solid particles. It is not necessarily true, either, that the shape of the curve is symmetrical. The downslope is understandably often steeper.

\begin{tabular}{crr} 
Pollutant & \multicolumn{2}{c}{ EKC Turning Point } \\
\cline { 2 - 3 } & \multicolumn{1}{c}{$\mathbf{1 9 8 5}$ US } & \multicolumn{1}{c}{ 2001 US\$ } \\
\hline Carbon Dioxide & $\$ 22,500-\$ 34,700$ & $\$ 37,000-57,000$ \\
Carbon Monoxide & $9,900-10,100$ & $16,300-16,600$ \\
Nitrates & $15,600-25,000$ & $25,600-41,000$ \\
Nitrogen Oxide (industrial) & $14,700-15,100$ & $24,100-24,800$ \\
Nitrogen Oxide (transport) & $15,100-17,600$ & $24,800-28,900$ \\
Sulfur dioxide & $5,700-6,900$ & $9,400-11,300$ \\
Sulfur dioxide (transport) & $9,400-9,800$ & $15,400-16,100$ \\
Suspended particulates (non-transport) & $7,300-8,100$ & $12,000-13,000$ \\
Suspended particulates (transport) & $15,000-18,000$ & $24,600-29,600$ \\
\hline
\end{tabular}

Note: The values in 2001 U.S. dollars are approximate.

Source: Cole, Rayner, and Bates (1997).

Table 3-3. Selected pollutants and income (based on Cole-Rayner-Bates, 1997)

Expert estimates suggest that the peak of the inverted parabola, the socalled turning point, is situated at very different per capita GDPs for various pollutants. For carbon monoxide, as mentioned above, decreases start to occur at only \$35-57000 GDP per capita, while the GDP per capita of the USA is still far below this level. For sulphur dioxide the amount is $\$ 9400-11300$; above this range improvements are already noticeable.

The situation is even more complex with water pollutants, although there is solid data-based evidence concerning changes in biological and chemical oxygen demand and the potable water supply and connectivity of homes to a wastewater treatment system (see Figure 3-14. - Langeweg et. al., 2000).

In Figure 3-14. it can be seen that at more than \$10000-15000 / GDP per capita the problem of potable water and wastewater treatment system connectivity can usually be considered solved. This is what Grosmann and Kruger's graph also indicates. As a general statement, it is obvious that for the riskiest pollutants (Arsenic, Cadmium, and Coliform) the turning points occur at relatively low values of GDP. 


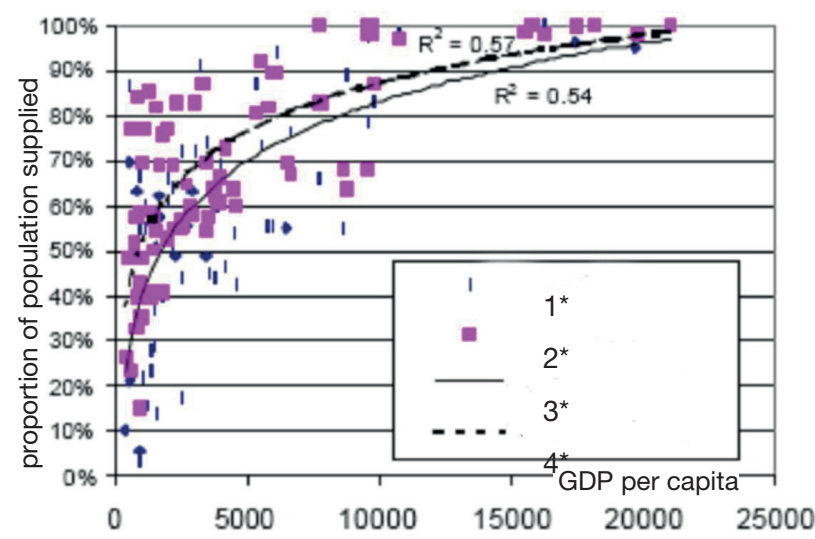

Legend: $1^{\star}=$ Proportion of homes connected to wastewater treatment system (\%)

$2^{*}=$ Proportion of homes with potable water (\%)

$3^{\star}=$ Log. (proportion of homes connected to wastewater treatment system (\%)

$4^{\star}=$ Log. (proportion of homes with potable water (\%)

Figure 3-14. Changes in proportions of population supplied with safe potable water and connectivity to wastewater treatment system by GDP per capita (Langeweg, 2000).

\begin{tabular}{|c|c|c|c|}
\hline \multirow[t]{2}{*}{ Water Pollutants } & \multicolumn{3}{|c|}{ EKC Turning Point } \\
\hline & 1985 USD & $\begin{array}{c}2001 \text { USD } \\
\text { (approximate) }\end{array}$ & $\begin{array}{l}\text { Air pollution } \\
\text { (USD from } \\
\text { different years) }\end{array}$ \\
\hline Arsenic & 4900 & 8000 & \\
\hline $\begin{array}{c}\text { Biological oxygen } \\
\text { demand }\end{array}$ & 7600 & 12500 & \\
\hline Cadmium & 5000 & 8200 & \\
\hline $\begin{array}{l}\text { Chemical oxygen } \\
\text { demand }\end{array}$ & 7900 & 13000 & \\
\hline Faecal coliform & 8000 & 13100 & \\
\hline Nitrates & 2000 & 3300 & \\
\hline Lead & 10500 & 17200 & \\
\hline Total coliform & 3000 & 4900 & \\
\hline $\mathrm{SO}_{2}$ (emissions) & & & 8691 \\
\hline $\mathrm{NO}_{\mathrm{x}}$ (emissions) & & & 14810 \\
\hline SPM (emissions) & & & 9811 \\
\hline
\end{tabular}

Table 3-4. Pollution and income; EKC turning points (Grossman-Krueger, 1995, Van Alstine-Neumayer, 2010) 
Heavy metal pollution or drug residue content, etc. in waters make the situation more complex. Some researchers speak about the existence of $\mathrm{N}$-shaped (cubic exponent) environmental Kuznets curves (Grossman and Krueger 1994, Shafik 1994, Grossman 1995).

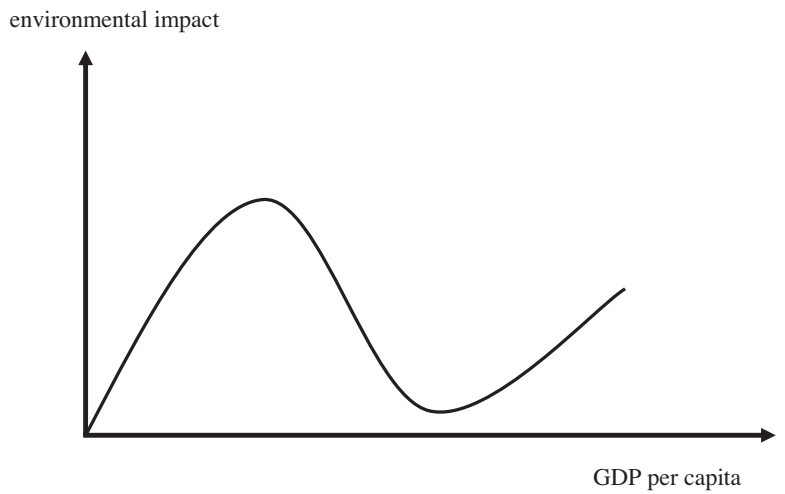

Figure 3-15. N-shaped environmental Kuznets curve approximated with cubic polynomial) (Borghesi, 1999)

Especially in the case of some water pollution indicators, pollution begins to fall at above a certain level of GDP, then starts to rise again at an extremely high standard of living (see Figures 3-16.). The latter is exemplified with the case of garbage disposal. Richer households allow most kitchen waste to leave via waste water systems (through in-sink garbage disposal units) instead of bothering with collecting this solid waste selectively, which dramatically raises the biological oxygen demand of the waste water ${ }^{5}$.

Experience of the post-1970s development of advanced countries gives grounds for some optimism. As Figure 3-16. indicates, GDP and pollution increase together until a certain level of development, even if a society starts to make efforts to protect the environment.

However, later in time and at above a certain level of development, GDP does not grow in relation to level of pollution; on the contrary, the level of pollution may dramatically fall. The theory is well supported with emission data from the USA which indicate that (with the exception of nitrogen oxides), the emissions of usually very harmful pollutants (lead, sulphur dioxide, dust, etc.) decrease.

5 BOD is the volume of oxygen lost through the aerobic biochemical decomposition of organic substances in water over a given period of time (usually 5 days). $\mathrm{BOI}_{5}=\mathrm{mg}$ $\mathrm{O}_{2} / \mathrm{L}$. 


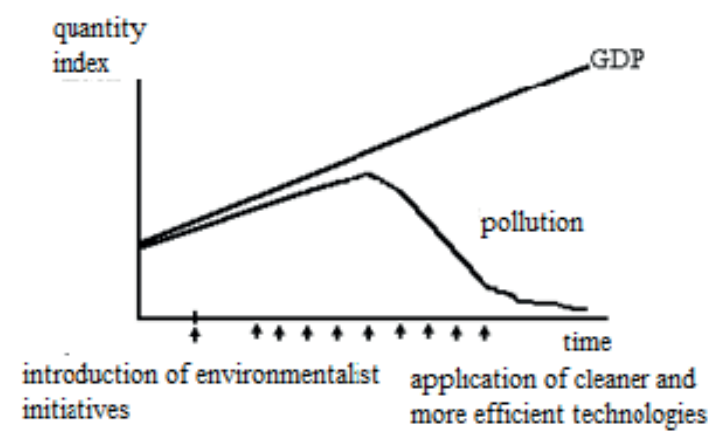

Figure 3-16. Decoupling of the link between GDP and pollution as a result of growth (based on Presentation by David Pearce in Budapest, 1994 and Shafik-Bandyopadhyay, 1992)

In the two figures below, the emissions of some air pollutants in the USA are plotted for the time between 1900 and 1998, in addition to 1970 and 2012. Disregarding PM10, it is clear that they take the shape of an inverted U-shaped curve. Figure 3-17. still shows a phase of growth, but sometime in the 1970s the trend changes: due to the level of development, (welfare) society starts spending more on environment protection, and pollution levels begin to fall. For dust pollution we see a cubic parabola. Partly due to the spread of diesel engines, the PM 10/2.5 concentration in the atmosphere temporarily rises. In urban areas, PM 2.5 is primarily composed of sulphates, nitrates, organic carbon (OC), and, to a lesser degree, elemental carbon (EC) and crustal material.

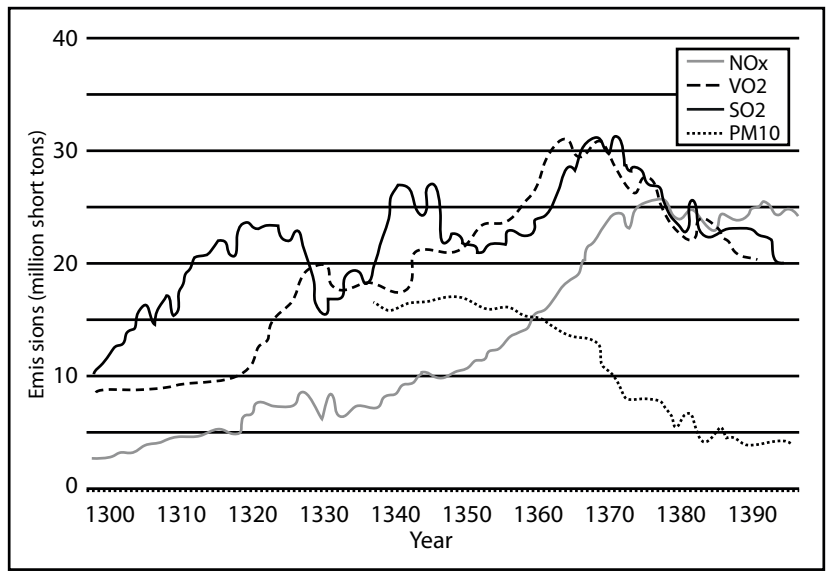

Figure 3-17. Trends in National Emissions (1900-1998) in USA Source: http://www.epa.gov/ttn/chief/trends/trends98/trends98.pdf 


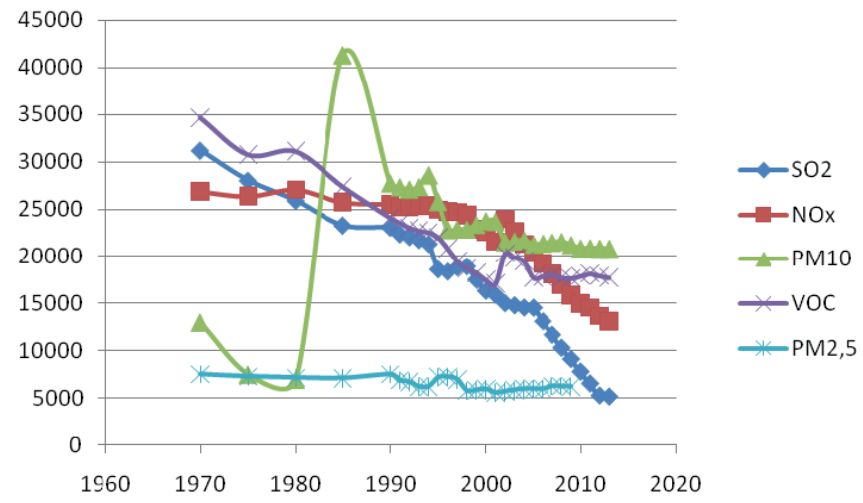

Figure 3-18. Emission of air pollutants in USA, thousands of tons (1970-2013) (Source: http://www.epa.gov/ttn/chief/trends/ downloaded 26 Aug 2014 ) $^{6}$

Concerning environmental Kuznets curves, we thus summarize (Borghesi, 1999):

1. Not all changes in indicators can be described using Kuznets curves

2. Changes in the indicators showing environmental impact which more closely correlate to the health of a population and their standard of life are more likely to follow the Kuznets curve than those whose effect is more difficult to perceive. Waste production or carbon-dioxide emissions, for example, do not follow the downslope of the Kuznets curve because such effects can be externalised (see data in Figure 3-18.).

3. Regarding the empirical observations that are used to describe the changes in the indicators plotted on the Kuznets curve, the opinions of researchers are divided as to what level of GDP can initiate a change in the indicators, and whether the pollution emitted during any phase of growth is irreversible (i.e., how high the peak of the bell curve will go). The latter is called in the literature the 'shade effect' (Figure 3-19.).

Either no or insufficient information exists about the shaded area in Figure 3-19., and whether emissions at that level or above cause irreversible changes. It would obviously be ideal to move from point $A$ to point $C$ without touch-

6 Notes to Figure 3-18.: Particulate Matter 2.5 Micrometers in Diameter and Smaller (PM2.5) National Totals with Condensibles from 1999 - 2003 (thousands of tons) made up of several different chemical components. Particulate Matter 10 Micrometers in Diameter and Smaller (PM10) National Totals with Condensibles from 1999 - 2006 (thousands of tons) $\mathrm{SO}_{2}, \mathrm{NO}_{x}$, VOC National Emissions Totals (thousands of tons) 
ing point $\mathrm{B}$. This necessitates employing environmental protection measures which would reduce the emissions of the risky substance to significantly below the 'business as usual' level.

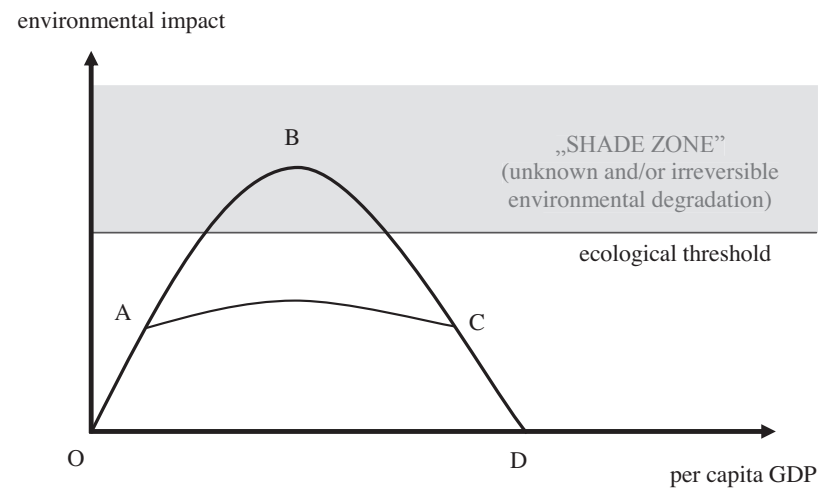

Figure 3-19. Inverted parabola-shaped environmental Kuznets curve, where values near the maximum environmental impact may have irreversible or unknown consequences. This area is indicated by shading. (Munasinghe et al., 2006)

In an article, Munasinghe (1999) suggests that it is not always effective to wait to reach the downslope of the Kuznets curve, but the risky zone should, by way of some intervention, be avoided. A state similar to the 'shade' zone of the Kuznets curve may very often occur in reality. In Munashinge's figu-re (Figure 3-20.), Point $C$ indicates the environment impact of a 'developed country', which, as should be clear, is already over the limit considered to be risky. Point $B$ represents the environmental impact of an economy which has just started growing. Munashinge suggests that instead of waiting to arrive at Point $E$ with the 'help' of economic development, it would be more effective to find a 'tunnel' to prevent environmental impact from even entering the high-risk zone.

According to the authors, there is a fair chance that such tunnels can be found, because

- some initiatives can be equally efficient from an economic and ecological perspective (double-dividend solutions),

- through different ex-ante tests, significant environmental risks may be prevented and avoided, first of all through the preparation and development of a system of institutions,

- economic growth (involving the whole economy) may be fine-tuned to avoid overshoot. 


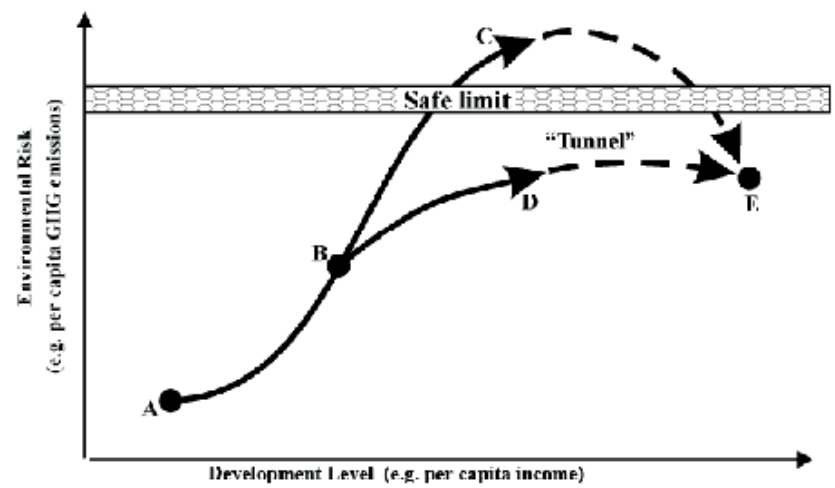

Figure 3-20. 'Tunneling' beneath the Kuznets curve (Munasinghe et al., 2006)

Such searching for tunnel is well exemplified by the international efforts that have helped - hopefully still in time - to stop the disastrous depletion of the ozone layer, the expansion of deforestation caused by acid rains, the increase in low atmospheric concentrations of lead, and the accumulation of volatile organic contaminants in the atmosphere. In the past, the ozone layer started to deplete due to the use of halogenated volatile organic compounds, but in the Montreal Protocol the states of the world banned the use of freons, creating hope that the ozone layer will regenerate in the coming decades. Sulphur dioxide emissions are also regulated by international agreements which may have been made early enough to eliminate the threat of deforestation. Twenty years ago, tetraethyl-lead was commonly used for improving the compression tolerance of fuels, but later it turned out that lead released into the atmosphere damages brain function. Today the use of lead compounds is also regulated by international agreements; the issue of their replacement may be considered satisfactorily solved.

A tunnel could also have been found regarding the emission of greenhouse gases, but science and politics have been in dispute about the issue and related warning signs for so long that tunnelling through is now too late. Developed countries have far exceeded the safe zone, and although many of them are now making significant efforts to cut down on the emission of greenhouse gases, due to the nature of the problem a climate disaster will be hard to avoid.

For a few countries that have started on a steep path of growth - such as China and India - the problem is that the development trajectory ahead of them is still unknown, and while we know that the absolute concentration of greenhouse gases should be reduced in the atmosphere, there is no realistic prospect of this; all we can do is to slow the rate of growth. It is already certain that we are over the 'safe limit'; the ques- 
tion is when (and whether) we will ever be able to reverse the trend to growth.

The correlation between development and the quality of the environment is contradictory. Quality characteristics such as potable water supply, sewage systems, etc. clearly improve with growth of per capita GDP. Easily externalisable environmental impacts such as per capita carbon dioxide emissions and volume of municipal waste grow together with GDP. While economic growth definitely helps solve problems related to pollutants that damage human health and ecosystem in the short term, it seems that in spite of these partial solutions, a deepening of the crisis with carbon dioxide and waste issues that cause global environmental impact is occurring.

Based on knowledge of the environmental Kuznets curves, politicians frequently think that economic growth will also solve environmental problems. It is clear now that in the case of easily externalisable pollution whose provenance cannot be easily established (i.e., when it is hard to assign liability, such as with greenhouse gases, and many forms of waste), or contamination that causes irreversible degradation (e.g. the accumulation of heavy metals, stable organic contaminants, etc. due to the shade effect) further economic growth will not help.

Political optimism about the omnipotence of economic growth is overshadowed by yet another contradiction regarding development. As can be seen in Figure 3-21., most of the world will not, even by 2030, reach the level of per capita GDP whereby the quality of environment should start improving. According to prognoses, the most developed countries in the world will reach and exceed a per capita rate of $\$ 50,000$, while the world average may produce only $\$ 12,000$ per person and $\mathrm{Asia}^{7}$ around $\$ 8000$. Even if the future deepening of the North-South divide were socially and politically tolerable (although obviously it is not), the situation is certainly intolerable in an ecological-environmental sense. The figures show that without a radical change in the conditions of distribution, squalor will remain permanent in the developing countries to such an extent that it will pose an obstacle to positive demographic and environmental change. Taking the delay caused by feedback into consideration, should this prediction come true we will most probably have to count on the occurrence of a disaster.

Unfortunately, for many politicians and mainstream economists sustainable development is typically perceived of as economic growth. There is some truth in the idea because GDP usually contains a decisive proportion of services (i.e., a decreasing proportion of GDP is generated by material assets). However, in the physical sense this decreasing proportion usually creates significant growth in pollution even with improvements in material and energy consumption and pollution emission indicators. In terms of humanity's wasteful consumption hab-

7 In support of the reliability of these estimates, we note that a World Bank study in 1990 forecast the per capita GDP of Asia for 2030 at only $\$ 1,000$. A more recent estimate (2005) put the value at eight times this amount. The present data are values calculated at purchasing power parity. 
its, a habitable future Earth requires a break in consumption trends in developed

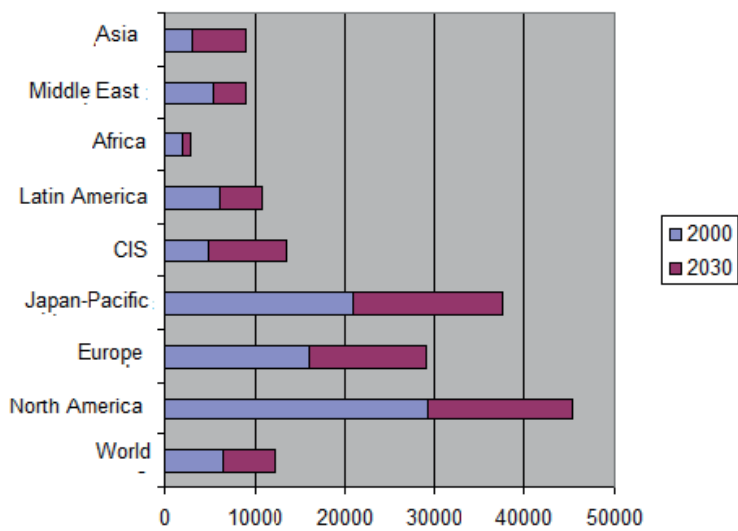

Figure 3-21. Estimated changes of per capita GDP between 2000 and 2030 in certain regions of the world (USD) (author's own compilaton based on Worldbank data)

countries above all. Unfortunately, little trace of willingness to make steps towards this goal can be seen. Since the 1970s the world appears to have been making efforts to cut down on carbon dioxide emissions, but in reality per capita energy consumption has significantly grown (at different rates from country to country, but expressed in absolute figures the growth of the per capita consumption of developed countries is dominant). According to 'normal' ideas about development trends, energy consumption should at least have stabilised in these countries; moreover, due to improvements in the efficiency of energy use and having overcome the stage of extensive growth (infrastructure in such countries is now well developed) per capita energy consumption should have fallen. Regarding the average of the past twenty years, only Denmark, Canada, The Netherlands and the United Kingdom have approached this situation; and mainly only because their energy consumption was rather wasteful in the 1970s.

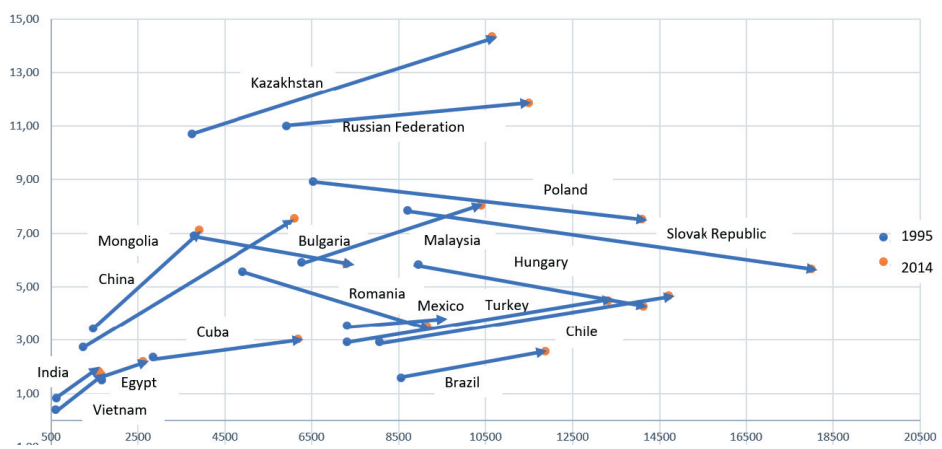

Figure 3-22. Development of per capita $\mathrm{CO}_{2}$ emissions in tonnes (y-axis) and per capita GDP in selected countries between 1995 and 2014 (author's own compilaton based on Worldbank data) 
Figure 3-22. shows the development of per capita $\mathrm{CO}_{2}$ and per capita GDP in selected countries between 1995 and 2014.

The figures show clearly that per capita GDP has doubled, while per capita $\mathrm{CO}_{2}$ emissions have grown at a rate over the global average in the past twenty years in developing countries. The above illustration contains those countries in which per capita GDP was less than 10,000 USD in 1995, and no more than 20,000 USD in 2014 . The lengths of the arrows are nearly proportional to the growth of GDP. Some countries witnessed relatively large GDP growth while - unfortunately - $\mathrm{CO}_{2}$ emissions also rose. The economic growth of China, Mongolia, Malaysia and Kazakhstan is extremely energy intensive. Among the relatively favourable examples are Romania, Bulgaria, Slovak Republic, Hungary and Poland. These countries were able to grow their per capita GDP while their $\mathrm{CO}_{2}$ emissions significantly decreased. Chile, Turkey - and perhaps Brazil - also saw significant economic growth with limited $\mathrm{CO}_{2}$ emissions. However, the general picture is not encouraging because even those countries in which $\mathrm{CO}_{2}$ decreased, the phenomenon is new and the starting level of emissions was extremely high. Even today they have a far higher level of emissions than is desirable for their state of development.

\subsection{Jevons Paradox and the rebound effect}

According to the Jevons Paradox, improvements in energy efficiency should using a historical example - have resulted in a decrease in the demand for and use of coal, but did not. In his book (The Coal Question, 1865), William Stanley Jevons stated that, in contrast to expectations, an increase in the efficiency of the use of coal did not cause a drop but an increase in consumption (York, 2006). The first steam engine (constructed by Thomas Newcomen and Thomas Saverey in 1712) worked at an energy efficiency rate of 1-2\%, while the first versions of James Watt's steam engines reached five times this level, or even more, and these improvements took as long as sixty years. If a steam engine works at an efficiency rate of $15 \%$ instead of $5 \%$, this should decrease the consumption of coal by one-third. However, the historical consumption of coal kept growing because the operation of high-efficiency steam engines was cheaper. The first steam engines were used in the vicinity of coal mines because they required such a significant amount of coal that their use elsewhere was unprofitable. The new steam engines, however, were installed in an increasing number of places. Steam boats and steam mills were built, and the use of steam engines gained ground everywhere. This triggered the first Industrial Revolution.

'Consumption of the most common type of office paper (uncoated freesheet) increased by $14.7 \%$ in the U.S. between the years 1995 and 2000 (Sellen and Harper 2003), embarrassing those who predicted the emergence of the paperless office (Brundtland, 1987).' Sellen and Harper (2002, p. 13) also 
point to research indicating that 'the introduction of e-mail into an organization caused, on average, a $40 \%$ increase in paper consumption.' This observation suggests that there may be a direct causal link between the rise of electronic data storage media and paper consumption, although further research is necessary to firmly establish the validity of this possible causal link.

There is no need for further research to know that we are facing a paradox, but this is not hidden in the world of computers but rather in the world of printers and photocopiers, and increasing levels of mistrust. There has been dramatic growth in business transactions and forgeries, and since printing and copying are now commonplace, politics has taken another wrong turn by increasing administrative bureaucracy. Causality has not been established between the use of e-mails and the increase in paper consumption. Moreover, another important reason for the increase in paper use in offices is the information explosion. We a rather facing what Keynes (Keynes, 1963) once called 'the painfulness of readjustment between one economic period and another'. Due to the information explosion, electronic data-storage media begin to replace paper in offices, but only after at least a forty-year delay. Today it is no longer typical that everything is printed out. Should trust in economic administration improve, paper consumption would probably begin to scale down.

Back then, the coal mining industry considered improvements in the efficiency of steam engines a threat as it feared industrial competition. Today, improvements in eco-efficiency are partly the result of price competition. Everybody tries to sell their products more cheaply. This creates demand for new branches and services, and in this sense, plays an important role in economic growth. In some sense, this is also a paradox, because due to improvements in eco-efficiency the increase in GDP should slow, but it seems to be gaining speed rather than slowing down. In environmental studies, the term rebound effect is used to describe the phenomenon that any savings made by an increase in eco-efficiency lead to an increase in consumption because the money that is saved is recycled to make purchases in other fields. Increases in eco-efficiency could have a favourable impact on GDP growth if the savings made therefrom were spent on structural development.

In his study on the Steady State Economy, Herman Daly (Daly, 1974) points out that unlimited economic growth is impossible on a limited Earth. In the past century, economic growth has been realised at a rate that, regarding Earth's limited resources, cannot be continued. Another path is available, however (see also Grossman and Krueger's /1995/ argument earlier in the Chapter about 'the effect of economic growth on environment pollution'). Structural economic growth could help create opportunities for those who are currently excluded from income-generation activity (the unemployed) and provide them with purchasing power on the market. This proposal is in close harmony with the ideas of Grossmann, and what Weizsäcker and Lovins (Hawken, Lovins, \& Lovins, 1999) call the shift from a 'stock' economy to a 'flow' economy. 
Countries with low raw material consumption per capita have significantly diminished their good environmental performance in the past two decades (this list also includes fairly opulent countries). Countries that have achieved fast economic growth (like Finland and Singapore) have done so through the large-scale consumption of raw materials and resources. There are, however, developed countries, which have managed to generate wealth at a relatively low level of per capita resource consumption. Finland, supposedly an environmental 'rolemodel', has a per capita resource consumption more than double that of Italy, which is considered to be lagging behind in environmental matters.

Regarding these figures, and accepting the premises of macro-economics that economic growth is a necessary condition for the accumulation of wealth, a major question arises: what type of economic growth causes the least damage to the natural environment, or rather serves the goals of sustainable development? Ecological economists and scientists (Vida, 2012) deny the existence of such a positive outcome of economic growth. However, there is a concept of economic growth that supports sustainable development that we may call 'structural economic growth'. Eco-efficiency may be increased in a way that supports the division of labour within society. Supported by such an increase, the consumption of services in the economy would significantly develop at the expense of material consumption, which would mean the replacement of a stock economy with a flow economy. Instead of buying washing machines, refrigerators, and kitchen equipment, individuals would buy clean clothes from the laundry and eat out in restaurants. We would hire specialists, rather than do it ourselves at home. Specialists equipped with professional tools would clean our homes. This approach would create economic growth because due to the division of labour we would pay for these services, but instead of spending our money on buying washing machines, we would only need to settle our laundry bills. These days, television sets replicate the feeling of being at the movies, but we could just go to the movies and 400 of us could watch one film on one 'set'. High-income individuals can afford home movies because the necessary technology has become cheap enough. A television set that meets nearly all needs, providing 3D-quality images, only costs three hundred thousand forints. The price of cinema tickets is now multiples of that of hiring a film on DVD. 'Technology' is cheaper, while the cost of services is growing, largely due to wage increases. However, such up-to-date technology (a modern TV, for example) may consume 150 watts of energy 'in the background'. According to careful estimates, this means that while we watch TV, at least two strapping 'energy-slaves' are required to provide us with power (How Many Energy Slaves Do We Employ?, 2012). Each energy-slave is capable of providing power for a $75 \mathrm{~W}$ light bulb. Thus if we leave a $75 \mathrm{~W}$ bulb on, one, and if we go to sleep in front of the TV, two slaves will be doing unnecessary work (Grossman \& Krueger, 1995). It is easy to realise how the environmental impact of the change in our entertainment behaviours has changed just over 
the past five years. The energy consumption per capita of a movie projector is nothing in comparison with the consumption of an individual watching TV alone.

\subsection{The sustainability of public deficits}

Not only are developing countries indebted, but often developed ones too. Borrowing often stimulates the economy, but when excessive may endanger a country's budget. Poorly spent credit imposes a burden on the economy such that a state cannot fulfil its basic functions. These basic functions are to provide public goods such as a clean environment, adequate education or good health care. In this chapter, therefore, we deal with the sustainability of budgetary public deficits.

The sustainability of fiscal policy has already been addressed by the classic authors of economic texts. Their primary concern was investigating the role that public deficit plays in financing public expenditure. After examining the distribution of public deficit among generations, Ricardo proposed (but was not a believer of) the invariance theorem of public deficit (Barro, 1988). Keynes argued for the need for a deficit to ensure full employment, and proposed that public deficit should be a burden on the shoulders of the generation that has created it. According to Keynes, the borrowing generation pays the opportunity cost incurred by financing a deficit, as the latter merely involves a transfer between taxpayers and asset holders, provided that the securities remain within the borders of the country concerned. This is expressed in the classic phrase, 'we owe the public debt to ourselves' (Krejdl-Banka, 2006). Today it is no longer the norm that individual countries finance their expenditures internally; however, we also know that there are countries (such as Japan) where Keynesian conditions prevail, and there is also a welcome tendency in Hungary for domestic buyers of government securities to finance an increasing share of the public deficit.

Others, including Barro (1979) and Neck-Sturm (2008, p. 7), have analysed the tax-smoothing effects of debt, and find that in certain circumstances public deficits can improve welfare. (Krejdl-Banka, 2006)

Some researchers from the field of finance and accounting perceive a fundamental conflict between international financial capitalism and sustainability. Gray writes the following: 'At the core of accounting and finance is a truly fundamental conflict between sustainability and modern international financial capitalism. Our choices between these are likely to be a great deal more than matters of methodological nicety or intellectual convenience. Social and environmental accounting and finance offer a way to recover a moral and productive accounting and finance that places survival of the species at its very heart' (Gray, 2002).

However, financial bureaucracy uses the term 'sustainability' to mean something completely different from what Gray refers to in the above passage concerning the chances that species will survive. For economists, including financial professionals, sustainability means something similar to what Dolenc 
defines in the following: 'It is broadly accepted that Maastricht fiscal criterium [sic] is connected with long-term public finance's sustainability and that countries [...] fulfilling these criteria [...] cannot get into public finances difficulties: their public finances are therefore 'healthy'. (Dolenc, 2006)

A general consensus exists in the profession that the funding of public finances is sustainable as long as there are no major changes in the ratio of debt to budgetary revenues. Sustainability is not defined simply as the capability of a country to maintain its solvency, but also its willingness to fulfil its debt-servicing obligations. It is also generally agreed that it is better for a country to finance its debt by borrowing than by relinquishing control of inflation, which is commonly done by means of printing money. Nevertheless, if a country allows the stable growth of public debt, it can get caught in a trap, which can sooner or later render it incapable of servicing its public debt obligations (Dolenc, 2006). It might be relevant to note that in the literature (e.g. Sorci, n.d.) this state of affairs is referred to as a Ponzi trap. The term dates back to 1920, when private investor Charles Ponzi gained notoriety for running what is called a pyramid scheme today. Ponzi deceived the market by offering an investment opportunity that promised a profit of $50 \%$ in 90 days when banks paid only $5 \%$ on deposits. $\mathrm{He}$ lured a large number of people to join his venture in the postage coupon trade. He paid high returns to the first few investors, which enticed them as well as others to purchase additional coupons. The cycle ended when he quit the 'business', scooping up large profits. Curiously, this style of investment keeps recurring, and many modern Ponzi traps are set up as projects associated with the environmental features of sustainable development. Today's 'cheats' arrange for high-yield 'investments' into afforestation, goat farming, biofuel production, and other ventures.

In a paper published in 1984, McCallum makes an implicit attempt to determine the optimal level of indebtedness, and demonstrates that, to be sustainable, the long-term public debt-to-GDP ratio should not exceed the nominal interest rate paid on public debt (Dolenc, 2006).

Researchers have widely proposed that the optimal level of public debt is determined by using the following macroeconomic equation commonly referred to as the dynamic budget constraint of a country (Dolenc, 2006) (Blanchard-Chouraqui, Hagemann-Sartor, 1991).

$$
\frac{d B}{d s}=\mathrm{G}+\mathrm{H}-\mathrm{T}+\mathrm{i} \cdot \mathrm{B},
$$

where

$$
\frac{\mathrm{dB}}{\mathrm{ds}} \text { is the increase }(+) \text { or decrease }(-) \text { of public debt, }
$$


$G$ is the government's purchases of goods and services at nominal value,

$\mathrm{H}$ is the value of transfers (stipends, social security, etc.),

$T$ is the value of tax revenues collected, and

$\mathrm{i}$ - B is interest paid on public debt (Dolenc, 2006, p. 270)

The sum of government purchases and transfers less tax revenues is commonly referred to as primary deficit, and is denoted by $\mathrm{D}$ (Blanchard et al., 1991).

As the use of precise figures would make the equation difficult to apply, in practice there is a preference for expressing government spending and revenues as proportions of GNP. Each of the terms in the equation may be expressed as a proportion of GNP, whereby the equation can be written as follows.

$\frac{\mathrm{dB}}{d s}=g+h-t+(r-\Theta) b=d+(r-\Theta) b,($ Blanchard et al., 1991, p. 10)

where

$\Theta$ is the real growth rate of GNP, and

$r$ is the ex-post real rate of interest ( $i-\pi$, where $\pi$ is the inflation rate).

The equation shows that the sustainability of the budget depends on two factors. The first, derived by combining the three terms reflecting rules for expenditures, transfers and taxes applicable in the year concerned, is referred to as primary deficit. The second factor is determined by legacy issues such as the proportion of debt that has accumulated in the past to GNP, and the difference between the real interest rate and the real growth rate. If this difference is positive, a primary surplus is needed to maintain a constant ratio of debt to GNP. (Blanchard et al., 1991, p. 11)

Article 103 of the Maastricht Treaty on the European Union (1992) contains provisions on the coordination of economic policies, and Article 109j sets out the qualification criteria for participation in the euro zone. The two key qualification criteria are the following: (1) the ratio of government debt to GDP must not exceed $60 \%$, and (2) the government deficit to GDP must not exceed $3 \%$. The two criteria have attracted significant criticism since the very beginning. In effect, the $60 \%$ was equal to the average indebtedness of euro area Member States; i.e., the criterion was not met by all Member States. A number of theoretical critiques have demonstrated that the first criterion was unreasonable. The first criterion was therefore eased, and now it considered sufficient that the rate of indebtedness should not exceed the benchmark applicable to the country concerned. The most powerful argument against the original criteria was put forward by Italian economist Pasinetti (1998), who demonstrated that problems may arise from the dynamics of indebtedness rather than its actual rate. When the rate of indebtedness decreases or remains constant over time, this is considered to be a sustainable state of affairs: 


$$
\left(\frac{B}{Y}\right)_{(s)} \leq\left(\frac{B}{Y}\right)_{(0)}
$$

where

$B$ is the country's outstanding debt

$Y$ is the country's GDP,

$S$ is the number of years,

0 is the reference year.

The concept of prospective sustainability is concerned with policies that should be implemented to eliminate the need for any additional future adjustments (KrejdlBanka, 2006, p. 10). It is obvious that, apart from the rate of economic growth and interest rates, indebtedness today is also influenced by other unexpected risk factors. This has made the sustainable rate of indebtedness extremely complicated to determine. Whether directly or indirectly, the sustainability of the budget affects all three features (natural, social and economic) of sustainable development. When a country is highly indebted, the debt trap prevents resources from being allocated either to addressing social issues or to the conservation of natural assets. When indebtedness is financed by foreign investors, there is little point in fostering economic growth as most the benefits of this must be committed to making interest payments. The economy may be capable of producing the resources needed to service debt, but it will not necessarily be capable of producing the resources required to resolve social tension and to compensate for the amortisation of natural assets. There is a vast body of financial literature about fiscal sustainability, covering virtually every aspect of the subject. 


\section{ENVIRONMENTAL ECONOMICS}





\section{The economics of natural resources}

\subsection{Introduction}

A variety of ways of classifying natural resource are known about. In this chapter, we do not follow the classification used in earth sciences but we classify natural resources on an economic basis. For an economist, the scarcity of natural resources does not depend on the concentration of element in the earth's crust. We are more interested in knowledge of natural resource markets. As we will see, resource exhaustion and scarcity are not necessarily a problem. For us, the most interesting questions involve the cost of access or the security of access to natural resources. In the case of renewable resources, overuse is a market issue as well. Overfishing of the seas or the sustainable use of a lake is one matter for scientists but a totally different one for economists. In this chapter, we describe the theoretical underpinning of these issues.

\subsection{The concept and significance of biodiversity}

'A community of co-existing and largely interdependent living beings creates an ecosystem with the elements of the inanimate environment. Ecosystem takes its definition within arbitrary limits. A particular part of space like a certain type of forest, its constituting species and the interacting inanimate physical-chemical environmental factors (e.g. air, soil, bedrock, the composition of solutions, sunlight, temperature, humidity, etc.) are analysed, and the effects arriving from outside an arbitrary limit are evaluated as external input and output factors. The narrower the limits are drawn around the system, the more significant the role of the factors will be. Reversing this, i.e., maximum possible expansion of the system, we shall arrive at the great global ecosystem encompassing the whole planet. An interesting and important characteristic feature of this is that its energy input-output balance is nearly zero (the difference between the energy arriving from the Sun and the heat emanated to space), and its material movements create a close cycle.' (Vida, 2012)

Biodiversity is the variety of wildlife. The term may be interpreted on several levels: it can mean the variety of habitats found on Earth, the totality of species, or genetic diversity within a species, but it is also applicable to smaller areas (e.g. the biodiversity of the Carpathian basin, or even a garden pond). 
Biodiversity, biological variety: live nature's inherent form of existence expressed at several levels of biological organisation. The final form of the immense variety of living beings is the mutation of genes. The genetic diversity of a species - be it a bacterium, alga, animal or flowery plant - shows itself in the variety of its individuals grouped into populations. Communities organised from populations of different species constitute the next level of $\sim$. On every previous and further organisational level (thus within a community complex, a landscape, a biome and finally the biosphere) we can define the elements the number of which numerically express $\sim$ (diversity). Through its components, $\sim$ is exposed to constant change: creation, mutation, destruction. This is the dynamics of biodiversity. Fossils indicate that most species are evanescent and over $95 \%$ of all species that ever existed are now extinct (extinction). The average life span of a fossil species (extinct mammals, marine invertebrates) is between 1 and 10 million years. There are a number of different mechanisms of the formation of new species. This process - speciation - has three typical phases: it may start with an existing species, involve genetic mutation, or be due to the strong influence of ecological factors. Phylogeny shows that speciation does not progress at an even speed: at times rapid multiplication occurs in totally different taxonomic groups. Extinction is the opposite process. Its rate is accelerating these days; there are a variety of reasons, but ultimately it is due to growth in the human population. Extinction may refer to the species itself (that is, all of its populations) or only certain ranges (local extinction). The extinction of $2-24 \%$ of groups of butterflies, birds and mammals in the British Isles and the Netherlands have been documented. As for plants, those species are considered extinct that have not been seen in the past 50 years. Plants re-discovered in the past ten years are called missing (extinct plant species). Vegetative units are not constant in space, either; they reversibly or irreversibly transform due to exposure to successive or deteriorative processes triggered by different effects. The basic components of all ecosystems are the species representing different trophic levels and which appear in great numbers (trophic structure in the ecosystem). The ecological significance of $\sim$ is indicated by the fact that any loss of species is to the detriment of the system. Decreases in genetic variability within populations reduces flexibility, which helps the given species adapt to changes in its environment. The loss of species (but also the appearance of new ones) may have a significant effect on the operation of the ecosystem. Each species plays a definite role in the operation of the ecosystem (fixing nitrogen, absorbing water, etc.); their disappearance therefore affects its functioning. There is evidence that there is a positive correlation between the regenerative ability of an ecosystem - e.g. ability to withstand an extreme climatic event - and the number of species. The fragmentation and disturbance 
of vegetation has a strong influence on how it operates because, for example, these effects may cause the balance of existing species to shift: large, long-living species will be replaced by smaller, shorter-living ones. This will have effects such as - for example - diminishing the system's food storage capability. The simplifications through which high-yield agricultural crop systems with few or single species (monocultures) are created leads to spectacular declines in the stability of the ecosystems, which can only be corrected with additional nutrient input and pesticides. In a more or less climatically, geologically integrated geographical space, the units of vegetation and communities appear repetitively (and sometimes in community complexes). A lowland landscape (e.g. the sandy region between the rivers Danube and Tisza) is a mosaic of wooded steppe-oak residues, dry scrubs, sandy grasslands, steppe meadow fragments, desiccating dunes of oneday fens combined with occasional vineyards and orchards. The communities within the landscape are not independent: the relationship established among them is partly due to , because stocks that frequently meet trigger species exchanges and propagulum flow (or matter exchange and energy transfer among ecosystems). The total of related landscapes (practically vegetation landscapes) constitute biomes. As the elements of $\sim$ are constituted by species composed of different numbers of individuals, the vegetation landscape is constituted by communities that appear in different dimensions and weights. This is landscape-level biodiversity. (Láng, 2002)

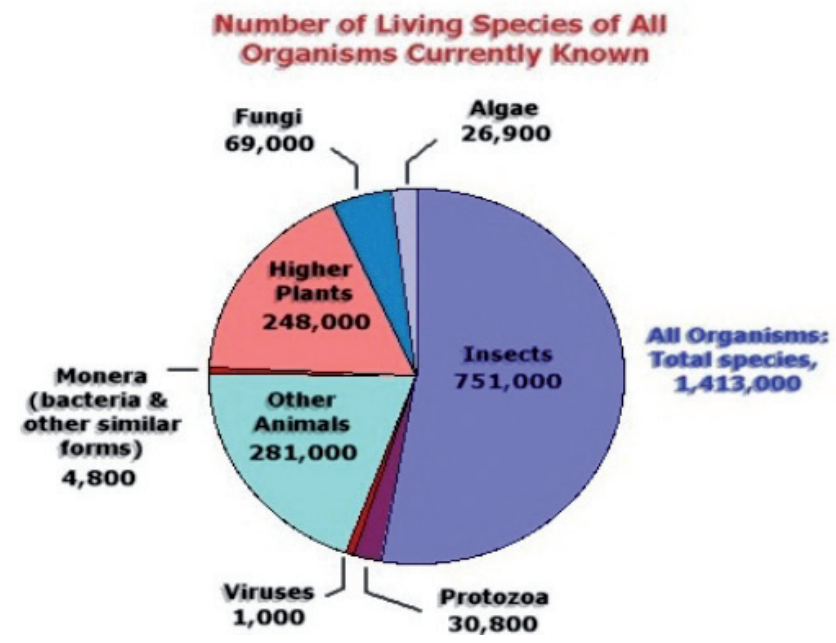

Figure 4-1. Estimated biodiversity in different taxonomic classes of organisms (source: https://www. slideshare.net/chemsant/biodiversity-16315413' (accessed on 02/09/2018)) 
As Figure 4-1. illustrates, insects and higher plants are of greatest diversity, but the figure also indicates that only a minimal fraction of bacteria and viruses species are yet known.

Certain habitats - like wetlands - have very high biodiversity, while the diversity of other habitats - like deserts - is typically very low. The biodiversity of an island is usually proportionate to the size of the island. Roads cut ecosystems into 'islands', decreasing total biodiversity.

The significance of biodiversity is shown in Table 4-1., which classifies ecosystem services.

\begin{tabular}{|c|c|c|}
\hline Provisioning services & Regulating & Cultural services \\
\hline Ecosystem Products & $\begin{array}{l}\text { Benefits generated by the } \\
\text { regulation of processes } \\
\text { going on in ecosystems }\end{array}$ & $\begin{array}{c}\text { Nonmaterial benefits of } \\
\text { ecosystems }\end{array}$ \\
\hline \multirow[t]{2}{*}{$\begin{array}{l}\text { - Food } \\
\text { - Fresh water } \\
\text { - Fibres } \\
\text { - Biochemicals } \\
\text { - Genetic resources }\end{array}$} & $\begin{array}{l}\text { - } \text { Climate control } \\
\text { - } \text { Wisease control } \\
\text { - Water control } \\
\text { - } \text { Potler purification }\end{array}$ & $\begin{array}{l}\text { - Spiritual and religious } \\
\text { - Recreation and } \\
\text { - eco-tourism } \\
\text { - Aesthetic } \\
\text { - Inspiration } \\
\text { - Educational } \\
\text { - Cocation detection } \\
\text { Cultural heritage }\end{array}$ \\
\hline & Supporting services & \\
\hline \multicolumn{3}{|c|}{ Services necessary for the production of all other ecosystem services } \\
\hline $\begin{array}{l}\text { - Biological diversity } \\
\text { maintenance }\end{array}$ & - Nutrient recycling & - Primary productivity \\
\hline
\end{tabular}

Table 4-1. The classification of ecosystem services (See also Table 4-11.)

The biomass produced by ecosystems provides us with food, while the control services of ecosystems are also indispensable. The micro climate that exists in a forest plays a role in creating rain. Bees are of immense benefit to humans through their honey-producing as well as pollination activities. Most of our medicines are also 'produced' by wildlife. No human life could exist without ecosystem services. 


\subsection{The concept of natural resources}

For the purposes of this chapter, a broad definition of natural resources is used. The mineral resources and fossil fuels found in the Earth's crust are natural resources that are of equal importance to the potential for development of new living creatures or the capability of the environment to receive, absorb and neutralise pollutants.

Natural resources: resources available for a given community at a given time or in a given period which are either entirely independent of voluntary human activity, or their existence inseparably and decisively depends on natural factors. According to their physical qualities they fall into two categories: non-exhaustible and exhaustible. Solar and wind power belong to the first, while mineral resources and forests to the second category. Exhaustible resources can also be classified into two groups: renewable and non-renewable, the former exemplified by forests, and the latter by mineral oil stocks. An important difference from an economic perspective is that part of the non-reproducible is of limited availability (soil), while another part has abundant availability (air). That is to say, in the first case ownership rights are well definable and a fee may be paid for their use, while the latter fall into the category of public assets, which are traditionally to be considered as gratis gifts of nature. (Láng, 2002)

Natural resources may be classified in a number of ways. For the sake of simplicity, a distinction should essentially be made between two groups, as shown in Table 4-2., although in many cases the classification will not be unambiguous. For instance, both water and air may be classified as either stockor flow-type resources.

\section{Classification of natural resources}

- Non-renewable (exhaustible) natural resources

- fossil fuels

- other mineral resources
- Renewable natural resources

- Stock type

- living biomass (fish, forest, pasture, etc.)

- arable land

- water system and atmosphere

- Flow type

- sunlight, wind, geothermal energy 
A rather wide range of natural resources have no markets, and therefore no price can be attached to them. Such resources include, for example, clean air, stratospheric ozone, etc. For the purpose of economics, what matters is their significance in terms of production and consumption.

\subsection{Overuse of public goods: 'The Tragedy of the Commons'}

In an economic sense, environmental problems arise when resources are allocated inefficiently, i.e., when they are not used at the time and for the purpose they should be. In a neoclassical approach, and in terms of Pareto optimality, this means that resource use is efficient when it maximises the welfare function of society. However, efficient use is only one prerequisite for avoiding environmental problems, the other being that we should not bequeath to future generations worse conditions than those available to us now.

Generally, market economies meet efficiency criterion through the exchange of property. For this to work, efficient ownership structures are required. The requirements for an efficient structure of ownership are the following:

1. The first requirement is universality. Private ownership of resources exists when all rights are fully specified.

2. The second requirement is exclusivity, which assumes that all the benefits and costs associated with the ownership and use of a resource exclusively influence the owner's welfare (wealth).

3. The third requirement is transferability, i.e., that the owner should be granted the possibility to transfer title to property freely.

4. Finally, efficient ownership structure requires enforceability, i.e., that title should be protected against forceful appropriation.

As long as the above criteria are met for property, the laws of the market will ensure that property works efficiently, because they will make the owner interested in selling property to a party that can derive greater benefit from it.

However, what happens if title to property is not specified; if, for example, a pasture or a fish pond is part of the village commons, or, from a rather broad perspective, what about public goods such as oceans, the atmosphere of the Earth, etc.?

A highly illustrative answer to this question is provided by G. Hardin, whose arguments are accurately rendered by Elemér Hankiss. For the sake of simplicity, the following is cited from Hankiss' book, Social Traps:

In 1968, Science carried Garrett Hardin's paper, The Tragedy of the Commons, which attracted plenty of attention. Hardin the biologist regarded the 
apparently inevitable population explosion as one of the greatest 'social dilemmas' of our age, and used an example taken from a 19th century mathematician for his analysis of the mechanism he deemed fatal (Lloyd, 1833; Hardin, 1968).

Suppose the existence of a commons on which, according to the traditions established in the village, one cow is grazed by each of the ten resident farmers. For the sake of simplicity, assume that each of the cows grazed here weighs 1,000 pounds, i.e., collectively they weigh 10,000 pounds. One day, one of the farmers is struck by the idea that in order to double his profits, he might as well turn another cow out to grass. (For the moment, let us disregard the fact that in historical reality, this did not lead the community to abandon the institution of the commons.) At this point, then, eleven cows are grazed on the commons. However, since in the new arrangement each of the cows can graze slightly less grass, each will be reach up to 900 pounds in weight instead of 1,000 . On balance, the farmer with two cows will gain 800 pounds (having two 900-pound cows instead of a single 1,000-pound cow), whereas the rest of the farmers will lose 100 pounds each. Collectively, they will lose 100 pounds each, because eleven 900-pound cows weigh only 9,900 pounds instead of the original 10,000 pounds. That is still not a big deal. But what if another farmer, and yet another, and yet others, and finally all of them are to reckon that they should each turn another cow out to grass to double their profits. If each new cow were to reduce the weight of each of the other cows by 100 pounds, the process would be as shown in Table 4-3.

What conclusion can be read from this table, and what is suggested by the above example?

- As long as each farmer adheres to the established rules of coexistence, or using a technical term, each follows a cooperative strategy, the collective returns of the community will be the highest (10,000 pounds).

- The more of them violate the established rules of coexistence (i.e., the more of them follow a deserting strategy), the lower the collective returns of the community will be (decreasing from 10,000 pounds to 0 in the end).

- The more farmers desert, the lower the collective returns of the remaining cooperative farmers with a single cow each (decreasing from 10,000 pounds to 0).

- The more farmers desert, the lower the returns of each of the deserters (decreasing from 1,800 pounds to 0 ). Moreover, the decrease will be so fast that although it would still be worthwhile for four farmers to desert because each would then earn 1,200 pounds instead of 1,000 , desertion would not be worth it for five farmers, because each would have two cows weighing only the same as the initial one (1,000 pounds). 


\begin{tabular}{|c|c|c|c|c|c|}
\hline $\begin{array}{c}\text { Number of } \\
\text { cows }\end{array}$ & $\begin{array}{c}\text { Weight of } \\
\text { one cow }\end{array}$ & $\begin{array}{c}\text { Collective } \\
\text { weight of } \\
\text { two cows } \\
\text { owned by } \\
\text { a single } \\
\text { owner }\end{array}$ & $\begin{array}{c}\text { Gains of } \\
\text { each farmer } \\
\text { turning out } \\
\text { a second } \\
\text { cow }\end{array}$ & $\begin{array}{c}\text { Total weight } \\
\text { of cows }\end{array}$ & $\begin{array}{c}\text { Loss of total } \\
\text { weight }\end{array}$ \\
\hline 10 & 1,000 & 0 & - & 10,000 & 0 \\
\hline 11 & 900 & 1,800 & 800 & 9,900 & 100 \\
\hline 12 & 800 & 1,600 & 600 & 9,600 & 400 \\
\hline 13 & 700 & 1,400 & 400 & 9,100 & 900 \\
\hline 14 & 600 & 1,200 & 200 & 8,400 & 1,600 \\
\hline 15 & 500 & 1,000 & 0 & 7,500 & 2,500 \\
\hline 16 & 400 & 800 & -200 & 6,400 & 3,600 \\
\hline 17 & 300 & 600 & -400 & 5,100 & 4,900 \\
\hline 18 & 200 & 400 & -600 & 3,600 & 6,400 \\
\hline 19 & 100 & 200 & -800 & 1,900 & 8,100 \\
\hline 20 & 0 & 0 & $-1,000$ & & 10,000 \\
\hline
\end{tabular}

Table 4-3. The tragedy of the commons (described by Hankiss, 1983, p. 24)

- However, once desertions have started, will they stop after the fourth farmer? They will not. And that is because although the fifth farmer may not gain anything compared to the original 1,000 pounds, he will definitely be better off compared to his current state. Namely, once the first four farmers have deserted, the fifth farmer's own cow can only reach 600 pounds in weight, but if he also were to turn out another cow, he would have two 500-pound cows, i.e., 1,000 pounds in total. He will thus turn out a second cow. And the next farmer will follow suit, because he too may gain 500 pounds with one cow, and 800 pounds with two, and so on until the ninth farmer, who, as can be seen from the table, will gain nothing by turning out a second cow because, just like the rest of the deserters, he will have two 100-pound cows instead of a single 200-pound one.

- What happens then? One possibility is that the chain reaction of desertions will run its full course and will lead to the destruction of the commons, whereby twenty cows will all starve to death and the pursuit of individual gain will result in a 100\% loss for each farmer.

And the other option? This involves creating a strategy of cooperation or enforcing it (e.g. through state intervention, or, as we have seen in the foregoing, the establishment of an efficient structure of ownership). In this case, the 
market will ensure efficient resource use. Historically, with village commons the latter option was pursued: the commons were abandoned and transferred into private ownership, with the social consequence that some farmers were reduced to poverty.

\subsection{Non-renewable (exhaustible) natural resources}

\subsubsection{Stocks of non-renewable (exhaustible) natural resources}

With exhaustible resources such as coal, mineral oil or ores, the question arises whether they should be used now, or they should be reserved for future use. More specifically, the question is whether a particular exhaustible natural resource should be put to economic use at all, and if so, at what rate.

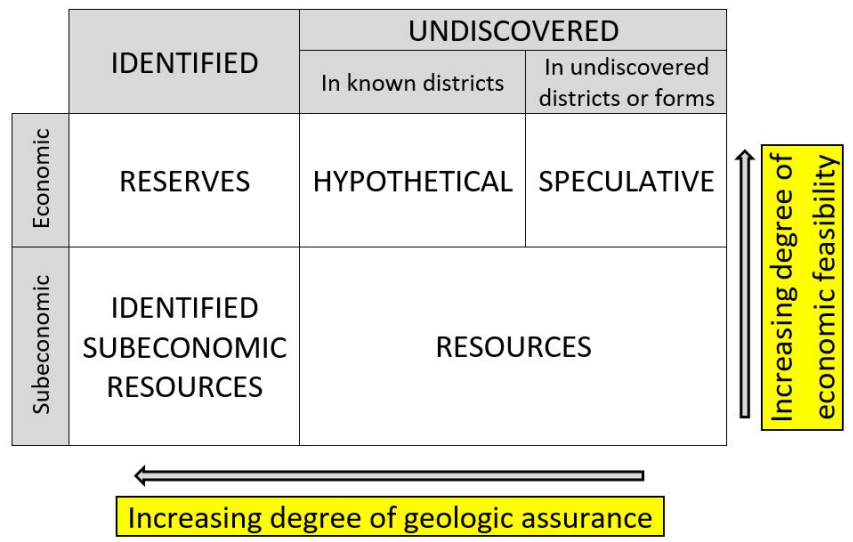

Figure 4-2. A categorization of resources

(U.S. Bureau of Mines, 1976, Wolfbauer, 1977, Tietenberg, 1992, p. 127)

As shown in Figure 4-2., not all mineral resources have been identified, and even the identified part comprises reserves only to the extent that they can be recovered and processed economically at a given level of development. In practice, this means that the volume of mineral resources may be estimated roughly from the frequency of specific elements on Earth, i.e., that scientists can determine the types of rock in which, for example, mineral oil, mineral coal, iron ore or other economically important mineral resources may have been formed during the history of the Earth, and where such resources may be found today. However, whether a particular mineral resource is actually part of pre-existing reserves depends on the level of technological development, transport conditions, and in some cases even international diplomacy. 
For example, at the level of technological development at the turn of the twentieth century, copper ore needed to contain about 6\% copper in order to be suitable for use. Today, floatation technology enables the economical processing of ores with a copper content of less than $0.5 \%$.

If prices on the world market are high, reserves will increase. With aluminium, for example, at above a certain price level thermal processes may also become economically viable, in addition to electrolytic reduction, making even bauxites with relatively low aluminium content economically suitable for processing (i.e., making them part of reserves).

Occasionally, armed conflict and political tension also influence the accessibility of raw materials, and therefore the size of the reserve. The reserve is the part of mineral resources which, given prevailing technological and economic conditions, is of positive in-situ value, i.e., the gains from its use are also sufficient to cover mining royalties, as discussed earlier. With all the foregoing taken into account, it becomes clearer why forecasts are so inaccurate at predicting the scarcity of exhaustible natural resources.

In 1949, the geologist Dr. Marion King Hubbert produced an estimate for US mineral oil production (Fig. 4-3). The bell curve initially rises sharply to reach a distinct maximum, referred to as the Hubbert peak, with production subsequently declining.

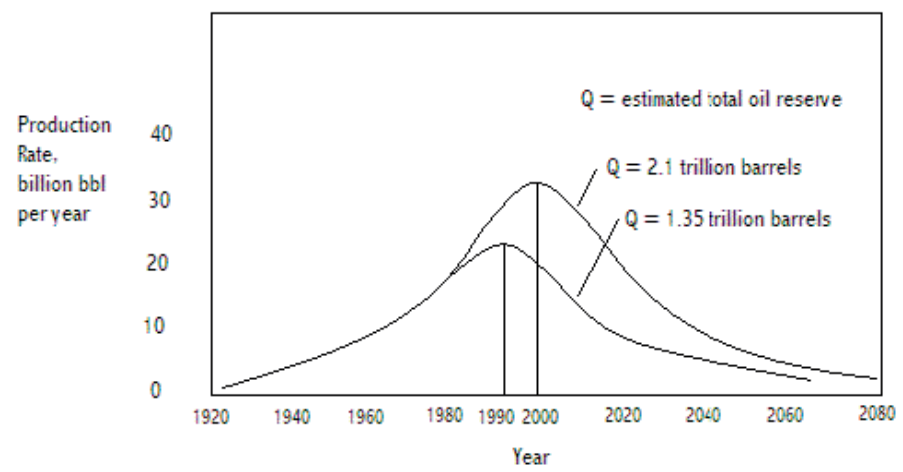

Figure 4-3. Hubbert's Curves Describing World Oil Production under Two Assumptions about total world oil reserves (Hubbert, 1956)

The initial sharp rise is due to the fact that fields are discovered rapidly, and initially production is concentrated in those areas where extraction is simple. When approximately one-half of the total reserve has been extracted, a progressively lower number of new fields will be discovered, and extraction will become increasingly difficult. Production declines and its cost increases. Older wells will become depleted. The cycle that captures this initial exponential rise - the peak and the subsequent decline - is referred to as the Hubbert cycle. The size of the world's mineral oil reserve was initially estimated at 1.35 
trillion barrels. According to a more recent estimate, the size of the reserve is now about 2.1 trillion barrels. However, even with such a significant difference, the Hubbert peak has been postponed by a mere 10 years from 1990 to 2000 . Since the mineral oil reserve is represented as the area under the curve, a relatively minor change in the time axis near the peak will understandably lead to a major change in production. Based on the Hubbert curve, with reasonable approximation the oil era is definitely expected to end around 2050.

As shown in Figure 4-4., production readings are closely aligned with the calculated Hubbert curve. Although as a result of the first oil price shock in 1973 production dropped temporarily, after some years it returned to a course that is still considered to fit the curve.

\section{THE HUBBERT CURVE}

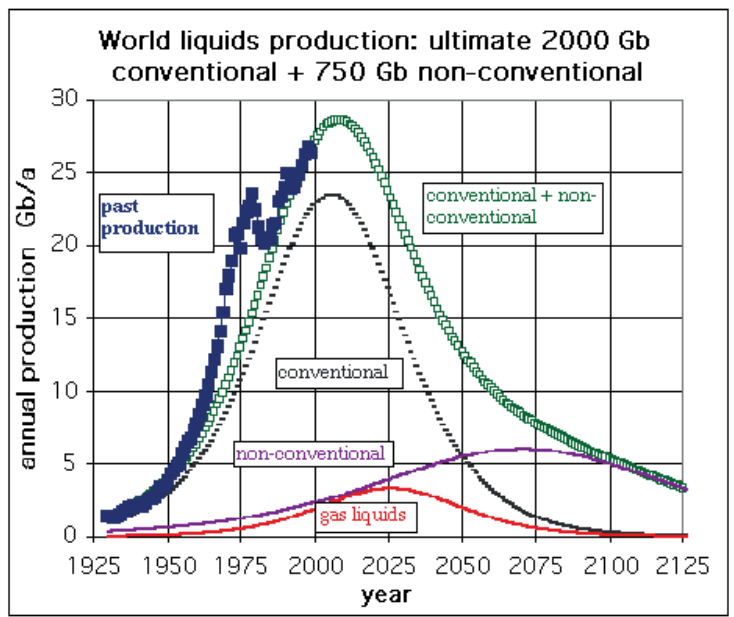

Figure 4-4. Hubbert's Curves for World liquids production (Clark, 2003)

Due to rising prices resulting from the enormous demand for mineral oil, in addition to conventional mineral oil the products of secondary extraction technologies and other products (shale oil, heavy oils, etc.) have also entered the market. However, not even the appearance of these non-conventional products will bring about a meaningful change in the situation, and in around 2050 we will witness the end of the era of mineral oil. 


\subsubsection{The optimal use of exhaustible natural resources}

Exhaustible natural resources are different from ordinary assets in that they are available in limited quantities, and they cannot be reproduced. As a result, the production and use of a unit of a non-renewable resource is associated with an opportunity cost, which is equivalent to the value that could be obtained should the resource not be used now (only at a later point in time).

In determining the rate of use of an exhaustible natural resource, this opportunity cost must also be taken into account; that is, in order for the use of the exhaustible natural resource to be considered optimal, its price should cover both the marginal cost of production and the opportunity cost.

As seen in Figure 4-5., the conventional efficiency criterion that price $=$ marginal cost of production will, for exhaustible natural resources, become price = marginal cost of production + opportunity cost. Figure 4-5. also shows that the use of an exhaustible resource is considered optimal if its current rate of production is lower compared to what would be optimal for its reproducible equivalent.

In order to ensure that the resource is optimally distributed in time, rather than producing a volume of $\mathrm{y}^{\star \star}$, the entrepreneur must incorporate a positive difference of $A B$ between price and production costs, and limit the volume of production to $y^{*}$. $A B$ is commonly referred to as rent, marginal profit, royalty, etc. In order to ensure that the use of an exhaustible resource is indeed optimal, the level of $A B$ (royalty) must be constant over time. In practice, this means that the royalty must increase by some percentage corresponding to the interest on capital over time; i.e., it is the discounted royalty value that should remain constant.

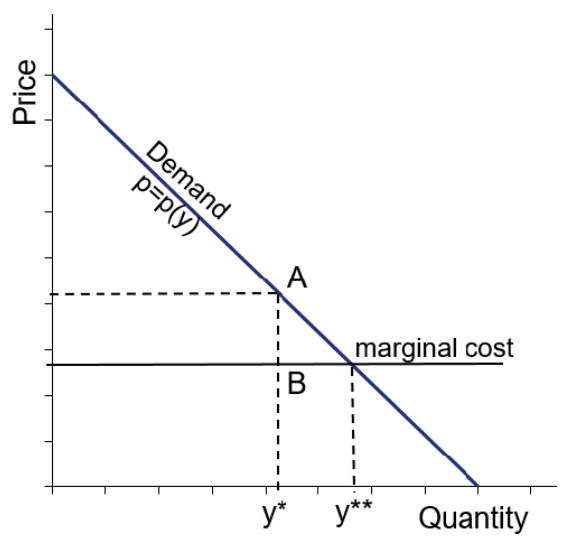

Figure 4-5. Use of exhaustible natural resources (Fisher, 1981, p. 13) 
The change in an exhaustible natural resource over time can also be written as a formula. As stated above, the royalty will increase in alignment with the interest rate if the marginal cost of production is assumed to be constant. In such a case, the royalty for the next period may be described as:

$$
\left(P_{1}-M C\right)=\left(P_{0}-M C\right) *(1+r)
$$

from which the price for the next period is

$$
P_{1}=M C+\left(P_{0}-M C\right) *(1+r)
$$

or generally for period $t$

$$
P_{t}=M C+\left(P_{0}-M C\right) *(1+r)^{t}
$$

The formula might suggest that the price of a unit of an exhaustible resource will increase steadily over time. In fact, this is not so; first, as shown in Figure 4-5., at a certain price demand is reduced to zero, and second, substitutes (other resources or technologies) often exist which are suitable for the same purpose, and may even be cheaper. In the case of mineral oil or natural gas, possible substitutes include coal, nuclear energy, and solar energy. That is, at a certain price level the economy will revert to a substitute (backstop) resource or technology.

Of course, in reality the situation is more complex, since each natural resource tends to be used for multiple purposes. As a result, a number of options for substitution may exist, each with their corresponding price. For example, apart from being used in energy production, mineral oil is also used in the chemical industry, and in the field of energy the substitution options are different than those for transport and for industrial heating. Obviously, its use in the chemical industry may come at a higher price than its use for energy purposes, etc.

The foregoing material has involved a relatively simplified discussion of the problem. The interested reader will find full details in the literature.

\subsection{Renewable resources and their optimal use}

It is rather difficult to define a clear borderline between renewable and exhaustible resources, or at least the conceptual limitations are hard to define. 'Renewable' resources such as forests or the fish population of a lake may in fact become exhausted, and in some cases 'exhaustible' natural resources may become renewable if technological development is taken into account. The situation is exemplified by copper, of which a temporary surplus has now 
accumulated due to the widespread use of glass fibre. There are also other examples where, as a combined result of waste recycling and technological development, solutions have emerged that virtually eliminate the need for additional primary raw materials for supporting the functioning of the economy. We have approximated such a situation in the case of platinum and lead. With other raw materials, the latest technologies enable the processing of ores at a concentration that the rocks that contain them would previously have been considered 'dead' (i.e., without value).

While major progress has been made in decelerating the exhaustion of resources that are conventionally considered exhaustible, in a peculiar way the renewability of resources otherwise considered renewable, such as rain forests and biological diversity, is now seen as compromised. This is more dangerous than, for example, a shortage of raw materials or energy, because any disasters caused by the latter may be corrected within a few years or generations, whereas the elimination of damage to biodiversity or the genomes of living creatures will take millions of years.

Adopted at the 1992 UN 'Earth Summit', the Convention on Biological Diversity was ratified by UN Member States relatively quickly, although the United Nations Environment Programme (UNEP) could not escape the conclusion in 1995 that $2-25 \%$ of all species that inhabit rain forests could disappear over the next quarter of a century, which corresponds to 1,000 to 10,000 times the rate of natural extinction.

Biodiversity is of critical importance to humankind for the following reasons:

- in ecosystems, biodiversity provides essential functions (services) that are indispensable for keeping Earth habitable (maintenance of the carbon cycle, hydrological cycle, soil conservation, control of surface temperature and micro-climate, etc.);

- biodiversity serves aesthetic, scientific, cultural and other universally recognised purposes which cannot be measured in monetary terms;

- biodiversity is the source of numerous products, including foodstuffs, textile components, medicines and chemicals. It also serves as a highly important information base for biotechnologies;

- biodiversity is the source of varietal diversity in plant and animal farming, and the creation of new varieties;

- the uniqueness and beauty of the variety of ecosystems represent a source of recreation and ecotourism.

Ratified by over 130 countries to date, the Convention requires all signatories to protect biodiversity by providing that '[e]ach Contracting Party shall, as far as possible and as appropriate, adopt economically and socially sound 
measures that act as incentives for the conservation and sustainable use of components of biological diversity'.

Ecologists are perhaps right to be sceptical about the above passage, due to past experience that any mention of 'economically sound' conservation generally implies the sacrifice of nature for short-term economic development.

It is difficult to question the arguments of conservationists and ecologists, and in particular the facts underlying their scepticism.

Economic growth in the twentieth century caused massive destruction in the natural environment in terms of both scale and method, and losses of biodiversity are undoubtedly the most regrettable because they are irreversible. Nevertheless, or precisely for that reason, more attention is being paid to economic growth and to some economic findings that have emerged recently, or have been neglected to date.

In normal circumstances (i.e., under conditions of 'reasonable use'), renewable natural resources regenerate, such as fish in seas and rivers, wood in forests, etc. Even with renewable natural resources, consideration should be given to the rate at which they may be used. Considering determination of the requirement for sustainable use, the scientific answer appears to be relatively simple: renewable natural resources should be used at a rate that allows them to regenerate. In economic terms, the answer is somewhat more complex. Ideally, the ownership of a renewable natural resource is well established. For example, a fish pond is operated by a farm, or a pasture is maintained by a cooperative. In this case, the amount of fish that may be bred or harvested in the pond annually, or the amount of livestock that may be grazed on a pasture will be determined by the carrying capacity of the area concerned. Under the law of natural growth, growth is considered a function of a resource set. The law of density dependent growth assumes the existence of an optimally sized set (i.e., a number of individuals, or size of biomass) that provides for the maximum sustainable yield. The owner of a pasture or fish pond will obviously seek to achieve and maintain that state.

With renewable resources (stock of fish, woods, pastures, etc.), growth in the quantity of a particular resource will depend on both the initial size or population count of the natural resource and the carrying capacity of its environment. Initial size determines the number of individuals suitable for breeding, and carrying capacity the abundance of available food. Initially, the resource may grow at a rapid rate to the extent that the environment provides an abundant food supply to a relatively small population. As the population grows, each individual will find it increasingly difficult to find food due to reasons of scarcity, which will reduce the growth rate of biomass. 
In Figure 4-6. the law of density dependent growth is illustrated through the example of a pond on a farm.

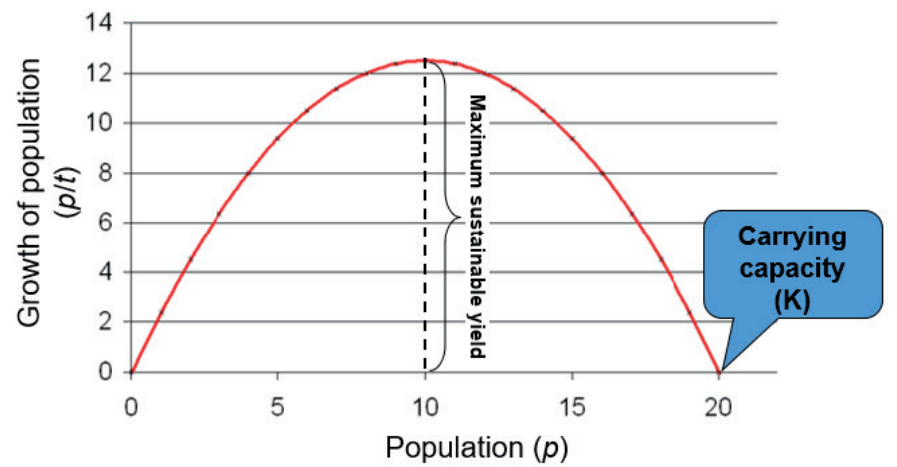

Figure 4-6. The law of density dependent growth (Milner-Gulland-Mace, 1998)

The horizontal axis on the chart represents the number of individuals in the fish population, and the vertical axis the growth generated by the given number of individuals over a unit of time. In the present case, the maximum growth is observed for a fish population of ten million, which corresponds to the optimum number of individuals in terms of sustainable use that maximises yield (sustainable number of individuals), at 12.5 million per unit of time on the chart. According to the chart, the carrying capacity of the pond is 20 million fish, which indicates the maximum number of fish that can live in the pond, and zero growth. The maximum yield is determined as ten million fish. Supposing there are only three million fish in the pond, only six million should be harvested to prevent the population from decreasing. Interestingly, a population of seventeen million fish will only produce growth of three million; however, in the case of a larger harvest (e.g. of four million), the remaining sixteen million fish will produce a larger yield the following year than the seventeen million fish in the previous year. That is, a decrease in the number of individuals will improve the living conditions of the remaining population, and consequently economic results as well.

That said, there is a significant difference between the two situations in environmental terms. When the number of individuals drops below a sustainable amount, overfishing risks destruction of the population, whereas excessive growth in the population will only reduce the annual yield of the pond without the risk of destroying the population as a whole. That is, in the first case some intervention to limit harvests is required to prevent the overuse of the natural resource in order to preserve the fish population in the pond, whereas in the second case no such intervention is required, and the matter may be entrusted to nature's care. 
With some addition to the fish population chart, Figure 4-7. allows us to provide a relatively accurate definition for the protection and conservation of a renewable natural resource in the economic sense. The value $S_{\text {MIN }}$ shows that below a certain number of individuals a population is no longer able to grow and is at risk of disappearance unless direct intervention is made to increase the number of individuals to above $S_{\text {MIN }}$. Many species have been saved from extinction by artificial breeding.

For centuries the supply of and demand for fish in publicly owned seas and lakes was characterised by such equilibrium, without the need to raise the issue of conservation. However, the situation has changed recently (Figure $4-8$.$) , and due to the scarcity of resources an equilibrium of supply and de-$ mand cannot be reached if the volume of fishing exceeds that of sustainable use. Without intervention, resources will rapidly become exhausted, a situation which calls for restrictive conservation measures on the grounds that individual producers (fishers) who control a mere fragment of the market do not care whether the fish population declines in the future, but even if they do, they can so little to preserve it that their efforts qualify as impractical in economic terms.

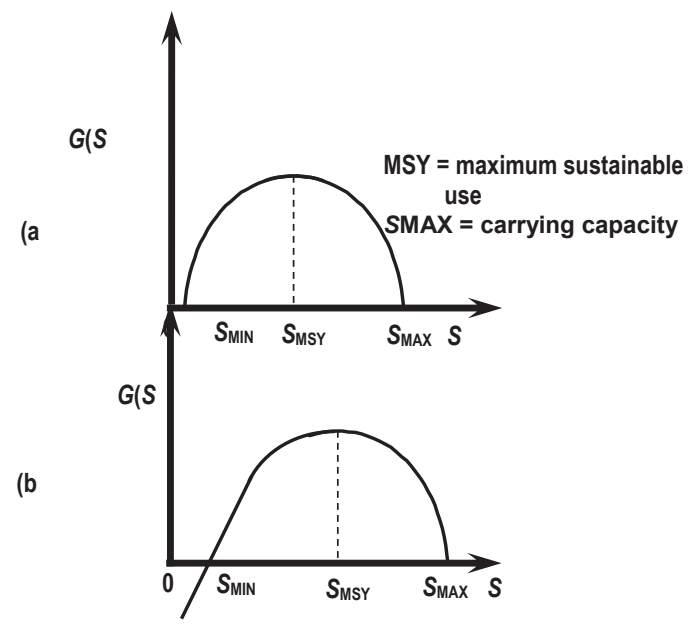

Figure 4-7. Types of density dependent growth curves (Tietenberg, 1992, p. 306.)

Suppose that a large number of fish pond owners sell fish to a large number of consumers (that is, a perfect competitive market exists where the price is determined by the market). However, for reproducible assets in such an arrangement the supply curve would be derived as the aggregate of individual marginal cost (MC) curves, while for renewable natural resources such as fish farms, forests, etc., the correct supply curve would be above that derived from sellers' MC 
curves, because sellers are under pressure to incorporate costs incurred from any reductions in the next period's yield due to what is harvested in the current period.

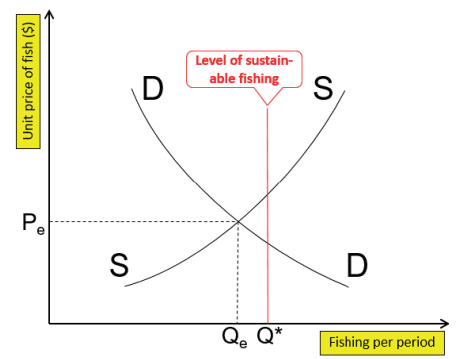

Figure 4-8. Supply, demand and sustainability of a renewable resource: population is saved within the market (Fisher, 1981)

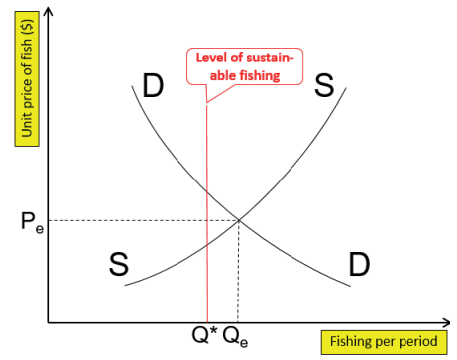

Figure 4-9. Supply, demand and sustainability of a renewable resource: population cannot be saved within the market (Fisher, 1981)
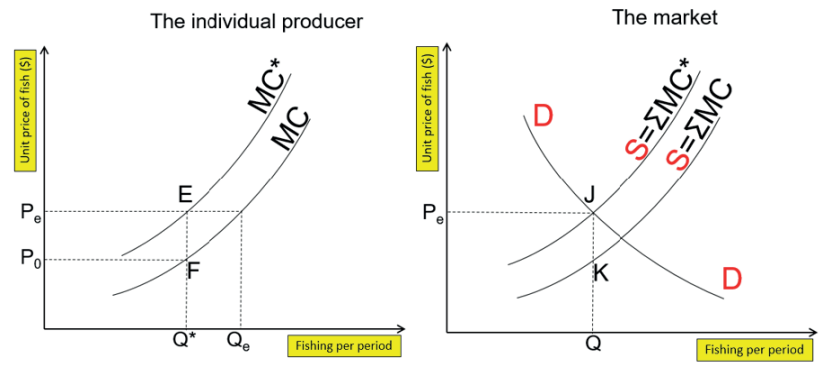

Figure 4-10. Supply, demand and sustainability of a renewable resource: derivation of aggregate supply (Fisher, 1981)

As shown in the left panel of Figure 4-10., for the individual producer the marginal cost curve $(\mathrm{MC})$ has shifted to the left $\left(\mathrm{MC}^{*}\right)$, as a result of which the equilibrium price will be $\mathrm{P}_{\mathrm{e}}$ rather than $\mathrm{P}_{0}$. The establishment of the equilibrium 
price is shown in the right-hand panel, where the supply curve of the market is derived as the aggregate of individual marginal cost curves $\left(\mathrm{MC}^{*}\right)$ that also incorporates future costs. At quantity $\mathrm{Q}$, the equilibrium price $\mathrm{Pe}$ will be determined by the intersection of that supply curve and the aggregate demand curve of the market. Section EF on the left panel (i.e., the difference between the two supply curves) is commonly referred to as the individual producer's reservation price, and the $\mathrm{JK}$ difference on the right simply as the reservation price. As shown on the left, due to the reservation price the individual producer's profit will be maximised at quantity $Q^{*}$. The reservation price (i.e., the difference between $P_{e}$ and $P_{0}$ ), will compensate the individual producer for any losses resulting from reductions in future yields.

Naturally, the reservation price is influenced by the bank interest rate ${ }^{8}$, and, curiously, will be reduced by a high bank rate and increased by a low bank rate. This situation is explained by the fact that a high interest rate provides an incentive for a producer to sell goods on the market promptly, and deposit the proceeds with a bank in order to earn interest. Obviously, expected developments in the price of the resource are also relevant. When a significant price increase is expected, the reservation price may also be inflated. That, of course, will not reduce the influence and importance of the interest rate. When the expected price increase exceeds the interest rate, it may be more worthwhile to keep the fish in the pond for another year, otherwise there is no rationale for this, and the reservation price will be reduced. Expected developments in fishing costs may also be of interest. Obviously, if fishing costs are expected to increase (e.g. due to a rise in wage costs), it is reasonable to take goods to market promptly, which may also reduce the reservation price. Certainly, the reservation price will also be influenced by the current size of the fish population relative to the carrying capacity of the pond, as well as to the population size that provides for the maximum sustainable yield. Clearly, the producer has no interest in maintaining an excessive fish population, because, as shown above, that would reduce growth; therefore, the reservation price may be reduced to zero in cases where the population exceeds what is required for the maximum yield, and conversely, be inflated in cases near the optimum.

The reservation price will certainly also be influenced by the cost of activities which, in one way or another, affect carrying capacity, optimum population size, etc. Such activities may include the introduction of juvenile fish into a pond, artificial feeding, afforestation, fertilisation, etc. Such methods will of course enable the yield to be influenced, and the economic viability of interventions of this kind may also be determined subject to the factors mentioned above.

8 More specifically, the ratio of the interest rate to the natural growth rate of biomass. An interest rate exceeding the growth rate of biomass will provide an incentive for overuse of the natural resource. 


\subsection{The theory of public and collective goods}

Collective choices made in the political space are largely related to the management of public goods. A public good is '[a] commodity or service which if supplied to one person can be made available to others at no extra cost. [...] One person's consumption of the good does not reduce its availability to others'. (Pearce, 1993) The two key attributes of a public good are nonexcludability and non-rival consumption. A typical such public good is air, the consumption of which must be granted to everyone, while no-one will have less air because others breathe. In addition to public goods, there are also collective goods, the consumption of which must be granted to everyone, but which are not available in unlimited quantities, and may be expensive to produce. Such collective goods include drinking water and waste disposal. The provision of collective goods is a matter of collective choice. Whether access to drinking water by users who do not pay for it is provided in their residence or only from a public fountain depends on decisions made by the community. Whether locally or nationally, access to collective goods is regulated by the community. The supply of public and collective goods is financed from the tax revenues collected by the state. In specific cases, the production of collective goods may also be financed from user contributions.

The difficulties of interpreting the situation with public goods will be illustrated below through some practical examples. Although the common benefit derived from paving a road leading up to a vineyard would far exceed the expenditure required, it is not certain that such a road will actually be paved. In most cases, seeing differences of opinion and willingness to make sacrifices, the 'organiser' will give up organising the community for this purpose. Transaction costs can be determined both in principle and in practice, but may be excessive in the case of large groups where the phenomenon of free riders can become so dominant as to prevent the action from being taken even if the benefits of the decision are likely to outweigh the expenditure of each individual.

For millennia, states have been successful in providing certain public or collective goods, and have failed with the provision of others. States tend to tackle problems related to national security, protection against epidemics, and more recently, safeguarding against ozone depletion. In the field of environmental protection, for the most part they have overcome problems posed by direct and particularly harmful forms of pollution. With highly visible incidents of harmful natural pollution, the tendency towards free riding is less marked; however, public policy is not particularly effective in the cases when the existence of the 'public good' remains in the background, is not directly visible, and is difficult to understand for the public at large. This is clearly the case with biodiversity, and for the most part also with climate protec- 
tion. These are public goods just like clean urban air, but are less widely understood, and perceptions are that the degradation of such public goods is of little risk to human survival. This partly explains why governments do little to provide such public or collective goods to present and future generations in sufficient quantity and quality. In some very poor countries of the world, states are incapable of ensuring even the supply of public goods required to meet the most elementary needs. Extreme poverty is frequently accompanied by a lack of access to drinking water of adequate quality. In economics, free access to public goods is considered one of the causes of environmental damage. It was largely in accord with Hardin's article that literature rediscovered the problems with the inevitable overuse of goods used collectively. (See the chapter earlier: Overuse of public goods: 'The Tragedy of the Commons')

Finally, Hardin concluded the following: 'Individualism is cherished because it produces freedom, but the gift is conditional: The more the population exceeds the carrying capacity of the environment, the more freedoms must be given up. As cities grow, the freedom to park is restricted by the number of parking meters or fee-charging garages. [...] On the global scale, nations are abandoning not only the freedom of the seas, but the freedom of the atmosphere, which acts as a common sink for aerial garbage. Yet to come are many other restrictions as the world's population continues to grow [...but] the slightest attempt to limit this freedom is promptly denounced with cries of Elitism! Big-Brotherism! Despotism! Fascism! and the like. We are slow to mend our ways because ethicists and philosophers of the past generally did not see that numbers matter. In the language of 20th-century commentators, traditional thinking was magnificently verbal and deplorably nonnumerate. One of today's cardinal tasks is to marry the philosopher's literate ethics with the scientist's commitment to numerate analysis.' (Hardin, 1998) Almost a decade has passed since Hardin shared these thoughts. Since then, the population of the Earth has grown by another billion, and in 2015 the first great migrations of the twenty-first century started. Having respect for the numbers imposes a task of extreme urgency on social scientists and policymakers. Brooding over the past only makes sense if it helps to create a better vision of the future. The Earth is undoubtedly 'packed' with people, and the limits of carrying capacity have been breached on some continents, a fact which remains true even if the very people who should be racking their brains in an effort to find solutions are now failing to grasp the situation because they are busy exercising power. 


\subsection{The trap of present value calculation}

The second half of the twentieth century brought about increasing societal awareness that the capacities of our Earth were finite, whereas earlier, public goods that had previously been considered infinite and free, such as clean air, healthy drinking water, waste disposal, and certain biosphere services, had been classified as being among the public goods to be provided by governments on a mandatory basis, as part of public services. One representative of neoclassical economics, Arthur Pigou (Pigou, 2013), proposed that externalities be taxed, then Ronald Coase (Coase, 1960), the founder of institutional economics, sought to internalise externalities by means of market bargaining. However, problems remain, since the market economy, relying on the calculation of present value for its functioning, is hardly capable of managing projects of more than 30 to 50 years, whereas respecting the limits of the Earth would require thinking using a time horizon of several hundred years. The social discount rate desirable for sustainable development would often be significantly lower than the market discount rate.

Even relatively simple projects that would, for instance, create considerable energy savings, generally involve significant investment costs. Some projects are implemented over a period of 30 to 50 years, and the rules of present value calculation generally produce a negative net present value, where the social discount rate is defined at 6 to $8 \%$ or above, and practitioners hardly ever apply lower rates.

To illustrate the problem, let us consider a very simple and widely known example. Afforestation is regarded as a means of fighting climate change. Trees fix carbon dioxide, for which they only use solar energy through photosynthesis. Their growth is often a lengthy process, as a result of which they keep fixing carbon dioxide for extensive periods. Wood is an excellent raw material for a number of industries, and ultimately may also be used as a renewable source of energy. Moreover, forests play an important role in human recreation, and provide a great number of biosphere services. Let us consider it a given that wood is a valuable good: it is not by coincidence that the destruction of forests has been prohibited by law for centuries. This should obviously make it worthwhile to invest in afforestation. With any investment, the investor assesses the investment opportunities available and identifies the one that offers the highest return. This requires an assessment of the risks of the investment, as well as the expected returns and cash flows associated with it. Underlying those calculations is the answer to the simple question of which is better: purchasing government securities that offer relatively low returns but are virtually free of risk, or 
taking part in an undertaking that involves slightly higher risk, but also offers higher annual returns compared to the government securities. The problem is well known, and specialist books on finance recommend using net present value calculations to answer the question (Brealey-Myers-Allen-Mohanty, 2012).

The net present value of any investment may be calculated using the following formula:

$$
N P V=\sum \frac{C_{t}}{(1+r)^{t}}-C_{0}
$$

where

$t$ is the time of the cash flow concerned (e.g. 3 represents year three);

$n$ is the entire term;

$r$ is the interest or discount rate;

$C_{t}$ is the net cash flow at time $t$ (positive for gains and negative for investments or expenses);

$C_{0}$ is the amount of money invested at time 0 .

Specialist books offer detailed arguments that demonstrate that whenever the above formula produces a positive net present value, a return will certainly be made on the investment provided that the presuppositions are valid. One such key presupposition is the estimate of the discount rate included in the formula. The discount rate shows the investor's expectations about the returns on the investment. Higher discount rates are applied to riskier investments (e.g. when the economic environment is uncertain, the area is exposed to extreme weather due to climate change, or the protection of property right cannot be fully guaranteed). A higher discount rate is warranted by these and similar circumstances. In a relatively stable and less risky economic environment, expected returns are lower, and so are the discount rates applied. On balance, it may be assumed that if NPV $>0$ the investment is viable.

Let us now consider the case of afforestation referred to earlier. With forests, the two extremes are represented by energy forests on the one hand, and forests comprising valuable native species on the other, which provide a variety of benefits but grow at a very slow rate. A good example of the first is a forest of locust trees, which are fast-growing trees but nonnative to Hungary, and of the second, an oak or beech forest. Reaching maturity takes 20 to 22 years in the former case, and 110 to 120 years in the latter. The table below shows details of the various utilisation parameters for the two forest types, taking into account the time that elapses after planting: 


\begin{tabular}{|c|c|c|c|c|c|c|c|c|c|}
\hline \multirow[t]{2}{*}{ Species } & \multicolumn{2}{|c|}{ Clearance } & \multicolumn{2}{|c|}{$\begin{array}{l}\text { Selection } \\
\text { thinning }\end{array}$} & \multicolumn{2}{|c|}{$\begin{array}{l}\text { Increment } \\
\text { thinning }\end{array}$} & \multicolumn{2}{|c|}{$\begin{array}{c}\text { Final } \\
\text { harvest of } \\
\text { plantations }\end{array}$} & \multirow[t]{2}{*}{ Note } \\
\hline & age & $\mathrm{m}^{3}$ & age & $\mathrm{m}^{3}$ & age & $\mathrm{m}^{3}$ & age & $\mathrm{m}^{3}$ & \\
\hline Oak & 15 & 5 & $\begin{array}{c}30 \\
- \\
50\end{array}$ & 20 & $\begin{array}{c}60 \\
- \\
80\end{array}$ & 60 & 100 & 400 & $\begin{array}{l}\text { In normal cases, } \\
\text { several rounds of } \\
\text { thinning may be } \\
\text { required, and a } \\
\text { final harvest may } \\
\text { also be made in the } \\
\text { form of progressive } \\
\text { regeneration cutting }\end{array}$ \\
\hline Locust & 8 & 5 & 15 & 20 & 22 & 30 & 30 & 140 & $\begin{array}{l}\text { The final harvest } \\
\text { is mostly made by } \\
\text { clear felling, and } \\
\text { regeneration by } \\
\text { sprouting }\end{array}$ \\
\hline
\end{tabular}

Table 4-4. Harvesting methods (University of West Hungary:

Theoretical considerations of evaluating economics of continuous cover forestry, n.d.)

The Hungarian data show that in an oak forest, the final harvest will yield approximately 400 cubic meters of high-quality wood per hectare, with another 85 cubic meters of firewood produced by thinning. After 30 years, a locust forest will yield 140 cubic meters of wood that is also valuable, but of more limited use. In 100 years, a locust forest will yield approximately 420 cubic meters of valuable wood, and an additional 165 cubic meters of less valuable material.

There is an extensive body of literature about the problems with selecting the appropriate social discount rates. Using data from one such paper (with some adjustments), we have calculated the net present values for the two forest types. Given that the life span of an oak forest is very long, 114 years in our example, whereas that of a locust forest is only 22 years, we assumed that the locust is clear-felled every 22 years and replanted immediately afterwards, which allowed us to obtain comparable data by calculating the net present value of both types for 114 years. As our numerical example is fairly well aligned with the findings of professionals from the University of West Hungary (see the table above), we may be excused for dispensing with some of the details. Based on the English paper, the following tables present the expenditure related to plantation and the expected returns on sales of wood. 


\begin{tabular}{|c|c|c|}
\hline Years & Activities & $\begin{array}{c}\text { Real expenses and } \\
\text { returns (thousand HUF } \\
\text { per hectare) }\end{array}$ \\
\hline 0 & Preparation of area & -20 \\
\hline 0 & Plantation & -80 \\
\hline 0 & Road construction & -30 \\
\hline $0-60$ & Annual operating expenses & -8 \\
\hline 1 & Weed control & -20 \\
\hline $4,7,10,13$ & Pruning and thinning & -6 \\
\hline 8 & before sale & 80 \\
\hline 12 & Thinning (1) & 140 \\
\hline 16 & Thinning (2) & 200 \\
\hline 22 & Thinning (3) & 1,600 \\
\hline
\end{tabular}

Table 4-5. Plantation and maintenance costs of a locust forest at the time they are incurred (based on Straka-Bullard, 1996; Davis-Johnson, 1987)

\begin{tabular}{|c|c|c|}
\hline Years & Activities & $\begin{array}{c}\text { Real expenses and } \\
\text { returns (thousand HUF } \\
\text { per hectare) }\end{array}$ \\
\hline 0 & Preparation of area & -40 \\
\hline 0 & Plantation and protection & -320 \\
\hline $0-60$ & $\begin{array}{c}\text { Annual administrative } \\
\text { costs }\end{array}$ & -8 \\
\hline 1 & Weed control & -40 \\
\hline 5 & Pruning and thinning & -80 \\
\hline 60 & before sale & 1,600 \\
\hline 80 & Thinning (1) & 3,200 \\
\hline 100 & Thinning (2) & 4,000 \\
\hline 120 & Thinning (3) & 4,800 \\
\hline
\end{tabular}

Table 4-6. Plantation and maintenance costs of an oak forest at the time they are incurred (based on Straka-Bullard, 1996; Davis-Johnson, 1987)

In both cases, the present value is calculated over a period of 114 years. Annual cash flows are summarised in Table 4-7. The net present value of each alternative is shown in Table 4-8. The lowest discount rate that is applied is 1\%; however, an investor who would accept an annual return of $1 \%$ is very unlikely to exist in reality. The examples provided in specialist books on finance hardly ever assume discount rates of below $6 \%$. Our highest discount rate is $15 \%$. Such high discount rates are also rare in practice, but could actually occur in the case of 
high-risk investments or high inflation; indeed, in developing world countries foreign investors use even higher discount rates in their present value calculations.

\begin{tabular}{|c|c|c|c|c|c|c|c|c|c|c|c|c|c|c|c|c|c|c|c|c|}
\hline $\mathbf{0}$ & $\mathbf{1}$ & $\mathbf{2}$ & $\mathbf{3}$ & $\mathbf{4}$ & $\mathbf{5}$ & $\mathbf{6}$ & $\mathbf{7}$ & $\mathbf{8}$ & $\mathbf{9}$ & $\mathbf{1 0}$ & $\mathbf{1 1}$ & $\mathbf{1 2}$ & $\mathbf{1 3}$ & $\mathbf{1 4}$ & $\mathbf{1 5}$ & $\mathbf{1 6}$ & $\mathbf{1 7}$ & $\mathbf{1 8}$ & $\mathbf{1 9}$ & $\mathbf{2 0}$ \\
\hline-130 & -28 & -8 & -8 & -14 & -8 & -8 & -14 & $\mathbf{7 2}$ & -8 & -14 & -8 & 132 & -14 & -8 & -8 & $\mathbf{1 9} 2$ & -8 & -8 & -8 & -8 \\
\hline-360 & -48 & -8 & -8 & -8 & -88 & -8 & -8 & -8 & -8 & -8 & -8 & -8 & -8 & -8 & -8 & -8 & -8 & -8 & -8 & -8 \\
\hline $\mathbf{2 1}$ & $\mathbf{2 2}$ & $\mathbf{2 3}$ & $\mathbf{2 4}$ & $\mathbf{2 5}$ & $\mathbf{2 6}$ & $\mathbf{2 7}$ & $\mathbf{2 8}$ & $\mathbf{2 9}$ & $\mathbf{3 0}$ & $\mathbf{3 1}$ & $\mathbf{3 2}$ & $\mathbf{3 3}$ & $\mathbf{3 4}$ & $\mathbf{3 5}$ & $\mathbf{3 6}$ & $\mathbf{3 7}$ & $\mathbf{3 8}$ & $\mathbf{3 9}$ & $\mathbf{4 0}$ & $\mathbf{2 1}$ \\
\hline-8 & 1,592 & -130 & -28 & -8 & -8 & -14 & -8 & -8 & -14 & $\mathbf{7 2}$ & -8 & -14 & -8 & 132 & -14 & -8 & -8 & 192 & -8 & -8 \\
\hline-8 & -8 & -8 & -8 & -8 & -8 & -8 & -8 & -8 & -8 & -8 & -8 & -8 & -8 & -8 & -8 & -8 & -8 & -8 & -8 & -8 \\
\hline $\mathbf{4 1}$ & $\mathbf{4 2}$ & $\mathbf{4 3}$ & $\mathbf{4 4}$ & $\mathbf{4 5}$ & $\mathbf{4 6}$ & $\mathbf{4 7}$ & $\mathbf{4 8}$ & $\mathbf{4 9}$ & $\mathbf{5 0}$ & $\mathbf{5 1}$ & $\mathbf{5 2}$ & $\mathbf{5 3}$ & $\mathbf{5 4}$ & $\mathbf{5 5}$ & $\mathbf{5 6}$ & $\mathbf{5 7}$ & $\mathbf{5 8}$ & $\mathbf{5 9}$ & $\mathbf{6 0}$ & $\mathbf{4 1}$ \\
\hline-8 & -8 & -8 & -8 & 1,592 & -130 & -28 & -8 & -8 & -14 & -8 & -8 & -14 & 72 & -8 & -14 & -8 & 132 & -14 & -8 & -8 \\
\hline-8 & -8 & -8 & -8 & -8 & -8 & -8 & -8 & -8 & -8 & -8 & -8 & -8 & -8 & -8 & -8 & -8 & -8 & -8 & 1,592 & -8 \\
\hline $\mathbf{6 0}$ & $\mathbf{6 1}$ & $\mathbf{6 2}$ & $\mathbf{6 3}$ & $\mathbf{6 4}$ & $\mathbf{6 5}$ & $\mathbf{6 6}$ & $\mathbf{6 7}$ & $\mathbf{6 8}$ & $\mathbf{6 9}$ & $\mathbf{7 0}$ & $\mathbf{7 1}$ & $\mathbf{7 2}$ & $\mathbf{7 3}$ & $\mathbf{7 4}$ & $\mathbf{7 5}$ & $\mathbf{7 6}$ & $\mathbf{7 7}$ & $\mathbf{7 8}$ & $\mathbf{7 9}$ & $\mathbf{8 0}$ \\
\hline-8 & -8 & 192 & -8 & -8 & -8 & -8 & -8 & 1,592 & -130 & -28 & -8 & -8 & -14 & -8 & -8 & -14 & 72 & -8 & -14 & -8 \\
\hline 1,592 & 0 & 0 & 0 & 0 & 0 & 0 & 0 & 0 & 0 & 0 & 0 & 0 & 0 & 0 & 0 & 0 & 0 & 0 & 0 & 3,200 \\
\hline $\mathbf{8 1}$ & $\mathbf{8 2}$ & $\mathbf{8 3}$ & $\mathbf{8 4}$ & $\mathbf{8 5}$ & $\mathbf{8 6}$ & $\mathbf{8 7}$ & $\mathbf{8 8}$ & $\mathbf{8 9}$ & $\mathbf{9 0}$ & $\mathbf{9 1}$ & $\mathbf{9 2}$ & $\mathbf{9 3}$ & $\mathbf{9 4}$ & $\mathbf{9 5}$ & $\mathbf{9 6}$ & $\mathbf{9 7}$ & $\mathbf{9 8}$ & $\mathbf{9 9}$ & $\mathbf{1 0 0}$ & $\mathbf{1 0 1}$ \\
\hline 132 & -14 & -8 & -8 & 192 & -8 & -8 & -8 & -8 & -8 & 1,592 & -130 & -28 & -8 & -8 & -14 & -8 & -8 & -14 & 72 & -8 \\
\hline 0 & 0 & 0 & 0 & 0 & 0 & 0 & 0 & 0 & 0 & 0 & 0 & 0 & 0 & 0 & 0 & 0 & 0 & 0 & 4,000 & 0 \\
\hline $\mathbf{1 0 2}$ & $\mathbf{1 0 3}$ & $\mathbf{1 0 4}$ & $\mathbf{1 0 5}$ & $\mathbf{1 0 6}$ & $\mathbf{1 0 7}$ & $\mathbf{1 0 8}$ & $\mathbf{1 0 9}$ & $\mathbf{1 1 0}$ & $\mathbf{1 1 1}$ & $\mathbf{1 1 2}$ & $\mathbf{1 1 3}$ & $\mathbf{1 1 4}$ & & & & & & & & \\
\hline-14 & -8 & 132 & -14 & -8 & -8 & 192 & -8 & -8 & -8 & -8 & -8 & 1,592 & & & & & & & & \\
\hline 0 & 0 & 0 & 0 & 0 & 0 & 0 & 0 & 0 & 0 & 0 & 0 & 4,800 & & & & & & & & \\
\hline
\end{tabular}

Table 4-7. Cash flows for oak and locust trees between years 0 and 114 (author's own compilation)

The results in Table 4-8. speak for themselves. In the case of oak, whenever the discount rate is higher than $3 \%$ all NPV is negative, indicating that the investment should not be made. Conversely, in the case of locust NPV enters negative territory only with discount rates above $12 \%$, showing that locust forests could be planted on a market basis, whereas oak forests most probably could not.

\begin{tabular}{|c|c|c|c|}
\hline Discount rates & NPV (locust) $\mathrm{t}=114$ & $\mathrm{NPV}$ (oak) $\mathrm{t}=114$ & NPV (locust) $\mathrm{t}=22$ \\
\hline $1 \%$ & 4,415 & 4,512 & 1,325 \\
\hline $2 \%$ & 2,571 & 1,449 & 1,048 \\
\hline $3 \%$ & 1,617 & 256 & 825 \\
\hline $4 \%$ & 1,074 & -220 & 646 \\
\hline $5 \%$ & 739 & -413 & 500 \\
\hline $6 \%$ & 517 & -490 & 382 \\
\hline $7 \%$ & 363 & -518 & 287 \\
\hline $8 \%$ & 251 & -525 & 208 \\
\hline $9 \%$ & 168 & -524 & 145 \\
\hline $10 \%$ & 104 & -519 & 92 \\
\hline $11 \%$ & 54 & -512 & 50 \\
\hline $12 \%$ & 15 & -505 & 14 \\
\hline $13 \%$ & -16 & -499 & -15 \\
\hline $14 \%$ & -41 & -493 & -39 \\
\hline $15 \%$ & -61 & -487 & -59 \\
\hline
\end{tabular}

Table 4-8. Net present value of locust and oak forests at various discount rates and terms (author's own compilation) 


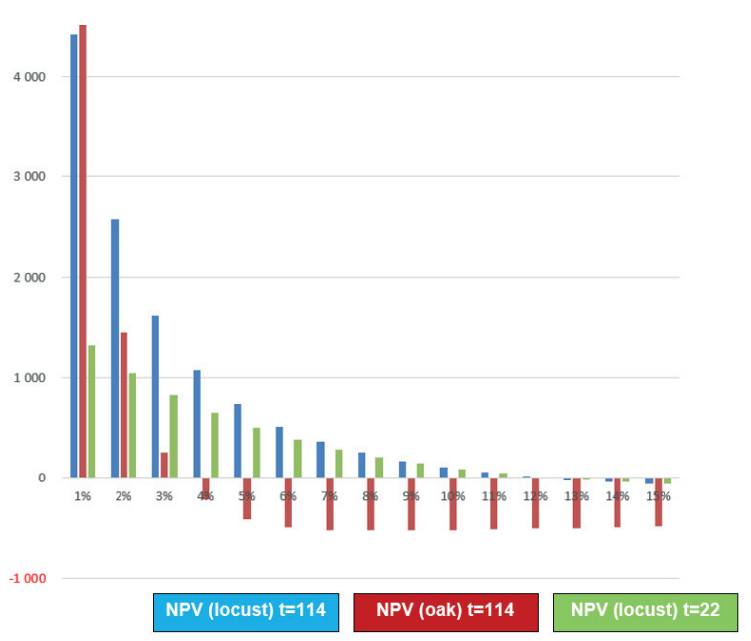

Figure 4-11. Present value of locust and oak forests assuming a 114-year (and a 22-year) cycle and various discount rates (based on Table 4-8.) (author's own compilation)

The above figure shows clearly that planting oak trees appears to be more advantageous than locust trees only when a discount rate of a very low $1 \%$ is applied. With any discount rate above $1 \%$, it would be better to plant a locust forest. That said, the ecosystem services of an oak forest are known to be much more valuable compared to those of a locust forest, although such intangible services are disregarded for the purposes of present value calculations.

With such long-term projects, it would be reasonable to use tiered discount rates. In Britain, the discounting practice of Her Majesty's Treasury Department (Treasury, 2003) provides a good example of the discount rates which may be applied to long-term investments. The guidelines recommend the application of a discount rate of $3.5 \%$ for the first thirty years of a project, followed by discount rates of $3 \%$ to $1 \%$ (see Table 4-9.).

\begin{tabular}{|c|c|c|c|c|c|c|}
\hline $\begin{array}{c}\text { Term in } \\
\text { years }\end{array}$ & $\mathbf{0 - 3 0}$ & $\mathbf{3 1 - 7 5}$ & $\mathbf{7 6 - 1 2 5}$ & $\mathbf{1 2 6 - 2 0 0}$ & $\mathbf{2 0 1 - 3 0 0}$ & $\mathbf{3 0 1 +}$ \\
\hline $\begin{array}{c}\text { Discount } \\
\text { rates }\end{array}$ & $3.5 \%$ & $3.0 \%$ & $2.5 \%$ & $2.0 \%$ & $1.5 \%$ & $1.0 \%$ \\
\hline
\end{tabular}

Table 4-9. Discount rates recommended in HM's Treasury Green Book (2003) 
Naturally, tiered discount rates are not only suitable for the economic valuation of forest plantations. Their use is desirable with utility services such as sewerage, fixed-track public transport, investments in nature conservation, etc. These investments require public participation since private investors cannot be expected to maintain public or even quasi-public goods. In our example, an energy forest (e.g. involving the locust species) which can be clear-felled after twenty years may also be planted on a commercial basis; however, the plantation of an oak forest with a desirable life span of 100 to 120 years will require artificially 'mandated' discount rates to show a positive net present value, but will, apart from its timber yield, also play an important role in preserving biodiversity and a healthy environment. In order to ensure the provision of such welfare-increasing services as public goods, it is appropriate that the state should intervene and grant subsidies to compensate private investors for the lower returns on such investments. Fortunately, most states do provide such subsidies in order to maintain an adequate supply of public goods.

\subsection{The economic valuation of environmental changes - monetary evaluation}

\subsubsection{The relationship between total economic value and ecosystem services}

Total economic value (TEV, Kerekes-Szlávik, 2001; Marjainé Szerényi, 2005,2011 ) is a core concept in the monetary evaluation of environmental change. From a human perspective, the concept aggregates the reasons and arguments which may explain our preferences for goods being valued, which definitely lends a human dimension to the concept of valuation itself. The two key components are use values and non-use values, both of which may be further subdivided into more detailed components. Use values are comprised of the components of direct use, indirect use and option values, whereas non-use values may include, for example, bequest, altruistic or existence values. The related formula looks like this when written down:

Total economic value (TEV) = use values (direct use, indirect use and option value) + non-use values (bequest, altruistic, existence, etc.).

Use values, as their name suggests, incorporate the preferences of individuals who either actually use an environmental good or would have an opportunity to use the good in the present (i.e. members of the present generation), whereas non-use values primarily represent the preferences of 
future generations. Direct utility is derived from any change that affects our lives in apparent and perceivable ways, or is effectively taken advantage of. Although individuals are generally not aware of indirect values, they are fundamental determinants of our lives. Constituting the third component of this type, option value is associated with the possibility that value may be associated with a positive environmental change (or the avoidance of a negative change), even if the environmental resource concerned (or a specific service provided by it) is not currently used, but there is a need to preserve it in the hope of future use. Non-use values represent the possibility that even if the present generation does not use a natural resource for any particular purpose, it attaches importance to its preservation and improvement, either for the sake of future generations, or to preserve its intrinsic value.

\begin{tabular}{|c|c|c|c|c|}
\hline & \multicolumn{4}{|c|}{ Total economic value } \\
\hline \multirow{2}{*}{ Components } & direct & indirect & option & \multirow{2}{*}{$\begin{array}{c}\text { Personal non-use } \\
\text { values }\end{array}$} \\
\hline & & & & \\
\hline 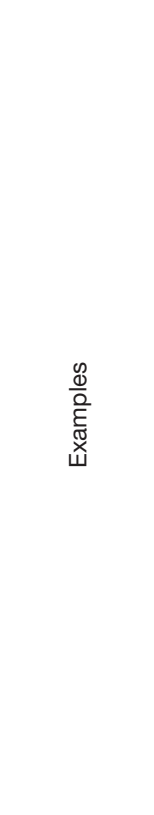 & $\begin{array}{l}\text { - A park serves } \\
\text { for recreational } \\
\text { purposes } \\
\text { (walks, hikes) } \\
\text { and provides } \\
\text { sports facilities. } \\
\text { - Decreases in } \\
\text { noise improve } \\
\text { people's } \\
\text { quality of life } \\
\text { (e.g. they may } \\
\text { open windows } \\
\text { without making } \\
\text { it impossible } \\
\text { to talk, watch } \\
\text { television, or } \\
\text { listen to music). } \\
\text { - A small piece } \\
\text { of wood on } \\
\text { the outskirts } \\
\text { of a town } \\
\text { accommodates } \\
\text { a variety of } \\
\text { living creatures, } \\
\text { which visitors } \\
\text { may observe. } \\
\text { - A lake near a } \\
\text { town is suitable } \\
\text { for angling. }\end{array}$ & $\begin{array}{l}\text { - A park } \\
\text { contributes to } \\
\text { cleaning the air } \\
\text { of a town. } \\
\text { - The trees in } \\
\text { a forest help } \\
\text { retain soil, } \\
\text { reducing } \\
\text { erosion } \\
\text { processes. As } \\
\text { a habitat, it } \\
\text { accommodates } \\
\text { not only living } \\
\text { creatures that } \\
\text { are visible to the } \\
\text { naked eye and } \\
\text { are of primary } \\
\text { importance to } \\
\text { humans, but } \\
\text { all forms of } \\
\text { life, thereby } \\
\text { stabilising } \\
\text { symbiotic } \\
\text { relationships. } \\
\text { - Reducing noise } \\
\text { prevents short- } \\
\text { and long-term } \\
\text { deterioration in } \\
\text { health. }\end{array}$ & $\begin{array}{l}\text { - The } \\
\text { conservation } \\
\text { of an } \\
\text { environmental } \\
\text { good } \\
\text { provides an } \\
\text { opportunity } \\
\text { for future } \\
\text { use even to } \\
\text { people who } \\
\text { currently do } \\
\text { not use its } \\
\text { services, } \\
\text { which may be } \\
\text { a reason for } \\
\text { them to value } \\
\text { this option } \\
\text { among their } \\
\text { preferences. }\end{array}$ & $\begin{array}{l}\text { - Even if } \\
\text { representatives } \\
\text { of the present } \\
\text { generation do not } \\
\text { want to use a specific } \\
\text { environmental } \\
\text { resource either } \\
\text { today or in the } \\
\text { future, they may still } \\
\text { consider it important } \\
\text { and its existence/ } \\
\text { preservation as being } \\
\text { in the interest of } \\
\text { future generations. } \\
\text { - An example is that of } \\
\text { bustards, which we } \\
\text { rarely see, and which } \\
\text { do not directly affect } \\
\text { our personal lives, } \\
\text { yet their preservation } \\
\text { enables members of } \\
\text { future generations to } \\
\text { come into contact } \\
\text { with important native } \\
\text { species. }\end{array}$ \\
\hline
\end{tabular}

Table 4-10. Examples of components of total economic value (Kerekes-Marjainé Szerényi, 2015, with modifications) 
Use values can be captured with great accuracy and with a variety of methods, whereas non-use values are more difficult to capture, and the range of available methods is limited.

As the goods being valued frequently include ecosystem services, involving the role of such services may be highly instrumental in the determination of total economic value. The concept of ecosystem services may be given a valid interpretation in both the natural and social sciences (Kovács et al. 2011a, 2014). The relationship between ecosystems and socio-economic systems is illustrated in Figure 4-12. Ecosystems have a variety of functions (ecological processes, networks of links among living creatures, genome diversity, etc.) that provide ecosystem services from which benefits to humans accrue which contribute to well-being. Their valuation will be influenced by the extent to which such benefits are perceived to humans (the 'valuers') (MAES, 2016). The chart also shows that people (through their activities, institutions, etc.) influence the functions (state) of ecosystems, allowing for (cyclical) changes in the network of relationships, which might if negative reduce the level of ecosystem services, and if positive, increase both the quality and quantity of services provided to humans. In recent years, policymaking has developed a tendency to apply the Common International Classification of Ecosystem Services (CICES), wherein apart from the cultural and provisioning services of MEA, regulating and maintenance services are recognised as a distinct category, comprising MEA regulating services and some supporting services (such as soil fertility) (Haines-Young-Potschin, 2013). International and Hungarian policies about conservation and biodiversity increasingly rely on this conceptual framework (Kovács et al. 2011a, Kovács, 2014).

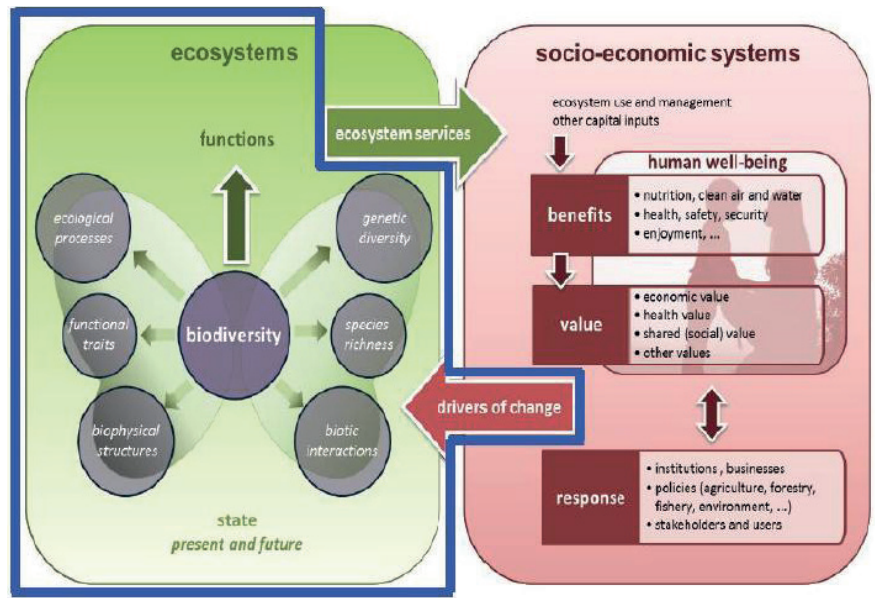

Figure 4-12. Relationships between ecosystems and socio-economic systems (MAES, 2016, p. 13.) 
Additional aspects are captured by the dimensions illustrated in Figure 4-13. A prominent feature of this approach is that ecosystem services are located at the intersection of natural and social sciences: ecosystems represent the supply side (i.e., their provisioning function) by virtue of their place and functions in biodiversity, whereas the demand (social) side represents the contribution of such ecosystem services to human well-being. Values may be based on both cultural and economic considerations. The concept of total economic value, as explained earlier, and the methods of monetary evaluation reviewed briefly in this chapter are used to identify economic values, whereas cultural values are identified by means of socio-cultural evaluation (see the end of this chapter for more detail). The integrated approach is reinforced by the fact that it also provides a spatial outlook that represents local, regional and global effects.

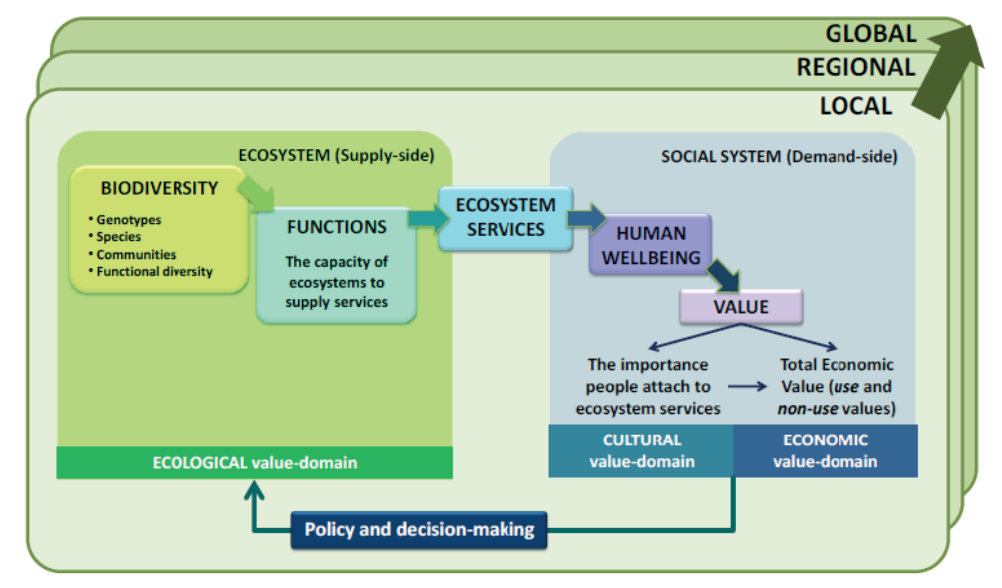

Figure 4-13. An integrated multi-dimensional approach to valuation (OpenNess, 2014, p. 5.)

The process of identifying the total economic value and ecosystem services of the good being valued may also involve stakeholders, as in the case of a 2017 survey concerning the Old Drava Oxbow (Marjainé Szerényi, 2017). This survey included two focus group discussions for experts and one for residents to identify the ecosystem services characteristic of the cut-off channel. The information that was collected is presented in Table 4-11. 


\begin{tabular}{|c|c|}
\hline $\begin{array}{l}\text { Ecosystem service } \\
\text { group }\end{array}$ & Ecosystem service \\
\hline \multirow{8}{*}{ Provisioning services } & mushroom picking \\
\hline & plant harvesting (herbs, edible plants) \\
\hline & game products (e.g. meat) \\
\hline & firewood \\
\hline & irrigation water \\
\hline & vacation resorts \\
\hline & fish \\
\hline & honey \\
\hline \multirow{12}{*}{ Cultural services } & tourism, recreation, relaxation \\
\hline & landscape significance \\
\hline & angling \\
\hline & environmental education \\
\hline & hunting \\
\hline & scientific research \\
\hline & artistic inspiration \\
\hline & ancient trees \\
\hline & fowling \\
\hline & information \\
\hline & traditions \\
\hline & nature trail \\
\hline \multirow{12}{*}{$\begin{array}{c}\text { Regulating } \\
\text { (and habitat) services }\end{array}$} & $\begin{array}{l}\text { biodiversity in the cut-off channel } \\
\text { (habitat for plant and animal species) }\end{array}$ \\
\hline & self-sustenance, regeneration capacity \\
\hline & water retention \\
\hline & water purification (water quality control) \\
\hline & riparian gallery forest \\
\hline & ground water supply and control \\
\hline & air purification \\
\hline & climate control \\
\hline & autumn feeding and resting place for migratory birds \\
\hline & breeding areas for amphibians and fish \\
\hline & habitat (cut-off channel) \\
\hline & accretion \\
\hline \multirow{3}{*}{ Supporting services } & soil formation \\
\hline & nutrient cycle \\
\hline & primary production \\
\hline
\end{tabular}

Table 4-11. Ecosystem services provided by the Old Drava (based on focus group discussions) (Marjainé Szerényi, 2017) 


\subsection{Monetary evaluation methods}

\subsubsection{Classification of methods of evaluation}

The literature on economics proposes a number of methods for the monetary valuation of environmental goods, of which those most frequently used are included in the overview below.

One possible taxonomy classifies the methods according to temporal (present or future preferences) and market characteristics (conventional, implicit, and constructed) (Munasinghe, 1993). Methods based on conventional markets generally seek to establish links between environmental change and market goods, the value of which can be considered for economic evaluation. A market is described as implicit when valuation relies on past human actions in its attempt to identify behaviours that may be linked to the environmental good being valued. Finally, a constructed market involves the creation of hypothetical situations (markets), through which people are requested to share their opinions about any changes. The system of classification and methods is shown in Table 4-12.

\begin{tabular}{cccc}
\hline & Conventional market & Implicit market & Constructed market \\
\hline $\begin{array}{c}\text { Based on actual } \\
\text { behaviour }\end{array}$ & $\begin{array}{c}\text { Effect on production } \\
\text { Defensive/recovery costs }\end{array}$ & $\begin{array}{c}\text { Travel cost } \\
\text { Hedonic price method }\end{array}$ \\
\hline $\begin{array}{c}\text { Based on future } \\
\text { behaviour }\end{array}$ & Replacement cost & $\begin{array}{c}\text { Contingent valuation } \\
\text { Contingent ranking } \\
\text { Contingent selection }\end{array}$ \\
\hline
\end{tabular}

Table 4-12. A possible classification of valuation methods (based on Munasinghe (1993), p. 25, with modifications)

Methods based on implicit and constructed markets may be subdivided further according to whether they employ direct or indirect valuation (MitchellCarson, 1989). Direct methods include those based on a conventional market, as well as contingent valuation for constructed markets, and indirect methods include those which rely on implicit markets, while contingent selection can be classified under constructed markets. Another important consideration is whether the methods measure real changes in welfare; i.e., if they rely on a demand curve for their valuation, or a demand curve cannot be derived thus they do not qualify as economically sound methods, despite which they can still provide decision makers with useful information (Turner-Pearce-Bateman, 1993). The former group includes methods classified under implicit and constructed markets, and the latter those based on conventional markets. Mention must also be made of the benefit transfer method, which cannot be in- 
corporated into the above classification due to one of its essential features - it uses the appraisals produced using one of the methods in the table, and adapts them to a different situation.

The relationships between total economic value, ecosystem services and the methods discussed are clearly illustrated in Figure 4-14.

Ecosystem services, total economic value and economic methods

(groups of concepts)

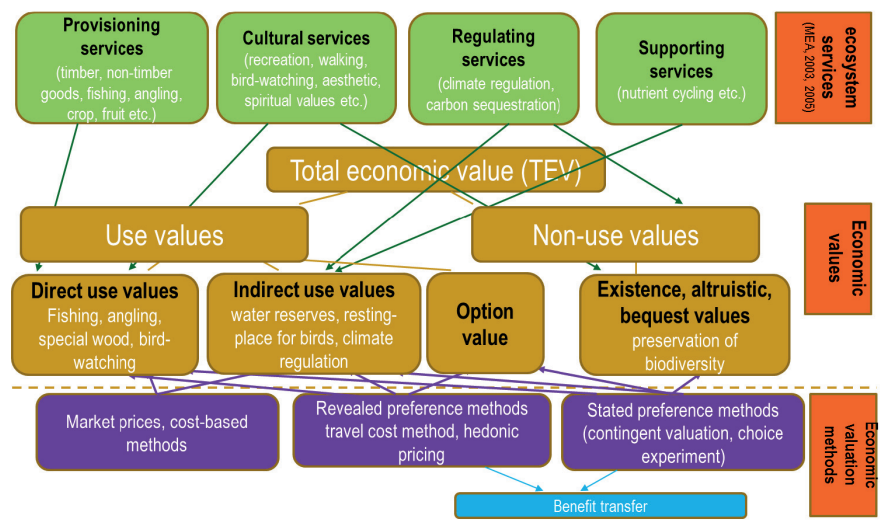

Figure 4-14. Relationships between ecosystem services, total economic value, and monetary evaluation methods (Marjainé Szerényi, 2015)

\subsubsection{Methods involving estimates based on conventional markets}

Methods that rely on conventional markets primarily seek to identify the costs that are incurred by repairing damage to the environment and ecosystems, or the costs that may be avoided by preventing such changes (Markandya et al., 2002). This requires identification of the market goods with which the change concerned may be most closely connected. For example, if the self-cleaning capacity of a lake changes negatively, that change may be corrected either by improving the lake's capacity or by using the lake more sparingly. A possible example of the former approach is to increase the oxygen concentration in the lake water (thereby improving its self-cleaning capacity), and of the latter to avoid discharging even treated wastewater into the lake. The introduction of oxygen requires sufficient technical equipment, energy and labour, the costs of which can be estimated, whereas the introduction of treated wastewater may also be avoided through the implementation of certain technical solutions involving costs of the same nature as in the previous example. In such cases, 
therefore, the price of equipment, maintenance and labour can be used in the evaluation process. The examples show that instead of directly assessing the preferences of the individuals who are concerned (as we do not know the value they attach to a positive environmental change), the measurement concerns the minimum cost of achieving positive changes. The following brief overview describes three evaluation methods based on conventional markets: effect on production, defensive cost, and replacement cost.

Effect on production is primarily used to assess the environment as an input through the changes (quantitative and/or qualitative) observed in agricultural products (as outputs) (Markandya et al., 2002). Reduced water supply to the soil, for example, could result in a decrease in wheat crop yield, but may also impair the qualitative characteristics of the wheat. In its simplest application, the method is used to calculate lost revenue due to reduced crop yields or quality (as a product of the market price of wheat and the change in yield), which is considered to be the value of the reduction in groundwater level. In this case, the effect is assumed not to influence market equilibrium; i.e., not to cause a price change in the market product (wheat) $)^{9}$. In Hungary, for example, the consequences of diverting the course of the Danube in connection with the Gabčíkovo-Nagymaros Dams (GND) were assessed through the resulting changes in wheat and corn crop yields in the Middle Szigetköz (Kerekes et al., 1998).

As its name suggests, the defensive cost (and the very similar 'recovery cost') method captures the costs that may arise in the course of preventing or avoiding a negative environmental change. Let us take the example of noise. When a municipal government adopts the position that the construction of noise barriers could significantly improve the quality of life of residents who live alongside busy roads, it may undertake the costs of such an investment and have barriers constructed. In this case, the investment and maintenance costs of the noise barriers can be used to represent the value of reducing noise levels, or more precisely, the benefits to residents living in the vicinity of the roads (a similar issue is addressed in Harangozó-Marjainé Szerényi, 2014).

The replacement cost method can be used in cases when it is possible to replace the functions and services provided by an environmental (non-market) good with those provided by a market good. When the self-cleaning capacity of a river is reduced, it may be supplemented by the installation of a wastewater treatment plant (this method is very similar to the defensive cost method). In this case, an estimate is made of the cost incurred by society relating to the construction and operation of the plant. When this method is applied, it is important to ensure that the replacement market product (in this example,

9 Of course, the valuation may also take into account changes in market equilibrium; however, this will make the analysis (i.e. the model) much more complex. 
the wastewater treatment plant) provides the same service as the environmental (non-market) good - in this case, self-cleaning capacity (Markandya et al., 2002). In Hungary, and also in connection with GND, calculations have been made to estimate the performance (and cost) of the purification capacity required to compensate for the reduction in the self-cleaning capacity of the Danube (Kerekes et al., 1998).

The advantage of this group of methods is that they allow simple and fast estimations to be made concerning the value of environmental changes. On the other hand, they have the drawback that their assumptions are often not valid: for example, a specific change may be a consequence of multiple effects (the fall in Szigetköz wheat crop yields may also have been due to factors other than the construction of the dams). Another negative feature is that only a minimum estimate is provided for the monetary value of environmental changes, whereby benefits are assumed to be equivalent to costs (which is often not the case). These methods can thus only be used to estimate a narrow segment of total economic value.

\subsubsection{Valuation methods based on implicit markets}

With evaluation methods based on implicit markets, inferences about the value of an environmental good are made from past market activity. The hedonic price method is based on the assumption that when people purchase property, they pay the purchase price for the aggregate of the characteristics of the property. For example, the value of good air quality may be estimated by breaking down the price into individual characteristics. When using the travel cost method, the value of an environmental good is calculated as the amount of money that people are willing to spend in order to travel to a scenic spot. The valuation is carried out by referring to data about property sales and methods of travel.

The hedonic price method is based on characteristics theory (Lancaster, 1966), which assumes that demand for a good equals the aggregate of the demand for its individual characteristics. According to the theory, the utility derived from the good is determined by the level of each characteristic: supposing there are two properties which are completely identical except for air quality, it is obvious that a higher value will be attached to the property located in an environment with better air. Ultimately, the method seeks to establish a link between the price and characteristics of a property. From the perspective of environmental economics, environmental characteristics are the most important. The characteristics of a property are generally classified into four categories. Structural characteristics capture the physical features of a property (floor space, number of rooms, floor, main building material, etc.). Environmental and neighbourhood characteristics include those features for 
which there is no market (air quality, noise level, scenic landscape, etc.) that require general valuation; whereas access characteristics (distance from and ease of access to shops and the centre) describe how frequented and accessible a property is. Finally, the price of a property may also be influenced by the socio-economic characteristics of its neighbourhood (unemployment rate, crime level, etc.). The method seeks to identify the direction in and extent to which property prices are changed by specific characteristics (in particular, environmental ones), from which a demand curve and ultimately utilities may be quantified (i.e. people's willingness to pay for property are used to calculate the utilities derived from the environmental good in demand). For the estimate, data about property purchases and sales are collected, taking care to ensure that the pool of property is sufficiently heterogeneous as regards individual characteristics (e.g. properties with one, two and three rooms, or properties with good, medium and poor air quality). In Hungary, the method has been applied on two occasions: In Debrecen, the hedonic price method was used to evaluate soil contaminated by a landfill (Kaderják-Szekeres, 2000), and in Budapest, the effect of free spaces and green areas on property prices was investigated (Takács, 2016).

The hedonic price method has the advantage that estimates are based on actual market behaviour and, if the data are available, a value can be assigned to the environmental/natural good in question following a relatively simple analysis. One of its drawbacks is that a reliable result can only be obtained by using a large quantity of data and information that is occasionally difficult to find. The method provides an estimate for the part of total economic value that is related to use.

The travel cost method is also based on consumers' actual behaviour on the market. The method can be used to evaluate prices for areas or goods which may be visited by people. The travel cost method is based on the assumption that the costs that people are willing to pay to visit a particular area will be equivalent to the value of that area. Such costs may include:

- the actual cost of travel (the price of train or bus tickets, or petrol, etc.);

- entrance fees;

- the value of the time spent travelling, or in the area being valued.

Researchers obtain data about travel costs and the annual number of visits from statistics and questionnaires, which allow them to determine the demand curve of visiting a specific area; i.e., the relationship between the frequency and cost of visits. In principle, the greater the distance between an individual's residence and the area being valued, the less frequently the individual will visit that area within a specific period of time. There are two approaches to us- 
ing the method: at the zonal, and individual level. In the zonal approach, the regions (districts, counties, etc.) in the surroundings of the area under valuation are divided into zones, then information about travel from those zones is obtained from various statistical and other databases (e.g. in connection with distance covered). Mostly by means of questionnaires, the individual travel cost method allows data to be collected separately about each individual visitor regarding both the number of visits and the cost of travel, potentially producing far more accurate results compared to the other approach that uses the same method (Marjainé Szerényi et al., 2005). The advantage of the method is that valuation is based on actual market behaviours, and that estimates can be made relatively simply when the appropriate data are available. However, the method also has a number of drawbacks:

- What consideration should be given to costs incurred by people who only visit the area because of its proximity to their 'real' holiday destination? Or those of people who have holiday homes in the area, and travel from those locations?

- For the purposes of the method, local residents are considered not to incur any costs in connection with their visits, while it can reasonably be assumed that they in fact may have purchased property in the area because of their significant appreciation of the good being valued, which clearly shows that their preferences are not reflected in travel costs.

- In specific cases, consumers may use the services of a significant number of substitute areas. How should this issue be addressed in the estimation process?

- The estimate only includes the part of TEV that is related to use (KerekesMarjainé Szerényi, 2015).

\subsubsection{Valuation methods based on constructed markets}

Among valuation methods based on constructed markets, the identification of individuals' preferences (willingness to pay) is done directly in contingent valuation, and indirectly in contingent selection.

Contingent valuation is one of the most frequently used methods of environmental valuation, which is primarily due to the suitability of the method for assessing virtually any environmental change or ecosystem service. Essentially, respondents are presented with a change (program) concerning which their willingness to pay is investigated (Mitchel and Carson, 1989). Data are collected by means of questionnaires. The program describing the change explains the current state of the good being valued, the essence of the change, and the form in which payment is requested (e.g. voluntary contributions for five years). The most convenient method for administering 
a survey is the personal interview because questionnaires tend to be long, and prompt respondents to answer questions they have never encountered before (e.g. how much would they be willing to pay for a specific degree of improvement in the water quality of Lake Balaton) (Mourato et al., 1999). Not only is the method suitable for determining willingness to pay, it can also be used to identify the factors that influence the amounts offered by individuals. The value of the good is derived as the product of the size of the relevant population (comprised of the affected individuals) and average willingness to pay.

The advantage of the method is that it also measures non-use values, and is suitable for both ex-ante (before a change) and ex-post (after a change) appraisals, which also enables its use in cases where development has not yet started, and therefore environmental changes have yet to occur (this is primarily important when an intervention would negatively affect the state of an environmental good). Some of the drawbacks of the method are that it only concerns the valuation of a specific change and thus cannot be extrapolated to other situations, and that it is also hypothetical (as is the payment itself). Due to the nature of the questionnaire survey involved, it is a time-consuming and expensive method to implement. It is also more expert-intensive compared to the methods that have previously been mentioned. Contingent valuation is one of the most frequently used methods. It has been used in a number of studies in Hungary (Mourato et al., 1999; Marjainé Szerényi, 2005; Marjainé Szerényi et al., 2011a, 2011b).

Entering the environmental economics evaluation toolkit only in the mid1990s, contingent selection has become increasingly popular ever since. The method identifies individual preferences by prompting affected individuals to select between various changes. The selection situations comprise independent characteristics of the good being valued, and the levels of those characteristics (e.g. in research on the Által-ér, a tributary of the Danube, the characteristics were water quality and flood risk, the former taking the levels of medium, good and very good, and the latter identified as occurring once every 5, 25, 50 or 100 years; see also Marjainé Szerényi et al., 2011b). The characteristics always include a cost factor, which represents the component through which willingness to pay may be estimated. The method involves a questionnaire survey, which is most frequently carried out by means of personal interviews (the questionnaires are even more complex than those used in contingent valuations). The characteristics and their levels may be used to construct a number of scenarios such as those shown in Figure 4-15. (e.g. Scenario A or B), of which those that are feasible and reasonable may be used to compile selection situations (cards). A selection situation will always include a status quo option to accommodate the possibility that a respondent will find the development unacceptable at 
the cost indicated, which discourages them from selecting either Scenario A or B; in such cases, the status quo will be maintained, and the individual will not be required to pay.

\begin{tabular}{|c|c|c|c|}
\hline Characteristics & Scenario A & Scenario B & Current situation \\
\hline Flood frequency & $\begin{array}{c}\text { Once every } 25 \\
\text { years }\end{array}$ & Once every 5 years & \multirow[b]{2}{*}{$\begin{array}{c}\text { I select neither } \\
\text { Scenario A or B, I } \\
\text { prefer the status } \\
\text { quo }\end{array}$} \\
\hline Water quality & Good & Very good & \\
\hline $\begin{array}{l}\text { Additional monthly } \\
\text { water bill cost }\end{array}$ & HUF 50 & HUF 200 & HUF 0 \\
\hline $\begin{array}{l}\text { My selection } \\
\text { (identify as } \\
\text { appropriate) }\end{array}$ & Select $A \square$ & Select B $\square$ & Select neither $\square$ \\
\hline
\end{tabular}

Figure 4-15. Example of a selection card for use in contingent valuation (Based on Marjainé Szerényi et al., 2011b)

Contingent selection is considered to be one of the most advanced methods, because its use is not limited to the valuation of specific environmental changes as is the case of contingent valuation, but it provides for the individual valuation of each characteristic (the willingness to switch between the characteristics), changes between the levels of each characteristic, as well as any scenario that may be constructed from the characteristics and their levels. Another advantage of contingent selection is that it also enables the measurement of the non-use value components of total economic value, and that it is suitable for the valuation of almost any hypothetical change. It can also be used ex ante. Drawbacks include the difficulty involved in choosing characteristics (i.e., in maintaining their mutual independence, and in the fact that an excessive number of characteristics and levels will make selection very difficult for respondents), the large sample size required for a reliable result, and the extreme complexity of data analysis, which makes the method highly expertintensive. As a combined result of the above, this method is the most time consuming and most expensive. Despite all these drawbacks, the method is becoming increasingly prominent in the monetary evaluation of environmental changes. In Hungary, it has been used in connection with efforts to enhance the natural features of the environment surrounding the Által-ér tributary (Mar- 
jainé Szerényi et al., 2011b), as well as with the valuation of caves (Krajnyik, 2008).

\subsubsection{The benefit transfer method}

The economic (monetary) valuation of environmental goods often requires estimates to be made within a short time in the absence of initial surveys. Such cases may be addressed using the benefit transfer method, which does not fit into the classification followed in this chapter, because it adapts the results of previous research to a situation that may be considered similar to the subject of the original analyses. The benefit transfer method may be used subject to the prerequisites that: the problem under investigation is similar to one in the context of which results have already been estimated; the supposed consequences of the change to be investigated are similar to those involving the changes taken into account in prior findings; the valuation methods used in existing studies were carried out at an adequate level of accuracy and due care; and the staff, funding and time required for carrying out an original investigation are not available. Adaptation can be either spatial (to a different area) or temporal (to a subsequent point in time). Cases of simple value transfer involve the direct transfer of original results without regard to the special characteristics of the population of the area chosen for adaptation. This may be adjusted by adapting willingness to pay relative to the average income of the population. Some solutions are even more complex: in transferring the utility function, consideration may also be given to differences in socio-economic characteristics other than income, whereas in the course of meta-analysis (the most complex method of benefit transfer), the results of multiple studies may be taken into account collectively. In this order, benefit transfer becomes increasingly more complex, time consuming and expensive.

The greatest advantage of benefit transfer is its simplicity, which only applies to simple transfers and transfers adjusted for income. The method applied in the original survey will determine the parts of total economic value that may be estimated using this method. In Hungary, this method has been used on several occasion to estimate the value of environmental goods (e.g. Kerekes et al., 1998, Brouwer et al., 2016). 


\subsection{Beyond monetary evaluation}

At first sight, the monetary evaluation of environmental goods clearly implies that the economic value of changes can be measured in monetary terms, which does indeed appear to be the most convenient option. However, economists have long been concerned with the issue of examining the preferences of people who have insufficient income, as is typically the case in most developing countries. When asked about their willingness to pay, individuals with a low income may have nothing to offer, which could lead an investigation to conclude that the environmental change under evaluation is of no value to such people (i.e., willingness to pay may converge to zero), while in fact the exact opposite may be true (as pointed out, for example, by Holland, 1995). Based on an analysis of eight stated-preference studies conducted in developing countries, Whittington (2010) finds that, in these countries, regarding almost any environmental or health issue, willingness to pay (as measured using money) is low in both absolute and relative terms compared to income. So, how can we measure environmental changes in monetary terms in societies where people are struggling to make ends meet, and are both unable and unwilling, even in theory, to support environmental changes that they consider a luxury, or to preserve existing natural assets? (Kocsis-Marjainé Szerényi, 2018)

Environmental economists offer several answers to that problem. Rather than money, one option is to use commodities and products that people are familiar with and encounter in their daily lives, and whose fair value is presumably better known to them. For example, Shyamsundar-Kramer (1996) used rice as a substitute for money in a survey conducted among Madagascar's population to find out how much rice would buy people's willingness to disclaim an area which they had previously cultivated so that it could be used for the establishment of a national park.

Another option is to allow respondents to offer their time and labour for a cause, which could then be converted into a monetary equivalent by experts. There exists much greater equity with time or labour than with money (i.e., there is a lower degree of inequality of time than there is with wealth and income): everybody has 24 hours in a day, which makes everyone equal in this regard. In the literature, a variety of interchangeable terms are used to refer to contributions of time or labour, such as willingness to spend time (WTST), willingness to work (WTW), or willingness to contribute labour (WTCL). Although time (labour) as a measure of willingness to pay for environmental goods is primarily used in developing countries (precisely due to low incomes), there are also related findings from developed countries (Ninan et al., 2007; Tilahun et al., 2013; Rai-Scarborough, 2014; Lankia et al., 2014). 
From the literature that investigates how to establish the relationship between money and the amount of contributed time, or to estimate the value of time, some conclusions may be drawn:

- comparisons between willingness to pay (WTP) and willingness to spend time (WTST) are becoming increasingly frequent in the literature;

- the monetary value of time offered tends to be much higher than values measured directly in terms of money in both developing and developed countries;

- the amount of labour offered is strongly dependent on the context: other than the amount of people's spare time, willingness to contribute labour is also affected by the quality of labour that may be offered (light vs. hard), the time any work takes to complete, and the nature of the respondent's daily work;

- the literature offers a great many examples of how to determine the opportunity cost of time, ranging from the objective (wage based) to the subjective, all of which produce a different result;

The foregoing observations show that the use of money still has the greatest number of advantages over other measures (time, commodities) in efforts to determine people's preferences with regard to environmental goods.

Although the focus of this chapter is monetary evaluation and its methods and concepts, brief mention must also be made of another approach, namely non-monetary (for our purposes: socio-cultural) valuation. As shown earlier, the identification of ecosystem services and, consequently, of the components of total economic value often starts with a non-monetary valuation. In addition to monetary valuation, ecological economists propose the use of multi-criteria, participation-based, socio-cultural non-monetary valuation methods, which are designed to capture a wide range of ecosystem services. For example, such evaluations could be instrumental in identifying conflicts that arise from different ideas about landscape use, as well as in community planning for sustainable landscape use (Kovács et al., 2011b, Kelemen-Pataki, 2014b, Kelemen et al., 2014). The figure provided in Scholte et al. (2015) is a clear illustration of the criteria that are applied in these types of valuation (see Figure 4-16.). These criteria concern three interrelated areas: the characteristics of the natural environment, the interactions between beneficiaries and ecosystem services, and the characteristics of the beneficiaries. Socio-cultural value is derived as the aggregate of these characteristics, which may represent either group or individual values. The chart indicates the more detailed factors and issues that may be investigated in each field which also affect the nature of the values. In Hungary too, a number of examples of non-monetary (socio-cultural) evalu- 
ation exist (see e.g. Kelemen et al. 2009; Pataki et al., 2014; Kalóczkai et al., 2014; Fabók et al., 2014; Kalóczkai et al., 2015; Kovács et al., 2015a).

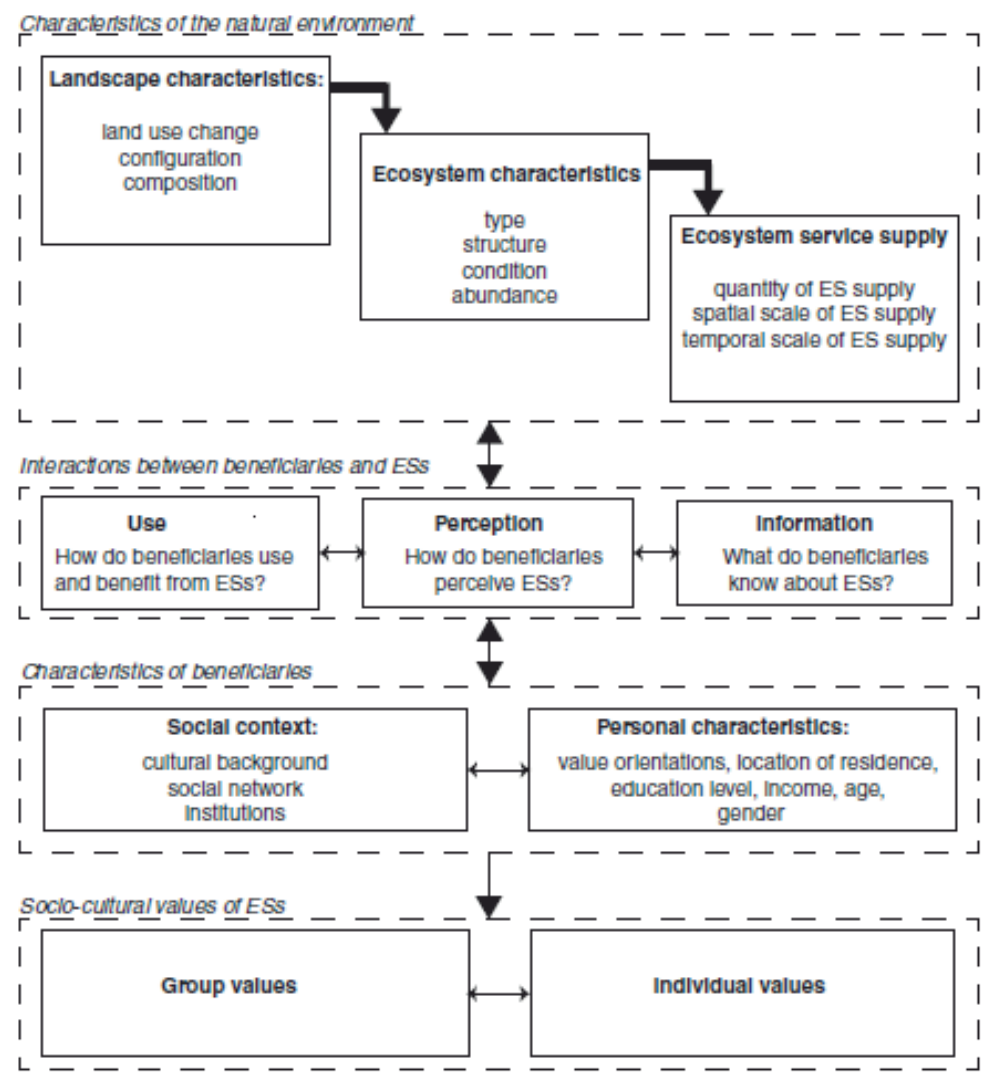

Figure 4-16. Determinants of the socio-cultural values of ecosystem services (Scholte et al., 2015, p. 69, Figure 1.)

Non-monetary valuation explores the significance of natural capital and ecosystem services, proposing arguments that may be cognitive, emotional or ethical, but which may also express preferences, needs and demands (Pandeya et al, 2016). Although non-monetary valuation is a suitable complement to monetary valuation, and may provide an alternative to and, at least partially, address the critical issues raised in connection with monetary valuations, nonmonetary valuation, as used in the evaluation of ecosystem services, still lacks a consistent and established methodology, despite the pressing need for one to complement monetary evaluations. 


\section{The economics of environmental pollution}

\subsection{Introduction}

The classic economics-related publications saw the key to the efficient distribution of resources in the functioning of the market. However, the market functions perfectly only if competition is free and all influential factors are taken into consideration in market transactions. It was realised relatively soon that such a situation is hardly likely to exist, and one reason for this is the existence of external economic influences ('externalities') such as environment pollution, which damages the environment, but the cost of which is not incurred by those who engage in the damaging activities. The following chapter presents the economic theory about the treatment of such external influences and the related practical possibilities for their remediation. From neo-classical solutions we arrive at a presentation of the theoretical foundation of institutional economic remedies.

\subsection{The Theory of Economic Externalities}

At the turn of the twentieth century, Alfred Marshall introduced the terms external costs and benefits in a work entitled Principles of Economics. He used these terms to describe when an entity with financial autonomy, like an enterprise, directly influences the position of another financially independent entity, an enterprise or consumer without them coming into contact on the market. A frequently cited example of such an influence that is excluded from the traditional economy is environment pollution. The existence of such externalities disturbs the functioning of the market, which is why neo-classical economists found it important to involve them in economic accounting.

The theory of internalising externalities originated with Arthur C. Pigou (1877-1959). His famous work that laid out the necessity of taxing pollution was entitled the Economics of Welfare and was published in 1920.

To illustrate externalities (i.e., external economic influences), let us examine two examples:

1. A bee-keeper places his hives near an orchard so he can get his bees to make honey for him. The bees do their work: they produce lots of honey for the keeper and en passant pollinate the flowers of the fruit trees, which thus fertilised will yield more fruit. From an economic perspective, this qualifies as a positive external influence (a positive externality) insofar as the bee-keeper unwittingly creates benefits for the owner of the orchard who is helped out by the 'pollination service'. The owner of the orchard 
does not pay the bee-keeper for this service; what is more, they may even think of forbidding the bee-keeper from placing the hives nearby. Occasionally, the owner of the orchard is so ungrateful that they even fail to notify the bee-keeper that they spray against insecticides, by which they cause significant damage to the bee-keeper. This latter damage is the negative external impact of the spraying.

2. In supplying electricity for surrounding factories and homes, a lignitefired power plant also douses them with sulphur dioxide, carbon monoxide and a foul mixture of dust and smoke. Those who live nearby suffer badly from the pollution from the plant, while those living in more favourably situated homes are blessed with the advantages of an electric power supply but only a negligible amount of pollution. In this case, we may speak about a definitely negative external influence. There are three things in common to the examples above which define the character of the externalities, namely:

a) The activity modifies the welfare function of a third party or parties. Positive externalities increase welfare (the fruit producer will enjoy an increase in yield), while negative externalities reduce welfare (e.g. those living near the power plant will suffer from more frequent illnesses, which will reduce their income).

b) When welfare increases (in the case of positive externalities) or falls (in the case of negative externalities), the third party is not made liable to pay for the benefits or compensate any damages.

c) The influence of the third party is not brought about willingly; that is, the bees mentioned in the example are not deliberately located in that orchard to help with pollination, and the power plant does not deliberately emit pollutants to cause nuisance to nearby residents. To briefly summarise the concept of such external economic influences after Mishan, we can state that they are nothing more than involuntary impacts created by one economic participant that affect another participant's standard of welfare (Mishan, 2007).

\subsection{Types of external influences}

External economic influences can be positive or negative. They can affect producers and consumers equally.

We speak about a negative external influence when a party suffers damages as a result of the external influence. This may or may not be expressed in a pecuniary way (either directly or indirectly).

In the case of a positive external influence, the given externality affects the consumer favourably. If the influence involves a businessman, their profit increases; if it involves a consumer, their standard of welfare grows. 
In our example, the lignite-fired power plant is a typical form of negative externality caused by a producer, while the bee-keeping example may involve a positive producer or consumer externality.

It is common for negative and positive externalities to occur due to an activity. Let us take a Hungarian example. The motorway to the Balaton significantly contributed to tourists 'overloading' the lake in the 1980s and increased environment pollution. However, the positive externality of the motorway was that the prices of properties around the Balaton rose and improved locals' income-earning opportunities through apartment rentals (this latter qualifies as a pecuniary external economic influence). Interestingly enough, however, the extension of the motorway to the Croatian border is assessed as a negative pecuniary externality from the perspective of Hungarian tourism, because, according to the evidence, most tourists now seek out recreation at the Croatian seaside, ignoring the Balaton.

Infrastructural development is mentioned as a special example, usually having complex external influences. In a telephone system, for example, every new subscriber represents a positive externality for others, because more and more contacts will be available within the network. With no changes in the standard of technology, however, the positive externality may turn into a negative one if delays occur and miscalls occur due to overloaded lines.

For a long time the development of the public road system created a dominantly positive external influence. Today, however, the influence of a busy road such as a motorway is rather variable. On the one hand, through pecuniary externalities it may boost the price of some producers' and service providers' properties, while causing significant (pecuniary) damage to residential properties and natural assets. No wonder home owners and conservationists protest against new motorways, while entrepreneurs hail them.

Through the examples above we have sought to illustrate the diversity of the topic, rather than classify different types of externalities into a rigid system.

Since environmental economics expressly focuses on negative externalities, from now on when externalities are mentioned they should automatically be understood as a form of 'public bad'; that is, as negative externalities.

To speak about externalities in an economic sense, the (technical) determination of the physical existence of a negative influence is not enough: individuals must also be aware of its existence. While, for example, in an ecological sense DDT has obviously caused environmental pollution since it was first used, it has been considered a negative externality in an economic sense only since its harmful side-effects were discovered.

Externalities may be classified in more ways than previously described. The most basic have been mentioned already. Positive externalities increase one's welfare, while negative ones decrease it. 
Within the class of negative externalities further differences can be identified. Accepting Viner's classification, we may differentiate between technological and pecuniary externalities. From the perspective of conservationism, technological externalities are more relevant. In the case of the aforementioned lignite-fired power plant, sulphur dioxide emissions are the result of technology (i.e., they represent a technological externality). The environmental problems caused by slurry produced at an animal-rearing farm are also technological externalities.

An example of a negative pecuniary externality is a shopping mall built outside the city to which customers are attracted, as a result of which the sales and profitability of small shops in the city centre decrease. The same case may be thought of as a negative technological externality insofar as due to the construction of the mall outside the city - as a part of 'sales technology' shopping-related car traffic and harmful emissions increase.

Besides pecuniary and technological externalities, Bator (1958) and Head (1962) differentiate between externalities linked to public goods (undepletable; unlimited availability) and private goods (depletable) (Baumol and Oates, 1988, p. 14.).

A typical example of undepletable externalities is polluted air, the amount of which will not decline through being breathed in by others; this public bad will remain 'available' to everyone. Whether an externality is undepletable can be decided by checking if it is divisible, and whether individuals can be excluded from consuming it.

It is more difficult to find environmental examples of private-goods-related externalities. A typical case is waste, which once deposited on someone's plot cannot be simultaneously deposited on someone else's. Waste is consequently a 'private' externality. This having been decided, the only question left is which plot is the 'best place' for the waste; i.e., an environmental policy should be pursued that ensures the division of waste among plots so that society will suffer the least possible reduction in welfare.

Environment-related externalities are usually linked to public goods; the example above about waste management is rather an exception, but here the public good quality of the externality has specific environment political consequences. Usually, when we focus on internalising externalities it is all the same from the perspective of pareto-optimality whether the externalities concern private goods or public goods. From an environmental perspective, the real problem is not posed by the type of externalities, but rather that the size of the externality is different from the perspective of the polluter and those who suffer from the pollution. This asymmetry is unsolvable using a single market price. A tax collected from the polluter may be enough to compensate a victim, in theory. If, however, we collect a tax ('p') that we pay the victim in compensation, we cannot be sure we have created an economically efficient situation. In many cases it is not at all practical to compensate victims to any extent. We shall return to these problems later on. 


\subsection{Two basic types of environment pollution: flow and stock pollution}

As stated earlier, a pollutant triggers a harmful effect when it exceeds the quantity that the environment can dispose of. The relationship between pollution that occurs as a result of economic activity and pollution-related environmental damage is shown in Figure 5-1.

Depending on its chemical qualities and the conditions that predominate in the receiving environment, the pollutant emitted into the environment may behave in a variety of ways, a fact which must be accounted for by environment policy. One basic type of pollution, flow type, when emitted into the environment temporarily grows in concentration, while its harmful environmental effects depend on the quality of the material, the extent of the growth in concentration, and the conditions of the receiving environment. The same emission may cause different impacts in different circumstances (e.g. weather conditions). The extent of the damage also depends on the pollution-absorbing capacity of the environment. We usually speak about environment pollution when material/energy emissions accumulate more rapidly than the environment is capable of 'disposing' of them. Flow-type pollution is thus material and/or energy flow that damages the environment, but since the extent of damage depends only on actual emissions, damage involves a one-off event. The pollution breaks down through dilution, chemical and biological processes and loses its environmentally damaging qualities over time.

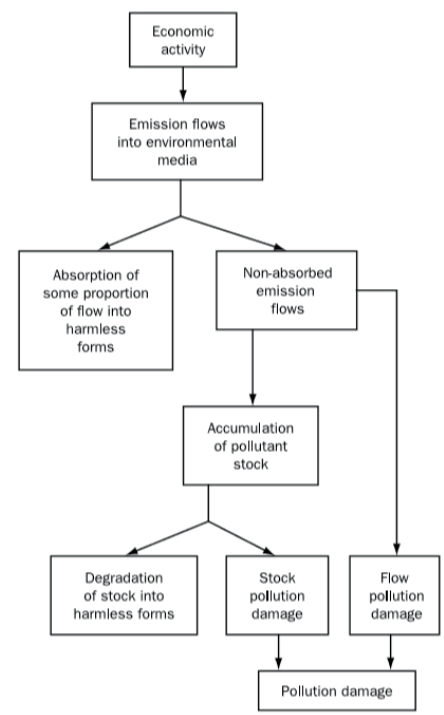

Figure 5-1. The relationship between economic activity, pollution emissions and environmental damage (Perman et al., 1996, p. 198.) 
Most environment pollution is the result of flow-type pollution. It is thus not unexpected that the theory of environmental economics was built around such pollutants. Noise pollution is one of the most obvious examples of flow-type pollution. Depending on wavelength and intensity, noise is rather disturbing, but only while it lasts. Once the activity that generates the noise ceases, the noise also ceases to exist by fully dissolving in the environment and becoming nearly undetectable. The size of any new noise pollution is not influenced by earlier noise-producing events.

From an environmental perspective, stock-type pollution is again of two basic types: one is fully stable, involving pollution that accumulates; the other also involves accumulation, but slow decomposition occurs.

Fully stable, accumulating stock-type pollution is exemplified by heavy metal pollutants such as mercury, lead, cadmium, etc., which accumulate in the soil, water, and organisms where their concentration continuously increases. Every new emission of these materials increases environmental impact, serving as good support for theories that advocate the finiteness of growth. In such cases, new emissions are added to earlier ones, working their effect through repeated increases in concentration.

Other stock-type pollution slowly but finally decomposes. This group of materials include DDT and plastic waste, and even more typically radioactive isotopes with precisely known half-lives that indicate their speed of decay. While the previous example supports ideas about the finiteness of growth, the latter exemplifies the principle of sustainable development: the maximum emissions of slowly degradable waste should not exceed the speed of their disappearance from the environment. In the case of the above-mentioned isotopes, for example, the maximum additional isotope impact that does not increase background radiation can be precisely calculated.

\subsection{The economic consequences of externalities}

Insofar as the environment can be freely used by an individual producer, which is to say that they will fail to sense if their activity causes damages to others, this can lead to major disturbances in the functioning of the economy. How do these disturbances manifest?

1. The polluting activity (e.g. the production of goods) becomes excessive; i.e., there is significant oversupply compared to the quantity of good needed in a healthy economy. This may be the situation with cars, cigarettes and other excisable goods today, but in so-called consumer societies the situation also applies to wrapping and even certain foodstuffs.

2. Nothing encourages pollution to decrease, causing 'overpollution'. Here it should suffice to mention the environment pollution brought about by inef- 
ficient energy consumption, high-performance prestige cars, or flights of only a few hundred kilometres.

3. The price of the polluting product or service is 'too low', which creates excessive demand on the market. If, for example, the price of cigarettes covered the functioning of an additional health service that provided suitable treatment for the victims of smoking, multiples of the present price should be paid for cigarettes. If the price of electricity contained the cost of fully eliminating the damage caused by acid rain, we would also be required to pay multiples of the present electricity tariffs. These higher prices would significantly depress demand for these goods.

4. While the cost of pollution is external (i.e., is not incurred by the producer or directly by the user, but others) nothing will encourage a decrease in pollution per unit of production, which will make the pollution level for the unit of product too high.

5. The fact that emitting pollution into the environment is so 'cheap' hinders its reduction; what is more, in an economic sense it hinders the reuse of waste, and the recycling of pollutants. Nearly every solution for reducing pollution involves a cost. The composting of household waste, for example, typically involves expenditure and work that the value of compost does not cover. When household waste can be dumped in abandoned mine pits or other public areas nearly free of charge, composting will never be competitive against this traditional method of disposal.

\subsection{The economically optimal level of environmental pollution}

Environment pollution, as seen above, reduces the welfare of society. Citizens, just like scientists, should obviously consider the existence of environment pollution to be outrageous and strive to fully eliminate it. In an economic sense, the situation is a bit more complex. According to neo-classical economics, the goal should not be to eliminate pollution but to achieve the economically optimal level of pollution. This suggest that there exists an optimal size of externalities which maximises the difference between benefits and expenses in social terms.

To clarify this, examine Figure 5-2., which illustrates the benefits and costs of pollution-creating production from a social perspective under circumstances of free competition.

As the figure shows, the aggregate private costs of supply are significantly lower than the social costs, including external influences. This means that the production of the pollutant $Q_{m}$, is more than if the effects of the pollution were taken into consideration, in which case only quantity $Q^{*}$ would be produced. 


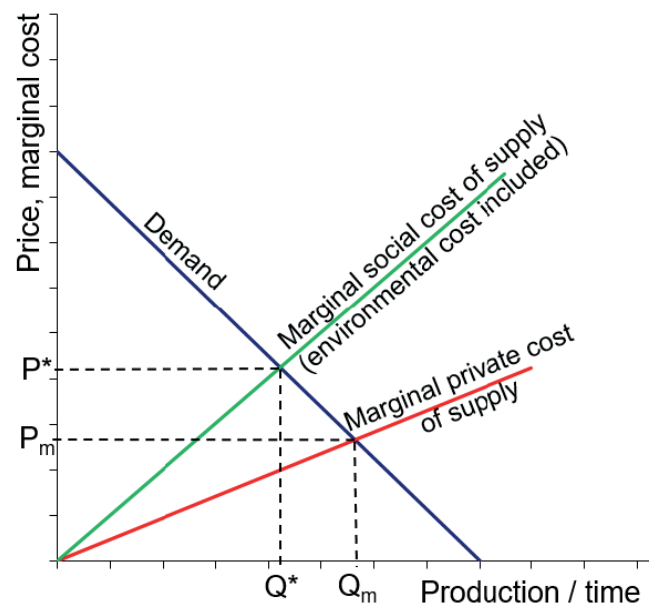

Figure 5-2. The private and social costs of production (Kerekes-Szlávik, 1989, p. 56.)

The price would, of course, increase from $P_{m}$ to $P^{*}$ if the damages caused by pollution were incorporated into the price of the product.

As we can see, the figure supposes that, with the existence of free competition, environmental pollution is proportionate to production, which, as clarified later, is not necessarily correct. The figure also indicates that the environment can endure pollution within certain limits without suffering any irreversible change. While the science of economics seems to be well grounded enough to decide whether the first two suppositions are correct, examination of the accuracy of the latter supposition remains outside the scope of our discipline. It is important that we state this right at the outset, because our conclusions can only be acceptable if these suppositions are true. Unfortunately, just as there is no perfect situation of free competition, neither is there a level of pollution which is perfectly reversible. We should strive not to render an over-optimistic evaluation of the propositions of micro-economics, as described below.

\subsection{The optimal size of externalities}

After this short digression, let us see what would happen if our suppositions were correct: what would the optimal size of externalities be? The situation is illustrated in Figure 5-3. 


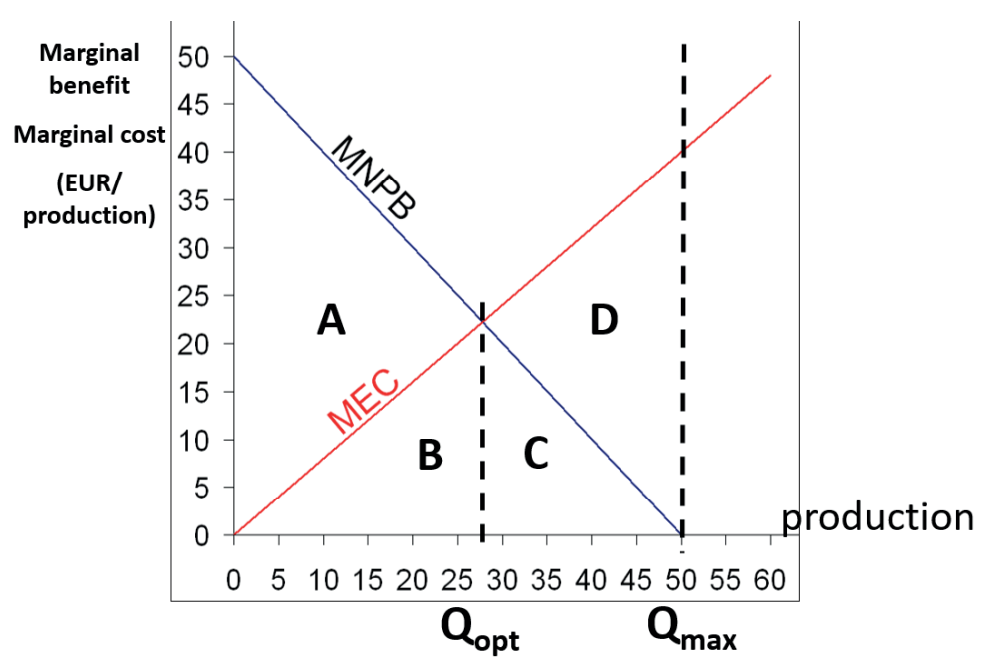

Figure 5-3. The economically optimal size of externalities (Pearce-Turner, 1990)

It is clear that, in the case of free competition, changes in a single producer's supply do not influence price, thus the demand function remains parallel to the $x$-axis. We can calculate the individual net marginal benefits that originate from a competing producer's polluting activity by subtracting the individual producer's marginal costs from the price. The line indicating the producer's marginal benefit (MNPB: Marginal Net Private Benefit) shows the additional profit created by the extension of the private producer's polluting activity by one unit. It is obvious that total benefits are maximal if production is at level $Q_{\max }$. The profit of the company equals the size of the sub-MNPB area, which in reality describes the net profit of the company. If this is contrasted with the external marginal costs generated on a social level - that is, at the level of third parties (MEC: Marginal External Costs), the intersection of the two curves at $Q^{*}$ indicates the quantity of activity where the private producer's marginal benefits are just equal to the marginal damages caused to society. This is the Pareto optimal point, because in the case of less activity benefits would still be increasable, while in the case of a larger volume of activity their suppression would increase the benefits. Areas under the curves have a special meaning:

B the economically optimal level of externalities,

$A+B$ the social optimum of net private benefits,

A the maximum social net benefits,

C $+D$ those externalities that should be avoided,

C those net private benefits not recognised by society, 


\section{$Q^{*} \quad$ the socially optimal level of economic activity, \\ $Q_{\max }$ the level of economic activity \\ where private benefits are at a maximum.}

The figure expressively indicates that in the case of production exceeding $\mathrm{Q}^{*}$, benefits will be evaluated lower by society than the damage associated with the production that accrues to society.

Provided our presuppositions are accepted (i.e., a situation of free competition exists, and environment pollution is proportionate to the activity), the figure convincingly proves that environment protection is not cost-free, and that producers will not decrease their performance to the desired $\mathrm{Q}^{*}$ level unless forced to do so by an external intervention such as regulation that internalises any damages that are caused.

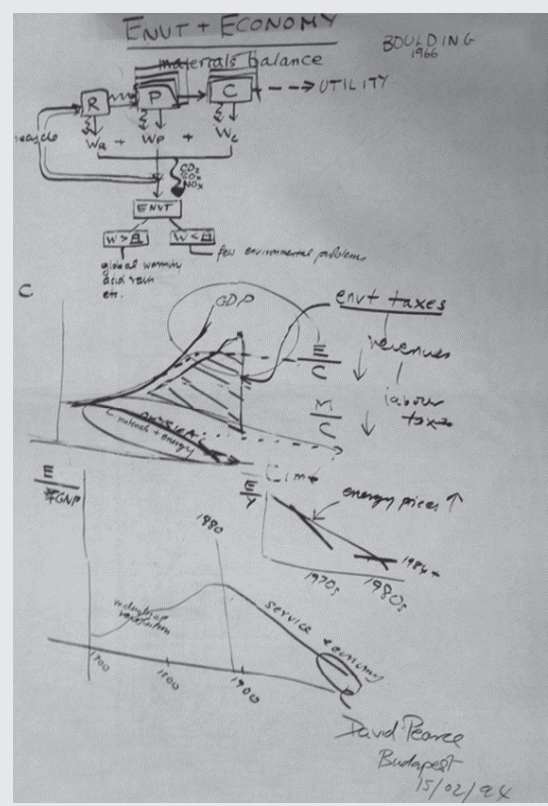

On 15th of February, 1994, David Pearce visited Hungary. As an expert, he was asked to comment our paper on environmental problems related to the GabčíkovoNagymaros Dams. At the Faculty of Business Administration at the University of Economics (used to be Karl Marx University of Economics Budapest), we have been teaching environmental economics for four years already, and we have been using the book which was written in 1990 by David Pearce and Kerry Turner (Economics of Natural Resources and the Environment). This book, and Pearce's earlier book (PearceMarkandya-Barbier, 1989) has had significant impact on me, because it was the first book which stimulated the readers for actions. What I read before, related to the environment they dealt with the 'limits to growth', ozone depletion, with acidification etc. so with the catastrophic situation of the natural environment. Please do not forget the beginning of transition, we had a huge economic recession in Hungary and we had no resources for environmental protection, and we had a strange political situation as well. So, we felt the natural catastrophe, and we could not imagine that there is light in the end of the 
tunnel. There was relatively little work in social sciences. Maybe I was misleaded by my previous profession chemistry as well. The blueprint was the first comprehensive and relatively optimistic book in my hands. Blueprint encouraged action and did not say less than to avoid the disaster and even to change the operation of the economy is possible and not so difficult. With immense pleasure and respect, but with a rather pessimistic view of the world, I waited for David Pearce to meet him. And then it happened. David gave a lecture to my PhD students, and before we went to dinner, I took a bottle of wine to the table in my office room and I tried to convince David, that the situation is hopeless at least from the perspective of an environmental scientist of the former eastern bloc. The glass wine was sold out slowly and David drew the essence of environmental economics on the flipchart above. Today, I'm surprised to find that in 1994 he summarized the essence in three graphs. Firstly, the circular economy, secondly the decoupling and Kuznets curves and thirdly the flow economy - instead of stock economy. He took me to the optimistic side in less than 15 minutes. Since then, our profession is still muddling around these concepts. David, unfortunately, passed away, but I and my colleagues kept him and his visions. Teaching university students is a fantastic job, but even greater responsibility. One must believe that David Pearce did that we can shape our future and, of course, even in the Anthropocene there is hope for positive change.

Ten years later, in March 2005, I invited him again. He passed in May, but he wrote to me: All good wishes and I hope to see you again some day. (Kerekes, 2018)

\subsection{Handling externalities in economic theory - the size of the Pigovian tax}

Pigou considered society's expenses to be internalizable with the help of uniform taxes levied on production. According to the scholar, if a tax of $t^{\star}$ quantity is levied on a unit of production, it will encourage companies to reduce their volume of production from the - disregarding external costs - economically 'ideal' Qm to $Q^{*}$, considered socially optimal. It is obvious that the optimal size of the tax will be equal to the external marginal cost of the optimal level of pollution. Consequently, in order to calculate the optimal extent of the tax we should know the trend and trajectory of both external marginal costs and private net marginal benefits. Unfortunately, we encounter serious difficulties with this in practice. Private producers are usually aware of the trend of their own net marginal benefits at least theoretically, but regulatory authorities know little about them. On the other hand, private producers have no knowledge of the damages their activities cause to society. This creates information asymmetry, making the practical use of the concept extremely difficult. 
Figure 5-4. illustrates a producer's marginal benefits reduced with a uniform tax, obviously being zero at $Q^{*}$ levels of performance and declining thereafter, signifying that production (pollution) that exceeds this level is not considered by society to be useful.

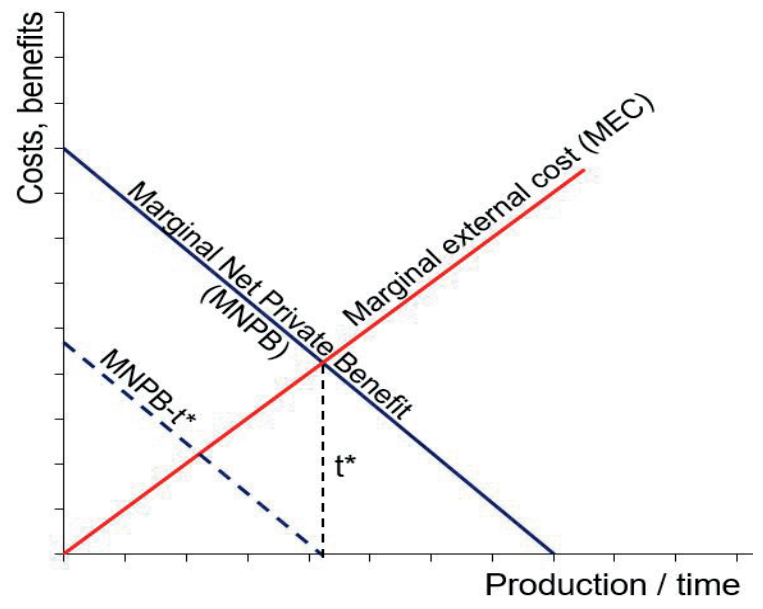

Figure 5-4. The optimal size of the Pigovian tax (Pearce-Turner, 1990)

The theoretical significance of Pigou's point is undebatable, but a few of the underlying suppositions are incorrect.

One blemish in Pigou's model is that it supposes fair competition, which does not occur in reality. Competition is always based on a market riddled with monopolistic conditions. This is of principal importance because a monopolistic producer has the opportunity to create a product shortage to increase their prices. A further increase in this artificial shortage (e.g. through the use of a pro-environmentalist tax) would obviously be harmful from a social perspective.

The other shortcoming of Arthur Pigou's model is related to the fact that it supposes that one unit of production involves one unit of pollution, and that levying taxes on production is enough to create balance.

The situation, however, is that the production of any type of good, depending on the raw materials, the technology and the environmental technologies employed, may result in quite different pollution emissions.

There are usually a variety of technologies involved in manufacturing a product, which certainly differ in terms of emissions. The sulphur dioxide emissions of an electric power plant can be reduced, for example, by using low-sulphur coal as fuel, or by introducing gas instead of solid fuel. Opportu- 
nities are rich because demand for products is usually 'derivative', meaning that it is not aimed at a specific product - which may involve an environmentally polluting method of manufacture, or involve a specific product that is a pollutant (e.g. DDT) - but rather at the satisfaction of a demand (e.g. eliminating insects), which can be done using other, less harmful technologies or products.

A tax levied on production is obviously unsuitable for encouraging the spread of technologies that involve less environment pollution.

This drawback is avoidable if such a tax is not levied on production, but directly on pollution, but this necessitates the measurement of pollution and raises the costs of applying the tax. However, there exist means of simplification such as calculating the emissions caused by a given technology, making the ongoing measurement of emission unnecessary. This solution, however, is not feasible for use in the regulation of certain types of pollution (e.g. pollution caused by accidents).

Of course the greatest problem regarding the Pigou model - as mentioned earlier - is posed by the need to define the amount of pollution. This is exactly what challenges the applicability of this instrument.

In relation to the Pigovian tax, reference must be made to one more problem. Namely, the size of the tax, which, as we know, is determined by the external marginal costs of the optimal volume of emissions, which may be several times higher than the marginal manufacturing costs of the given product. According to some calculations, the Pigovian tax on cigarettes, for example, should be at least (approximately) 3000\%, which, of course, seems irrational, even in an economic sense. The consequences of price adjustments of such an extent would be completely unpredictable. Similarly high taxes would also be incurred by engine fuels and some pesticides, etc.

Another consideration that is perhaps worth mentioning here is that while a Pigovian tax, or other similar penalty, may help control production quantity, whether or not it mitigates or eliminates the environmental impact of the units produced will depend, in part, upon how these collected tax monies are used. This economic solution may not result in an equal environmental solution. Of course, if the externalities tax motivates the producer to redesign the product or production process so as to eliminate the associated emission (and therefore avoid the tax), then both concerns can be met.

\subsection{Coase theorem}

In opposition to Pigou, Ronald Coase claims that there is no need for government intervention because the market will create socially optimum outcomes as a result of transactions if proprietors ownership rights' (perhaps also including the right of disposal) are well defined (regardless of by whom the rights are held). 
To prove Coase's statement, let us first consider the example below. A wood processing plant is located beside a river, which receives the timber floated down the river from the nearby logging camp. The timber is protected against fungal contamination by impregnation with a fungicide. Part of this chemical dissolves into the river while the logs float along. Further on, the river flows into a lake which has a lakeside hotel. The guests at the hotel are mainly attracted by the favourable fishing conditions in the river and the lake. However, ever since the guests have learned that chemical residues are accumulating in the food chain, they have been concerned about the pollution in the lake. A few of them have even found another place to stay. What would Coase consider the solution to be? Let us suppose first that the wood-processing entrepreneur hires the right of disposal and that the logging plant happens to be owned by the hotelier himself. The hotel owner could stop the plant from polluting the river because they have the proprietary right. Since, however, up to a certain volume of production and level of pollution the profits of the plant exceed the hotelier's loss of income from the pollution, the plant manager can compensate the hotel for the loss and continue production. This situation will continue while the plant manager's net profit is greater than the hotel's marginal external cost. But what happens when the hotelier is not the owner of the wood-processing plant, and the polluter is also the owner? Then the hotelier cannot prohibit the polluting activity (remember: one prerequisite was that the government cannot interfere) so the timber plant manager actually has the right to pollute. In this case, the plant manager will seek to make the most profit possible, thereby causing the hotelier considerable damage. The hotelier's damages may be considerably higher than the profit the plant manager generates from the increase in production. In this case, it is logical that the hotelier should compensate the plant manager for transporting less wood down the river (i.e., for his loss of profit) - i.e., the injured party should pay to decrease the damage. This will be a profitable strategy for the hotelier as long as the potential external marginal damage is greater than the woodprocessing plant's net marginal benefit.

To understand the example even better, take a close look at Figure 5-5.

Let us first examine the case involving the injured hotelkeeper who has the right of ownership (and perhaps the right of disposal).

In this case, the starting point is certainly at the origin (at zero pollution), because the injured individual does not want to be affected by pollution. When can the deal take place? See what happens if the parties involved would like to arrive at Point $d$. Then polluting would be profitable according to area Oabd, causing damages to the injured party that match area Ocd. Since area Oabd is a lot larger than Ocd, the polluter can easily compensate the injured party, because even if they overpay they will be left with significant profit. It is clear 


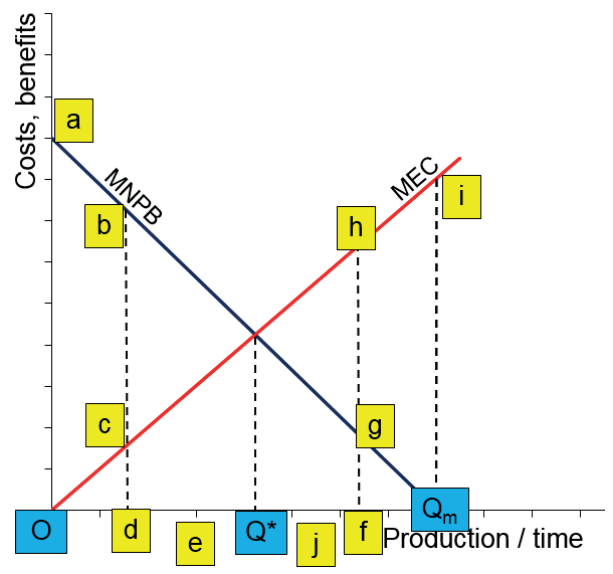

Figure 5-5. The development of the optimal level of pollution by way of a deal (Pearce-Turner, 1990, p. 72.)

that the situation in Point e would be similar; moreover, there is still reason to strike a deal as long as Point $Q^{*}$ (the point considered to be the social optimum), is reached. Production at levels higher than $Q^{*}$ causes damage that exceeds profit, and thus the polluter will be unable to compensate the injured party.

What happens if the polluter has rights of ownership (disposal) - is there any motivation for them to reach the economic optimum level of pollution?

Check Figure 5-5 again. In this case, we would probably start from Point $Q_{m}$ because this represents the maximum possible profit for the producer. Pollution will move to point $f$ only if the injured party is willing to pay more than the lost profit of the polluter. As is clear, this condition exists at Point $f$, because the damage of the injured party $\left(Q_{m} f h i\right.$ area) is a lot larger than area $Q_{m} f g$, the polluter's profit. The injured party then, at relatively minor expense (for an amount somewhat more than $Q_{m} f g$ ), may be able to eliminate damage causing much greater cost. Proceeding using similar logic, we can see that the parties are motivated to arrive at a deal by even moving as far as Point $j$; moreover, the bargain may reach the optimal value $Q^{*}$. It is obvious that such solutions may offend our sense of justice in places, but they are Pareto optimal, and thus are rational in an economic sense.

The figure thus proves that Coase is right: in theory there is no need for government intervention, and market mechanisms are capable of handling externalities. 
Coase claims no less than for an equitable reduction in pollution it is not always the polluter that the tax should be levied on, but at times the injured should pay the polluter to reduce their emissions. The agreement is theoretically feasible through negotiations between the polluter and the injured party, and the negotiation would also deal with the question of the size of any payment. Coase's model, however, involves a few suppositions which seem incorrect in practice. One is that the transaction costs of the bargain are omitted from consideration, and another that the cost of the negotiations are not accounted for, which may, in the case of many producers and injured parties, be sizable. Another theoretical supposition of Coase is that free competition exists, which it does not in practice, as we know.

In addition, the following objections may be made about Coase's theorem:

- The model does not describe the real world very accurately. Only twoplayer deals (in this example, anglers/hotel owners and producers) are rare or non-existent: it was also neglected from our example that the insecticide would also endanger the living standards of further generations and harm biodiversity, and it would reduce the wellbeing and decrease the welfare of sensitive environmentalists to know that the lake is polluted, etc. Involving all those individuals who are affected (consumers and other injured parties) into the bargain is unrealistic, even in theory. This is especially true if we take into consideration that the pollution may last for decades, some of the injured parties (future generations) have not yet even been born, and identification of their preferences is impossible: who then is supposed to represent them in any deal? In the case of the public goods discussed in the previous chapter, who should negotiate with whom? Another problem is that it is often hard to tell who the injured parties or the polluters are; moreover, the information needed to determine the extent of injury is difficult to obtain, substantially increasing transaction costs.

- The transaction costs of the bargain may far outweigh any profit. Thus we may easily arrive at the standpoint that the currently existing level of every externality is optimal, since overly high transaction costs will obviously outweigh any bargains, so indeed we have reached the Pareto optimum.

- Another important counter-argument is that only a few practical cases exist when a bargain has brought about a solution, and not even in obvious cases when conditions for negotiations were ideal. On the contrary, many examples prove that parties involved in such disputes are not inclined to reach agreement, and will rather devolve such solutions to society. 
Based on the above-mentioned information, we could say that Coase's statement about the lack of necessity for government intervention can be considered a specious theory. Coase's institutionalist approach has, however, recently gained significance in practice. It is in Coase's theorem where the theoretical basis of the market for pollution rights is to be found. This is true even if the American creators of the market for pollution rights typically fail to refer to it. This is interesting, because the market for pollution rights exemplifies an opportunity to engage in the practical realisation of the theory. As already mentioned, the weightiest argument against Coase's theorem has been the lack of practical examples of its application.

\subsection{A few environmental-political consequences of Pigou's and Coase's theories}

Approaches that prioritise self-regulation have been receiving more appreciation in the European Community' practice of environment regulation. Involving the full range of environment management, the ISO 14000 series of standards, for example, expressly supports companies' self-regulatory activity aimed at improving environmental performance. The theoretical background of these efforts is again to be found somewhere in Coase's theorem, although let us admit that direct parallels are hardly recognisable. As a company, bearing its own interests in mind, will only limit its pollution because this is worth doing even in an economic sense, the point is exactly that it is the institutional system (corporate goodwill, the expectations of clients and consumers, social pressure, government regulation, etc.) that can further decrease transaction costs to such an extent as to make the company realise it is worth operating in a more environmentally friendly way. A company can be compensated to reduce environmental damage by customers. Obviously, even this case tells us nothing but that Coase's theorem still works. A different question, of course, is whether Hungarian practice has only now arrived at the point where, with the introduction of product fees, we are on our way to practically applying a more-than-70-year-old theory (Pigou's theorem).

The use of Coase's theorem in an economic sense is a lot more obvious and, of course, more market-friendly. Hopefully, we need not wait for its practical application for seventy years. There is a problem with its application, however. It does not generate money for redistributing in national budgets. Its application of course has several benefits, such as the fact that the environment will be cleaner, and what is more: cleaner at less social cost. This will also mean more socially redistributable money in the long run. The question is whether politicians who are responsible for the economy are (or will be) patient enough to employ the long-term approach, and whether inefficient means of environmental protection will prevail, if any are used at all. 


\subsection{Two methods of reducing pollution in the case of one polluter}

Returning to Pigou's concept, in the case of government intervention the producer has several options to select from. One possibility is to reduce the volume of production, thereby approaching the optimal level of pollution. The other option is to reduce emissions per unit of product through the use of pollution-reducing technology. Obviously, this latter solution can happen only if any government intervention is tailored to emissions instead of the volume of manufactured products.

In order to clarify the options, let us modify our original figure a little. Figure 5-6. focuses on the relationship between the private producer's marginal abatement costs and external marginal costs. For this purpose, the horizontal axis does not show the usual economic activity but the size of pollution. As is obvious, very small amounts of pollution have relatively high abatement costs, and major pollution lower abatement costs. This situation matches the practical experience that pollution-reducing technologies (including so-called endof-pipe technologies - e.g. a filter fitted to the end of a piece of equipment, but also brand new, lower-emission so-called 'cleaner' technologies) cheaply reduce most pollution that is generated in high concentrations, while the further abatement of already low-concentration pollution is relatively costly. For example, the removal of the first ninety per cent of the phosphate content of waste water costs less than cleaning up the remaining ten per cent; the situation is similar with air pollutants and other emissions.

Figure 5-6. shows the external marginal cost curve somewhat differently. This time, the starting point of the curve will, according to the practical experience and considering nature's pollutant assimilation capacity, not be located at the origin but at Point $Q_{a}$, slightly to the right of the origin. With this, we acknowledge that there is a level of pollution which causes no damage to society. Let us examine based on the figure how a polluter would react to the effects of an internalising type of tax, or any other government intervention.

The polluter will obviously select the solution (from the options mentioned above) that is associated with the lowest expense. In Figure 5-4., one possible means of abatement is to reduce the polluting activity to the level of $Q^{\star}$. If, according to Figure 5-6., we also take the marginal abatement cost (MAC) curve into consideration, production need not be reduced by all means; it is enough to reduce the pollution associated with the production-related activity. In this case, the optimal level of pollution will be found where MAC = MEC. When the marginal cost of abatement is lower than the marginal cost of the externalities, the company will keep on reducing pollution until it reaches an economically optimal level of waste emission.

The MAC curve is similar in shape to the MNPB (Marginal Net Private Benefits) curve, but notice that the similarity is only in shape. However, the MNPB 
curve can undoubtedly be considered a marginal abatement cost curve insofar as the only option for abatement is reducing the quantity of production.

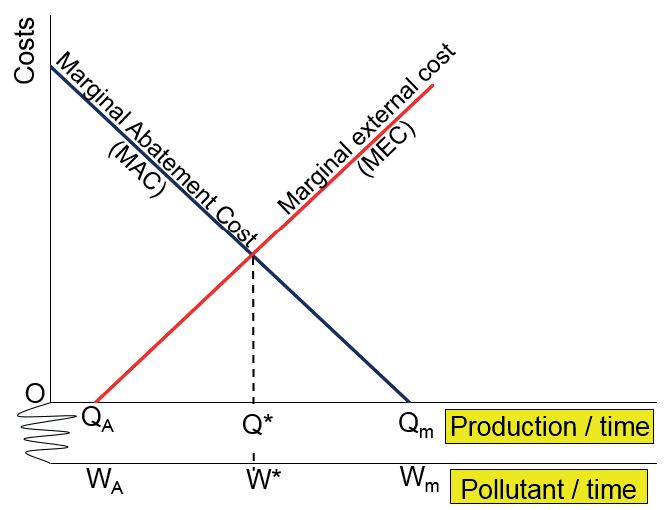

Figure 5-6. The optimal level of pollution taking assimilation capacity into consideration (Pearce-Turner, 1990)

\subsection{Cost-effective sharing of abatement obligations among several polluters, or abatement options}

So far we have spoken about the polluter's options and cost-minimising possibilities; moreover, the theoretical justification of the victim's obligations to assist in abatement activity. Next, we focus on how to share abatement obligations among several polluters in order to minimise costs (based on the facts mentioned earlier, it is obvious that this solution is also feasible when there is only one polluter, but there are several pollution reduction technologies. Further on, we shall discuss the case of only two polluters, leaving the job of generalisation to the reader).

First, let us suppose that pollution is immediately and perfectly mixed in the environment, which is why it is immaterial where the polluting sources are situated relative to each other. Based on Figure 5-7., let us suppose that we have two polluters who have each emitted 15 units of pollution into the air. Environment quality regulations permit only a total of 15 units of emission, which is why the two polluters must remove 15 units of pollution in total. How should we share the abatement costs between them if we know the marginal abatement cost curves?

In Figure 5-7., the abatement cost curves of the two pollution sources (plants) are shown with joint abatement costs being exactly 15 units at every point. It is obvious that the area beneath the two curves is smallest exactly at the value belonging to the intersection (in the present case, at 10+5). Of course, we would arrive at the same result with more than two polluters, so we can 


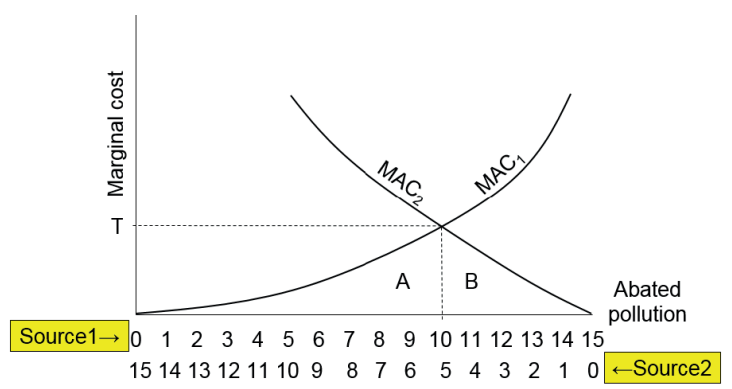

Figure 5-7. Sharing abatement obligations between two polluters in the case of the perfect mixing of pollution (based on Tietenberg, 1992, p. 371.)

generalise the theory that the costs of abatement of a given size are minimized if and only if the marginal abatement costs are equal for all polluters (i.e. it is always the polluter who should reduce pollution for whom it costs the least). The rest of the polluters must of course compensate the one who reduces the pollution for them. It is largely this theory on which practical systems designed to minimize abatement costs are based.

Pollution does not always mix perfectly, which is why it happens that identical types and amounts of pollution emitted from different sources have different effects. The pollution of a factory situated far from a city disturbs the residents of the city less than that of one built in a residential district. In this case, calculating the share of abatement obligations is a little more complicated because, besides marginal abatement cost curves, so-called pollution transfer coefficients that characterise the spread of pollution, must also be taken into consideration. Pollution transfer coefficients express how many units of pollution can be detected in an area from a single emission unit of an individual pollution source. In the case of equal emissions and identical marginal abatement cost curves, in the example above the greater abatement obligation would apply to the source closer to the city. The share of abatement obligations in the case of identical cost curves would match the proportions of the transfer coefficients.

\subsection{The regulatory matrix of environmental load}

Economists have identified many forms of market failure, of which, in the field of environmental protection, the most prominent concern externalities. Pollution involves the negative external effect of production which is initially disregarded. On these grounds, the product concerned is said to have been produced in excessive quantities, and priced too low relative to the social optimum. The point is to increase the price of the polluting products (whether the pollution is direct or indirect), and/or to limit their production in line with the social optimum. 
It should be noted that each method of serving the above objective may be classified into one of four standard cases. In one extreme case, both the price and volume of pollution (thus the product) are regulated directly by the state, and market mechanisms are left with no influence regarding meeting the social optimum.

Command and control: One of the main types of environmental regulatory tools. According to polluting companies should meet given standards. In the case of failure, different sanctions (penalties, criminal procedures, and closure) are applied. type measures may be especially important in the case of substances that poison the environment or deteriorate health, where exceeding the limit is not allowed. The $\sim$ approach is mostly a tool for pollution reduction that occurs at the end of a process (end-of-pipe regulation). is less applicable in the case of a high number of scattered pollution sources. The application of $\sim$ usually receives criticism for its high administrative costs and relatively low efficiency when compared to market tools (Láng, 2002)

In the other extreme case, the price and volume of pollution (product) continue to be regulated by the market, while the state remains in the background to the greatest possible extent, and in remedying market failure its role is 'limited' to attempts to exert a positive influence on market conditions. In terms of determining price and volume, the first case involves a pure state solution, and the second a pure market solution, with two possible hybrids in between. In one of these cases, the price of pollution introduced into the environment is determined by the state, and the actual volume of pollution is established on the market; in the other case, the state determines the volume of pollution that may be introduced into the environment, and lets the market establish a price for the pollution. In Figure 5-8. - these four standard cases are arranged in a matrix, with each cell indicating the methods most frequently employed and the most prominent proponents of the corresponding theory.

\begin{tabular}{|c|c|c|}
\cline { 2 - 3 } \multicolumn{1}{c|}{} & $\begin{array}{c}\text { Volume of } \\
\text { environmental load } \\
\text { determined by the state }\end{array}$ & $\begin{array}{c}\text { Volume of } \\
\text { environmental load } \\
\text { determined by the market }\end{array}$ \\
\hline $\begin{array}{c}\text { Price of } \\
\text { environmental load } \\
\text { determined by the state }\end{array}$ & $\begin{array}{c}\text { direct regulatory } \\
\text { instruments } \\
\text { (command and control) } \\
\text { (standard, offset, netting) }\end{array}$ & $\begin{array}{c}\text { Pigou } \\
\text { (emission tax, } \\
\text { deposit refund, } \\
\text { abatement subsidy) }\end{array}$ \\
\hline $\begin{array}{c}\text { Price of } \\
\text { environmental load } \\
\text { determined by the market }\end{array}$ & $\begin{array}{c}\text { market for pollution } \\
\text { rights } \\
\text { (bubble policy, } \\
\text { emission banking) }\end{array}$ & $\begin{array}{c}\text { Coase } \\
\text { (establishment of } \\
\text { property rights, } \\
\text { legal liability) }\end{array}$ \\
\hline
\end{tabular}

Figure 5-8.: Regulatory matrix of environmental load 
In pursuit of direct regulation, the state takes all tasks over from the market and defines detailed environmental protection standards for all companies. The volume of pollution that may be emitted will be clarified by means of prohibitions and norms (standards), and any company failing to comply with these will pay a penalty in proportion to its excess pollution, which is equivalent to setting the price of emissions. The standard may regulate the technology that should be employed by companies (providing them with no incentive to develop at all), as well as the permitted emissions or ambient pollutions (such standards may, even if to a minimal extent, encourage companies to improve the effectiveness of their pollution abatement). With more advanced forms of direct regulation, emission or ambient pollution norms (standards) are made applicable collectively to several plants at a specific company, or several companies in a specific region. Examples include emission offset systems, emission netting, plant overhaul clauses and compensation proceedings (see also Kerekes-Szlávik, 2001, pp. 191-193). In such cases, new investments may be implemented subject to compliance with the standards applicable collectively to the premises of a company, or the companies of a region. These latter methods are the forms of direct regulation that most strongly promote innovation.

Pigou assumed that for internalising environmental externalities, the state should levy a tax to be charged per unit of product, applicable universally to all producers (see earlier in Chapter 5.8). The theory is also viable in cases when a tax is charged per unit of pollution, which will be assumed in the following example. In this case, the state will, so to speak, determine the price of pollution that has previously been emitted free of charge, prompting companies to choose between paying a tax and abating the pollution based on their own costs and benefits (i.e., on market terms). The concept also works when rather than charging a tax per unit of pollution that is emitted, the competent authority offers companies a fixed subsidy per unit of pollution that is abated. A hybrid form of Pigouvian taxes and subsidies is the deposit refund system, where the tax collected through the sale of an environmentally harmful product is deposited in a financial fund that is subsequently used to support the collection of depleted products (as in the case of batteries).

Environmental practices based on Pigouvian theory are generally contrasted those based on Ronald Coase's theory (see earlier in Chapter 5.9). According to the latter, the problem of externalities should be remedied without direct state intervention through a trade-off between the companies at fault and the injured parties. The theory supports the perception of the injured parties that above a social optimum of production, the damage they suffer exceeds in value the profit of the producers, which makes it reasonable for them to contact the company and cover any loss of profit involved in maintaining production within the confines of the social optimum. Coase argues that once the rights pertaining to the use of the natural environment have been established 
(which is all the state is supposed to do), the problem of externalities will be resolved by the market on its own. The establishment of a legal environment in which companies can be called to account effectively works on the same principle. In this case, a company must be prepared that the parties injured by its operations will take legal action to recover their damages, which will make it unreasonable for the company to raise its output to a level above the social optimum when the expected amount of damage is higher than the profit earned from production.

Finally, in the 1970s in the US the idea emerged that in certain cases it is simpler for the state to specify the maximum amount of pollution that may be emitted by companies in a region, then to issue polluters with the corresponding number of pollution rights, which they can trade freely among themselves. In this arrangement, companies are required to abate pollution that exceeds the regional maximum, but the share of each company in the abatement effort will be determined by their individual costs and benefits through the price of pollution rights (i.e., on market terms). Varieties of this kind of arrangement include bubble policy and emission banking, where any excess pollution rights obtained through technological development may be sold by one company to another (see also Kerekes-Szlávik, 2001, pp. 189-193).

While there are alternative taxonomies with which to classify the above-described pollution regulation instruments, the foundations of such taxonomies are adequately highlighted in the regulatory matrix of environmental load. For example, direct regulatory instruments may be considered centralised solutions where everything is controlled by the state, to be contrasted with methods associated with Coasean theory, which are aimed at creating decentralised responses to the problem of externalities (see also Field, 1997, p. 179). In the latter case, market participants solve the problem on their own, and the state is responsible for the establishment of the legal environment required for them to do so. The two hybrid solutions (Pigouvian taxes and the market for pollution rights) are also referred to as economy or incentive-based instruments on the grounds that they provide strong incentives for corporate innovation. In these cases, the state makes a partial intervention in market mechanisms (which have failed due to the existence of the externality) by defining either the price of (previously free) environment use (a tax), or the maximum amount of total pollution that may be emitted (supply of pollution rights).

Today's practice also makes use of voluntary agreements, by which companies or industry associations enter into voluntary contracts with a competent authority in order to reduce pollution (see also Kerekes-Szlávik, 2001, pp. 196-197). Under such agreements, the state undertakes not to tighten up regulations, while companies commit themselves to the timely implementation of abatement measures. A key element of this arrangement is public disclosure. Depending on their nature, such agreements may be located in 
various cells within our matrix. Where a single company is involved and noncompliance with an agreement is expected to be punished by state sanctions, the case is one of direct regulation, whereas if a company is more likely to be punished by the market for non-compliance (for example, by a reduction in demand for the company's products due to an ethical breach), Coasean theory is more relevant. In this case, when negotiating the terms of the agreement the state virtually undertakes to represent the parties injured by the negative externality, but leaves enforcement of the agreement to the market. Finally, in cases where contracting takes place between the state and an entire industry or professional advocacy organisation, the system will resemble the market for pollution rights. Under such an agreement, the state will recognise the desirable rate of abatement (which is also equivalent to defining the total volume of pollution that may be emitted), and companies in the industry will allocate the required abatement opportunities on market terms. In such an arrangement, companies will also monitor one another to prevent the problem of free riding (when a company fails to comply at the expense of the rest).

\subsection{Choosing environmental policy tools (taxes and normative regulation)}

We demonstrated above that environmental protection requires government intervention. The most common means of government intervention is setting standards. Recently, however, the application of economic tools has become more popular in the field of regulation for environmental protection. Politicians are gradually accepting the idea that resources are limited, pollution cannot be entirely eliminated, and, this being the case, they are expected to develop environment policy which is efficient in an economic sense. The criterion of efficiency may be briefly summarised in the following sentence: a policy is efficient when it creates the desired environment quality at the lowest possible expense.

In the next chapter we return to the other requirements of environmental regulation and a discussion of the tools of regulation in detail. Now, however, let us briefly clarify only the economic background regarding the choices between two groups of tools. To do this we return to our basic figure (Figure 5-9.), where you find illustrated the consequences of quantitative (standard-based) regulation.

Let us examine two cases. In the first one, the regulatory authority allows the production of $Q_{s}$ quantity, or the emissions of maximum $w_{s}$ pollution. The activity level required by the standard is far below the optimum, as the positions of $Q_{s}$ and $Q^{*}$ illustrate. The keeping of rules is usually enforced by imposing penalties, but the size of a penalty $(P)$ may not be sufficient to force the meeting of either standards or the level of activity that is commensurate with the level of pollution considered economically optimal, because 


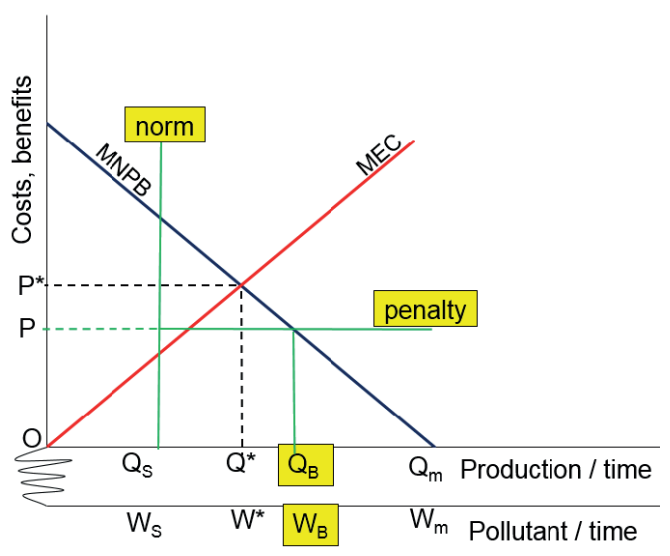

Figure 5-9. Unsatisfactory normative regulation (Pearce-Turner, 1990)

private producers - in addition to any penalties - will find their activity worth continuing until the point $Q_{B}$. In the given case, regulatory authorities will have no choice but to trust that the producer is decent enough to abandon their own economic interests and act in the spirit desired by the regulatory authority by maintaining production at the level specified in the norm. In a favourable social situation, the regulatory authority could have even this strange-sounding wish come true. Of course, the regulatory authority may accidentally hit $Q^{*}$ while defining the standard $S_{2}$, and if they happen to impose a penalty $\left(\mathrm{P}^{*}\right)$ corresponding to this level, the producer will be motivated by his economic interests to undertake activity at the level considered socially optimal. This situation can certainly be generated deliberately. It requires nothing more than a well-informed regulatory authority that is aware of the situation of marginal net private benefits (MNPB) and marginal external cost curves.

We may draw the conclusion from the above-mentioned example that in a well-informed case the choice between regulation by standards or taxes should lead to the same result, but which one is applied is not a question for economic deliberation.

In reality, a regulatory authority is never well-informed enough; moreover, its information is 'asymmetrical', being more precise in terms of marginal external costs and less so about producers' marginal benefits. Regulatory intervention thus relies on estimations. The estimation of environmental impacts is problematic in itself. Pollution usually has spill-over effects; damages are not easily confined in space or in time. Even with well-known examples such as smoking, there are a number of disputable issues. The external costs of smoking will obviously include the costs of treatment, operations for lung cancer, sickness 
benefits and other support for patients, along with the cost of a loss of working hours, etc. Opinions are split, however, about whether pecuniary compensation for deteriorations in others' living standards are justified. The costs to the victims of secondary smoking are hard to identify even statistically. Marginal net private benefits are likewise difficult to estimate. Thus the question is not whether regulatory authorities make mistakes, but rather how bad those mistakes are, and how bad the economic consequences of a regulation based on fallacious estimations is. From the perspective of choosing between taxes and norms, there are three basic options (Weitzman, 1974):

1. MNPB and MEC curves run in opposite directions but are nearly identical in slope, as shown in Figure 5-10.

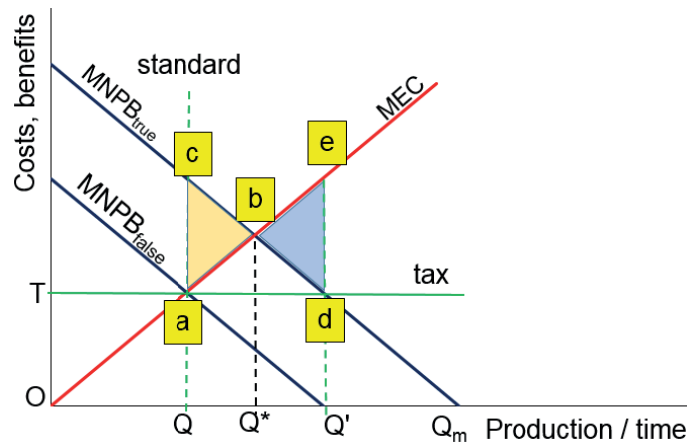

Figure 5-10. Norms and taxes are equally effective (Baumol-Oates, 1988)

Let us suppose that the regulatory authority correctly estimates the MEC curve and guesses the slope of marginal net private benefits, but gives a slightly low estimate of benefits. Resulting from this mistaken estimation, the norm will be set at $Q$ instead of at the optimal $Q^{*}$. Consequently, the producer will be forced to reduce their volume of production, and society will have to give up the benefits that correspond to the area enclosed by the triangle abc. The producer will manufacture quantity $Q$ instead of $Q^{*}$, which is why their benefit will be less - as defined by the area $Q c b Q^{*}$. Society, however, will not have to suffer the externalities matching the area $Q a b Q^{*}$. The difference between private benefits and social damages is the area of the shaded $a b c$ triangle. This is benefit lost to the producer, and also to society, of course.

If an underestimation is used to create a tax instead of a norm, the amount of the tax will be too low, and producers will receive 'false signals' through the

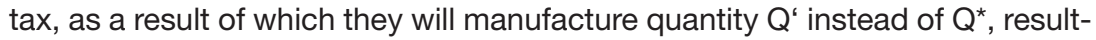
ing in damage to society that matches the shaded area bde. Since the $a b c$ and bde triangles are congruent, we may draw the consequence that provided the 
MNPB and MEC curves are opposite in direction but identical in slope, it makes no difference whether regulation takes the form of a norm or tax, because due to the inaccurate estimate the damage to society will be identical.

It therefore follows that norms and taxes are equally efficient if the regulatory authority is perfectly informed, or if the slope of the MEC and MNPB curves is identical or nearly identical.

2. What happens if the MEC curve is steeper (a) or flatter (b) than the MNPB curve?

Case (a) happens with forms of environment pollution which are especially dangerous and cause significant damage. These pollutants include heavy metals, many carcinogenic compounds, and also water pollutants in lakes (nitrates, phosphates, etc.).

As Figure 5-11. shows, the consequences of errors based on underestimating the MNPB curve are a magnitude less in the case of standards than with taxes. The shaded triangle that is associated with the difference between $Q^{*}$ and $Q$ ' shows that the social damage generated by the erroneous imposition of a tax is a lot bigger than the loss of benefits that society suffers due to the stricter norm. In such a case, regulation using norms has another advantage; namely, that in near-disaster situations, limitation of production does not have to be encouraged only for economic reasons.

It follows from the above-mentioned example that if the MEC curve is steeper than the MNPB curve, regulation using standards is more effective.

We can give a more general explanation of the considerations relating to regulation. In the case of steep marginal external cost curves, tax-type regulations are usually unfeasible. This is first because incorrect estimates may result in substantial social damage, and second, because the steep MEC curves signal that the environment is very sensitive to the given pollution, and it is quite ineffective to rely on an economic solution when the need to avoid a disaster is pressing. Thus, for example, it is inadvisable to use taxes to regulate the lead content of petrol, the mercury or phenol content of sewage water, or the use of pesticides, etc. In such cases the market for pollution rights may be of good service because this combines norms with economic tools that define the maximum permissible level of pollution.

In case (b), when the MEC curve is flatter than the MNPB curve (Figure 5-12.), we may make a worse mistake when using standards if, due to an overly strict standard, the benefits to society are less than the standard permits, while in the case of an underestimated tax the social damages generated by environmental externalities will not be too dangerous. This type of regulation can appropriately be applied to reduce energy consumption or sulphur dioxide emissions, etc. The flat MEC curve means that the emissions of the given pollutant will not cause changes in the environment that lead to major damage. 


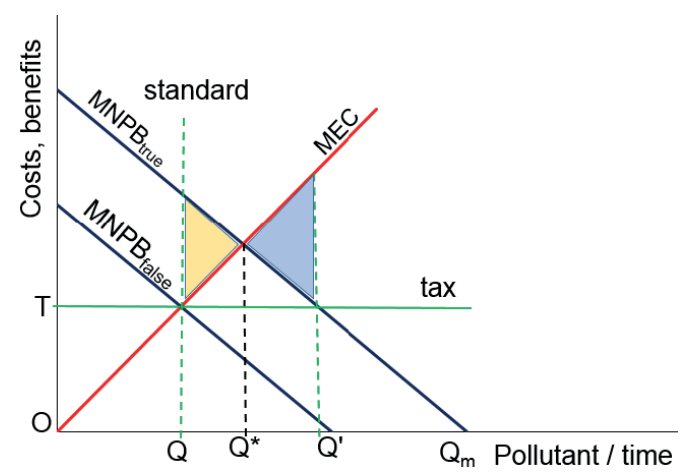

Figure 5-11. In the case of steep marginal external cost curves, the use of standards is more effective (Baumol-Oates, 1988)

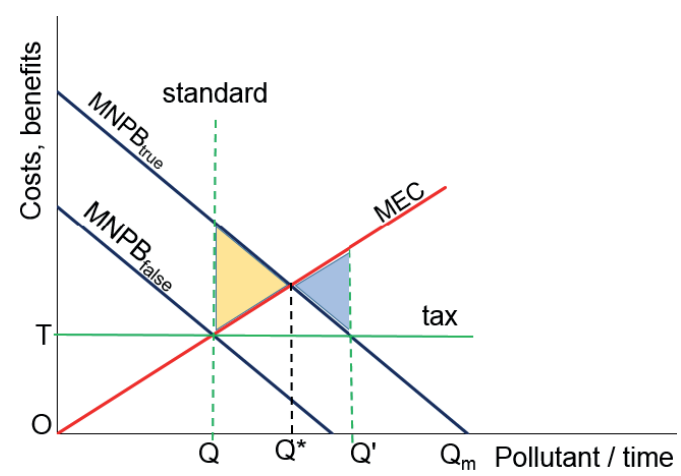

Figure 5-12. In the case of flat marginal external cost curve, the application of taxes is more effective (Baumol-Oates, 1988)

\subsection{Does normative regulation spur innovation?}

The role of regulation in motivating or hindering technological change is graphically presented by Mendelsohn (1984), who arrives at the conclusion that technological-development-motivating effect of regulation through taxes and norms largely depends on the steepness of the marginal abatement curves. According to his final conclusion, regulation through norms motivates innovation better than economic regulation.

This conclusion is available in a relatively simple but more understandable figure which enables us to draw some conclusions for environmental policy. Let us first look at a company's adaptation to a given environment policy, and for now ignore the fact that environmental policies may and do change (Fig 5-13). 


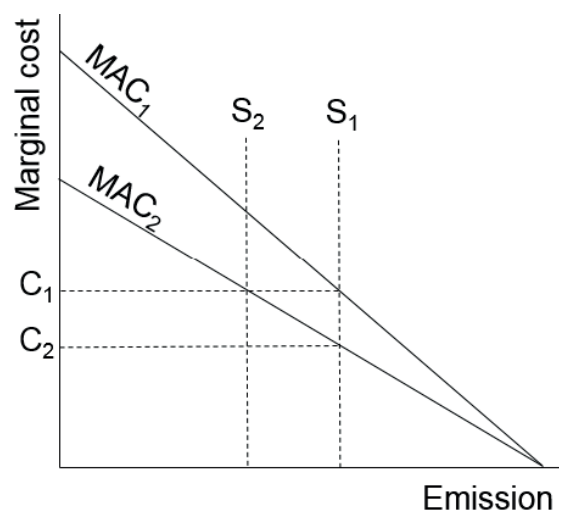

Figure 5-13. The effect of stricter norms on marginal abatement costs (Mendelsohn, 1984)

If the authority prescribes keeping to the $\mathrm{S}_{1}$ norm, this will be possible for the producer at $\mathrm{C}_{1}$ marginal cost, and their total cost will match the area under the MAC ${ }_{1}$ curve. Keeping to the $S_{1}$ norm can be encouraged by the authority by imposing a penalty of over $\mathrm{C}_{1} \mathrm{HUF} /$ pollution unit. A company can decrease its costs and save the amount that matches area $m$ if it changes for $\mathrm{MAC}_{2}$ : a technology with lower marginal costs. As the figure indicates, the potential savings are significant. Using a penalty of more than $\mathrm{C}_{1} \mathrm{HUF} /$ pollution unit, the probability that the limit will be exceeded after innovation will fall, yet nothing encourages or forces the producer to decrease pollution that is emitted at over the limit.

Let us see what would happen if taxes were used. At the start, emissions matching $S_{1}$ will be achieved by the authority using a tax defined as $C_{1}$ HUF / pollution unit. According to the figure, the environmental expenditures of the company will consist of two parts: the tax matching the area below line $\mathrm{C}_{1}-\mathrm{S}_{1}$, and the area below the section of the $\mathrm{MAC}_{1}$ line up to point $\mathrm{S}_{1}$, as the real abatement cost. In the case shown in the figure, the larger part of the cost is created by the tax. This tool thus motivates technological development, because if a company implements $\mathrm{MAC}_{2}$, a technology with lower marginal costs, its environmental expenditures will significantly fall. Here, however, the proportion of cost reduction is smaller than with normative regulation because the share of costs originating from the payment of tax is definitive. While with normative regulation the motivation for cost-reducing innovation is equally significant with both steep and flatter MAC curves, the steepness of cost curves affects the intensity of motivation when taxes are applied. With steeper marginal cost curves, the motivation is more moderate. Regulation through taxes, however, has the obvious environment political advantage that due to cost-reducing innovation the state of the environment will improve even when tax rates are unchanged because emissions are lower.

As seen in the example presented in the previous section regarding regulation 
through taxes, enterprises may cooperate to hinder innovation in order to cut down on their environmental expenditure. Unfortunately, similar alliances may also develop as the result (or threat) of normative regulation. According to environmentalists, all harmful emissions that can be stopped should be stopped. This means, in practice, that the benefits of making cost reductions as a result of technological development may not be realised by entrepreneurs. Authorities, in the knowledge of opportunities for cost reduction, may tighten up norms. Thus a company may be unable to reduce its marginal abatement costs to $\mathrm{C}_{2}$, marginal costs will stay at $C_{1}$ (unchanged), while the standard shifts from $S_{1}$ to $S_{2}$, which will improve the state of environment but decrease the profit of entrepreneurs.

Since when establishing norms health limits and ecological expectations are equally taken into consideration as economic arguments (i.e., norms involve making so-called economically acceptable compromises), the tightening up of norms is a continuous process. This makes companies interested in hiding the results of emission-reducing-related innovation that is at their disposal for fear of norms becoming stricter. Normative regulation thus also creates engineers' so-called 'cartels of silence' (Scharer, 1984).

\subsection{The effect of externalities on a monopolistic market}

We examined earlier what happens when the volume of activity and the volume of pollution become decoupled; i.e., when there exists some technology for abating pollution. Pigou's second supposition was that competition on the market is perfect, which is why a private producer cannot affect prices. Let us see now how Pigou's concept is modified in the presence of a monopolist market. We can do this analysis ${ }^{10}$ based on Figure 5-14.

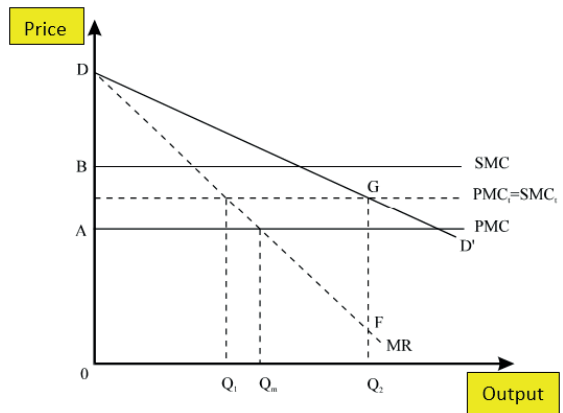

Figure 5-14. The effects of externalities in the presence of a monopolistic market (Baumol-Oates, 1988)

10 For more detail, see Baumol-Oates (1988) pp. 80-90. 
As seen in the figure, the line DD' shows the market demand for the monopolist's activity, and DMR line the marginal revenue. Let us suppose that the monopolist's private marginal cost (PMC) is constant, but for others the monopolist's activity creates costs. Without intervention the monopolist's activity creates $A B$ quantity of pollution cost per unit; i.e., the real social marginal cost of their activity (SMC). If we do not take this external cost into consideration, the monopolist will target $Q_{m}$ level of emissions to maximise their profit (the intersection of the DMR and PMC lines).

Let us see now what happens if we impose a tax proportionate to pollution, which will motivate the monopolistic actors to reduce pollution per product unit. This tax will have a dual effect, as clearly shown in our figure. On the one hand, marginal costs (PMC) will increase, while on the other, after the monopoly makes efforts to decrease the pollution emission per unit of production due to the tax, the social marginal costs (SMC) of the activity will fall. The social cost of the activity will probably be at a minimum where $\mathrm{PMC}_{t}=\mathrm{SMC}_{\mathrm{t}}$ (the $\mathrm{t}$ index refers to the size of marginal costs provided that a Pigovian tax is levied). In this case, the company will opt for a manufacturing process which, considering that input costs also reflect external influences (including the costs of the harmful emissions) will minimize production costs. As indicated in the figure, the monopoly, in the case that the pollution tax is levied, will aim to create $O_{1}$ quantity (the intersection of DMR and $\mathrm{PMC}_{t}=\mathrm{SMC}_{\mathrm{t}}$ lines), which involves further unfavourable movement away from the Pareto-optimal point. To achieve the $\mathrm{OQ}_{2}$ Pareto optimum quantity of production (the intersection of the DD' demand curve and the $\mathrm{PMC}_{\mathrm{t}}=\mathrm{SMC}_{\mathrm{t}}$ social marginal costs curve) we must do two things: First, we must levy a tax on harmful emissions, by which $\mathrm{SMC}$ will drop to $\mathrm{SMC}_{\mathrm{t}}$; second, however, per unit support (GF) must be offered (the difference between marginal cost and marginal revenue) in order to raise the volume of production to the optimal level. Since the existence of the monopoly and the externalities are two different issues, it is obvious that the environment policy needs two regulatory tools to achieve the optimal state. Taking these facts into consideration, one does not need to conduct quantitative analysis to see the complexity of the issue we face, and to understand how difficult it is to plan and actually implement environment policy that is efficient both in the environmental and the economic sense.

\subsection{The case of joint application of direct and indirect tools}

The amount of damage generated by pollution emitted into the environment not only depends on emissions but also environmental conditions. Harmful materials that enter the air do not, in the case of favourable weather conditions (rising air currents), cause environmental harm when properly diluted, while the same emissions that are not carried away may lead to the development of smog and easily escalate into a disaster. A similar example involves water 
pollution, where the influx of wastewater of a stable quantity into a river may or may not cause environmental damage depending on the water output, the water temperature and other parameters of the river. As indicated in Figure 5-15., the ambient pollutions that develop as a result of a pollutant exceed the desired marginal value ( $\mathrm{D}$; see shaded areas) at times, while at other times ambient pollutions remain within the level of tolerance.

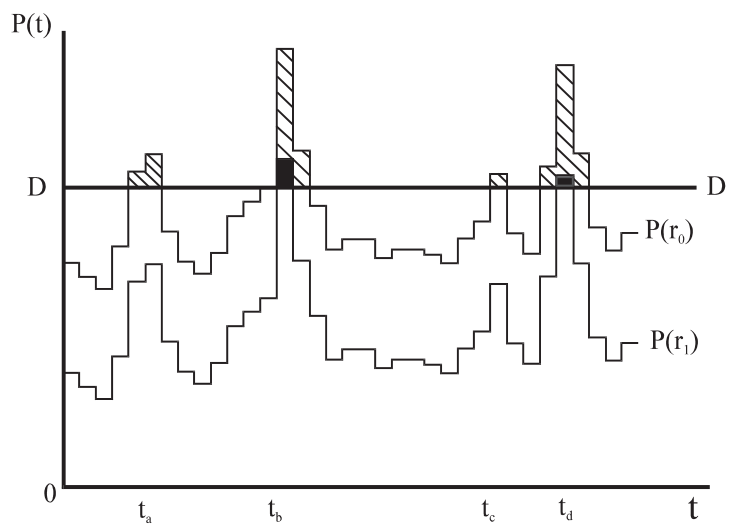

Figure 5-15. Changes in the incidence rate of pollutants over time (Baumol-Oates, 1988)

The question now is what environment policy would be effective, and what regulatory tools can we use in such a situation.

If we would like to solve the problem with a Pigovian tax, the tax must be calculated so that ambient pollutions developing in regulation-led circumstances should never exceed the DD' threshold. Let us suppose that $r_{0}$ tax is levied to keep the average value of pollution at below the DD' level considered to be dangerous. The $P\left(r_{0}\right)$ curve in the figure indicates the temporal distribution of the developing levels of pollution. For the majority of the time, pollution stays at below the authorised marginal value and temporarily exceeds this concentration only at the indicated time points $t_{a}, t_{b}, t_{c}$, and $t_{d}$. By imposing a higher $\left(r_{1}\right)$ tax, we can make sure that the highest peak (in this case, $t_{b}$ time point) stays near the marginal value, but then the average concentration would be far below the DD' marginal value that we desire to define using regulation. This would not be a problem in itself if the regulation were cost-free, but it is not. The correct environmental policy in this case would be that which involves minimal cost to ensure that the pollutant concentration should never exceed the DD' marginal value. Such an environmental policy solution applies taxes and direct intervention in a combined way. A levied tax helps $\left(r_{\text {opt }}\right)$ reduce ambient pollutions to a level where direct intervention (for example, a smog 
alert in the case of air pollution, or higher-level waste water treatment in the case of water pollution) need to be imposed less frequently. The optimal rate of tax can be defined by constructing pollution distribution curves that match different tax rates, and by analysing the transaction costs of a combined regulatory system.

In Figure 5-16., the T T' curve shows the development of the full cost of regulation using tax depending on the rate of tax $r$.

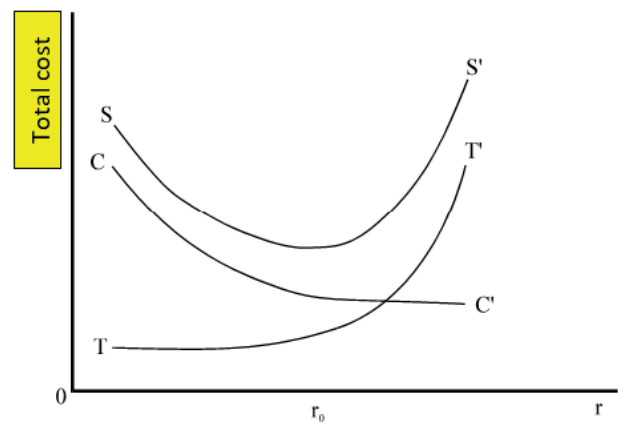

Figure 5-16. The optimal level of economic and direct regulation in the case of combined regulation (Baumol-Oates, 1988)

At over a certain rate of tax the total cost of regulation grows exponentially. The CC' curve indicates the total cost of direct intervention, which, in accordance with our expectations, reverses (i.e., at higher rates of tax - where limit exceedance is less frequent - the total cost of direct intervention needed to prevent limit exceedance decreases). The minimum point of the SS' curve constructed by the vertical summation of the two curves will obviously be the tax rate at which the marginal costs of direct and indirect (by tax) regulation match.

\subsection{Environment regulation in the case of non-stationary pollution}

Interestingly enough, the library-size literature of environmental economics relatively rarely focuses on the issue of the economic regulation of pollution that occurs due to malfunctions and accidents, which typically cause the worst environmental-ecological problems.

Environment economic analyses normally suppose the existence of pointlike pollution sources with stationary emissions in most cases. However, in practice, the cases that have most public impact (Bhopal, Chernobyl, etc.) are due to accidents, which is why this special type of pollution deserves more attention. 
It is largely due to a lack of regulation that some of the pollution events that originate from accidents and malfunctions create 'issues', thereby enabling us to study all the deficiencies of environment regulation.

In recent years, a significant amount of money has been spent on efforts to eliminate operational hazards. In Great Britain, techniques called 'hazop' (hazard and operability studies) and 'hazan' (hazard analysis) have been developed (Kletz, 1985).

Hazop methods explore systematically and as completely as possible the sources of danger that exist during a process, and the options for their elimination and protection against their consequences. The hazan technique helps with estimating the significance of sources of danger and deciding how far it is worth incurring the extra costs of any changes needed to reduce the risk.

These decisions are very complex and often involve serious social conflict. Legislators are called on to decide about issues such as what fatality rate is 'acceptable' to society, which involves taking a great deal of responsibility.

Posing such questions may seem cynical, but safety comes at a price, and higher levels of safety consequently cost more. Resources are not limitless, and money spent on improving safety must be spent in the most efficient way possible. We cannot afford to continue with hazardous operations without an analysis of possible sources of danger, or consideration of the probability and severity of accidents, or without calculating the hazard to life caused by technological processes. Briefly: we cannot bury our heads in the sand.

On the other hand, we should not throw money out of the window in the spirit of humanism in an attempt to completely eliminate hazards which we already know of, while other - possibly more serious - sources of danger are left out of consideration.

The prevention of environmental disasters that originate from accidents and malfunctions requires special environmental protection regulation. Existing laws need to be reinforced with stricter financial and civil rights sanctions. To avoid specific types of pollution and to reduce risks, one efficient tool would be to force companies to be legally liable, regardless of who is at fault. In such a case, entrepreneurs would have to take responsibility for the consequences of their activities even if misconduct on their part could not be established. This suggestion - especially for entrepreneurs used to the 'polluter pays' principle - may sound unfair, but it would make improving safety measures worth it for companies.

The environment pollution risk of malfunctions and other accidents can also be reduced by adequate societal preparations for eliminating the consequences of such mishaps. International experience proves the usefulness of maintaining suitable emergency response organisations. However, it is still not clear who (and in what proportions) should bear the costs of the maintenance of such emergency organisations, nor what size and technical equipment requirements are justified. 


\subsection{The issue of inflation and price elasticity regarding green taxes}

A further issue with Pigovian taxes is that, due to inflation, taxes 'devalue' and lose their power to motivate. This is what happened in a very short time with some environmental taxes (for example, fuel taxes) that were applied in Hungary. In consequence of the inflation that is customary in developed countries, taxes need to be increased on an ongoing basis, which usually causes social protest. A process of tax indexation would be relatively easy to manage, but would lead to inflation in itself. The inflationary effect of taxes is the main argument against environmental taxes in any case, and justifies the wariness of politicians about these instruments.

The main purpose of the imposition of environmental taxes is very frequently to use the revenue they generate in environmental protection. This was the purpose of the fuel product fee in Hungary, and this is the primary goal of the packaging material product fee, and the product fees imposed on batteries and tyres as well.

In the case of fundraising taxes, authorities may easily be surprised if they leave the price elasticity of consumption out of consideration. Among product groups usually subject to eco taxes (e.g. energy sources, cigarettes, packaging materials, artificial fertilizers), some are subject to dramatic decreases in demand when their price rises (for example, aerosol dispensers with gas propellants; see Figure 5-17.) while there are others with clearly non-elastic demand. A $300 \%$ price rise in crude oil, for example, according to German statistics, decreased demand for oil by 'only' $30 \%$ (see Figure 5-18.).

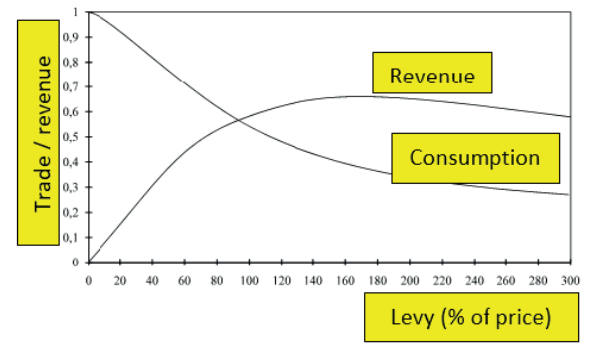

Figure 5-17. Aerosol dispensers with gas propellants - the price elasticity of consumption (Weizsäcker et al., 1997)

From the perspective of filling up environmental funds using taxes, the tax levied on aerosol dispensers with gas propellants is a rather insecure revenue source, because at a tax rate of $100 \%$, demand drops by half, and at even higher tax rates the fall in demand may result in an absolute decrease in tax revenue. Taxes that are levied on such products will mean that they lose market share. This also means 
that substantial environmental taxes must be levied on products with high price elasticity if the goal is to achieve a dramatic reduction in their consumption. This is exactly what the tax on CFC-based aerosol dispensers was meant to achieve.

For environmental protection authorities, taxes imposed on products with a stable demand are a safe source of revenue. As Figure 5-18. shows, the curve indicating revenue linearly increases in such cases.

It is true, however, that a green tax receives more social support if it is imposed on a product with elastic demand than one with non-elastic demand. No wonder there is such resistance in the US to taxing fuels, while otherwise the environmental attitude of American society is considered to be fairly positive - at least by American experts!

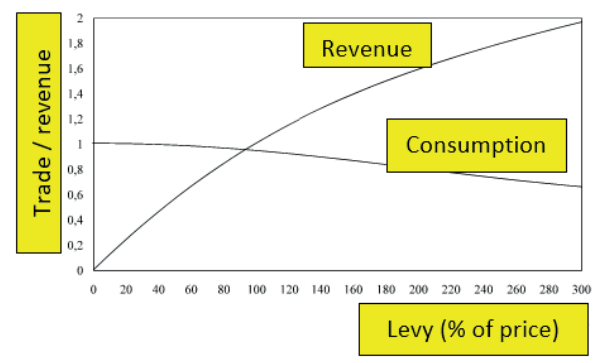

Figure 5-18. Crude oil - the price elasticity of consumption (Weizsäcker et al., 1997)

\subsection{Accumulating externalities}

In the literature, the theory of having decentralised state functions dates back to the 1950s. The theory of fiscal federalism was most prominently advocated in the works of Wallace Oates. Later, Oates' followers published a collection of essays to pay homage to the work of the outstanding scholar, whereby they also promoted the concept of environmental federalism on a wider scale. The debate about the approach known as the TOBM (Tiebout, Oates, Buchanan, Musgrave) model is periodically reignited both in the economic literature and in public policy. At the level of the EU, one element in that debate is the incorporation of the principle of subsidiarity into the Maastricht criteria, which makes a general organising principle of the need to decentralise state functions. Today it is generally accepted that local government and local civil society play a vital role in the provision of local public goods. Since the provision of local public goods largely requires fundraising and the allocation of funds, a major part of the related task involves the field of finance. This book addresses both finances at the level of local government, and the civil initiatives periodically prompted by dissatisfaction with the 'official' financial system. The theory of 
sustainable development and global issues such as climate change, loss of biodiversity, or demographic problems such as overpopulation and ageing in certain regions, as well as massive migration due to regional differences in development, have added intriguing new dimensions to the interpretation of local public goods.

Understandably creating a stir, the otherwise excellent Stern report (Stern et al., 2007) attributed climate change to the failure of the market, a debatable assertion. It is to be feared that climate change is not only attributable to market failure, but to the general failure of humankind. Even if energy use could be priced appropriately, people would still go on travelling, heating and air conditioning, only slightly less. This would at most decelerate but by no means stop harmful emissions. The market is typically an ex-post regulator rather than ex-ante one. Foresight has never been an attribute of the market; this is a human characteristic, in fact mostly possessed by people involved in science who are not likely to be concerned with the current state of the market. This is a distinction worth addressing, because if climate change was 'a mere market failure' the problem could be solved by means of economic intervention. However, it is not particularly appropriate to consider climate change purely as a market failure. It is a mistake to think that the heavy taxation of fossil fuels could stop the increase in the concentration of $\mathrm{CO}_{2}$. Our wasteful consumption habits and values will certainly not be changed by the market, which is capable of producing the very opposite effect. As soon as demand was shown to exist for the perhaps most energy intensive new form of tourism, the 'product' was introduced to market almost immediately. Just one week after the release of an ominous EU report on climate change, humankind embarked on tourist voyages into space, and suppliers are now looking to diversify their offer. Therefore, despite the fact that climate change is not considered only a case of market failure, an inquiry is warranted into the specificities of climate change as an externality. Climate change is commonly seen as a new type of externality, but one significantly different from the externalities addressed by classic economic authors. The key differences are that, as an externality, climate change

- is global in terms of both its root causes and consequences - as regards the effect of the emission of an additional ton of carbon dioxide, it makes no difference whether it occurs in Australia or Europe, whereas in the case of other air pollutants, the environmental circumstances of the emissions are very relevant to the specific harm caused to health and other effects;

- may potentially evolve over the course of centuries due to the effects of greenhouse gases, and there is often a lag in the climate's response to changes in concentration, with long-term and permanent effects;

- is unpredictable both in terms of risks and economic consequences; 
- probably produces irreversible effects, leading to economic consequences that are not marginal. The effects of climate change may have a significant impact on members of society, and cannot be addressed by simply 'redesigning' some projects.

Owing to these specificities, climate change cannot be addressed using the same economic approaches as conventional externalities. The theories of both Pigou and Coase are based on marginal analyses of the cost and benefit type, and seek to identify optimums along MAC and MEC curves. Climate change is not marginal in nature, as any minute shift along the axis of $\mathrm{CO}_{2}$ emissions could lead to changes that are in many cases unpredictable and virtually impossible to map on the axis of marginal damage. The effect of current pollution abatement efforts also depends on the characteristics of future emissions and abatement attempts. It will be readily apparent that as regards the $\mathrm{CO}_{2}$ concentration of the Earth as a whole, in principle it is completely indifferent where emissions are made and where they are reduced. Conversely, in terms of economic effects, the economic circumstances under which remediation efforts are made do actually matter. For all these reasons, conventional techniques of analysis may only serve as points of reference, and a novel approach is needed to solve the problem. Achieving lower concentrations of $\mathrm{CO}_{2}$ takes greater effort, which will act as a major drag on economic growth. The actual effects of climate change may only be shown on balance sheets. Initially indicating a deterioration in welfare, the related curve is of major concern to both policy makers and theoreticians since it 'demands' the seemingly altruistic sacrifice of present generations, implying a certain intergenerational inequality. It may appear that, as regards climate policy, present generations are giving up a part of their welfare (by investing in natural capital) to protect future generations against a radical decline in welfare. Obviously, in moral terms there is presently a need to make up for the negligence of generations following the industrial revolution, and it is precisely in response to this that some of the current population are asking, 'Why these generations?', and, 'Of all people, why us?'

\subsection{Towards strong sustainability: Expanding the notion of negative environmental externalities}

After many years of teaching about environmental economics and external costs, there seems to be nothing more natural for us than to accept that external effects are unintended. The presence of a smoking chimney or exhaust pipe itself is not the ultimate purpose of activity, of course. The purpose is to produce electricity or move from point A to point B in space, and any environmental load or pollution is only an unintended by-product of this process. However, by broadening our view and studying all of the possible technologi- 
cal options for achieving our goals it is possible that we will come to realize that these outcomes are not so natural and unintended. The use of a specific technological solution clearly reflects values and preferences because we also accept the distribution of the costs created by the chosen technology. This choice ultimately informs us not only about the fate of 'third persons' who unintendedly suffer, but also tells a lot about the 'first persons' (producers), and second ones too (consumers). These individuals accept the technological solution by which a specific product or service is 'manufactured', and they all accept the patterns of cost distribution associated with the related production and consumption by opting for a specific technology.

Of course, producers and consumers can all refer to the general status quo by which technological practices are generally accepted by humankind, often in historical terms measured in hundreds of years. If a farmer uses artificial fertilizers and chemicals to decrease their own costs and increase productivity, is this an example of intentional 'cost spreading'? Is the farmer really freely able to choose an alternative; can they employ a more environmental and costly technological solution in an economic system based on competition?

When analysing 'intention' we never should forget the logic of our marketbased economic system with the principle of profit maximization at its core. Of course, profit has two basic elements: revenue and cost. Our focus is on the latter: cutting costs means an increase in profit, all else being equal. We usually describe technologies that operate at lower costs as better, more powerful, and efficient. But we seldom investigate the source of this efficiency, which might be easily found by widening the scope of analysis: the fact is usually that costs are externalized to people who live far away in space and/or time (Read, 2001; Hepburn et al., 2010); and/or, using an even wider analysis, by stepping over the boundaries of our anthropocentric world-view, by offsetting the cost to other living species like hens, pigs and other animals (see also Singer, 1995) which provide food and basic ecological services for our welfare, or just for our very existence.

In a 'full world' where frontiers disappeared long ago the sources of gains are usually losses somewhere else in space and time, and lots of scientific information about the potential costs of advanced technologies is available (or will shortly become available) to a wide audience.

Thus the concept of negative external costs can be broadened. The core of the concept of externalities (see Chapter 5.2) is that disadvantageous effects are left uncompensated, while other assumptions may be systematically removed. Thus, using a broader concept of externalities, we allow that a negative impact may be suffered by a second person (a consumer), by a first person (a producer) or even by a non-person (for example, a group of animals). The pursuit of profit by cutting costs in a highly competitive environment may result in cost-spreading strategies which are fully legal and rational in terms of economic 
theory that is based on profit maximization; and are fully rational - if not always completely legal - in standard business practice. Thus, even producers as first persons might use methods which are detrimental and unhealthy for themselves to meet the demands for low-priced products of monopsonistic buyers (see also Princen, 1997), especially in the developing world, but also elsewhere.

But the concept of externalities may also be broadened by removing the assumption that the effect is unintended. As mentioned, when well informed about the broad consequences of a technology or method it is hard to believe in the 'unintendedness' of producers who use a technology at a lower cost; and it is also hard to suppose that consumers who buy a product or service at a lower price than could be produced without externalized costs do so unintentionally. Table 5-1. summarizes all the possible cases of our broadened concept of externalities.

\begin{tabular}{|r|c|c|c|c|}
\hline & $1^{\text {st }}$ person & $2^{\text {nd }}$ person & $3^{\text {rd }}$ person & Non-persons \\
\hline unintended & & & & \\
\hline intended & & & $\downarrow$ & \\
\hline
\end{tabular}

Table 5-1. A broadened concept of negative externality. According to the definition, the first person is the producer, the second is the consumer, the third person is not involved in the market transaction, and animals are 'non-persons'. The shaded area indicates what is covered by the classic definition of externality. (author's own compilation)

Let us see the microeconomic consequences of the above! Suppose that the marginal net private benefit (MNPB) function is linear under perfect market conditions according to Fig. 5-19. As a basic scenario, we suppose that all costs are borne by the producer, and no external costs arise. Then the socially optimal level of production $\left(Q_{o p t}\right)$ is equal to the level of production that creates maximum profit $\left(Q_{\max }\right)$. In this case, the total profit of the user (and thus the whole of society) is represented by the triangle $A$, and there is no need for intervention.

However, in the case of 'material cost-shifting technological development' (Kocsis et al., 2018), as production costs decrease and profits rise for the producer, external costs are generated for the broader community (including other species). Using our linear model - for the case of technological development the MNPB function flattens and more product is created in the same period for a higher private profit (all else being equal; see the sum of triangles $A, B$, and C). However, in a finite world, and in the case of destructive development, all saved costs are offset elsewhere in the form of external costs (see triangles $B$, $\mathrm{C}$, and D under the Marginal External Cost /MEC/ function on Fig. X). Then $\mathrm{Q}_{\max }$ and $Q_{\text {opt }}$ become separated, a condition which cries out for market intervention 


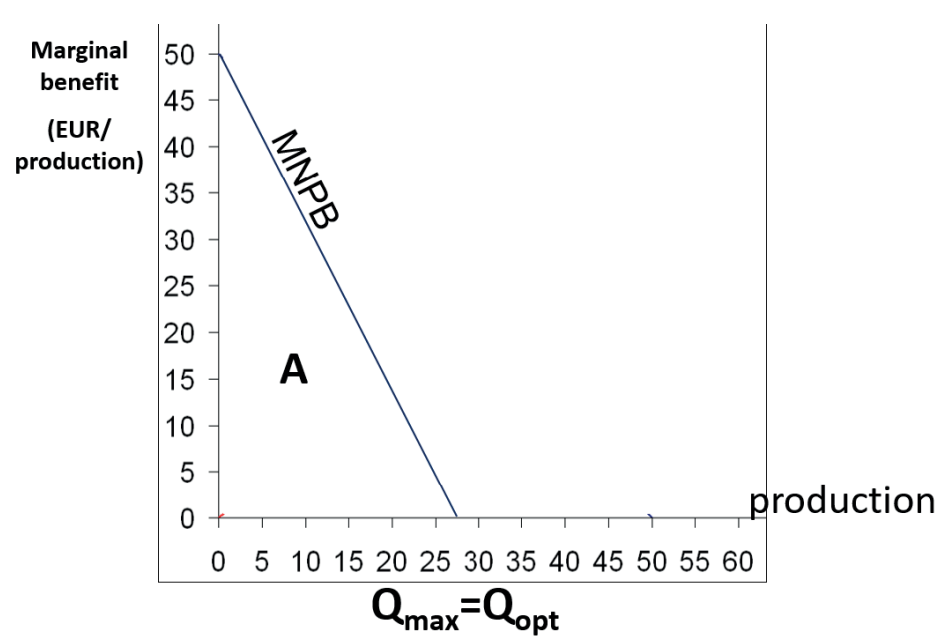

Fig. 5-19. Costs and benefits before cost-shifting technological development (no external cost) (Source: author's own compilation) (Note: Numbers are only illustrative)

(see earlier in this Chapter). It is worth noting that $Q_{\text {opt }}$ remains the same as it was in our basic scenario without external costs, and that triangle ' $A$ ' in Fig 5-19. is the same size as in Fig. 5-3, which means that the benefits derived from production at the whole - broadly defined - social level is the same in both cases. (Supposing that we are at the social-environmental optimum $\mathrm{Q}_{\text {opt}}$; in all other cases the net benefit is even lower in this second case). However, there is a big difference between the two cases: the distribution of costs of the activity dramatically changes!

It is clear that external costs in our economic and ecological system are not so neutral, technical, and unintended as most economic textbooks claim. Thus, the theory of cost-shifting technological development may form the basis for strong moral and political claims. A more political and ethical analysis of technological development and cost shifting (Kapp, 1978, Swaney-Evers, 1989; Broome, 2012) has been offered to re-evaluate the classical tools of environmental economics (norms, taxes, tradeable permits, the Coaseian bargain) in the light of finite resources and strong sustainability. 


\section{The economics of environmental risks}

\subsection{Introduction}

Economic theory is typically used to explain environmental problems as the existence of negative externalities and public goods. The economics of pollution deals with stationary processes. All of us are frustrated about the exhaust gases of cars or the chimneys of factories, the sight of litter dropped in the streets and polluted rivers. However, this kind of pollution that overshadows our everyday lives rarely makes it to the news, and hardly ever makes us think of 'environmental pollution'. Environmental issues are associated with scandals and disasters in news headlines. It may appear that 'accidents' that lead to environmental disasters, such as those of Bhopal, Seveso, Sandoz, Exxon-Valdez, Chernobyl, Prestige - and we could go on listing such cases - have become milestones in the development of environmental protection. In relation to climate change, the risk of the occurrence of natural disasters has increased. Some of the metropolises of the world (such as Tokyo and Los Angeles) were built on earthquake zones, while areas regularly threatened by floods have become densely populated (Holland and Venice). The increase in population is a risk factor in itself. The next chapter in this publication focuses on economic activities, while risks related to natural disasters will be mostly ignored, although we shall make it clear that the theoretical material we include may also be applied to natural disasters.

\subsection{Risk theory and its relevance to environmental disasters}

\subsubsection{The term risk}

Environmental risk refers to both the likelihood of the occurrence of a threat and the gravity of the consequences. Accordingly, when a risk is analysed it is first the frequency of occurrence of the natural event, and second the severity of the consequences of the event which are investigated.

- The risk $(R)$ of an environmental event $(x)$ is accordingly a function of the likelihood of occurrence $P(x)$ and the damage that is caused: $D(x)$.

- Risk is the expected loss or damage associated with the occurrence of a harmful event.

- $R(t)=P(t)^{\star} D(t)$

- An environmental hazard is defined to be exposure to toxic chemicals and dangerous substances that leads to sickness, injury or death. 
Risk, by definition, is the product of two factors: the amount of damage that is expected to be caused by an event that threatens people's lives and valuables, and the probability of that event occurring. Given the continuous growth in the population of the Earth (and the wealth it possesses), environmental risks are obviously increasing, no matter whether disasters are becoming more frequent.

\subsubsection{The acceptability of risk, the importance of technical and cultural rationality}

In consequence of the foregoing, what is deemed an 'acceptable risk' involves not only scientific but also social evaluation. The problem is only enhanced by the fact that science and non-professionals relate to risks differently. Professionals make their decisions based on 'technical rationality' while non-professionals rely on their social experience. As seen in the figure, the two types of logic barely have anything in common. Based on a technical rationale, a nuclear physicist considers electricity produced in a nuclear plant to be environmentally friendly energy, while an average citizen, however, will protest against nuclear plants for environmental reasons. The conflict is generated by the differences between the two approaches. Professionals sometimes forget that those who make their judgements based on culturally conditioned reflexes are more numerous. We should not forget - and numerous industrial accidents remind us - that the caution that is suggested based on cultural rationality could save mankind from disaster, while decisions that are made on the grounds of technical rationality usually do nothing but make certain people richer.

The environmental-ecological evaluation of specific products and technologies also involves a social contract. Economic or scientific rationalization concerning the use of the former is often pointless: if a social contract is not created, the use of a technology may never become widespread. Despite their favourable environmental and economic evaluations, the number of nuclear plants has increased significantly more slowly than was predicted fifteen years ago, despite the fact that some energy-related prognoses say there is no other option but to use them. The past ten years have witnessed some radical changes in the value systems of developed capitalist societies. Sensitivity, among other things, to very rare but 'unpredictable' accidents has increased, and there is also an increase in the fear of the long-term effects of environment pollution. 


\begin{tabular}{|l|l|}
\hline Technical rationality & Cultural rationality \\
\hline Trust in scientific methods, explanations, evidence & Trust in political culture and democratic process \\
\hline Appeal to authority and expertise & Appeal to folk wisdom, peer groups, and traditions \\
\hline Boundaries of analysis are narrow and reductionist & $\begin{array}{l}\text { Boundaries of analysis are broad, } \\
\text { include the use of analogy and historical precedent }\end{array}$ \\
\hline Risks are depersonalized & Risks are personalized \\
\hline Emphasis on statistical variation and probability & $\begin{array}{l}\text { Emphasis on impact of risk } \\
\text { on the family and community }\end{array}$ \\
\hline Appeal to consistency and universality & $\begin{array}{l}\text { Focus on particularity; less concerned about } \\
\text { consistency of approach }\end{array}$ \\
\hline $\begin{array}{l}\text { Where there is controversy in science, authority } \\
\text { depreciates }\end{array}$ & $\begin{array}{l}\text { Popular responses to scientific differences } \\
\text { do not follow the prestige principle }\end{array}$ \\
\hline Those impacts that cannot be defined are irrelevant & Unanticipated or unarticulated risks are relevant \\
\hline
\end{tabular}

Table 6-1. Factors relevant to the technical and cultural approaches to risk (based on Plough-Krimsky, 1987, p. 9.)

Practical experience proves that the more significant the expected risks are, the higher the social propensity to reduce those risks will be. The less society is capable of intervening to reduce risk, the higher the risk it will endure; moreover, it will underestimate the significance of these risks.

In peacetime, everybody pays a good deal of attention to vaccinating dogs against rabies, while during a drastic fall in living standards society is 'capable' of ignoring this issue.

It is likewise not equal how risks are shared among members of society. The share of risks is considered fair if those who bear the consequences of a risk accrue the benefits from the risky activity, and unfair if those who enjoy the benefits of high-risk activities can offset the consequences to other people. Whether society accepts a risk largely depends on how it evaluates the risk that is generated by the threat. A risk is obviously more welcome if the related activity delivers significant benefits, but there are also interesting social and sociological factors that influence such decisions.

Below is a comprehensive list of the factors that influence how risks are evaluated. This includes:

- the benefits of the activity,

- whether the risks and benefits are distributed among the same people,

- whether risks disproportionately affect vulnerable populations such as the elderly or children,

- whether they affect well-defined groups or are randomly distributed, 
- the costs associated with risk reduction,

- whether defining a lower level of risk conflicts with individual rights

- whether a risk is new or old

Fairness: distribution among participants in proportion to their contribution to the production of the object in question. The object to be distributed may be positive, negative or risky for participants. Injury to the principle of fairness will lead to the free-rider phenomenon when some participants will gain advantage to the detriment of others. (Láng, 2002)

Problems related to the evaluation of risks are enhanced by the fact that discounting of the size of risk occurs in several dimensions. It is a known fact that impacts that occur later in time are usually underestimated. Smoking is perhaps the neatest example of this. While a smoker smokes a cigarette, they consider the risk of lung cancer to be rather insignificant, although the statistics tell us that the risk is rather high.

Discounting of risk also occurs in space. People in Europe do not attach great importance to the risk of flooding in Bangladesh, or radioactive contamination in Kazakhstan (or at least not so much as to sacrifice anything to reduce these risks). Discounting also occurs in relation to how closely we are related to the individuals who are (potentially) affected by a risk. We would not be ready to allow our loved ones near the scene of a nuclear reactor accident, although we consider it natural that people unknown to us should work on remediating the impacts of such an accident. These phenomenon always lead to the discounting of long-term interests.

\subsection{Natural and environmental disasters, unlimited business for insurance}

We know that in areas exposed to natural disasters (for example, earthquakes) buildings are designed to be especially earthquake resistant, and, for example, dams and nuclear plants are not built in such zones, etc. Natural disasters, however, are not always predictable. They sometimes occur in places where people are not quite prepared. The example in the box below proves that some natural disasters may hit even powerful economies hard. A single hailstorm caused $\$ 5$ billion damage to Germany in 2013.

The most expensive event for the insurance industry in 2013 involved the hailstorms that hit regions of northern and southwestern Germany between 27 and 28 July. The firm noted that it was the most costly hail event in the country's history. Insurance losses from heavy hailstorms in July and August in Germany totalled $\$ 4.1 \mathrm{bn}$, with an economic loss of $\$ 5.2 \mathrm{bn}$. The hailstorms in late July, the firm said, alone accounted for $\$ 3.7 \mathrm{bn}$ of insured losses, with an economic loss of \$4.8bn. - See more at: http://www.theactuary.com/news/2014/01/munich-re2013-insured-catastrophe-losses-below-average/\#sthash.TWTI17k8.dpuf 
According to the World Economic Forum (2011) the top 10 risks by likelihood and impact combined are listed in ranked order below:

1. Climate change

2. Fiscal crises

3. Economic disparity

4. Global governance failures

5. Extreme weather events

6. Extreme energy price volatility

7. Geopolitical conflict

8. Corruption

9. Flooding

10. Water security

The list clearly indicates how broad the range of threats that mankind has to face in the twenty-first century is. Natural disasters, social inequality, financial crises and corruption are all found among the sources of threat. The economic significance that the illegal business sectors that endanger mankind have is surprising. Considering that $\$ 10-30 \mathrm{bn}$. would be enough to save Earth and the size of the market for illegal drugs is nearly $\$ 300$ bn., we may feel sorry about man's foolishness.

Counterfeit pharmaceutical drugs: 200

Prostitution: 190

Marijuana: 140

Counterfeit electronics: 100

Cocaine: 80

Opium and heroin: 60

Web video piracy: 60

Software piracy: 50

Cigarette smuggling: 50

Human trafficking: 30

Environmental crimes and

natural resources trade: 20

Logging: 5

Art and cultural artefacts: 5

Small arms: 1

Table 6-2. Rough estimated market size of illicit goods based on public sources (in USD billion) (World Economic Forum, 2011, p. 23.) 
Tom Massey, director of RWE Power, admitted in reply to a question that 'Fifteen years ago, companies were saying that climate change was not relevant to business. You could not measure it, companies had no individual responsibility for it and there were no global regulations to control it. Many companies argued it was not happening at all. Scientific evidence and government action have fundamentally changed this scenario.'

In the field of environmental protection we have become accustomed to the fact that any significant and dangerous problem that is recognized by science or the public is initially denied, or stakeholders attempt to neglect it. The carcinogenicity of asbestos had long been proven by science when large building material producers were still insisting that slates and asbestos-cement pipes were harmless. It also took a long time to convince economic actors that halogenated hydrocarbons damage the ozone layer, and to limit or prohibit their production and use.

The front page of the world-renowned economics periodical The Economist has hardly featured anything but climate-change-related news for the last couple of years. Still, it is rather certain that it is not these articles but rather those about extreme weather events (like the 2005 Hurricane Katrina that killed more than 1800 people and flooded the city of New Orleans) that call the attention of the public to the potentially disastrous impacts of climate change. The tsunami that followed the Great Sumatra-Andaman earthquake which killed 225,000 people has had a more significant effect on humanity than all the UN development summits that have been held for years. These phenomena have made the public realize that, in spite of all our ingenuity, humanity does not 'rule over' nature. It took more than 225,000 lives to make us consider that all we have 'achieved' so far is to create a weapons stockpile which, even in the case of an accidental misunderstanding, is powerful enough to destroy civilization. We have not, however, developed anything to protect us from drought-triggered famines, or AIDS, and even less from earthquakes, the latter which we cannot even forecast. Even the most sophisticated models fail to cope with nature's 'inventiveness.'

We are surrounded by natural and industrial disasters. The threat is growing continuously despite humanity's enormous effort to avoid risks. Figure 6-1. makes it obvious that even although international effort has increased, industrial disasters have not become any less frequent. The waves stirred by Hungary's 2010 red mud catastrophe had not even settled before we were already in the middle of a nuclear crisis at Japan's tsunami-stricken power plant. 


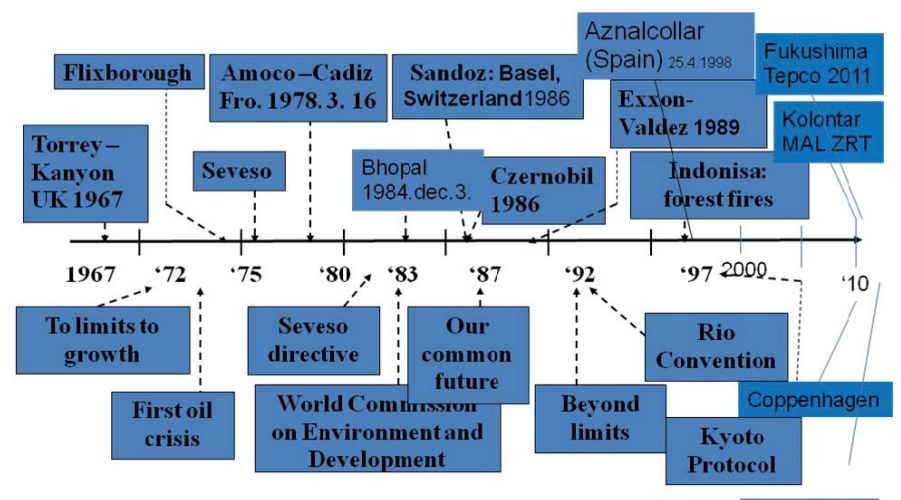

2011 Caúna

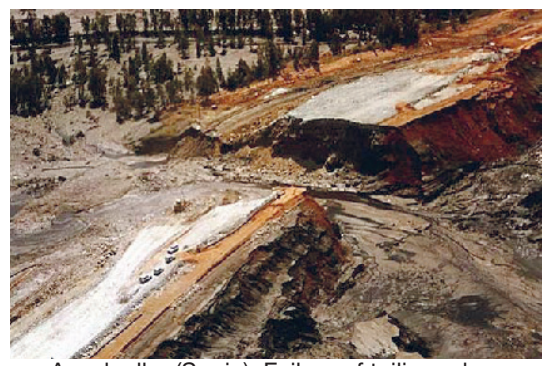

Aznalcollar (Spain). Failure of tailings dam retaining wall, 25 April, 1998.

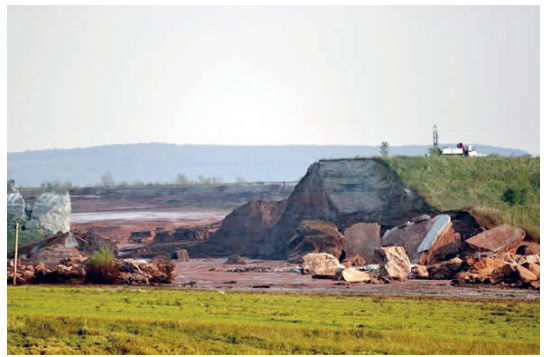

Kolontar (Hungary). Failure of the 'red mud' dam retaining wall, 12 October, 2010.

Figure 6-1. Historical overview of accidents and two photographic example (Kerekes, 2011)

Still, the answer to the popular question whether today's world is actually more dangerous than in the past is rather unclear. Have natural disasters really become more common, or is it just the damage that is caused that has increased? There is no definitive answer. As a result of a globalizing world and advanced communication infrastructure, the number of known / reported catastrophes is relatively high, but that does not necessarily mean there has been an increase in their frequency. The total number of victims of these is also not above the average of many years. 


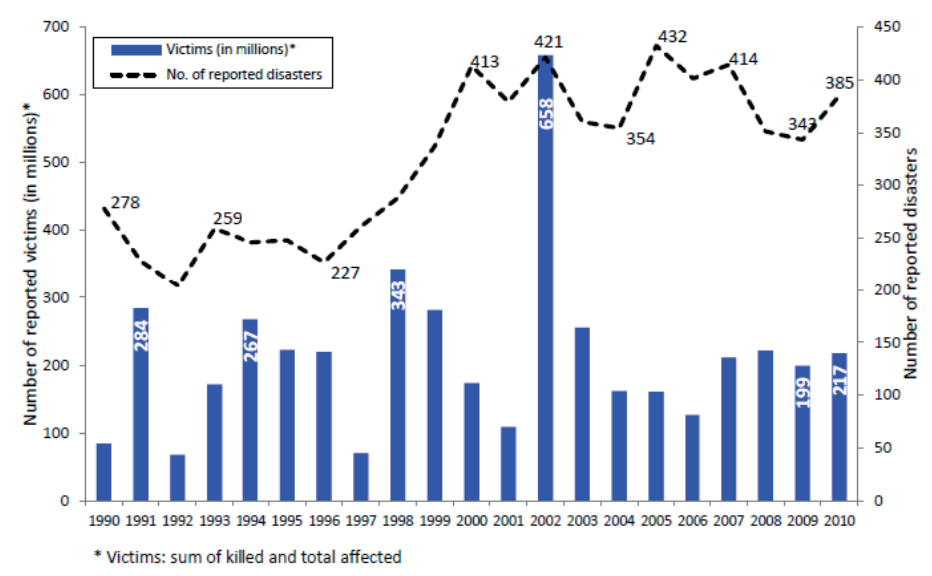

Figure 6-2. Columns show the numbers of victims in millions, while the dashed line represents the number of reported events (Guha-Sapir et al., 2011, p. 3.)

Considering per capita damage, the picture is even more confusing. The population of the Earth continues to grow exponentially, thus the denominator also grows rapidly. Yet while the number and severity of disasters fluctuates, there is no clear upward trend. This would suggest a drop in relative risk. The increase in risk, consequently, is instead caused by the rapid growth in wealth, which is also behind the increase in the value of insured damage (see Fig. 6-3).

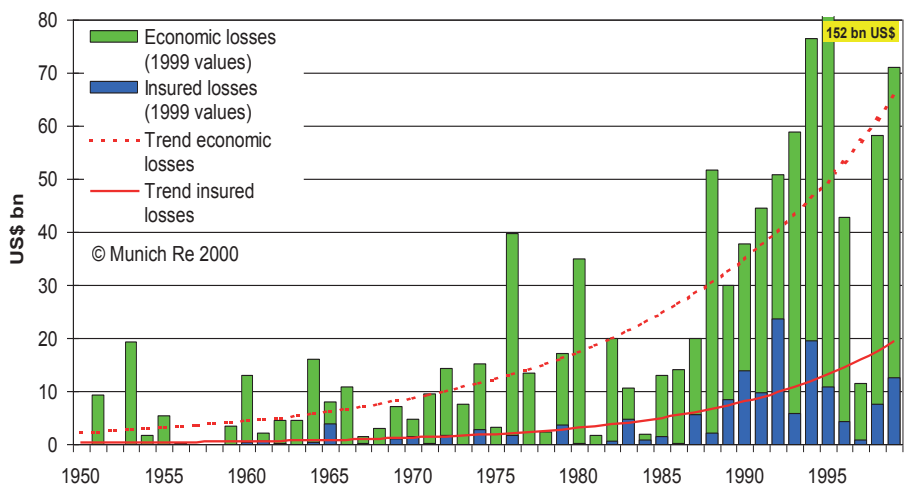

Figure 6-3. Changes in Economic Losses (green columns) and Insured Damage (blue columns), 1950 to 2000. (Hoeppe, 2000)

Even conservative professionals have no doubt that risks related to climate change have actually increased. Among other phenomena, floods are often 
associated with climate change and are apparently becoming more and more common in Europe. As evinced by the two tables below, European statistics about the frequency of and the damage caused by floods do not fully support the former assumption: although floods have indeed become more frequent, both the numbers of people affected and the amount of damage has fallen during the last ten years. The improvement indicated by these figures is, of course, a consequence of efficient flood control measures. As we can see, appropriate protection might offset or even reduce the growth in risk induced by the accumulation of wealth.

\begin{tabular}{|l|c|c|}
\hline & $1980-2009$ & $2000-2009$ \\
\hline Number of floods & 239 & 147 \\
\hline $\begin{array}{l}\text { Number of countries af- } \\
\text { fected }\end{array}$ & 22 & 511 \\
\hline Number of people killed & 1309 & 1.3 \\
\hline $\begin{array}{l}\text { Number of people affected } \\
\text { (millions) }\end{array}$ & 3.0 & 45.0 \\
\hline $\begin{array}{l}\text { Economic losses (billion } \\
\text { USD) }\end{array}$ & 92.3 & 19 \\
\hline
\end{tabular}

Table 6-3. Floods and their Impacts (total) in European Countries. (EM-DAT The OFDA/CRED International Disaster Database)

\begin{tabular}{|c|c|c|c|c|}
\hline Countries & $\begin{array}{c}\text { Number of } \\
\text { floods }\end{array}$ & $\begin{array}{c}\text { Number of } \\
\text { people killed }\end{array}$ & $\begin{array}{c}\text { Number of } \\
\text { people affected }\end{array}$ & $\begin{array}{c}\text { Economic } \\
\text { losses (billion } \\
\text { USD) }\end{array}$ \\
\hline Romania & 25 & 169 & 187,400 & 1.7 \\
\hline France & 14 & 34 & 22,500 & 1.6 \\
\hline Greece & 14 & 15 & 12,200 & 0.7 \\
\hline Italy & 13 & 72 & 20,000 & 2.1 \\
\hline UK & 12 & 26 & 379,500 & 16.6 \\
\hline Bulgaria & 11 & 52 & 13,300 & 0.5 \\
\hline Austria & 8 & 1 & 45,800 & 0.2 \\
\hline Hungary & 6 & 14 & 61,400 & 3.8 \\
\hline Czech Republic & 6 & 38 & 218,800 & 3.1 \\
\hline Germany & 6 & 29 & 331,600 & 14.1 \\
\hline
\end{tabular}

Table 6-4. European Countries most severely hit by Floods (2000-2009) (EM-DAT The OFDA/CRED International Disaster Database)

Nevertheless, the cost of protective measures is very high. Rich European countries already have appropriate flood protection systems in place, yet efforts still continue. In economically underdeveloped regions like Bangladesh floods still cause incredible devastation. The 1970 storm took more than half a million lives; the storm in 1991 killed 'only' 138,000, while the 2007 flood 
caused 1,042 deaths. Although flood control protection systems are being built in these regions too, the poor are more severely affected by natural disasters. Some storms and floods can at least be forecast in advance. There are, however, some natural disasters that cannot be predicted, and there is no suitable way of protecting against them. Earthquakes or tsunamis are some of these.

\subsection{Managing risk: the business approach}

\subsubsection{Risk assessment and its consequences}

Scientists and technologists usually pay a great deal of attention to the risk analysis of projects or technologies and these risks are usually taken into consideration during the design process. Practical experience shows that only events where both the likelihood of occurrence and the related effects are significant are considered to be risky. If both factors are nearly zero, it is usually not worth dealing with the risk. In the case of a gas leakage, see Table 6-5.:

\begin{tabular}{|c|c|c|}
\hline $\begin{array}{c}\text { If seals are made } \\
\text { conscientiously }\end{array}$ & $\begin{array}{c}\text { If any gas that leaks is not } \\
\text { dangerous }\end{array}$ & the activity is not risky \\
\hline $\begin{array}{c}\text { If seals are made } \\
\text { conscientiously }\end{array}$ & $\begin{array}{c}\text { If any gas that leaks is } \\
\text { dangerous }\end{array}$ & $\begin{array}{c}\text { the risk is small or } \\
\text { immaterial }\end{array}$ \\
\hline $\begin{array}{c}\text { If seals are not made } \\
\text { conscientiously }\end{array}$ & $\begin{array}{c}\text { If any gas that leaks is not } \\
\text { dangerous }\end{array}$ & $\begin{array}{c}\text { the risk is small or } \\
\text { immaterial }\end{array}$ \\
\hline $\begin{array}{c}\text { If seals are not made } \\
\text { conscientiously }\end{array}$ & $\begin{array}{c}\text { If any gas that leaks is } \\
\text { dangerous }\end{array}$ & $\begin{array}{c}\text { the activity is very } \\
\text { dangerous }\end{array}$ \\
\hline
\end{tabular}

Table 6-5. The risk of leaking gas (Vastag et al., 1996)

The likelihood that a gas leakage will not cause a problem depends above all on how conscientiously pipe seals are made and maintained. International statistics convince us about this fact, which is also well known by designers and manufacturers alike, because, interestingly enough, containers, pumps, valves, etc. used with hazardous substances leak a lot less frequently than those employed with less hazardous substances. This is a good example of the fact that professionals are capable of solving problems that they really want to when cost considerations are replaced by safety as the top priority.

The effectiveness of related mathematical formulae is strongly limited because there is no clear function-like relationship between the magnitude of damage and the occurrence of an event. If, for example, a reactor explodes during a night shift when only operator staff are nearby, or when shifts are changing, the consequences of the explosion will be rather different. What is more, the likelihood of occurrence and the size of damage are not totally independent. As seen from the example above, if a risk is high and damage po- 
tentially significant (e.g. a gas is very toxic), efforts will be made to reduce the frequency of occurrence, and vice versa. This is usually true at the plant/corporate level, while regarding the economy as a whole consideration of these correlations is very often neglected due to the complexity of the problem, the immaturity of decision-making mechanisms, and the underdevelopment of political-institutional systems.

Preventing risks (that is, environmental risk management) often meets with the dilemma of choosing between a more frequently occurring but less severe risk and a less frequently occurring but more severe outcome. These decisions are supported by risk analysis. As for when conducting a risk analysis is unavoidable, Figure 6-4. offers some guidance. While with high-frequency, highseverity events risk analysis is obligatory, low-frequency, low-severity events are usually considered more acceptable because society considers these a natural part of existence.

\begin{tabular}{|c|c|c|c|}
\hline \multicolumn{3}{|c|}{ Categorization of activities based on risks } \\
\hline \multirow{2}{|c|}{} & Low & Lrequency of environmental impact \\
\cline { 2 - 4 } $\begin{array}{c}\text { Consequence of } \\
\text { environmental } \\
\text { impact }\end{array}$ & severity & $\begin{array}{c}\text { Risk usually } \\
\text { acceptable }\end{array}$ & $\begin{array}{c}\text { Environmental } \\
\text { risk analysis } \\
\text { recommended }\end{array}$ \\
\cline { 2 - 4 } & High severity & $\begin{array}{c}\text { Environmental risk } \\
\text { analysis obligatory }\end{array}$ & $\begin{array}{c}\text { Project in } \\
\text { suggested form } \\
\text { not acceptable }\end{array}$ \\
\hline
\end{tabular}

Figure 6-4. Risk management efforts are a function of the frequency and severity of risk events (Vastag et al., 1996)

It is definitive not only from the perspective of company managers' existential safety but also the future development of a company whether it reacts appropriately to environmental challenges. Environment management that creates unduly strict requirements may also be dangerous. Instead of a higher level of safety, 'overprotection' may sometimes end up in negligence and a slackening of concentration. For example, fire brigades are well-organized and efficient only in cities where fires sometimes do occur. The same applies to environmental management. For a well-designed system work to work seamlessly, it must be used. When seeking to assess a companies' environmental management, the correct thing to do is simply to examine how much the management is capable of controlling the environmental risks of the company. 


\subsubsection{The appropriate environmental management strategy}

Any corporation that faces environmental management challenges must deal with three questions: (1) it needs to determine its foundational level of commitment to protecting the environment, (2) what is the appropriate level of environmental standards to which a company should adhere (and what is the prudent environmental management strategy that a company should follow); and (3) at what level of the organization should environmental issues be addressed?

Companies can make two types of errors when developing an environmental management strategy:

1. They can underestimate or overestimate the business opportunities created by growing worldwide concern for environmental protection;

2. They can underestimate or overestimate the costs and constraints created by legal and market demands for environmental management.

Both mistakes can significantly affect a company's competitiveness and profitability. If management does not recognize the business opportunities created by environmental awareness, it may overlook a growing market segment and eventually lose market share to more sensitive and agile competitors. On the other hand, overestimating environmental threats may result in unnecessarily costly expenditure, or constrain the company from undertaking otherwise profitable activities. If the business opportunities offered by the increase in demand for environmental protection are overestimated, a company may initiate projects that do not create revenue. But if a company does not spend enough to comply with regulations it may be unable to meet new or stricter requirements in the future, resulting in catastrophic costs, fines, penalties, or other legal liabilities that may threaten its competitiveness, profitability or survival. Unfortunately, companies are often led to make such errors by regulatory experts or consulting firms that try to impose common guidelines or universal standards on companies that do not all have the same characteristics and needs, or that do not operate in the same economic and social environments. The trend towards adopting international charters (see, for example, the ICC or CERES principles) or standards (see http://iisd.org , for example) that seek to impose the implementation of universal principles of sustainable development and environmental management often push corporations to adopt environmental management strategies that may be either inappropriate for their circumstances or imprudent. As Bartman (1993) points out 'no bright line standard exists for an environmental-compliance management framework.' Legal requirements often impose on companies what regulators consider to be ideal common standards. Although a sound environmental management strategy should be based on widely-accepted general prin- 
ciples, it must also be specifically designed to reflect the characteristics of the company and the external conditions that affect its operations.

\subsubsection{Endogenous and Exogenous Elements of Environmental Risk}

The primary criterion for designing an appropriate environmental management strategy is the company's ability to manage its environmental risks. A company's environmental risks can be defined as the probability of causing environmental damage and the severity of that damage. A company's environmental risk depends not only on its own activities but also on their environmental consequences, which are functions of external factors. Broad environmental consequences include not only those risks influenced by the physical environment but also those resulting from the social environment in which the company operates. Public reaction to environmental damage is often shaped not so much by facts as by the public's perception of the facts. This difference explains much of the debate that takes place between managers and engineers and the rest of the population after environmentally damaging incidents. 'Experts' and the public often perceive and evaluate the same facts differently because their knowledge of the facts, perceptions about the damage, and 'social environments' are different.

In reality, the environmental risk of an activity is always somewhat uncertain. As Wynne concluded from his studies of hazardous wastes: 'The scientific uncertainties about what happens chemically, physically, and biologically at a landfill site are huge, and the opportunities for examining and reducing them extremely limited. Thus, the effects of putting a given waste into a site can only be approximately known; these effects are not in any case determinate, but depend (inter alia) upon how the site is operated and managed. At which site a waste ends up, and in what condition, also depends upon many social unknowns and contingencies.' (Wynne, 1993)

A similar level of uncertainty attends the environmental consequences of other impacts of company activities, and attempting to predict either the real impacts or the public reactions to them is often impossible for managers. However, in practice, due diligence and responsible care may be sufficient strategies for most companies; scientific exactness is not required.

Based on these assumptions, we propose that a company's environmental risks can be analysed in two dimensions, although we are fully aware of the multidimensional nature of the problem. One dimension - endogenous environmental risks - involves the internal operations of the company, including the materials, technologies, and human resources used in the manufacturing process. The other dimension - exogenous environmental risks - are determined by the company's 'external world': its location, the ecological characteristics (biodiversity, winds, etc.) of the physical environment in which it operates, the demographics (population density, age, and income distribution, etc.), infrastructure (roads, tel- 
ecommunication networks, etc.), educational levels of the population, and their attitudes toward environmental hazards. Political institutions play an especially important role in exogenous environmental risks. As Wynne (1993) points out from an analysis of the hazardous waste practices of the United States and the United Kingdom, the impact of regulatory agencies in environmental risk is a function of political culture. In the United States, the response of regulators to the uncertainty about what happens to waste in landfills is accentuated by the fact that opponents expose and publicize these uncertainties, implying that any uncertainty is equivalent to a lack of safety and thus calls for a ban on the waste. The American social environment is conflictual, mistrustful and adversarial. In contrast, the political culture in the United Kingdom is such that 'the official attitude towards the same scientific uncertainties has been far more relaxed. The response has been that if things are uncertain they could therefore turn out to be better - there is no reason to assume the worst. ... If the risks depend upon sound operation and diligent waste handling, optimistic assumptions may be made unless strong evidence to the contrary exists.'

It is not always easy to decide if a company's suppliers and customers are part of the set of internal or external risks. We may claim that suppliers are selected by a company and therefore the latter should be responsible for any potential damage caused by their transactions with the company. The situation is different for customers, because a company has far less influence on them. But if customers use a company's products (e.g., fertilizers) improperly, this may cause significant pollution and destroy the company's environmental image.

Both endogenous and exogenous dimensions of environmental risk are complex, but they differ in terms of their implications. The first dimension - environmental risks created by the internal operations of a company - is more clearly under the control of management and regulatory authorities. The second dimension - environmental risks created by externalities - are usually beyond the influence or control of either the company or regulators. As a result, environmentalists and managers debate whether multinational companies should comply with the requirements of the host country in which they operate, or the home country in which they have their headquarters. One issue that became critical after the Bhopal accident, for example, was 'whether the Union Carbide affiliate was operating with equivalent procedures, safeguards, and equipment to those at comparable facility in the United States.' (Morelli, 1999) But even if Union Carbide had implemented American standards in India, these would have been inadequate because of the lower-level education of employees, less-developed infrastructure, and the increased exogenous environmental risks of a chemical company operating in this region of India. To lessen the environmental risks of the Bhopal plant, Union Carbide would have had to adopt a more stringent and constraining environmental management strategy than at its American plants to compensate for the differences in infrastructure and levels of education in India. 
The level of education and training of people who live around a plant are at least as important as the internal operations of the company in determining environmental risk. The Bhopal accident and the Chernobyl incident would have caused much less damage if the neighbouring population had been more concerned about environmental hazards and better trained in emergency procedures.

The importance of considering both endogenous and exogenous factors in determining a company's potential environmental risk can be further illustrated using an example from Hungary. In Hungary, many chemical companies that had originally been located well outside cities were later surrounded following the development of urban centres into suburbs and rural hinterlands. At the beginning, even heavily polluting companies did not cause a problem because they were relatively far from cities. Today, even those companies that meet all environmental regulations but which are now surrounded by cities may have environmental conflicts and problems. The 1993 explosion at a Budapest chemical plant - although the damage from the explosion did not extend beyond the fence - produced significant conflict among city officials and the public. Many people in Budapest demanded that the plant be closed, whereas forty years earlier people living in Budapest would not even have noticed that something had happened on the grounds of the plant.

\subsubsection{Environmental Management as a Function of Environmental Risk}

Based on endogenous and exogenous risks, alternative environmental management strategies can be categorized into four groups, as shown in Figure 6-5.

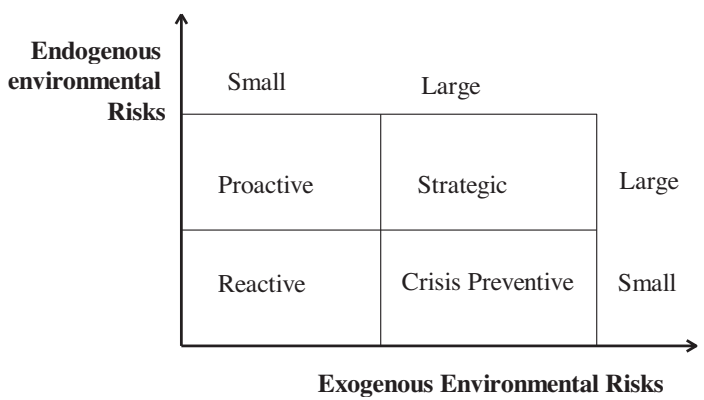

Figure 6-5. Exogenous and endogenous environmental risks (Vastag et al., 1996)

The endogenous environmental risks along the vertical axis and exogenous environmental risks along the horizontal access are, for the purposes of illustration, divided into small and large. The cells describe four environmental management approaches with these combinations of large and small exogenous and endogenous risks. 
1. Reactive Environmental Management (Group A): Group A consists of those companies, for example, that emit low levels of pollution and these pollutants are not environmentally dangerous, or the number of people that they affect is small. In this group, companies may use non-exhaustible resources as raw materials, production is not energy-intensive, and their activities do not involve the transportation of massive volumes of hazardous materials. Mass production industries such as textiles that use welldeveloped technologies, precision industries, and some food industries could appropriately adopt a reactive environmental management strategy. At these companies, environmental management calls merely for complying with environmental regulations without the need to take extraordinary precautions to prevent highly unlikely environmental damages. This approach does not have a significant influence on the company's operations, and responsibility for monitoring compliance can be carried out at the middle-management level by an environment and safety officer.

2. Proactive Environmental Management (Group B). Group B consists of those companies that have high levels of pollution or that produce pollutants that are environmentally dangerous. However, because of their location or good environmental infrastructure the adverse ecological and health consequences of these pollutants are small. At these companies the environmental function is more significant than in Group A; managers have to anticipate future changes in environmental regulations, technology and public opinion. The environmental management of these companies is often highly decentralized to the plants where the critical technologies are concentrated.

3. Strategic Environmental Management (Group C). This group consists of companies that are highly polluting and that operate in a social or physical context in which risks are further increased by the external infrastructure or public attitudes toward environmental hazards. At these companies, environmental management must be an important part of the company's wider business strategy and should be dealt with at the senior management level. These companies must often go beyond compliance with environmental regulations and employ more aggressive safeguards to prevent or reduce environmental damage. Their environmental management strategy should be well-defined, highly visible in company publications, and monitored carefully to protect managers against legal action.

4. Crisis Preventive Environmental Management (Group D). In this group, companies are not high-level polluters either because they do not use large volumes of inputs, or associated pollution happens indirectly (e.g., tourism, fast food chains) and their direct effect is not significant. Whatever pollution does occur, 
however, may be visible and affect large numbers of people or a wide territory. Examples include electrical energy plants that use clean energy sources, nuclear plants, and hydroelectric stations (except for flat-land based ones). The related environmental management strategy can be best characterized as crisis preventive, where public education campaigns are combined with elaborate technical precautions that assure the public that pollution is not worsening, and nor do they misperceive the dangers of the low-level pollution that is occurring.

\subsubsection{Comparing Reactive and Strategic Environmental Management}

The reactive and strategic environmental management approaches represent two extremes where external and internal environmental risks are balanced. In the former, there is no pressure to do anything beyond comply with routine regulations; in the latter, the company is under enormous pressure to go beyond compliance. In the other two approaches (proactive, and crisis preventive) the situation is unbalanced: either the perceived environmental damage or opportunities are overestimated or they are underestimated. In these cases, it may not be necessary or profitable to move from proactive or crisis preventive approaches to a strategic management approach. Through control of technology and public opinion monitoring, moving toward reactive management may be another option. The difference in costs and requirements between the reactive and strategic environmental management approaches are enormous, as illustrated in Table 6-6.

\begin{tabular}{|c|c|c|}
\hline Reactive & Activity & Strategic \\
\hline $\begin{array}{c}\text { Mid-level management } \\
\text { involvement, environmental } \\
\text { committee less critical. }\end{array}$ & management seniority level & $\begin{array}{c}\text { Senior management leadership, } \\
\text { environmental committee in key } \\
\text { position. }\end{array}$ \\
\hline There is time to fix problems. & $\begin{array}{c}\text { environmental management } \\
\text { reporting level }\end{array}$ & $\begin{array}{c}\text { Very high (Chairman or CEO } \\
\text { level). }\end{array}$ \\
\hline environmental management & cost control & $\begin{array}{c}\text { Serious and immediate } \\
\text { intervention is required. }\end{array}$ \\
\hline $\begin{array}{c}\text { Special training for experts and } \\
\text { for middle management }\end{array}$ & $\begin{array}{c}\text { Risk reduction is the critical } \\
\text { issue, cost does not matter. }\end{array}$ \\
\hline Emission reduction. & $\begin{array}{c}\text { Corporation-wide, specific } \\
\text { training for senior and middle } \\
\text { management. }\end{array}$ \\
\hline Monitoring and control. & main activity of environmental \\
management & regulatory focus & $\begin{array}{c}\text { Outstanding environmental } \\
\text { performance. }\end{array}$ \\
\hline Compliance with regulation. & Innovation and communication. \\
\hline $\begin{array}{c}\text { Use of (slightly) less than } \\
\text { state-of-the-art technologies is } \\
\text { acceptable. }\end{array}$ & $\begin{array}{c}\text { To be the industry standard. } \\
\text { innovation in pollution } \\
\text { prevention }\end{array}$ & $\begin{array}{c}\text { Technological innovation to } \\
\text { state-of-the-art level is critical } \\
\text { for staying in business; it is part } \\
\text { of competitiveness. }\end{array}$ \\
\hline
\end{tabular}

Table 6-6. Comparison of reactive and strategic environmental management (Vastag et al., 1996) 
A reactive environmental management approach does not mean that companies pay no attention to opportunities for emission reduction, waste management, or more stringent water treatment practices. But because these are not central to the operations of the company, they can be dealt with by middle managers or experts rather than by senior management. Problems normally do not require immediate intervention because their non-crisis nature leaves time to fix them. Not every employee will automatically be given environmental education and training; it may be enough to have activities monitored by company experts. Reducing pollution through monitoring equipment or 'end of pipe' filters is the primary goal of these companies. Demand for environmental investment comes from stricter regulations and norms, and these regulations and norms are the main forces driving these companies to make environmental improvements.

At those companies where environmental performance is a crucial element of business activities, environmental management has to be part of the company's overall business strategy, and is formulated and implemented by top management. A high-level environmental committee that includes outside experts should play an important role in environment-related decisions. The objectives of environmental management are derived from the company's longterm strategy and not from current environmental regulations. All employees should be educated about environmental hazards and environmental investments should include state-of-art technology and intensive attempts to reduce waste and pollution in the manufacturing process rather than relying on endof-pipe solutions.

\subsubsection{Lessons learned from a combined natural and industrial disaster}

The red mud spill in Hungary was a special combination of an industrial and a natural disaster. This is one of the reasons it is difficult to pinpoint who was responsible for the event. Natural disasters tend to raise questions about responsibility that are different from those of 'purely' industrial catastrophes. Interestingly, however, nature often plays an important role in industrial disasters. Extreme weather played a role in both the Exxon Valdez incident and the accident in the Gulf of Mexico. The role of exceptional weather conditions - rainfall amounting to ten times the average and a severe windstorm - was also mentioned in connection with the accident in Hungary. Yet is it also true that extreme rain and wind (extraordinary natural phenomena) can absolve corporate managers from their responsibilities, or limit the extent thereof? How should the important principles of environmental protection such as the 'principle of due diligence' or the 'precautionary principle,' be interpreted in the context of industrial disasters or activities associated with significant ecological risk? 
A Harvard case study treated the Exxon Valdez incident as a human resource issue. According to the study written by the world's leading business school the problem was that the tanker's captain was an alcoholic. Leaving the crew and the cargo to be transported by an alcoholic was no doubt an HR mistake.

It is surprising, however, that the case study did not mention the continuous environmental catastrophe that many huge oil tankers were causing at the time. These boats regularly pumped seawater into their tanks on the way back from port as ballast, and then pumped the oil-contaminated water back into the sea near the oil rigs. No one called to account the owners of such boats for this 'slow catastrophe'. Also, the case study never mentioned that the size of the tankers represented an unjustifiable magnitude of risk. Those enormous tankers were only built to economize on oil transportation costs. Accordingly, fuel was slightly cheaper in the US, while corporations' profits grew larger. Whether the saving of a few cents per litre is worth the increased risk of a potential environmental disaster has, 'naturally enough', never been investigated.

Morelli (1999) argues that business and industry are preparing for a dramatic shift in responsibility. Recent decades have shown that trust has become a fundamental issue for both governments and economic actors. According to Eurobarometer surveys, politicians and corporate managers are no longer trusted by European citizens, and neither are scientists. One could make the rather cynical argument that the public does not greatly trust NGOs either, even although it is members of the public who establish them.

It was apparently due to this mistrust that, besides Hungarian green organizations, two international NGOs - Greenpeace and Robin des Bois from France - also decided to create an on-the-ground presence at the site of the red mud catastrophe.

Based on the work of respectable scientists and a number of studies, a significant number of Hungarian institutions concluded that neither drinking water sources nor the soil were endangered by the material that had been spilt; nevertheless, the two NGOs flooded the media with statements claiming quite the opposite.

'Robin des Bois cannot really give credence to the statements of those Hungarian professors and scientists who claim that there is no risk of radioactivity, nor of heavy metal migration into the deep soil layers' (Nithart-Bossard, 2010). This is despite the fact that they only sent two experts to the affected area, who reported that 'The area flooded by the red mud spill in Hungary directly affects the lives of some 8,500 inhabitants. Only to mention a couple of examples: approximately 70 tons of arsenic, $70 t$ lead, $130 \mathrm{t}$ nickel, $650 \mathrm{t}$ chromium, $700 \mathrm{t}$ vanadium, $1600 \mathrm{t}$ sulphur and 114000 tons of aluminium were released into nature. Arsenic, nickel and chromium 6 have carcinogenic effects' (Nithart-Bossard, 2010).

And: 'On 4 October 2010, at 1:30pm, the western wall of one of a chain of red mud reservoirs operated by Magyar Alumínium ZRt - MAL collapsed, 
freeing about 600 to 1,000 thousand cubic meters of red mud, a waste product of the bauxite refining process' (http://greenprofit.hu/forum/viewtopic. php? $=34 \& p=28048$ ).

I have not actually checked whether these numbers are correct, but they do sound rather frightening. What I do know, however, is that those elements were not added to the mud during processing, but they were there originally, and their concentration could have at most doubled, and even then only if the bauxite had been of very good quality (in this case, sodium hydroxide would have dissolved at most half of the bauxite ore - only the aluminium oxide thereby increasing the concentration of various other elements in the remaining mud). Of course, nor does this mean that those elements would have been 'free', as they are present in the mud in the form of insoluble compounds.

A long citation such as the following one may not be exactly appropriate here, yet in this very case it might be worth knowing what the 'official' statement (albeit not really read by anyone outside Hungary) about the accident says:

'Based on the independent examinations of the National Institute of Environmental Health and the experts of HAS, there are no significant amounts of metal contaminants in the red sludge and the concentrations of toxic metals do not exceed the standard limits in the soil, but the $\mathrm{pH}$ measured from an aqueous extract of the industrial waste is 11.8 , which indicates a strong base. According to the analysis of the samples taken by the Institute of Materials and Environmental Chemistry of the Hungarian Academy of Sciences on October 5 th, the red sludge contained cadmium, chrome, mercury, nickel, lead and zinc in concentrations smaller (in some cases considerably smaller) than the values allowed for waste mud. The arsenic content of the samples taken from the area of Kolontár and analysed by the Institute of Materials and Environmental Chemistry was also less than the values allowed. The laboratory analysis of the soil samples taken on October 8, 2010 conducted by HAS' Research Institute for Soil Science and Agricultural Chemistry has shown that heavy metals from the red sludge did not reach deeper than 10 centimetres into the soil, and even there their level did not exceed the values permitted for contaminants. Based on these results, it is safe to conclude that the deeper layers of the soil and the first water-table are not in immediate danger.

Based on laboratory analyses, the Office of the Chief Medical Officer has issued a statement to the effect that the red sludge waste matter is dangerous to human health, living organisms, and the environment because of its highly basic effect.

Experts of the National Service for Radiation Health Emergency Preparedness examined the radiation levels of the affected area, mainly in Kolontár and Devecser. The spilled red sludge is not radioactive. The so-called activity-concentration of the samples gathered is close to natural values of soil, so it is safe to say that they do not pose health risks. According to the official statement 
of the National Service for Radiation Health Emergency Preparedness, the red sludge does not pose any health risk for those living in the area as far as radioactivity is concerned.

After the analysis of the samples taken according to strict regulations, The University of Pannonia and the National Public Health and Medical Officer Service announced that the amount of airborne dust in the affected areas has not exceeded the levels allowed since October 17, and the level of air pollution has decreased in every settlement examined. In order to continuously monitor the level of airborne dust in the affected areas, the National Service for Public Health and the Middle-Danube-Valley Inspectorate for Environmental Protection, Nature Conservation and Water Management have been operating an integrated monitoring system since October 11.

There is on-going quality control of drinking water in the area stricken by the disaster. Water can be safely consumed over the whole area. The Middle Transdanubian Regional Institute of the National Public Health and Medical Officer Service has conducted more than 120 examinations so far to monitor the quality of water, and all results are negative.' (http://mta.hu/mta_hirei/ osszefoglalo-a-vorosiszap-katasztrofa-elharitasarol-a-karmentesitesrol-es-ahosszu-tavu-teendokrol-125859/)

The debate, of course, is still ongoing. Interestingly, society has begun to pay more attention to the role of authorities and other political concerns, while limiting the responsibility of the company that operates the reservoirs to the issue of material compensation, just as good taxpayers do. The 'big' questions turn out to be who issued the permits, and who supervised the operation of the reservoirs? In this case, the question of responsibility is a multi-faceted one. Concerning the responsibility of the local notary or the mayor, one might ask why there were people living near the dam and how and why permits had been issued, or, if these individuals did not have the necessary permits, why was it not ensured that they were prohibited from actually living there? It is hard to imagine, however, how a local notary could be responsible for the building permits for the reservoir itself. Having some knowledge about how environmental authorities operate, we know that they also do not have the necessary expertise. The Office of the Parliamentary Commissioner for Future Generations suggested that the Hungarian Office for Mining and Geology might be the competent authority. Although we know this now, it was not very clear until now. Had we known of the competent authority, could we have avoided the disaster? Probably not. Satellite measurements might in theory have been used to detect whether soil was moving, and how fast. If it was actually moving, this could have indicated the likely failure of the dam. Then who should have conducted such examinations: the authorities, or the company that operates the reservoir? Probably both of them, but the 'principle of due diligence' would rather 
assign that responsibility to the operating party, especially as the authorities, following the 'precautionary principle,' can hardly be expected to know about all the potential risks, technologies, and sources of human error. The company has the necessary means for dealing with these issues, and they, too, receive the profit, not (or just very indirectly) the employees of the authority.

Risk theory distinguishes between fair and unfair risks. A risk is considered fair if the accidental and material damage of the hazardous activity is borne by the same 'person' who enjoys its benefits. This is, of course, merely a rational (or maybe even emotional) way of reasoning. It is almost certain that legislation could never deal in practice with such concepts. International experience and practice, which may serve as a starting point for solutions, does, nevertheless, exist in this field.

\subsubsection{Industrial disasters, and how they are treated}

Recently, the number of cases where managers have been subjected to criminal trial because of their companies' environmentally harmful activities has grown, primarily in Canada and the US. This is theoretically possible according to Hungarian legislation as well. Managers usually react defensively to actual legal practice. First, professional responses tend to emphasize the need for adjustments in legal practice, and the provision of increased personal protection for managers.

Corporate managers apparently consider complex, bureaucratic, and overdocumented environmental management systems (typically developed by external consultants) to be the best method of defence in civil law proceedings, although it is quite obvious from American examples that such an approach is not a sure-fire method of self-protection.

The environmental risk of any activity is inherently uncertain, even theoretically. Wynne makes a convincing point about this with respect to hazardous waste materials, 'Scientific uncertainty is rather high about what is going on inside a waste dump site in chemical, physical and biological terms, while opportunities for examining and reducing this uncertainty are very limited. Therefore we can only make approximations about the impact a dumpsite has on the surrounding area, as the effects are always dependent on how the dumpsite is operated. The conditions under which waste is transferred to a dumpsite and which site it is transferred to is also a function of a number of unknown social factors' (Wynne).

Considering Wynne's thoughts, one might conclude that corporate managers are asked to practice the 'art of the impossible' concerning environmental management. Yet we should not forget that the lack of a theoretical solution does not necessarily imply that there is no practical solution. Concerning the avoidance of environmental risks, scientific accuracy is not a requirement but, 
on the contrary, responsible conduct is (usually defined as 'due diligence' in legal terms) (Bartman, 1993).

For practical purposes, the environmental risks of any business activity can be analysed along two dimensions. One of them, in our opinion, is a function of the materials, technologies, and human resources that are used, since these are the factors that determine the company's inputs and outputs, and also the frequency and the nature of breakdowns. This dimension contains everything that depends on the company's internal systems.

The other dimension is the company's perception of the ever-changing external world. We consider this dimension to include the company's geographical location, the ecological characteristics of the surroundings, biodiversity and prevailing winds, in addition to demographics (population density, age, and income distribution), and other characteristics such as the existing infrastructure (roads, telecommunication networks, and the presence of hazard intervention systems), the population's educational level, environmental attitudes, employment levels, and political institutions.

Obviously, both dimensions are rather complex, but making a distinction is important as both corporate managers and regulators tend to devote serious attention to the first dimension (environmental risks pertaining to the company's internal matters), while the effects on risk of all the external factors are inclined to be forgotten by both directors and authorities. Typically, it is only after a major catastrophe that they realize the existence of these phenomena. Informing local citizens and preparing them for damage containment is at least as important to the future of a company as reducing the probability of occurrence. In the case of a potential accident, it is critical whether local inhabitants and disaster response organizations are prepared to reduce the adverse consequences of any accidents. Both the Bhopal and the Chernobyl disasters, and even the recent red mud catastrophe in Hungary, would have claimed far fewer lives if the authorities and inhabitants had been prepared for their possible occurrence.

We believe that companies should not limit their theoretical and practical environmental risk prevention efforts to their own premises, but should also take into account a constantly changing natural and social environment. Corporate environmental management must thus not be limited to within the company's own four walls.

What we can learn from the red mud accident in Hungary and from Bhopal and the other above-mentioned cases is that corporations are very often prepared for accidents, but even more often they are insured against them. Managers are ready to make any effort which reduces their personal responsibility. They often employ external experts, and preferably very highly respected ones; they are ready to pay for expensive insurance, and they are ready to cooperate with different authorities. However, all this effort does not protect them 
fully against accidents. Every company has to meet the strictest environmental and risk regulation standards, should have a good record of environmental performance, and should maintain good communications with people who live in the surrounding area. But they must also understand that good communication and environmental management systems, experts and advisers (and even the 'operating licenses' issued by different legal authorities) cannot neutralise their moral responsibility for society and for local communities. Those who directly benefit (profit) from an operation are and should be the real experts, so they should take full responsibility for them, even in the case of natural disaster or terrorist action directed against them. The moral responsibility of corporate leaders cannot be shared with external actors. 

III. WELFARE 



\section{The welfare effects of environmental regulation and environmental protection services}

\subsection{Introduction}

It is the responsibility of the state to ensure the good ecological status of certain reproducible goods such as clean water and surface waters, and to ensure that waste is properly managed. Unfortunately, we have to pay for all of these services. Members of society choose from the available options depending on financial circumstances, their value system, and on the political environment. But someone has to pay the bill. There is no doubt that we want to use the best sewage treatment technology, obtain the best quality drinking water, and operate state-of-the-art waste treatment processes. It is better to heat with gas than wood, but we cannot afford the best of everything. Infrastructural investment can lead to growth in prosperity, but can also reduce the wellbeing of society. Due to high public utility fees, some members of society are not able to pay their bills. Those who are free riders not only cause problems for public service providers but also generate social distain for themselves. Sometimes an environmentally 'weaker' public service better supports social sustainability than a strong one.

\subsection{The unfavourable consequences of the polluter pays principle}

At the time of their accession, new CEE entrants to the European Union, including Hungary, had substantial deficits in terms of environmental protection, primarily as regards the level of infrastructural development. They were lagging behind particularly in terms of sewage systems, wastewater treatment plants, and the conditions for waste disposal. On the other hand, they had a major advantage in terms of the level of conservation of nature and seminatural habitats. In acknowledgement of this lag, the European Union has been making efforts to make up for the disadvantages, especially through cohesion policy.

The EU's cohesion policy, which was specifically designed to eliminate regional differences in welfare, in fact increased welfare inequalities in the short term. The construction of motorways, sewage systems, wastewater treatment plants, modern landfills and natural gas pipes was financed from EU funds, and these investments were completed within a relatively short time. However, following the polluter pays principle, the maintenance and operational expenses of the new 'utilities' are borne directly by residents. 
Polluter Pays Principle, PPP: one of the most important economic directives of environment policy. When applied, the polluter shall cover any costs incurring from the prevention and the reduction as well as the regulation of pollution. The term was introduced by the OECD in a Council Recommendation in 1972. In 1974, the OECD ratified a new recommendation for the concrete application of PPP, saying that governments should not support polluters by bearing the costs relating to pollution reduction and regulation. This application was extended by the OECD to cover extraordinary pollution events in 1989. The principle was integrated into the Single European Act in 1987. In 1992, the PPP, as one of the most important environment-political principles, was incorporated into the Maastricht Treaty that focuses on integrating the countries of the EU. (Láng, 2011)

Some problems are caused because village populations are ageing, small villages are gradually becoming depopulated, and the related municipalities are experiencing an overall decline in economic activity, while the costs associated with environmental protection are rising due to infrastructural development. In the regions that have been the beneficiaries of cohesion policy, the incomes of the population have not increased, at least not in the short term. Infrastructural investments have been completed which are suitable for treating waste and wastewater in compliance with EU standards, but the utilisation of their capacities falls short of targets, which makes their specific maintenance costs unreasonably high, while their operation causes a major loss of welfare, especially for the residents of smaller municipalities. Paradoxically, developments in the field of environmental protection are also accelerating the depopulation of smaller municipalities.

\subsection{Excessive self-criticism, inaccurate situation assessment, wrong assumptions in Hungary}

The first environmental policy analyses produced after the change of regime showed a much grimmer picture of Hungary's environmental conditions than would have been warranted by the facts. For example, the country report produced for the 1992 Rio Conference gave an account of near-disastrous pollution, and not only in relation to abandoned Soviet barracks. The statistics that were cited seemingly demonstrated many problems, but only seemingly. One of the most striking errors in the report was its 'account' of Hungarian fertiliser overuse. The report highlighted nitrogen fertiliser use per hectare in 1987, and drew general conclusions from that piece of information. In Hungary, in 1987, nitrogen fertiliser use in agriculture indeed exceeded $400 \mathrm{~kg}$ per hectare, but that value was accurate for only one or two years, and was not characteristic of the decades either before or after those years. The high value for 1987 was attributable 
to the relatively low cost of Soviet natural gas at the time (a major component of nitrogen fertilisers). The authors of the reports made attempts to objectively describe indicators for sewerage supply, wastewater treatment capacities and landfills, but failed to address issues such as the effects of population decline and the migration of villagers to towns and cities. Paradoxically, the statistics were unsuitable for even showing ageing in the villages, mostly because aggregate statistics are significantly distorted by the Hungarian Roma population. This population is characterised by a relatively high number of children, and a relatively low proportion of people aged over 70. The aggregate statistics fail to show the real demographic situation because the Roma population is distributed unevenly. They are relatively concentrated in Szabolcs, Borsod-Abaúj-Zemplén and Baranya counties, while their proportion is insignificant in other countries. For example, Table 7-1. appears to show that in villages the proportion of young people (under 20 years of age) is higher $(21.9 \%)$ than the national average $(20.5 \%)$, and that the proportion of the elderly (above 60 years of age), at $22.9 \%$, is lower than the national average (23.4\%). This is obviously not the case. In fact, villages are ageing and are becoming depopulated, and where they are not, in villages inhabited by the Roma there is no effective demand for utility services.

\begin{tabular}{|c|c|c|c|c|}
\hline Age group & Population & Proportion & Combined age group & $\%$ \\
\hline \multicolumn{5}{|c|}{ Village population by age group } \\
\hline-14 & 483,338 & 0.1593 & $\begin{array}{c}\text { Population under } 20 \\
\text { years of age }\end{array}$ & 21.9 \\
\hline $15-19$ & 183,737 & 0.0605 & & \\
\hline $20-29$ & 353,193 & 0.1164 & Population aged $20-39$ & 26.2 \\
\hline $30-39$ & 443,785 & 0.1462 & & \\
\hline $40-49$ & 417,543 & 0.1376 & Population aged $40-59$ & 28.7 \\
\hline $50-59$ & 455,266 & 0.1500 & & \\
\hline $60-69$ & 344,957 & 0.1137 & $\begin{array}{c}\text { Population aged over } \\
60\end{array}$ & 22.9 \\
\hline $70-$ & 351,951 & 0.1160 & & \\
\hline Total & $3,033,770$ & 1 & & \\
\hline \multicolumn{5}{|c|}{ Total Hungarian population by age group } \\
\hline-14 & $1,447,659$ & 0.1456 & $\begin{array}{c}\text { Population under } 20 \\
\text { years of age }\end{array}$ & 20.5 \\
\hline $15-19$ & 593,534 & 0.0597 & & \\
\hline $20-29$ & $1,229,536$ & 0.1237 & Population aged 20-39 & 26.2 \\
\hline $30-39$ & $1,580,913$ & 0.1590 & & \\
\hline $40-49$ & $1,316,193$ & 0.1324 & Population aged 40-59 & 27.7 \\
\hline $50-59$ & $1,438,682$ & 0.1447 & & \\
\hline $60-69$ & $1,176,962$ & 0.1184 & $\begin{array}{c}\text { Population aged over } \\
60\end{array}$ & 23.4 \\
\hline $70-$ & $1,154,149$ & 0.1161 & & \\
\hline
\end{tabular}

Table 7-1. Village population by age group Source:

http://www.ksh.hu/nepszamlalas/tablak_demografia, accessed on 02/11/2015 
No analyses have been carried out, for example, to examine how consumption has been influenced by increasing water and gas tariffs, and by the increase in the efficiency of heating and water supply systems. Development goals derived from such identified trends ultimately led to the generation of excess and oversized capacities in nearly every field. The nearly $50 \%$ fall in the use of water shown in the statistics is rather spectacular, but it also led to a severe decrease in the efficiency of water supply and wastewater treatment. Figure 7-1. provides a good illustration of the radical fall in water consumption as a result of the increase in water tariffs between 1990 and 2013.

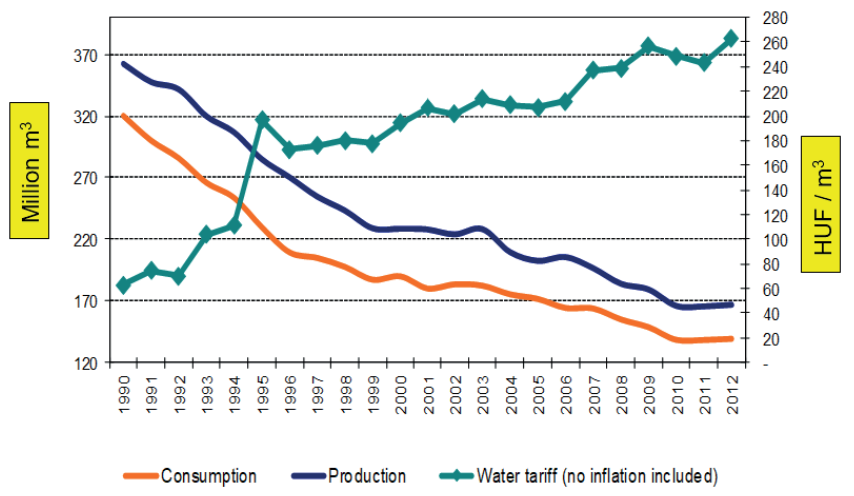

Figure 7-1. Changes in Hungarian water tariffs and water consumption, 1990-2012 (https://www.ksh.hu/docs/hun/xftp/stattukor/telepinfra/telepinfra13.pdf)

The tendency for sewerage and water tariffs to increase is also causing another problem of equal significance. Currently, certain wastewater treatment plants have extremely low capacity utilisation, and in some cases municipalities are unable to supply the quantity of sewage required for the operation of their activated sludge plants. The investment and operating costs of treatment plants are substantial, and the expected underutilisation of the intended networks will cause major losses on a countrywide scale. Statistics are unable to show the extent of the increase in the performance of local supply systems while the performance of piped supply has dropped by $40 \%$, despite major developments. In some supply arrangements, water is abstracted from local wells, but sewage is discharged into sewers. Despite the environmental benefits of such solutions, they add to the costs of the provider, putting upward pressure on utility tariffs. Such inaccurate 'forecasts' led to an unnecessary increase both in the specific costs of services and the utility tariffs charged to consumers. In summary, the foregoing situation suggests the conclusion that the documents underlying environmental policy simply ignored the likely welfare effects of proposed measures. 


\subsection{Socio-economic problems concerning the establishment and operation of environmental protection infrastructure}

According to analyses carried out in Hungary, with regard to with the environmental criteria concerning EU accession the greatest expense arises in connection with dealing with the problem of wastewater and, more specifically, with bridging the utility gap. This is the field in which the most detailed, and in technological terms, the soundest inventory was taken of tasks to be performed, yet most professional debates were sparked by plans relating to wastewater drainage and treatment. Since environmental protection policy makers are not demographers, they seek to bridge the utility gap even in cases where this is not necessarily justified on environmental grounds, including in municipalities facing complete depopulation.

Norms are standardised by EU directives at the European level, and by national regulations at the level of member states, generally without allowing for regulation based on municipality size. Although the Wastewater Directive only requires drainage for municipalities above a population equivalent to 2,000, it makes no distinction as regards permitted pollutant concentrations in the wastewater that is discharged. In the EU, the preference for a sewerage supply for municipalities with a population of below 2,000 was not due to an assessment of pro-rated costs and benefits, but to the fact that, as a result of their lower volume of pollution, the environmental pressure caused by smaller municipalities does not compromise catchment areas, or only to a limited extent. The EU directive on urban wastewater treatment (91/271/EEC) does not require nutrient removal in settlements with populations equivalent to or less than 10,000 individuals. Hungarian regulations are considerably tighter, because in Decree 28/2004. (XII. 25.) of the Ministry of Environment and Water on limit values of discharges of water polluting substances and their rules of application, the limits for 'sensitive' catchment areas as provided for in the EU directive were transposed as technological limits. The requirement in the EU directive that drainage must be in place by 2005 in all municipalities with a population of at least 2,000 provided a strong incentive and grounds for lobbying interest groups, intensifying such existing (partly negative) tendencies.

Due to the specific characteristic of Hungarian territorial administration that, with a view to the acquisition of city status and other reasons, smaller municipalities were merged or annexed to larger ones, there was a significant increase in the number of municipalities whose populations were under the limit provided for in the Directive. It would have been essential to make an adjustment whereby a distinction could be made between the boundaries of municipalities in terms of both physical geography and administration. The applicable EU regulations include the elements of both the level of sewerage supply depending on the categories of municipalities, and environmental 
sensitivity. The initial Hungarian concept was developed in this spirit: by 2010 , different levels of sewerage supply had been targeted according to the various categories of municipality, and $68 \%$ nationally. However, with the onset of 'sewerage fever', these targets were forgotten, and every municipality and mayor sought to achieve the highest possible level of sewerage supply, regardless of municipality size and the sensitivity of the local environment.

According to the Hungarian territorial classification, for receiving waters in sensitive areas, wastewater treatment is mandated without regard to the size of the discharging entity, and therefore typically to an extent far exceeding EU requirements (Kovács, 2011).

Since sewer construction and access to the required funds are a 'bargain' for major interest groups, facilities were also constructed in locations where this was not justified by environmental factors (soil conditions and sensitivity), or where the situation could have been improved through modifications of inappropriate and irregular individual drainage practices, and the enforcement of the applicable rules.

\subsection{The decline of utilities and villages}

In smaller municipalities, not only are there problems with raising the funds required for infrastructural investment, but the support of residents is also lacking for the implementation of environmental protection initiatives. According to Pickvance (2002), Hungarian public administration is fragmented; the average municipality size (3,290 residents) is the second smallest in Europe, which is one of the causes of constrained municipal resources. Low levels of revenue prevent local governments from employing a sufficient number of adequately qualified professionals. With an ageing population sustaining itself on pensions and allowances, significantly higher environmental costs will have to be paid by people who fail to 'perceive' the improvement in the quality of their environment.

While bridging the utility gap has clear environmental benefits, its welfare effects on the population are rather complex. It is an important issue whether a citizen perceives the improvement in environmental quality, or only perceives the need to contribute to the significant cost of that improvement. Residents of smaller municipalities did not perceive (or only to a minimal extent) the quality deficiencies of their environmental infrastructure. In most municipalities, the supply of drinking water was ensured and wastewater was collected in tanks. In quantitative terms, the collection and disposal of waste was also guaranteed, causing no nuisance to local residents. The failure of landfills to comply with norms was not perceivable; waste was disposed of in abandoned mine pits, which was seen by many as the 'utilisation' of the pits, as it were. In the short term, this practice did not give rise to any issues in terms of aesthetics or 
environmental quality; however, time bombs may count down slowly. Shortly after the completion of environmental protection investments that complied with EU directives, higher waste management tariffs were introduced, amounting to several times the previous charges. There was also a sharp increase in the cost of wastewater treatment; moreover, the costly water tanks constructed only a few years earlier were no longer needed, and their backfilling added to the financial burdens of authorities. Currently, sewer construction is accompanied by the re-drilling of previously backfilled wells, and the construction of local water supply systems. In addition to the problems caused by well water quality in terms of hygiene and therefore safety, this may also lead to severe disruptions in the operations of utility providers.

In smaller municipalities, the application of standard environmental norms involves a loss of welfare. Through the rapid increase in utility tariffs, even without an understanding of the theoretical context, rural residents understood that although their income had previously been lower compared to the capital, the costs of living were also much lower compared to urban populations. It is exactly this advantage that is being eroded by the increasingly stringent requirements of environmental protection through forced investment in infrastructure. The specific costs of constructing smaller systems are higher than those of larger systems based on economies of scale. This is dangerous because, in the longer term, it compromises the ability of villages to retain their populations. Differences in utility tariffs have a significant influence on the cost structure of small enterprises. Even in the case of a simple service such as a carwash, water and wastewater tariffs represent a major cost item. This cost differential may be offset by the differential in property prices and rents; in cases where it is not, subregions may be left without such services. Of course, this will not make villages uninhabitable.

The situation that emerged is well illustrated by the National Environmental protection Program for 2014-2019, drafted by the Ministry of Rural Development, which contains the following statement: 'By 2007, access to piped drinking water was provided in $100 \%$ of the municipalities in the country. In 2012, the homes connected to the water network exceeded $94 \%$. At the same time, the volume of water produced and supplied, including the drinking water supplied to households, continued to decline in the period between 2000 and 2012, due partly to rising water tariffs, and partly to consumers switching to supplies from their own wells. In terms of water production, this amounts to a $17 \%$ fall [...] The number of municipalities with access to sewerage more than doubled from 854 in 2000 to 1,833 in 2012. However, the municipalities without a public sewerage system also included 7 towns: Csanádpalota, Kadarkút, Nagybajom, Nagyecsed, Sándorfalva, Tápiószele and Tompa. The rest of the 1,314 municipalities without a public sewerage system are villages, of which 961 have fewer than 1,000 residents. A county 
breakdown shows that most small municipalities in Baranya (214), Somogy (150), Borsod-Abaúj-Zemplén (120), Szabolcs-Szatmár-Bereg (115), Zala (108) and Vas (97) counties have no access to a public sewerage network. These municipalities are typically located in areas where the operation of public sewerage is not viable economically.'

In 2000 more than $35 \%$, and in 2009 more than $24 \%$ of treated wastewater was discharged into receiving waters following only mechanical treatment. This degree of treatment fails to comply with the requirements for public health and environmental protection. The proportion of at least biologically treated wastewater within the total volume of treated municipal wastewater approximated 100\% in 2013 (up from 65\% in 2000), including the disposal of liquid municipal waste transported to treatment plants directly.

Mainly as a result of the development in sewerage and wastewater treatment implemented in Budapest in recent years, in 2013 the proportion of municipal wastewater transported to a treatment plant and only mechanically treated remained at $0.2 \%$, the level of 2012. Figure 7-2. shows the results that have been achieved with wastewater treatment. It is a welcome fact that the proportion of chemically treated wastewater within the total volume collected increased from $20 \%$ in 2002 to $80 \%$ to 2013 .

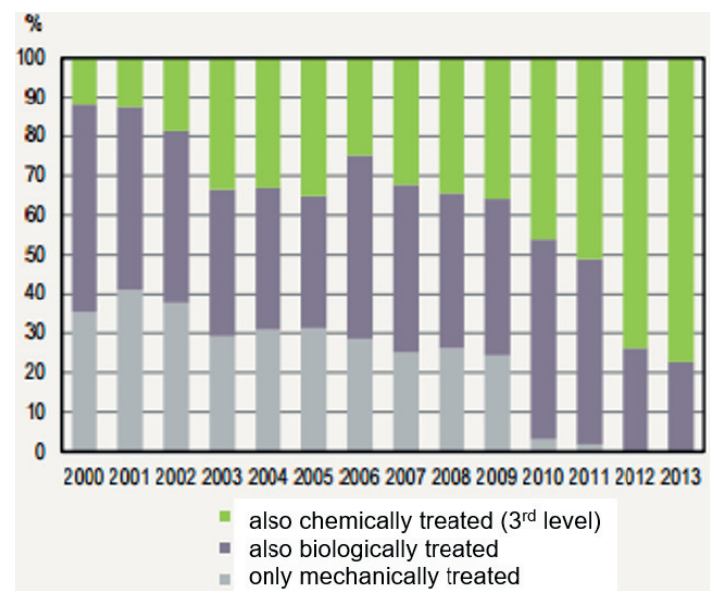

Figure 7-2. Public wastewater treatment

(https://www.ksh.hu/docs/hun/xftp/stattukor/telepinfra/telepinfra13.pdf)

One should acknowledge the fact that these results have indeed been achieved, but perhaps regret the twenty-five year delay. That said, it remains a fact that some present environmental problems are attributable to the infrastructural underdevelopment of the country, while the potentially negative environmental effects of inevitable development could be mitigated by the in- 
tegration of environmental considerations into spatial planning designs and programs. If small regions now seen as artificial ecosystems were conceived of as a single system, natural, economic and social effects could be addressed though a more integrated systemic approach. This would improve both economic and environmental efficiency and social satisfaction. In a mutually reinforcing way, environmental protection and urban planning could create numerous benefits.

\subsection{Rising utility tariffs, falling capacity utilisation}

Relying on surveys carried out in the Czech Republic, Somlyódy et al. (1998) showed that the specific costs of a wastewater treatment plant constructed for a population of 2,000 - 5,000 are 5 - 10 times those of a wastewater treatment plant constructed for a population equivalent of 100,000.

Since local governments are elected bodies and their members are also consumers of public services, 'as residents and consumers they share [...] other residents' interest in keeping the water utility tariff as low as possible' (Somlyódy, 1998, p. 308). According to most professionals, this is one of the reasons why tariffs fail to cover the costs of services, and why the capital raised for maintenance work is insufficient. Undoubtedly, this phenomenon exists. Local governments are not particularly active at assessing local taxes, and seek to reduce the cost of public services to the greatest extent possible. Critics of the phenomenon view artificially low prices as a political instrument, and have reason to cite such fundamental propositions of economics as full cost recovery (Somlyódy, 1998, p. 307). But is it right to seek the root cause of the problem in the lack of responsibility of municipal leaders? (ibid., p. 308) The description of the phenomenon, and the conclusion that the current practice is not sustainable because it leads to the depletion of water providers' assets, are valid. That said, can privatisation or market competition offer a solution to the problem, or is state intervention, even in the form of subsidised prices, needed in the long term? Even if the conditions for market competition are supported, which is not an easy feat due to supply obligations and the technical monopoly held by virtue of the utility network, neither the supply of drinking water nor wastewater treatment can be done on a market basis, and state intervention will continue to be needed (Kerekes, 2002).

There are substantial differences among various suppliers in terms of the producer price of water. In 1998, water tariffs varied between 80 and 2,300 $\mathrm{HUF} / \mathrm{m}^{3}$ (Somlyódy, 1998). Generally, water tariffs (varying between 80 and $400 \mathrm{HUF} / \mathrm{m}^{3}$ ) are insufficient to cover costs and are supported by significant subsidies. The annual growth rate of water tariffs is faster than would be justified by inflation or economic growth, and regional differences among tariffs also keep increasing. However, one major factor in cost increases is the 
significant shortfall in capacity utilisation compared to expectations, thus it is uncertain whether additional price increases could improve the economic viability of the supply of utilities. To date, price increases have led to a fall in capacity utilisation, causing specific costs to rise. In this light, it is not only up to the political insight of local government representatives whether sufficient profit will be generated for the sustainable use of utilities. If it is accepted that the production of water can cost anything between 100 and 2,000 HUF/m ${ }^{3}$, assuming a family with a low monthly consumption of $10 \mathrm{~m}^{3}$, this will mean that the same welfare gain would cost HUF 1,000 in a favourably situated city, and HUF 20,000 where consumers are connected to a less favourably situated, smaller water supply system.

If the principles of economics were fully applied, small municipalities would become depopulated, accompanied by further deterioration in the carrying capacity of the natural environment. The solution should not be limited to subsidised prices. There are obviously water supply systems which significantly reduce specific consumption and where 'water is expensive' such systems should be used. However, this could also mean that where the production cost of water is $2,000 \mathrm{HUF} / \mathrm{m}^{3}$, the public utility system that is needed will be different from one that could be used in a cheaper location. On balance, however, the differences in the tariffs paid for environmental protection services should not exceed what can be offset by the difference in the quality of the environment. The more an individual's welfare is improved due to better environmental quality, the more they may be required to pay for environmental protection services. For example, residents of the Balaton region use the catchment in a sensitive area, but enjoy the welfare effects of better water quality, which may in itself justify a higher sewerage tariff compared to the average. By contrast, in cases where the high costs of public services are not due to such differences but to considerations concerning economies of scale, they should be offset so that residents of an unfavourably situated supply area do not suffer a loss of welfare.

The establishment of this new infrastructure was accompanied by a sharp rise in environmental protection tariffs, and in many municipalities tariffs amounted to 30 to $40 \%$ of monthly income in some population categories.

An examination of the 1999 Decree which regulated the water and sewer tariffs charged by national companies shows major variability in tariffs (Table 7-3.). The tariff charged by the Danube Regional Waterworks (in Vác) is onehalf of that charged by the Transdanubian Regional Waterworks (Siófok), which in professional terms is probably justified by differences in environmental sensitivity. Nevertheless, residents of the northern coastal region of the Balaton may have the perception that they are being charged such a high tariff because 
of the capacity that has been created for holiday resorts that are only used on a seasonal basis.

\begin{tabular}{|c|c|c|c|}
\hline $\begin{array}{c}\text { Name of } \\
\text { waterworks }\end{array}$ & $\begin{array}{c}\text { Water tariff } \\
\left(\mathrm{HUF} / \mathrm{m}^{3}\right)\end{array}$ & $\begin{array}{c}\text { Sewerage tariff } \\
\left(\mathrm{HUF} / \mathrm{m}^{3}\right)\end{array}$ & $\begin{array}{c}\text { Combined tariff } \\
\left(\mathrm{HUF} / \mathrm{m}^{3}\right)\end{array}$ \\
\hline $\begin{array}{c}\text { Danube Regional } \\
\text { Waterworks (Vác) }\end{array}$ & 135.70 & 118.70 & 254.40 \\
\hline $\begin{array}{c}\text { Transdanubian } \\
\text { Regional } \\
\text { Waterworks } \\
\text { (Siófok) }\end{array}$ & 207.80 & 323.30 & 531.10 \\
\hline $\begin{array}{c}\text { Northern } \\
\text { Transdanubian } \\
\text { Waterworks } \\
\text { (Tatabánya) }\end{array}$ & 176.00 & 111.80 & 287.80 \\
\hline $\begin{array}{c}\text { North Hungarian } \\
\text { Regional } \\
\text { Waterworks } \\
\text { (Kazincbarcika) }\end{array}$ & 190.00 & 212.00 & 402.00 \\
\hline $\begin{array}{c}\text { Tisza Waterworks } \\
\text { (Szolnok) }\end{array}$ & 256.50 & 201.40 & 457.90 \\
\hline
\end{tabular}

Table 7-3. Maximum tariffs that may be charged for drinking water and sewerage use by stateowned waterworks (Decree 47/1999. (XII. 28.) KHVM, net of VAT) (http://www2.vizugy.hu/vir/vizugy. nsf/7efd30c51842ae20c1256a8900382968/2f31d8edc1efc3e6c1256a9000614e0f?OpenDocument)

The 1999 Decree has another peculiar feature. The difference between the lowest and highest items is twofold for drinking water tariffs, and threefold for sewerage tariffs. The lowest sewerage tariff is charged in Tatabánya, despite the well-known fact that the environmental pollution caused by the Által-ér river has given rise to constant water quality problems in Tata Old Lake, which is located in the catchment area. The situation has changed since 1999. In 2012, the water tariff charged in Tatabánya changed to 331 HUF/ $\mathrm{m}^{3}$, and the sewerage tariff to $261 \mathrm{HUF} / \mathrm{m}^{3}$, while in Oroszlány the sewerage tariff increased to $330 \mathrm{HUF} / \mathrm{m}^{3}$, clearly due to the application of the stateof-the-art membrane filter technology, which will be explained briefly below. All this has brought about a welcome improvement in the water quality of Tata Old Lake, providing visiting tourists and the residents of the town with a significant welfare gain, which will obviously be of little consolation to the citizens of Oroszlány, where one of the highest sewerage tariffs is charged among municipalities of similar sizes. In 2012, residents of the village of Szár paid outstandingly high tariffs: $499 \mathrm{HUF} / \mathrm{m}^{3}$ for sewerage and $415 \mathrm{HUF} / \mathrm{m}^{3}$ for water, net of VAT. 


\begin{tabular}{|c|c|c|c|c|c|}
\hline Municipality & $\begin{array}{c}\text { Provider } \\
\text { (data source) }\end{array}$ & $\begin{array}{l}\text { Net water } \\
\text { tariff } \\
\left(\mathrm{HUF} / \mathrm{m}^{3}\right)\end{array}$ & $\begin{array}{c}\text { Net } \\
\text { sewerage } \\
\text { tariff } \\
\left(\mathrm{HUF} / \mathrm{m}^{3}\right)\end{array}$ & $\begin{array}{l}\text { Combined } \\
\text { water and } \\
\text { sewerage } \\
\text { tariff } \\
\left(\mathrm{HUF} / \mathrm{m}^{3}\right)\end{array}$ & $\begin{array}{c}\% \text { of } \\
\text { Budapest }\end{array}$ \\
\hline Budapest & $\begin{array}{l}\text { http://www. } \\
\text { dbrt.hu/index. } \\
\text { php?id=49 }\end{array}$ & 218.85 & 385.95 & 604.8 & 100 \\
\hline Gyál & $\begin{array}{l}\text { http://www.gyal. } \\
\text { hu/informaciok/ } \\
\text { kozuzemi-dijak }\end{array}$ & 354.46 & 301.63 & 656.09 & 108.48 \\
\hline Győr, Nyúl & $\begin{array}{l}\text { http://pannon- } \\
\text { viz.hu/cikk/ } \\
\text { viz_es_- } \\
\text { csatornadijak. } \\
\text { html } \\
\end{array}$ & 220.22 & 444.12 & 664.34 & 109.84 \\
\hline Felsőpataj & $\begin{array}{c}\text { http://www. } \\
\text { dakov.hu/index. } \\
\text { php?pg=water_ } \\
\text { select }\end{array}$ & 289.2 & 402.5 & 691.7 & 114.36 \\
\hline Köröstetétlen & $\begin{array}{c}\text { http://www. } \\
\text { dakov.hu/index. } \\
\text { php?pg=water_ } \\
\text { select }\end{array}$ & 312.4 & 337.8 & 650.2 & 107.5 \\
\hline Monor & $\begin{array}{c}\text { http://www. } \\
\text { dakov.hu/index. } \\
\text { php?pg=water_- } \\
\text { select }\end{array}$ & 257.8 & 425.5 & 683.3 & 112.97 \\
\hline Valkó & $\begin{array}{c}\text { http://www. } \\
\text { dakov.hu/index. } \\
\text { php?pg=water_ } \\
\text { select }\end{array}$ & 255.3 & 416.6 & 671.9 & 111.09 \\
\hline
\end{tabular}

Table 7-4. Utility tariffs in some municipalities (author's selection) (based on http://www.saar-ujb.hu/files/00000938.pdf); http://www.kemma.hu/ komarom-esztergom/kozelet/igy-valtoznak-a-kozuzemi-dijak-a-varosokban-421417 )

Table 7-4. clearly shows that utility charges have increased significantly over the past one and a half decades despite state intervention, but also that regional differences are beginning to become more balanced. Due to economies of scale, the Budapest tariffs remain lowest, while those charged in small municipalities are only about $10 \%$ higher. This situation may be seen in a favourable light in terms of welfare requirements, but it is widely known that at best the tariffs cover operating costs, without any allocations for amortisations that would make the systems sustainable in the long term. In 25 to 30 years' time, today's new sewerage networks and wastewater treatment facilities will become rundown, with hardly any funds for their overhaul. Intervention by the state will become inevitable, but not unproblematic. The case described below concerns a wastewater treatment plant that represents the category of 'too 
good', while it also has environmental consequences that 'did not need to be considered' during the time of investment. The membrane technology that is applied meets all needs, but the operation of the pumps requires a large volume of electricity. Due to climate policy, this may have highly negative consequences.

\subsection{Wastewater treatment in the Által-ér catchment area - The case of a small town's wastewater treatment plant}

In order to protect Tata Old Lake and the Által-ér tributary in the same catchment area, strict limits must be observed with regard to wastewater treatment in accordance with the European Union's requirements for environmental protection. In water discharged from wastewater treatment plants in the catchment area of the Által-ér, total phosphorus concentration must not exceed $1 \mathrm{mg} /$ litre throughout the year, and total nitrogen concentration $10 \mathrm{mg} / \mathrm{litre}$ from 1 May to $15 \mathrm{No}$ vember. In order for the wastewater treatment plant to meet this requirement, it must reach a level of efficiency of at least $90 \%$ in terms of pollutant removal. This creates the need to improve the purification performance of the plant so that the quality of the treated water complies with the emission limits set out in the decision of the Northern Transdanubian Inspectorate for Environmental Protection, Natural Protection and Water Management. As part of the Environment and Energy Operational Programme (KEOP), the Northern Transdanubian Waterworks was granted assistance to the amount of HUF 2,223,488,650 for the development of the two wastewater treatment plants in the area. Using EU funds, development work on the plants started on 14 July 2011. For the larger plant, the total development cost amounted to HUF 1,459,864,000 of which HUF $1,112,497,000$ was granted in assistance by the European Union and the Hungarian State, while for the smaller plant the total cost of development amounted to HUF 1,307,049,000, of which HUF 1,110,991,650 came in the form of grants from the European Union and the Hungarian State. As the dominant service provider in the region, during the implementation of its development objectives the Northern Transdanubian Waterworks pays particular attention to complying with increasingly strict Hungarian and EU regulations for environmental protection. Additionally, it is also mindful of the need to provide a quality service that meets the needs and requirements of both consumers and local governments. As of 2015, the operation of the wastewater treatment plant is also expected to be taken over by the waterworks. The wastewater treatment plant meets the highest standards for water quality, and the water that is discharged clearly improves water quality in both the receiving Által-ér tributary and Tata Old Lake. However, the usual SWOT-type analysis of the wastewater treatment plant (i.e. a map of its strengths, weaknesses, opportunities and threats) does not show a clearly positive outcome. Table 7-5. provides a good overview of the strengths 
and weaknesses of the technology, helping decision makers to determine when to opt for this solution. Moreover, the table highlights the need to make further improvements to the project.

\begin{tabular}{|c|c|}
\hline Strengths & Weaknesses \\
\hline $\begin{array}{l}\text { - Possibility of compliance with the } \\
\text { highest standards of environmental } \\
\text { protection } \\
\text { - Modern, computer-controlled } \\
\text { management system } \\
\text { - Minimal staffing requirements } \\
\text { Minimal environmental charge due to } \\
\text { low pollutant emissions }\end{array}$ & $\begin{array}{l}\text { - High specific costs of wastewater } \\
\text { treatment plant } \\
\text { - Approximately } 1.6 \mathrm{kWh} / \mathrm{m} 3 \text { of } \\
\text { electricity required for treatment } \\
\text { - Significant dependence on electricity } \\
\text { tariffs } \\
\text { - Absence of a solution to sludge } \\
\text { utilisation }\end{array}$ \\
\hline $\begin{array}{l}\text { - Restoration of primary settlement and } \\
\text { use of sludge for the production of } \\
\text { biogas, and use of biogas to generate } \\
\text { electricity } \\
\text { - Separation of rainwater from } \\
\text { municipal wastewater to reduce costs } \\
\text { - Initiation of demonstration projects } \\
\text { relying on the vicinity of the } \\
\text { membrane manufacturer } \\
\text { - Ideal conditions existing at the plant } \\
\text { for research and development related } \\
\text { to wastewater treatment } \\
\text { - Possibility to develop the plant into } \\
\text { a national or even global example of } \\
\text { best practice }\end{array}$ & $\begin{array}{l}\text { - Insufficient capacity of the two } \\
\text { rainwater reservoirs to manage } \\
\text { torrential rains } \\
\text { - Inoperability of the wastewater } \\
\text { treatment plant due to prolonged } \\
\text { disruption to electricity supply } \\
\text { - Foaming at the biological treatment } \\
\text { facility due to major surfactant } \\
\text { pollution or inadequate ventilation, } \\
\text { causing the wastewater treatment } \\
\text { plant to be flooded with foam } \\
\text { Vendor dependence regarding } \\
\text { supply of parts and technological } \\
\text { components due to the membrane- } \\
\text { specific design of the technology }\end{array}$ \\
\hline
\end{tabular}

Table 7-5. SWOT analysis of membrane bioreactor wastewater treatment (Authors' compilation)

As can be seen from Table 7-5., the direct benefits of a project may be outweighed by its indirect benefits, which implies that a decision based solely on a cost-benefit analysis would be premature. In the case at hand, while the costs of wastewater treatment may exceed what could be achieved with other technologies, the project should be implemented even for demonstration and research purposes due to the vicinity of the membrane production plant. Therefore, it is certainly possible that use of the technology in question would only be reasonable under particular environmental and economic circumstances. It will be readily apparent that although a holistic approach would suggest rejection of the choice of this technology in the case at hand, some features of the evaluation still provide a rationale for the choice. However, this raises the question whether the costs of that 'other kind of rationale' should be borne by the small-town population. The ethical answer to that question is a 'no'. The high treatment costs resulting from the demonstration project would not serve the interests of the small-town population, but those of a broader community, 
or the owner of the innovation (the developer of the membrane technology); consequently, the high specific costs of treatment should not be borne by the citizens of the small town, but be distributed among all the parties that would subsequently derive profits from or enjoy better environmental quality as a result of the project.

If environmental protection services are provided to the population on a prorata basis at market prices, environmental protection efforts will have a peculiar market influence. With larger supply systems (wastewater treatment plants, waste disposal facilities, etc.), specific treatment costs and size are digressively proportional (i.e. involve successively lower costs). Due to this extremely high degressivity factor, all activities the cost structure of which include a high ratio of such costs will be established in the surroundings of major supply systems, creating a definite comparative advantage for larger municipalities. However, this direction of development is largely unfavourable from an environmental perspective because even environmental protection measures will accelerate urbanisation and the disappearance of small municipalities. The contradiction can be resolved through norms based on differentiation by municipality size, or through subsidy regimes.

\subsection{General trends in utility development in Hungary}

The acceleration of infrastructural investment motivated by environmental protection is well illustrated by changes in the sewer length per $1,000 \mathrm{~m}$ of water pipeline. After 1995, sewer construction accelerated as economic performance improved, which could be seen as leading to the closure of the utility gap. The sharpest change is observed in Pest County. In 1990, Pest County lagged far behind the country average in terms of access to utilities, but took the lead by 2000 , which is a major achievement considering the fact that in 1990 it recorded the lowest sewer length per 1,000 m of water pipeline.

Apart from improvements in economic performance, in this phase of development a major role was occupied was the peculiar development path of the Budapest agglomeration, which was by no means beneficial in environmental terms. The exodus of the higher-earning population from the capital powerfully stimulated infrastructural development. Additionally, the 'effectiveness' of these developments is well illustrated by the fact that in terms of sewer length per home, the situation is the worst in Pest County. While in 2000 Pest County had a sewer length per 1,000 m of water pipeline which was far above the national average, regarding the percentage of homes connected to the sewer network its rate of $35 \%$ still ranked among the worst. 

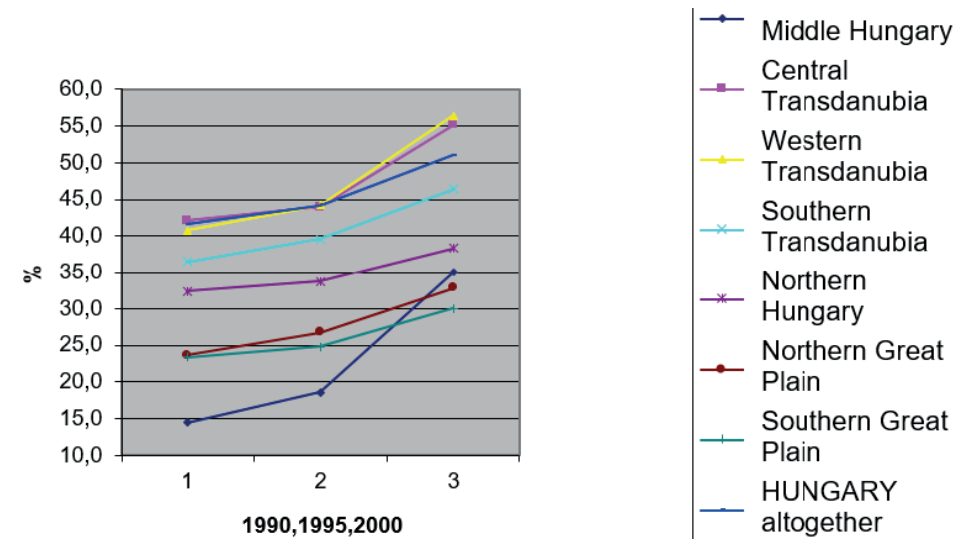

Figure 7-3. Change in the proportion of homes connected to the sewer network by region (\%) (1990-2000) (Kerekes, 2003)

Aggregate data show clearly that while sewer construction progressed rapidly and sewer length doubled, the proportion of connected homes increased by a mere $10-12 \%$, accompanied by an overall decline in the volume of drained wastewater. The latter is partly attributable to a sharp fall in water consumption. In this regard the only exception is again Pest County, due to the specific development path of the agglomeration. Owing to the exodus of the population from Budapest (largely those in the top income decile), Pest County saw an increase in both gas and water consumption, as well as in the volume of drained wastewater. Nationwide data are counterbalanced by the data from the capital and Pest County.

In terms of sewer construction, there are substantial differences across the country. In more advanced Transdanubian regions, sewer construction and network connections have developed in a relatively balanced manner, and utility development efforts are aligned with the income of the population in the region, whereas in the eastern part of the country developments are being implemented at a slower rate. Although the rate of trunkline construction significantly exceeds the growth rate of connected consumers even in these regions, developments are more balanced, yet the lag of these regions is becoming increasingly serious. 


\section{Characteristics of the utility supply of drinking water}

(based on Statisztikai Tükör, 2012)

The purpose of municipal water supply is to meet the needs of the population for drinking and household water, and to supply drinking quality water to commercial entities, public institutions and smaller industrial plants. Water may be supplied from private wells, public wells, through the proprietary waterworks of plants and institutions, and utility water pipelines. By 2007 , access to piped water was present in $100 \%$ of the municipalities in the country. In 2012, homes connected to the water network exceeded $94 \%$. The volume of water produced and supplied, including the drinking water supplied to households, continued to decline in the period between 2000 and 2012, due partly to rising water tariffs, and partly to consumers switching to supplies from their own wells. In terms of water production, this amounts to a fall of $17 \%$.

In 2000-2012, $3.247 \mathrm{~km}$ of pipeline was added to the drinking water network, the size of which reached 65,532 km in 2012, accompanied by an increase of more than 394,000 units in the number of homes connected to drinking water utilities.

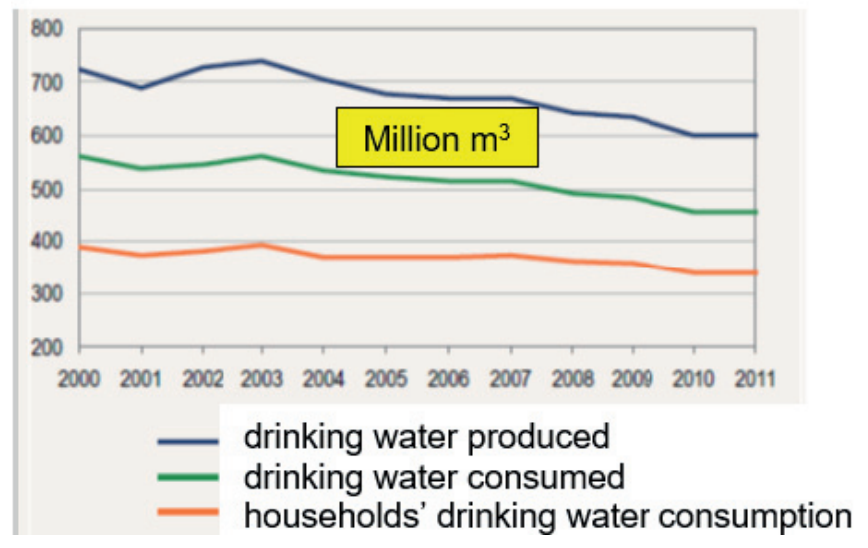

\section{Utility wastewater drainage}

Regarding the preservation of the purity of water reserves in the long term, the development of sewerage and wastewater treatment is of great importance. In international comparison, Hungarian municipalities have decent performance indicators in terms of utility drinking water supply. In the field of wastewater drainage, concerning the ratio of connected homes the utility gap still exceeds $20 \%$, but it is nevertheless being closed progressively as a result of the developments of recent years. 


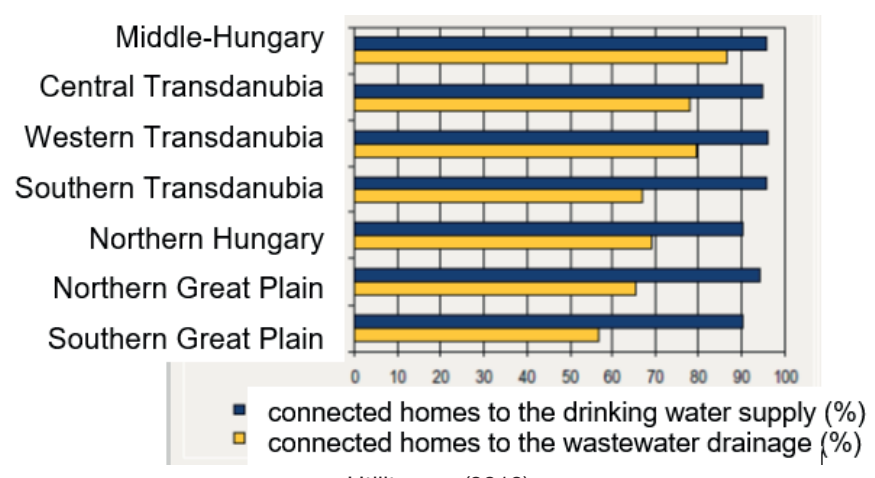

Utility gap (2012)

The number of municipalities with access to sewerage more than doubled from 854 in 2000 to 1,833 in 2012 . However, those municipalities without a public sewerage system also included 7 towns: Csanádpalota, Kadarkút, Nagybajom, Nagyecsed, Sándorfalva, Tápiószele and Tompa. The rest of the 1,314 municipalities without a public sewerage system are villages, of which 961 have fewer than 1,000 residents. Breakdown by county shows that most small municipalities in Baranya (214), Somogy (150), Borsod-Abaúj-Zemplén (120), Szabolcs-Szatmár-Bereg (115), Zala (108) and Vas (97) counties have no access to a public sewerage network. These municipalities are typically located in areas where the operation of public sewerage is not viable economically.

In 2000-2012, the number of homes connected to the sewerage network increased by more than 1.18 million from 2.079 million in $2000(51 \%)$ to 3.259 million in 2012 (74\%), making up some of the major shortfall compared to the number of homes connected to the water network. The volume of wastewater drained through public sewers, including the discharge from institutions, industry, proprietary wells and other wastewater sources as well as the volume of rainwater drained through combined sewerage systems, amounted to an average annual 529 million $\mathrm{m3}$ in the period 2000-2012. This corresponds to more than $79 \%$ of the average annual drinking water production of public waterworks (666 million m3). Similarly to the data for 2000, in terms of the number and proportion of homes connected to a public sewerage network, Bács-Kiskun, Békés, Szabolcs-Szatmár-Bereg, Heves and Tolna counties lagged far behind the average at the end of 2012. The situation is still the worst in Bács-Kiskun county (49.7\%). Even in the capital, which is in the best situation, certain areas on the outskirts with some 38,000 homes (4.2\%) remain unconnected to sewerage systems. 


\section{Wastewater treatment}

In 2009 , over $4.5 \%$ (24 million $\mathrm{m} 3$ ) of the wastewater collected through the utility network was discharged into recipient waters without treatment. Wastewater from the capital accounted for the vast majority of that, with approximately 22.4 million $\mathrm{m} 3$ being discharged directly into the Danube in Budapest.

In 2012, nationwide only $1.4 \%$ (6.3 million $\mathrm{m} 3$ ) of the wastewater collected through the utility network was discharged into recipient waters (mainly into surface waters) without treatment.

The efficiency of wastewater treatment plants varies depending on technical conditions, technology, capacity deployed, the volume of wastewater that is treated, the pollutant load, and the professional standards of operation, etc. at each plant.

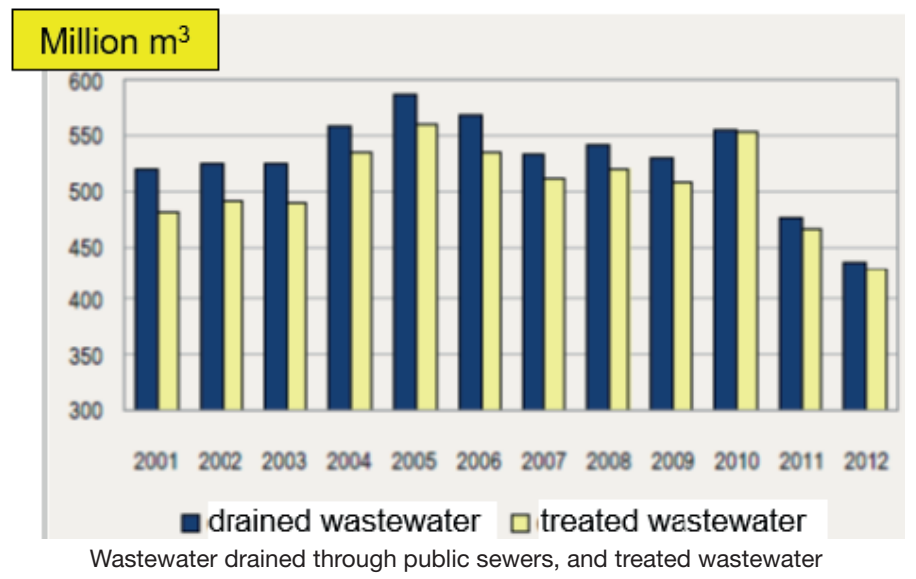

A rather large proportion of treated wastewater (more than 35\% in 2000 and still more than $24 \%$ in 2009) was discharged into receiving waters only following mechanical treatment. This level of treatment fails to comply with requirements for public health and environmental protection.

By 2012, the proportion of municipal wastewater drained to a treatment plant and treated only mechanically fell to $0.2 \%$. The proportion of at least biologically treated wastewater within the total volume of treated municipal wastewater approximated 100\% in 2012 (up from 65\% in 2000). This included the disposal of liquid municipal waste transported to treatment plants directly. The significant improvement is primarily attributable to the development of wastewater treatment in Budapest. 


\section{The characterisation of welfare, welfare indicators}

\subsection{Introduction}

Citizens expect successful economic policy to improve their standard of life and their welfare. Quality of life is not equivalent to material consumption, although we are inclined to define our individual standard of life in terms of financial income, while on the level of the national economy, the economic state of the country is expressed via the Gross Domestic Product indicator. Again, the devil is of course in the detail. GDP can be made more precise, of course (household performance can be considered, inequalities of distribution can be examined, and other modifications are also possible when computing GDP). GDP, however will never make a good welfare indicator because it indicates only one dimension, an economic one, and inaccurately, too. Many have experimented with other indicators that comprise more dimensions of the quality of life. One of the most successful of these attempts is the UNIDO Human Development Indicator, the structure and calculation of which is presented below. If, however, we think more deeply about the concept of welfare, we are bound to arrive at the conclusion that we cannot trust efforts to characterise our welfare and its changes with a single scalar. In this chapter we describe how nearly every single indicator system struggles with the same problems as those they were meant to replace; i.e., they tell us barely anything more than a more detailed analysis of GDP already has. At the end of the chapter we discuss how subjective well-being and sustainability relate to each other.

\subsection{The characterisation of inequality in the distribution of income}

The Gini coefficient was developed by Conrado Gini, an Italian statistician, to characterise inequalities in the distribution of incomes. Details were first published in a book by Gini in 1912. Its value varies between zero and one. If all the members of a given society receive exactly identical incomes, the value is 0.00 , while the value is 1.00 if one person receives all the income while the rest receive nothing. The calculation of the Gini coefficient is illustrated in the figure below. 


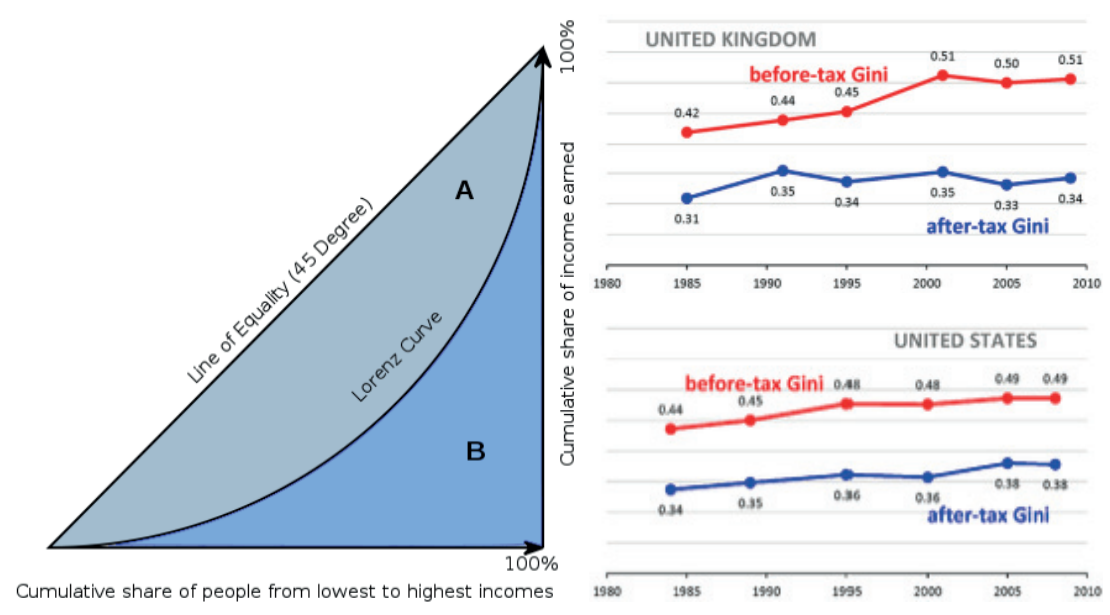

Figure 8-1. Calculation of the Gini coefficient (Source: http://en.wikipedia.org/wiki/Lorenz_curve)

The line in the figure is the so-called Lorenz curve, which can be shown when the cumulative population rate is indicated on the horizontal axis, while the vertical axis shows the income share received by the given population from the total, starting with the lowest-income individuals of the population. A diagonal means a perfectly equal share of income, while the larger the area between by the Lorenz curve and the diagonal, the larger the inequalities in the distribution of income.

To calculate the Gini coefficient, first define the area between the Lorenz curve and the $45^{\circ}$ diagonal and divide it by the area below the diagonal. If the distribution of incomes is perfectly equal, the Lorenz curve will coincide with the diagonal, making the coefficient 0.00 , while if only one person receives all the income (this never happens in reality, of course), the Lorenz curve will coincide with the axes, obtaining the quotient of the area of two congruent triangles; that is, 1.00 as the coefficient.

In reality, the value of the Gini coefficient is usually $0.2-0.5$, while the Gini index varies between 20 and $50 \%$. The lower values (25-35\%) are characteristic of the countries of the former communist bloc, and the socalled welfare states (including EU and Canada), while values between 35 and $40 \%$ refer to more substantial differences. The relevant group includes Italy, Latvia, Israel and Russia. Values over $40 \%$ reflect significant inequalities, but this group is rather heterogeneous, including the USA where the difference between the richest $10 \%$ and the poorest $10 \%$ is 'only' 15.9 fold, while this value is 24.6 -fold in Mexico and 40 -fold in Chile. If we had comparative data, the highest inequalities would surely be indicated by the Gini coefficients for the African continent, where according to 1995 data 
even differences of 100-fold are not rare between those belonging to the poorest and the richest decile.

Interestingly enough, the USA's already high Gini coefficient has continually grown in past years, signalling an increase in social inequality, while exactly the opposite would be desirable for more sustainable development. Figure 8-2. shows the income inequality in the USA between 1980 and 2016.

Researchers have arrived at a surprising result: the upper one-tenth, or rather one-hundredth of American society has become very rich again. Ninety per cent of society owns as little as $25 \%$ of total income, and the richest one per cent more than $10 \%$. The Golden Age of tycoons of the 1920s has now returned, while the middle class is disappearing again, which is rather threatening to social sustainability.

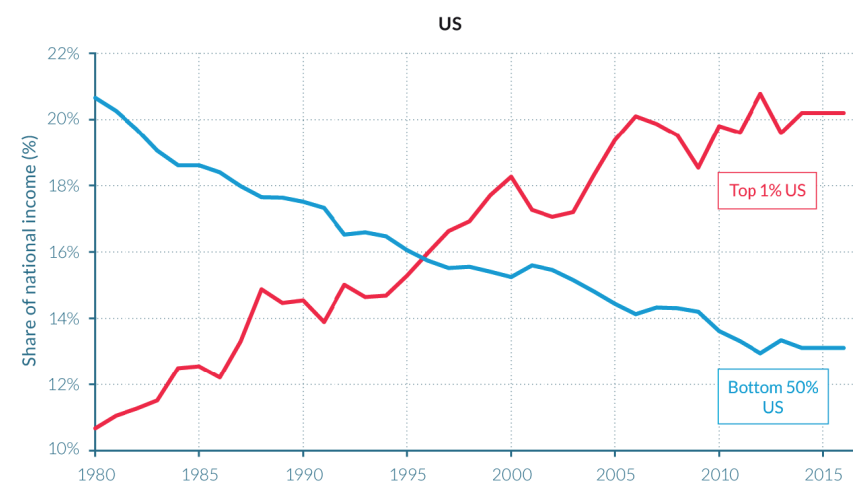

Figure 8-2. Income inequality in the USA (1980-2016) (WID.world, 2017, see http://wir2018.wid.world/methodology.html for data series and notes )

\subsection{The measurement of human development}

Until the late 1960s, quality of life was largely equated with material welfare. 'Quality of life' became a multi-dimensional concept, inseparably associated with factors that define living circumstances like health, social circumstances, or the state of the natural environment. Moreover, concerning the interpretation of the quality of life, a distinction is now made between objective (real) life circumstances and the subjective welfare of individuals. The latter reflect individual's expectations about their own life circumstances and subjective judgements about them.

The welfare concepts developed so far mainly fall into two groups (BergerSchmitt-Noll, 2000). One involves the so-called 'quality of life' concept, which may be split into several trends itself, and is relatively well supported with research and empirical analyses. The other, fairly new trend focuses on social dimensions of welfare such as social cohesion, exclusion, social capital, human development, sustainability, etc. 
Within the quality of life trend, two fundamental schools are differentiated. One was established by Scandinavian researchers of standard of life, while the other is rooted in the US.

\subsection{The quality of life model}

\subsubsection{The Scandinavian model - prioritising objective elements in quality of life}

The quality of life model is the product of Scandinavian research, and its elaboration is associated with the names Jan Drewnoski, who took the definition of man's objective needs as the foundation of the idea, and Richard Titmuss, who examined 'man's command-over-resources'. The researchers interpreted 'resources' rather broadly to include incomes, assets, education and knowledge, social relations and networks, etc. These scholars claim that an individual's command over resources is determined by the external circumstances of their life, so they also considered these factors as components of objective quality of life. That their scrutiny focused on objective quality of life did not mean that they attributed no significance to individual subjective aspirations, but since no government policy can be developed on the grounds of the former, the authors claim, the measurement of welfare must be based on objective elements.

\subsubsection{The American 'personal satisfaction' model}

The reverse of the Scandinavian resource-based concept is the American quality of life concept, which equates quality of life with satisfaction of individual needs; consequently, it considers quality of life to be approachable through an examination of individual-level factors (Berger-Schmitt-Noll, 2000; Husz, 2001). The self-evident goal of social development according to this approach is not to achieve objective goals concerning quality of life, but to increase individual subjective quality of life; i.e., to enhance individual satisfaction and happiness. The measurement of welfare in this approach is first of all possible through social indicators. Argyle says subjective welfare has three components: satisfaction, the existence of favourable effects, and a lack of unfavourable stress (Berger-Schmitt-Noll, 2000, p. 10).

According to Johan Galtung, basic needs can be expressed through the 'having, loving, being' triangle, where 'having' refers to material goods and human needs, 'loving' to the human relationships necessary for happiness, and 'being' to social integrity and a harmonious relationship with nature. Indicators that express these may capture the extent to which one takes part in politics, opportunities for doing rewarding work, or enjoying nature. 


\subsubsection{The quality of society model}

In the second half of the 1980s and the early 1990s, development theory that put the social dimensions of welfare into focus was published. In evaluating human development, this sought to examine the quality and liveability of society and aimed to define the 'good society'. Veenhoven (1996) differentiates four dimensions of the quality of nations: the first being 'liveability', which indicates national quality of life, the second the stability of the system and its subsystems, the third productivity, and the fourth the prevalence of principles relating to freedom such as independence and equality. There are two basic methodological approaches to measuring the goodness of societies. The first approach is based on input, and the other on output indicators.

Methods based on input indicators start by measuring the welfare of societies, which is characterised through the life circumstances supported by society. This factor is what is expected to create harmony between citizens' needs and abilities and includes welfare, political freedom, and access to education. As for the practicability of input indicators, two problems arise. One is that this method implicitly presupposes that we know societies' opinion about its needs and abilities, while the other (not necessarily fallacious) supposition is that in every dimension higher values also relate to higher quality.

With a method based on output indicators, researchers try to identify to what extent a given society provides prosperity for its citizens. Physical and mental health, general satisfaction and happiness may be indicators that express such prosperity.

The outstanding sociologist Emile Durkheim was the first to consider social cohesion a significant element in the analysis of the quality of society, which he defined as mutual dependence, shared values and solidarity among members of society (Berger-Schmitt-Heinz-Herbert, 2000, p. 15). As a consequence of the economic growth of the past decade, social cohesion is under threat, and probably this is why it has been under the spotlight of international politics. Jenson defined five areas of social cohesion:

- belonging - isolation: a sense of the existence of shared values, identity, and commitment,

- inclusion - exclusion: equal opportunities and access,

- participation - non-involvement,

- recognition - rejection: tolerance for different viewpoints and respect for pluralism,

- legitimacy - illegitimacy: respect for the institutional system designed to manage the conflicts that arise in pluralist societies. 
An increase in social cohesion, which is considered a positive factor from the perspective of sustainable development, assumes a decrease in social inequality and the simultaneous reinforcement of relationships within society.

\subsection{The UNDP Human Development Index}

The concept of human development was elaborated by Miles through a United Nations University project carried out in 1985 . The term became internationally known through the influence of the UNDP (United Nations Development Program) and received its final form through the work of the former Iraqi Head of the Human Development Report Office (HDRO) Mahbub ul Haq, and the 1998 Nobel Prize winner for economics, Amartya Sen. The first published issue of HDR was dominated by Amartya Sen's concept of 'capabilities', according to which 'Human development is a process of enlarging people's choices' (UNDP, 1990, p.1). Amartya Sen's 'capabilities' concept involves supporting the essence of welfare through 'functionings' (including 'doings and beings', like going to the movies and reading books, the existence of good health, and social integrity). Sen's approach can be considered an extension of the Scandinavian quality-of-life model.

The Human Development Index is used to characterise the level of development along the three basic dimensions of human development in the member states of the United Nations.

The Human Development Index, in the form conceived of in 1999, differentiates three dimensions of human development:

- Health and longevity expressed as average life expectancy at birth (I1)

- Educational attainment expressed in the literacy rate of the adult population (assigned a weight of two-thirds) and combined enrolment ratio in basic, secondary and higher education (one-third weight) (I2)

- Decent standard of living expressed in discounted USD (or its logarithm) in the form of purchasing power parity of GDP (I3)

The performance per dimension of the subject country is expressed using the following formula:

The index of the subject dimension $=\frac{\text { actual value }- \text { minimum value }}{\text { maximum value }- \text { minimum value }}$

$\mathrm{HDI}=\frac{\mathrm{I}_{1}+\mathrm{I}_{2}+\mathrm{I}_{3}}{3}$

The value of the index was at first influenced by the maximum and minimum values. If, for example, a new country was involved in the system, this not only 
changed the rankings but also the value of all indices. To monitor the changes in annual data over time, the maximum and the minimum values were then fixed. These values are shown in Table 8-1.

\begin{tabular}{|c|c|c|c|c|c|c|}
\hline \multirow{3}{*}{$\begin{array}{l}\text { Dimensions } \\
\text { Health }\end{array}$} & \multicolumn{3}{|c|}{$\begin{array}{l}\text { Previous (Aggregation : AM) } \\
\text { Indicators } \quad \text { Transformation }\end{array}$} & \multirow{2}{*}{\multicolumn{3}{|c|}{$\begin{array}{l}2010 \text { (Aggregation : GM) } \\
\text { Indicators } \\
\text { Transformation } \\
\text { Minimum Maximum }\end{array}$}} \\
\hline & \multirow{2}{*}{$\begin{array}{l}\text { Indicators } \\
\text { Min } \\
\text { Life expectancy } \\
\text { at birth (years) }\end{array}$} & \multicolumn{2}{|c|}{$\begin{array}{l}\text { Transformation } \\
\text { Minimum Maximum }\end{array}$} & & & \\
\hline & & 25 & 85 & $\begin{array}{l}\text { Life expectancy } \\
\text { at birth (years) }\end{array}$ & 20 & 83.2 \\
\hline $\begin{array}{l}\text { Know. } \\
\text { ledge }\end{array}$ & $\begin{array}{l}\text { Adult literacy } \\
\text { rate }(\%)\end{array}$ & 0 & 100 & $\begin{array}{l}\text { Expected years } \\
\text { of schooling }\end{array}$ & 0 & 18.0 \\
\hline & $\begin{array}{l}\text { Combined gross } \\
\text { enrolment ratio }(\%)\end{array}$ & 0 & 100 & $\begin{array}{l}\text { Mean years of } \\
\text { schooling }\end{array}$ & 0 & 13.1 \\
\hline $\begin{array}{l}\text { Standard } \\
\text { of living }\end{array}$ & $\begin{array}{l}\text { GDP per capita } \\
\text { (PPP US S) }\end{array}$ & 100 & 40,000 & $\begin{array}{l}\text { GNI per capita } \\
\text { (PPP US \$) }\end{array}$ & 100 & 107,721 \\
\hline
\end{tabular}

Table 8-1. Pre-2010 and post-2010 HDI Construction Methodology

(http://www.economicsdiscussion.net/human-development-index/human-development-index-hdian-overview/11782 - accessed on 25/04/2018)

One advantage of this index is that it characterises reality in a more comprehensive way than earlier, more one-dimensional concepts. The index has received a great deal of criticism since it was published in 1990. One group of concrete critiques object to the arbitrariness of the selection of components, claiming that freedom, safety, equality, etc. could equally well be dimensions of human development as a decent standard of living, longevity, or education (Lind, 1992, 1993; Diener, 1995). Substantial changes in the composition of the index have been made only once, when in 1991 the index of the adult literacy rate was supplemented with the estimated value of the average duration of schooling (Husz, 2001). This was necessary (among other reasons) because in developed countries the adult literacy rate approaches $100 \%$, which puts a stop to its further development. The last comprehensive reform of the calculation methodology for the HDI took place in 1999. At that time, the original method for discounting GDP was reinstated (between 1991 and 1999 other methods were used), so the index is now calculated using the logarithm of discounted GDP data measured as purchasing power parity. However, the involvement of GDP in the index raises yet other problems. It adversely affects economies where the distribution of labour is less developed, and cash flow is not as necessary for providing a livelihood for individuals. Critics of HDI find it problematic that, owing to arithmetic averaging, differences in one indicator can easily be compensated by improvements in another. In this respect, it may be found somewhat ironic that in a developing country a one-year increase 
in average life expectancy at birth (meaning a several-per-cent improvement in the index) can be compensated for by a raise in GDP of a few hundred USD, while compensation for the same increase in most developed countries would require an improvement of thousands of dollars. This situation gives the impression that the lives of the citizens of developed countries are 'more valuable' than those of developing countries.

Averaging raises yet another problem: that of the independence of the three indices. Critics claim that the correlation between the HDI and its constituent individual indicators is usually over 0.8 , and the correlation between the HDI and women's life expectancy at birth is even higher: this questions whether the indicator is a genuinely complex one.

However, the index is fairly resistant to criticism, probably because it provides simple and easy-to-interpret data for those involved in developmentrelated policymaking.

The HDI first became public in the 1990 United Nations HDR. Following this, the group of indices used in the calculation was broadened. Figure 8-3. shows the five most significant human development indicators and their correlations. Besides the classic HDI, the 2004 HDR published two types of poverty indices separately for developing and OECD countries.

The HPI-1 index expresses poverty through the probability at birth of surviving to age 40, the proportion of adult illiteracy, the proportion of population with sustainable access to an improved water source, and the proportion of children that are underweight for their age.

In OECD countries, poverty is characterised using HPI-2, which calculates the probability at birth of surviving to age 60 , the proportion of adults lacking functional literacy skills, the population below the income poverty line, and long-term unemployment.

The GDI (Gender-Related Development Index) indicates the inter-gender differences of human development. It considers the homogeneity of the inter-gender distribution of life expectancy at birth, inequalities between sexes in schooling and illiteracy, and the equality of gender-related income distribution. GDI alone cannot be used to make an international comparison of gender-related discrimination. Deductions can only be made through a comparison of the HDI ranking and the GDI ranking. If the given country is positioned lower in terms of $\mathrm{GDI}$ than $\mathrm{HDI}$, this implies disadvantageous discrimination against women.

The GEM (Gender Empowerment Measure) expresses the distribution of political and economic power between men and women.

The system of five indexes is shown in the figure below. 
HDI

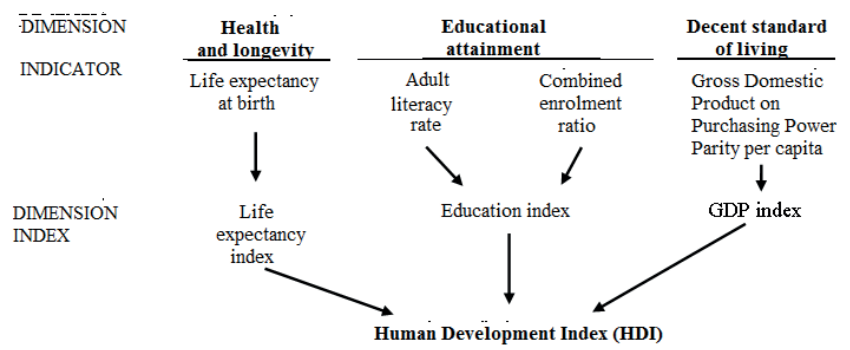

\begin{tabular}{|c|c|c|c|c|}
\hline \multirow[t]{2}{*}{ HPI-1 } & \multirow{2}{*}{ INDICATOR } & $\begin{array}{l}\text { Health and } \\
\text { longevity }\end{array}$ & $\begin{array}{l}\text { Educational } \\
\text { attainment }\end{array}$ & Decent standard of life \\
\hline & & $\begin{array}{l}\text { Probability at birth } \\
\text { of not surviving } \\
\text { to age } 40\end{array}$ & $\begin{array}{l}\text { Adult } \\
\text { illiteracy } \\
\text { rate }\end{array}$ & $\begin{array}{lc}\text { sustainable access } & \text { children } \\
\text { to an improved } & \text { under weight } \\
\text { water source } & \text { for age }\end{array}$ \\
\hline
\end{tabular}

HPI-2 DIMENSION

\begin{tabular}{l}
\multicolumn{1}{c}{$\begin{array}{c}\text { Health } \\
\text { and } \\
\text { longevity }\end{array}$} \\
\hline $\begin{array}{l}\text { Probability } \\
\text { at birth }\end{array}$ \\
of not surviving \\
to age 60
\end{tabular}

\begin{tabular}{c}
$\begin{array}{c}\text { Educational } \\
\text { attainment }\end{array}$ \\
\hline $\begin{array}{c}\text { Adult } \\
\text { functional } \\
\text { illiteracy } \\
\text { rate }\end{array}$
\end{tabular}

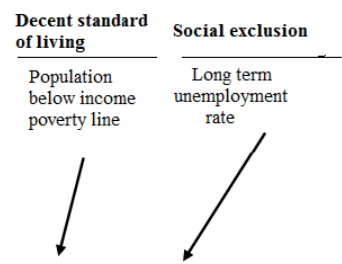

Human poverty index for selected OECD countries (HPI-2)

GDI

DIMENSION
INDICATOR
INDEX

INDEX OF
EVENNESS OF
DISTRIBUTION
BETWEEN
GENDERS
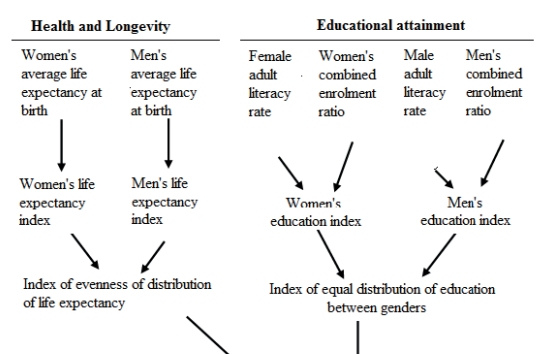

Decent standard of living Women's Men's estimated estimated literacy enrolment literacy enrolment rate ratio rate
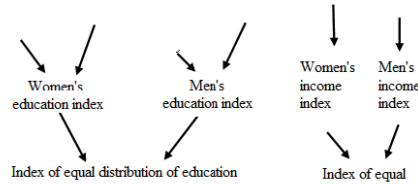

Women's Men's income income index index GENDERS

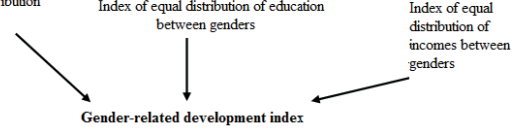




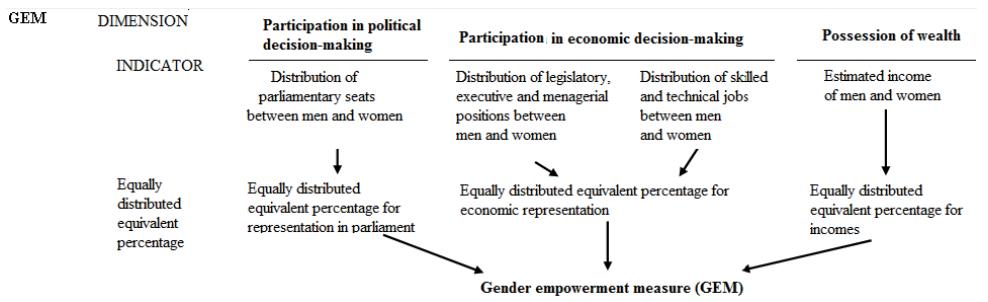

Figure 8-3. Components of the Human Development Index (based on HDR, 2005)

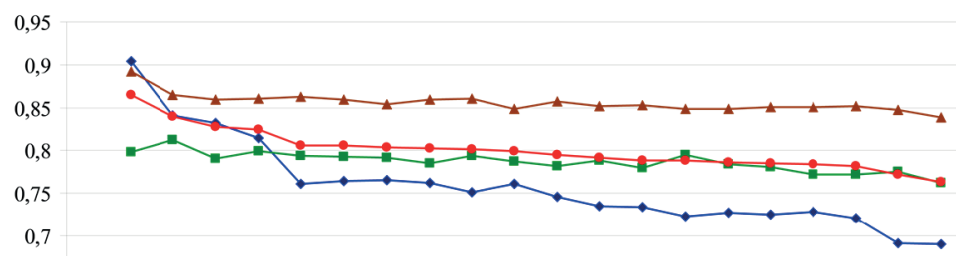

0,65

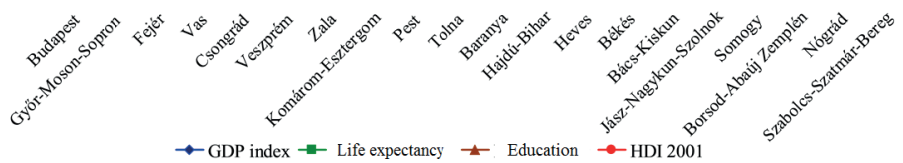

Figure 8-4. HDI values per county in descending order and component indicators in 2001 (Melinda Smahó: A humán fejlettség regionális dimenziói http://www.sze.hu/etk/_konferencia/publikacio/Net/eloadas_smaho_melinda.doc accessed on 16/04/2018)

The HDI is theoretically calculable using regional data if the differences are significant enough for the three component indicators. As the Hungarian data for counties show, the data only partially meet this condition. The fluctuation in the calculated HDIs are largely caused by regional differences in one indicator: GDP. Differences in life expectancy at birth and education are luckily not yet significant. In consequence of this, all the regional statistics indicate is that Budapest and Győr-Sopron favourably, and Szabolcs-Szatmár-Bereg and Nógrád unfavourably 'stick out' in terms of the HDI average.

\subsection{Sustainable consumption and the Easterlin paradox}

Developed by researchers of the far-from-environmentally-biased Massachusetts Institute of Technology (MIT), the petals of the sunflower of well-being clearly illustrate the components of the quality of life (Figure 8-5.). Value-system-dependent shifts can be made between individual dimensions. For example, we often give up our free time and risk our health to obtain material wealth. We appreciate making an immediate profit - such as a higher income - more than we value distant 
losses such as the inconvenience caused by a deterioration in our health or the irreplaceable joy of chatting and having fun with loved ones. The shifts may appear to involve independent decisions, but in reality we may be trapped. We all know well that a person who cannot be counted on during times of abundant work will soon remain without anything to do. Social value systems may also be centred on competitiveness, which has little to do with quality of life.

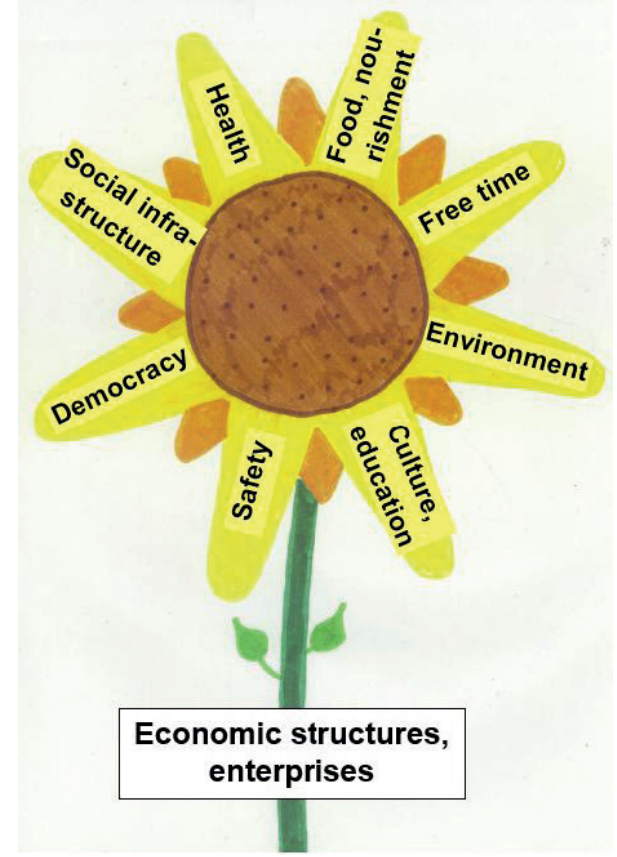

Figure 8-5. The Sunflower of well-being: primary components of the quality of life (graphic by Imola Kocsis, (C2018)

The idea that the main goal of a human life is 'self-fulfilment' has become a major theme in Hungarian public perception. In practice, 'self-fulfilment' does not mean maximising one's quality of life, but more strongly suggests the promotion of selfishness, which may be useful for the efficient operation of the economy, but has little to do with human happiness. Quality of life does not seem to be related to welfare or sustainable development; in reality, social perceptions about quality of life fundamentally influence sustainability. Making a differentiation between welfare and 'well-being' is important because if a 'shopping cart' contains more of a 'cultural component' (as broadly interpreted), any increase in well-being will require less growth in material and energy consumption, and thus have reduced environmental impact. 
Quality of life: a standard composed of the total of factors that affect one's life and well-being. The concept includes the components of living standard, as well as factors that are financially inexpressible yet which significantly influence our life and well-being. These include, for example, the social condition of individuals and groups, health situation, life expectancy, the status of cultural values, and the environment. Environmental impacts - beyond direct economic and biological effects - may also have psychological consequences which significantly affect quality of life. These can include feelings of discomfort and depression about the contamination and aesthetic deterioration of the environment, an increase in the risk of damage to health, or risk of industrial disaster. (Láng, 2011)

The market economy in its classic form was based on local support systems and cultures which are sustainable. Capitalism developed through radical growth in labour productivity and distribution, while material consumption has become 'glorified' as a value in itself. Material consumption has become the main driving force of the development and existence of the global economic system. Under conditions of globalised capitalism, the local market economy is outside the direct control of members of society and economic power dominates; consequently, the global economic system is not sustainable in an environmental sense.

According to estimates, the population of the Earth is still growing and will reach between seven and ten billion until 2050. It is also public knowledge that at present 800 million people are 'living' (starving) on less than $\$ 1$ per day, while nearly three billion live on less than $\$ 2$ daily (i.e., at poverty level).

This still means that the economy can be operational, because people who work 10-14 hours a day are fairly productive, and can 'finance' serious social support systems.

The focus on 'competition' generates the illusion that every 'game' in life is zero-sum. If tax revenue is spent on environmental protection, there will be no resources left for building motorways. If pensions are subsidised, there will be nothing left to support small enterprises. These suppositions that suggest that one goal can be realised only to the detriment of another are all too familiar.

Sustainable development needs a radically different way of thinking. 'Sustainability' refers to the multiple dimensions of development and can help erase the word 'or' from our dictionary (since the simultaneous development of multiple dimensions can only be expressed using the words 'and/both'). Favourable compromises always exist, while it is never true that there are only two options to pick from: typically, innumerable options exist in parallel. The sin of dominant paradigms is that during certain periods certain solutions are prioritised, and society is faced with a choice. It is precisely this situation that necessitates government intervention: a system of institutions operated by so- 
ciety is required without which there would be no environmental safety, or even an environment of tolerable quality.

It is notable, with reference to human needs, that in a study from 2000 Csíkszentmihályi questions Maslow's general thesis that consumers make rational decisions about how to satisfy their own needs (see Maslow's pyramid, Figure 8-6.).

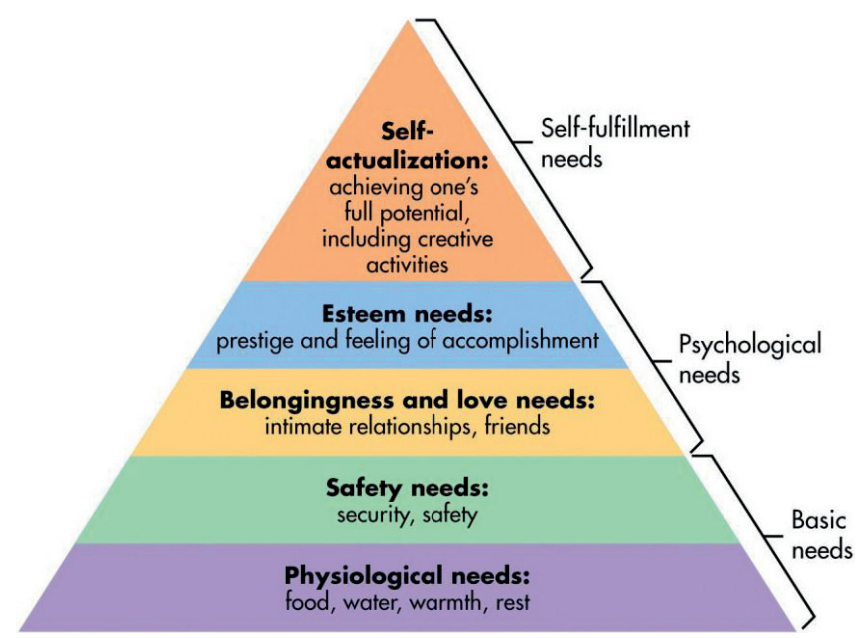

Figure 8-6. Maslow's pyramid (based on Maslow, 1954, https://www.simplypsychology.org/maslow.html - accessed on 16/04/2018)

Csíkszentmihályi (Csikszentmihalyi, 2000) states that in a welfare economy consumers care little about 'existence', itself but their attention turns towards satisfying 'experiential' needs. That is, they need to engage in activity to satisfy a need for practical experience. Interestingly enough, the consumer's main interest is no longer in merchandise, but the experience of shopping itself. This may have positive or negative consequences from the perspective of sustainable development.

Sustainability means ensuring the continuous existence of 'something'. GDP growth does not necessarily involve a growth in welfare, and even less that of well-being. Growth in well-being includes the development of education, an increase in healthy life expectancy, an improvement in life and social security, and even the improvement of factors such as personal freedom, which are all components of the quality of life.

According to the Easterlin Paradox (Easterlin, 1973), the satisfaction or happiness of people is poorly correlated to growth in wealth (Stevenson - Wolfers, 2008 ). Those who do not get preoccupied with statistical averages but have 
thought about individuals claim that over half of the active population suffer from depression, and this illness tends to attack those who are 'wealthy'. It is perhaps not only them, but this group certainly constitutes the basis for the diagnosis of depression as the endemic disease of the modern age. Earth's carrying capacity is limited, and seems to be failing under the environmental impact continually generated by mankind: the needless and mindless consumer habits of the rich, and the misery of the poor, since both overload the global ecosystem. ${ }^{11}$

Mária Csutora and her colleagues at the Institute of Environmental Science at Corvinus University revealed an interesting phenomenon about people's environmental awareness and ecological footprint. While one would expect the ecological footprints of environmentally conscious people to be smaller than those of non-environmentally conscious people, the related research found no such correlation. In a study with major international relevance, Csutora calls the phenomenon, which we might label the Csutora Paradox, the 'BehaviourImpact Gap'. The main point of the paradox is that the ecological footprints or the carbon footprints of so-called brown- (the least environmentally conscious) and green- (the most environmentally conscious) consumers do not significantly differ from each other. Ecological footprint depends on income, but the beneficial effect of environmental awareness cannot be demonstrated (Csutora, 2012).

Environmentally conscious consumers are ready to 'self-limit' in some ways (such as selectively collecting waste, turning off the tap, disconnecting the telephone recharger, etc.) that have only marginal effects on ecological footprint, while they refuse to make radical changes. They typically do not give up flying, or become vegetarians, or move into smaller homes. This certainly does not mean that environmentally conscious consumption does not have long-term beneficial effects. However, these long-term effects are structural in nature, and are difficult to express in figures.

There seems to be only one feasible option left, and that is to make consumption sustainable. This, however, also involves some challenges with definition.

UNEP 1999: 'Sustainable consumption is not about consuming less, it is about consuming differently, consuming efficiently, and having an improved quality of life'

National Consumer Council, UK, 2003: 'Sustainable consumption is a balancing act. It is about consuming in such a way as to protect the environment, use natural resources wisely and promote quality of life now, while not spoiling the lives of future consumers.'

11 For a comprehensive parallel analysis of subjective well-being, economic performance (GDP) and sustainability (ecological footprint) using the analytical 'Dataquadrate' tool, see Kocsis (2012). 
How can this be realised? According to SEPA's study, the following are the available options:

- Decrease the raw material content of products and services demate $\neg$ rialisation

- Lengthen the life cycle of products

- Increase eco-efficiency - the environmental impact associated with a unit of product/service

- More efficiently exploit the useful life span of a product

There is huge potential in every field. This is easy to realise if we consider how different the per-capita level of material consumption of individual countries is.

One of the structural differences involves the role of services in the economy. A high level of use of services is typical of the Italians (and Mediterranean people in general), who often eat out (the average use of 'outside' catering is as high as 7-15\%), while the rate is relatively low in North-European countries (4-5.5\%). There are exceptions, of course, but structural differences of such a scale in terms of food consumption (constituting $20-25 \%$ of total consumption) have significant employment-related and environmental effects. It may seem strange, but the specific per capita environmental impact of restaurant services is certainly lower than for those associated with home-made meals, which involve a lot of avoidable cost and indirect environmental impacts related to refrigeration, transport, etc.

\begin{tabular}{|c|c|c|c|c|}
\hline & Food & $\begin{array}{c}\text { Non-alcoholic } \\
\text { drinks }\end{array}$ & Alcoholic drinks & $\begin{array}{c}\text { Restaurants, } \\
\text { catering services }\end{array}$ \\
\hline EU27 & 11.9 & 1.2 & 1.5 & 6.9 \\
\hline Belgium & 12.5 & 1.1 & 1.7 & 5.2 \\
\hline Czech Republic & 14.1 & 1.5 & 3.7 & 5.2 \\
\hline Germany & 9.8 & 1.4 & 1.5 & 4.8 \\
\hline Greece & 16.0 & 0.8 & 0.9 & 10.4 \\
\hline Spain & 13.1 & 1.0 & 0.8 & 14.8 \\
\hline France (2010) & 12.2 & 1.1 & 1.5 & 5.4 \\
\hline Italy & 13.7 & 1.0 & 0.7 & 7.7 \\
\hline Hungary & 15.1 & 2.6 & 5.3 & 3.5 \\
\hline Malta (2010) & 13.6 & 1.9 & 1.4 & 8.6 \\
\hline The Netherlands & 10.7 & 1.0 & 1.2 & 4.5 \\
\hline Austria & 9.6 & 1.2 & 1.3 & 7.9 \\
\hline Poland & 18.2 & 1.8 & 3.8 & 2.2 \\
\hline Romania & 26.6 & 2.5 & 2.2 & 2.8 \\
\hline Finland & 11.9 & 1.1 & 3.7 & 6.0 \\
\hline United Kingdom & 8.5 & 1.2 & 1.7 & 8.8 \\
\hline
\end{tabular}

Table 8-2. Final consumption of foodstuff by households as percentage of total consumption (2009) (Eurostat, 2011/27)

If the rate of use of services increases, will this spur radical growth in the eco-efficiency of the economy? It is conceivable that such a shift would result 
in some change in the growth of the life cycle of products, and a decrease in the volume of resources that are consumed.

Is it possible that products will largely be replaced by services in the future? Does the path to the future really involve producers extending the life cycle of their products (with their main profile then being rentals rather than one-off sales) instead of striving to produce more and more new models to sell? As long as the provision of services involves a greater competitive advantage and less cost than production, companies will probably be inclined to use this business model that is more environmentally friendly. We should not forget, though, that companies are not altruistic: if a model or process is created that is more competitive and profitable, environmental interests may again take a back seat to business considerations.

\begin{tabular}{|l|l|l|l|}
\hline Product group & 2002 & 2011 & $2011 / 2002 \%$ \\
\hline Bread and cereals, total & 105.6 & 81.3 & 77 \\
\hline Beef and veal & 1.1 & 0.7 & 64 \\
\hline Pork & 17.2 & 15.3 & 89 \\
\hline Fowl & 21.4 & 16.2 & 76 \\
\hline Meats, total & $\mathbf{6 0 . 7}$ & 52.2 & $\mathbf{8 6}$ \\
\hline Fish, canned fish & $\mathbf{1 . 7}$ & $\mathbf{1 . 6}$ & $\mathbf{9 4}$ \\
\hline Milk (litres) & $\mathbf{6 6 . 4}$ & $\mathbf{5 0 . 4}$ & $\mathbf{7 6}$ \\
\hline Yoghurt, kefir, sour cream (litres) & $\mathbf{9 . 9}$ & $\mathbf{1 1 . 6}$ & $\mathbf{1 1 7}$ \\
\hline $\begin{array}{l}\text { Canned milk, milk powder, other } \\
\text { milk derivatives, cheese, quark }\end{array}$ & $\mathbf{4 . 9}$ & $\mathbf{5 . 6}$ & $\mathbf{1 1 4}$ \\
\hline Eggs & $\mathbf{1 9 5}$ & $\mathbf{1 4 1}$ & $\mathbf{7 2}$ \\
\hline Fat, total & $\mathbf{2 1 . 5}$ & $\mathbf{1 6 . 3}$ & $\mathbf{7 6}$ \\
\hline Citrus Fruit & 9.1 & 6.4 & 70 \\
\hline Bananas &.. & 3.9 & \\
\hline Apples & 14.7 & 9.6 & 65 \\
\hline Water melons & 9.2 & 4.9 & 53 \\
\hline Fruit, total & $\mathbf{4 8 . 1}$ & $\mathbf{3 8 . 9}$ & $\mathbf{8 1}$ \\
\hline Potatoes & 42.6 & 28.6 & 67 \\
\hline Vegetables and potatoes, total & $\mathbf{1 0 4 . 6}$ & $\mathbf{7 8 . 8}$ & $\mathbf{7 5}$ \\
\hline Sugar & $\mathbf{1 6 . 2}$ & $\mathbf{1 2 . 4}$ & $\mathbf{7 6}$ \\
\hline Fruit juices (litres) & $\mathbf{1 5 . 8}$ & $\mathbf{1 2 . 1}$ & $\mathbf{7 7}$ \\
\hline Wine, grape must (litres) & $\mathbf{7 . 9}$ & $\mathbf{5 . 7}$ & $\mathbf{7 2}$ \\
\hline
\end{tabular}

Table 8-3. Annual per capita food consumption in Hungary (2002-2011) [kg]

Domestic food consumption has significantly decreased in the past ten years in the main product groups, with the exception of a few dairy products. This may partly be explained by the ageing of Hungarian society, because the number of young children (with similarly low consumption) has also declined. From an environmental perspective, however, it is interesting that the per capita consumption 
of banana and citrus fruit is equal to that of apples. Domestic beef consumption - the item with the largest ecological footprint - is insignificant.

\subsection{To what end environmental pressure? A simplified model of human satisfaction}

The I=PAT formula (explained in Chapter 1-1) and the opportunity for measuring subjective well-being raise questions about how any human impact is exerted on the environment. The claim that a neutral mathematical formula also makes a value judgment would be a bold statement; however, it is difficult to put aside the thought that the conventional I=PAT equation appears to include environmental impact as an end in itself - as if the very essence of its meaning were absent; i.e., the formula suggests that there exists a rationale for transforming our environment if and to the extent that it will effectively improve human well-being (the point is also applicable to the concept of economic growth, which could become economically unviable beyond a certain level; see Daly, 1999). However, it is possible to formulate another equation to show the impact of the use of material resources on human happiness:

$$
I_{\text {happiness }}=P * A_{\text {material }} * T_{\text {happiness }}
$$

Here, impact (I) is measured in terms of happiness units of subjective wellbeing, population $(P)$ in the number of people, and affluence $(A)$ in per capita $\mathrm{gHa}$ (similarly to the measurement of ecological footprints in global hectares ( $\mathrm{gHa}$ ), see Chapter 3). This defines T (technology) as a unit of happiness over affluence $(\mathrm{gHa})$. At first glance, this would appear to be some sort of 'happiness efficiency' indicator, showing the amount of human happiness that can be associated with one global hectare of environmental pressure.

However, instead of communicating using such technical or technological 'efficiency indicators' it may be more appropriate to introduce the concept of celestial footprint, which also better captures the imagination. This makes the impact of the adjusted equation even more pronounced:

$$
I_{\text {happiness }}=P *(\text { per capita }) \text { ecological footprint * celestial footprint }
$$

Unlike with the original I=PAT formula, here the logic of 'the more the better' applies, which in today's growth-oriented civilisation may be a message more readily received than approaches that highlight environmental limits and imply restrictions.

One benefit of this adjusted formula is that, in taking into account the size of the population, it subdivides human satisfaction and happiness into 'earthly' and 'celestial' components, which are measurable factors. Another benefit is that increase or maintenance of overall happiness may be defined as an objective that 
is difficult to challenge. That said, the means of implementation and the issue of sustainability are of strategic significance: it indeed makes a difference what mix of various types of footprints are used to achieve a specific level of satisfaction.

The incorporation of human happiness and satisfaction into the analysis adds new meaning to the I=PAT formula, subdividing environmental pressure into multiple factors. Although even the original formula has the 'power of revelation' and creates a treasury of analyses (York et al., 2003), the solution proposed here places more focus on the potential inherent in the idea that man 'does not live by bread alone' (Matthew 4:4). Pressure on the environment (including economic activity) should not be considered the end, but the means of human existence.

\subsection{Celestial footprint, happy planet}

Above a certain 'level of development' at which the bare necessities of human life are, by and large, considered to have been provided (yet the finiteness of the environment is also perceived with increasing clarity), it may be of strategic significance to introduce into the general discourse an indicator that can be communicated well and is measurable with relative ease, such as the celestial footprint. At an acceptable level of material development, this indicator satisfies the requirement that 'the more the better'. That said, for the most part the concept provides a theoretical framework that can be populated with data in a number of ways. In this case, economic performance is quantified by GDP, environmental pressure by ecological footprint, and happiness and satisfaction by subjective well-being. The latter represents a typical individualistic western approach, which nevertheless allows respondents to assess their situation based on their own concepts of happiness. Giving consideration to this, in addition to GDP (which is frequently viewed as an objective indicator of material welfare) is definitely a step forward. Happiness (welfare) and environmental sustainability should be appraised in combination. The magnitude of the challenge is well illustrated by the combination of the scores for per capita ecological footprint and subjective well-being (happiness) in a single chart (Figure 8-7.). The 'higher' positions in the chart represent countries with greater material comfort, while countries with higher satisfaction/happiness scores are shown on the right. The chart suggests the striking fact that greater comfort is associated with greater happiness, and vice versa. This is not a surprise. However, the ideal is represented by the bottom right corner of the chart, where high happiness is associated with a level of material comfort below the current average. Currently, some Latin-American countries such as Costa Rica, Brazil, etc. come closest to that ideal (In Figure 8-7., Hungary is mapped around the middle of the chart, in the vicinity of China, with values approximating the global average in terms of both happiness and internal control).

The problem is also excellently specified by another analytical tool, the Happy Planet Index. This adjusts happiness according to per capita ecological 
footprint by deriving the ratio of the two, and also considers life expectancy at birth, and more recently income inequality as well. The indicator enables countries to be ranked (Jeffrey et al., 2016), again with Latin-American countries scoring the highest. In these countries, relatively low material comfort is associated with rather high levels of happiness. The bottom of the list is occupied mainly by countries in Sub-Saharan Africa, which are sustainable in an environmental sense, but offer living conditions that no-one wants to have - not even the residents of the countries concerned, the region being the unhappiest in the world. In Figure 8-7. these countries are shown in the bottom left corner.

Although by incorporating life expectancy and income inequality the Happy Planet Index introduces key variables into the analysis, there is still a point in establishing a less complex indicator that is as simple as pie to use. This is per capita ecological footprint according to subjective well-being. In a dull, technical sense, this could be referred to as happiness efficiency, or to use a more elevated term that is also more fortunate from the perspective of communication, celestial footprint. This is to say, celestial footprint is, in a sense, complementary to the earthly, material (ecological) footprint in terms of human well-being (completeness), but has a multiplicity of implications for natural sciences by including the feature human happiness that is typically addressed by the social sciences.

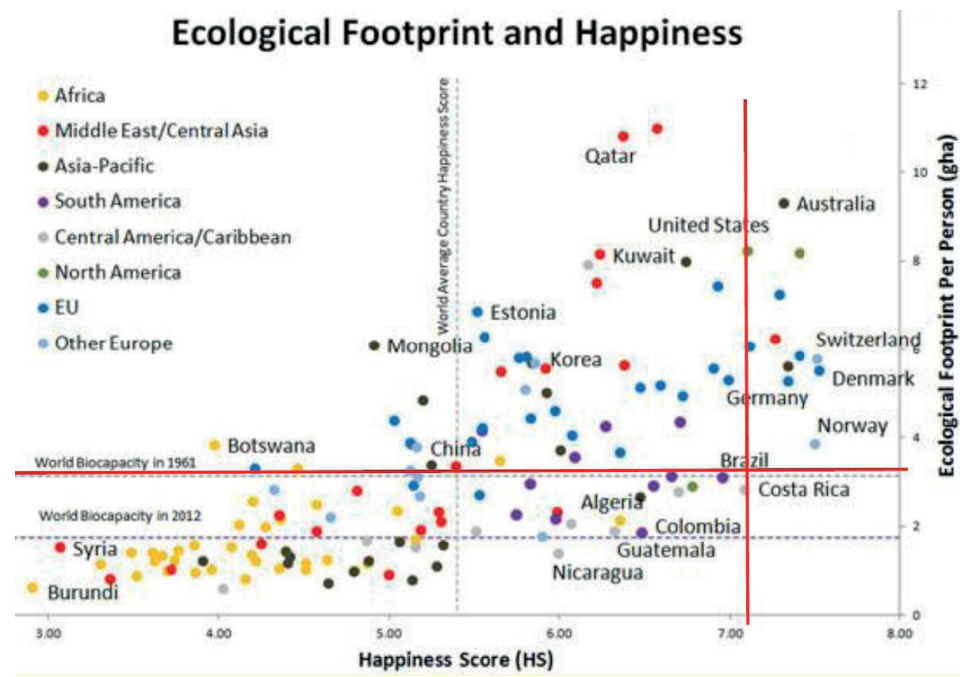

Figure 8-7. Per capita ecological footprint and happiness (subjective well-being) in 2012 (http:// www.footprintnetwork.org/2016/03/25/imagine-happiness-treading-lightly-earth/ accessed on 16/04/2018; the two perpendicular red lines are the author's completion)

One important direction for research is understanding the root causes of the differences in the 'performance' of various social entities in terms of ce- 
lestial footprint (happiness efficiency), and possible ways for 'underperformers' to adopt any good practices. Such research may, for example, seek to explain how Australia and Norway can achieve the same level of happiness at a completely different level of internal control, or how China (or Hungary) and Brazil can achieve completely different levels of happiness (i.e., celestial footprints of rather different size and composition) at the same level of material comfort.

\subsection{Voluntary simplicity}

Any inquiry that is not carried out nationwide, which is the level undoubtedly best covered in terms of economic and sustainability data, will find a number of good practices at the local level. One need not go as far as Latin America, nor the United States (see also Takács-Sánta, 2017), even though the emergence and spread of the voluntary simplicity movement in the latter is a rather remarkable phenomenon, given that the country in question is one of the most developed and richest in the world, and serves as an example in many respects (obviously not for its environmental sustainability). The philosophy and practice of the movement throws vivid light on the opportunity of exploiting the human potential inherent in controlling consumption, which does not amount to giving up but rather opening up a broader and freer form of human completeness.

For these reasons it is worthwhile examining some of the components of this lifestyle, which is equally characterised by a high level of subjective wellbeing (happiness) and resistance to material growth and consumerism. The voluntary simplicity movement, which is mostly present in the United States, can be seen as powerful in terms of both theory and practice (Gregg, 1936; Elgin-Mitchell, 1977; Elgin, 1993). The movement continues to attract general interest (Schreurs, 2010; Gambrel-Cafaro, 2010; Jackson, 2008; GandolfiCherrier, 2008; Shi, 2007). For reasons of space, the ramified concept cannot be explained here in full detail; therefore, the following is a description of the typical characteristics of proponents of voluntary simplicity.

The theory and practice of voluntary simplicity may also be seen as institutionalised resistance to consumer society. The essence of voluntary simplicity is a way of life which is outwardly simple, and inwardly rich (Elgin, 1993). It has its roots in the legendary frugality and self-reliance of the Puritans, Thoreau's naturalistic visions from his time at Walden Pond, Emerson's practical and spiritual espousal of simple living and high thinking, as well as the teachings and social philosophy of spiritual leaders with different authority such as Jesus and Gandhi. According to the advocates of voluntary simplicity, the current social and environmental crisis puts special emphasis on these ideas, urging people to lead a socially and environmentally responsible way of life (for more 
detail about voluntary simplicity and a critique, see Kocsis, 2002, Chapters 3 and 4). In their classic paper, Elgin and Mitchell (1977) distinguish between five core values of voluntary simplicity: material simplicity, human scale, selfdetermination, ecological awareness, and personal growth.

But who actually are the voluntary simplifiers? Key information about this can be found from the questionnaires used by researchers to investigate the movement. Intended to identify voluntary simplifiers, the following statements, evaluated by Shama and Wisenblit (1984), have also been frequently used in more recent empirical research: (1) I believe in material simplicity, i.e., buying and consuming only what I need; (2) I believe that 'small is beautiful', e.g., I prefer smaller cars over large cars; (3) I believe that a product's function is usually more important than its style; (4) I am interested in personal growth more than economic growth; (5) I am determined to have more control over my life as a consumer - e.g., stay away from buying on instalments; (6) I consider myself ecologically responsible (Shama-Wisenblit 1984, p. 233). Obviously, the values and commitments measured on the basis of the level of agreement with each of these statements are strongly correlated with life achievement characterised by lower material needs and stronger internal control.

Questionnaires about the practice of voluntary simplicity are often concerned with respondents' daily activities. Activities that were possible a good thirty years ago in California, which was then and still is one of the materially most developed regions of the world, have now spread worldwide. Consequently, the questionnaire administered in California by Dorothy Leonard-Barton in 1981 has since become more generally applicable, and continues to be used in a number of studies that investigate lifestyles and ecological sustainability in the context of voluntary simplicity. Typical proponents of voluntary simplicity make gifts instead of buying them; ride a bicycle for exercise, recreation or transportation; recycle newspapers and bottles or take them to a bottle bank; learn skills to increase their self-reliance (for example, decorating); intentionally eat meatless main meals; buy clothing at second-hand stores; buy major items of furniture second-hand (over 25 USD); make furniture or clothing for the family; exchange goods or services with others in lieu of payment in money; grow the vegetables the family consumes during the summer (Leonard-Barton, 1981, pp. 250-251; a simplified list). With regard to the voluntary nature of the above activities (if these phenomena were involuntary, they would imply material deprivation), there is good reason to assume that voluntary simplifiers are capable of significantly decelerating the material consumption of the economy.

Maslow's (1954) thesis about basic human needs is compatible with the supposition that voluntary simplicity may appeal to people following the full satisfaction of their basic physical and physiological needs (see earlier in this Chapter). 'Voluntary simplicity is thus a choice a successful corporate lawyer, not a homeless person, faces; Singapore, not Rwanda. Indeed, to urge the 
poor or near poor to draw satisfaction from consuming less is to ignore the profound connection between the hierarchy of human needs and consumption. It becomes an obsession that can be overcome only after basic creature comfort needs are well and securely sated' (Etzioni, 2004, p. 415). Thus, what voluntary simplicity seeks to restrict is consumerism, not consumption (Etzioni, 2004, p. 416).

The crucial question is therefore whether what can occasionally be accomplished on a small scale in smaller human communities can also be accomplished on a larger scale at a general level; i.e., whether it is possible for humankind to achieve happiness and sustainability at the same time. 


\section{Sources Cited}

Barro, R. J. (1979): On the determination of the public debt. The Journal of Political Economy, 940-971.

Barro, R. J. (1988): The Ricardian approach to budget deficits. National Bureau of Economic Research Cambridge, Mass., USA. Retrieved from http:// www.nber.org/papers/w2685

Bartman, T. R. (1993): Dodging Bullets FORTNIGHTLY, October 1, 1993, 21-22.

Bator, F. M. (1958). The anatomy of market failure. The Quarterly Journal of Economics, 351-379.

Baumol, W. J., Oates, W. E. (1988). The theory of environmental policy. Cambridge University Press

Berger-Schmitt, R., Noll, H-H. (2000): Conceptual framework and structure of a European system of social indicators. EUreporting Working Paper, No. 9. Mannheim: ZUMA; http://www.gesis.org/en/social_monitoring/social_indicators/EU_Reporting/pdf_files/paper9.pdf

Bianchi, M. (2012). A Joyful Economist. Scitovsky's Memoirs. History of Economic Althought and Policy. Retrieved from http://www.francoangeli.it/Riviste/ Scheda_Rivista.aspx? IDarticolo $=46615$

Blanchard, O. J., Chouraqui, J.-C., Hagemann, R., \& Sartor, N. (1991). The sustainability of fiscal policy: New answers to an old question. NBER Working Paper, (R1547). Retrieved from http://papers.ssrn.com/sol3/papers. cfm?abstract_id=227461

Borghesi, S. (1999). The environmental Kuznets curve: a survey of the literature. Retrieved from http://papers.ssrn.com/sol3/Papers.cfm?abstract_ id $=200556$

Brealey, R. A., Myers, S. C., Allen, F., \& Mohanty, P. (2012). Principles of corporate finance. Tata McGraw-Hill Education.

Broome, J. (2012): Climate Matters: Ethics in a Warming World. New York: W. W. Norton and Company

Brundtland, G. H. et al. (1987). World Commission on Environment and Development. Our Common Future. Oxford: Oxford University Press.

Bruni, L. (2006): Civil Happiness: Economics and Human Flourishing in Historical Perspective. Routledge, New York Carson, R. (1962): Silent Spring. Houghton Mifflin Company, Boston, Mass.

Clark, W. (2003): Revisited - The Real Reasons for the Upcoming War With Iraq: A Macroeconomic and Geostrategic Analysis of the Unspoken Truth (https://www.ratical.org/ratville/CAH/RRiraqWar.html - Accessed on 16/04/2018)

Coase, R. H. (1960). The problem of social cost. Springer. Retrieved from http://link.springer.com/chapter/10.1057/9780230523210_6 
Cole, M. A., Rayner, A. J., Bates, J. M. (1997): The environmental Kuznets curve: an empirical analysis. Environmental and Development Economics 2 (4), 401-416.

Csikszentmihalyi, M. (2000). The Costs and Benefits of Consuming. Journal of Consumer Research, 27.

Csutora, M. (2012). One more awareness gap? The behaviour-impact gap problem. Journal of Consumer Policy, 35(1), 145-163.

Daly, H. E. (1974). The economics of the steady state. The American Economic Review, 64(2), 15-21.

Daly, H. E. (1999): Ecological Economics and the Ecology of Economics: Essays in Criticism. Edward Elgar, Cheltenham, UK, Northampton, MA, USA

Daly, H. E. (2005). Economics in a full world. Scientific American, 293(3), 100-107.

Davis, L. S., Johnson, K. N. (1987): Forest Management. McGraw-Hill Book Co.

Dolenc, P. (2006). Doubtful Sustainability of Public Finances in Slovenia. Prague Economic Papers, 15(3), 268-281.

Easterlin, R. A. (1973). 'Does Money Buy Happiness?'. The Public Interest, 3-10.

Easterlin, R. A. (1995). Will Raising the Income of all Increase the Happiness of All? Journal of Economic Behavior and Organization 27:1, 35-47.

Elgin, D.m Mitchell, A. (1977): Voluntary Simplicity (3), The CoEvolution Quarterly, Summer, 4-19.

Elgin, D. (1993): Voluntary Simplicity: Toward a Way of Life That Is Outwardly Simple, Inwardly Rich, Revised Edition, New York: Morrow (first published in 1981).

Eom, Y.-S. and Larson, D. (2006): Valuing housework time from willingness to spend time and money for environmental quality improvements, Review of Economics of the Household 4 (3), 205-227.

Etzioni, A. (2004): The Post Affluent Society, Review of Social Economy 62 (3), 407-420.

Eurostat (2011/27). From farm to fork - a statistical journey along the EU's food chain. Eurostat.

Fabók Veronika, Kalóczkai Ágnes, Kelemen Eszter, Kovács Krasznai Eszter, Pataki György (2014): A Hevesi-sík koevolúciós fejlődése az ökoszisztéma szolgáltatások változásain keresztül. In: Kelemen Eszter, Pataki György (szerk.) Ökoszisztéma szolgáltatások: A természet- és társadalomtudományok metszéspontjában. Gödöllő; Budapest: Szent István Egyetem, Környezet- és Tájgazdálkodási Intézet; Environmental Social Science Research Group (ESSRG), 2014. pp. 110-129.

Field, Barry C. (1997): Environmental Economics: An Introduction; második kiadás, Irwin/McGraw-Hill, New York, NY 
Fisher, A. C. (1981): Resource and Environmental Economics. Cambridge Books, Cambridge University Press

Frank, R. H. (2011). The Darwin Economy: Liberty, Competition, and the Common Good by Robert H. Frank. Princeton: Princeton University Press.

Fredrick Taylor \& Management: Maximizing Productivity \& Efficiency - Video \& Lesson Transcript. (n.d.). Retrieved March 24, 2016, from http://study.com/ academy/lesson/fredrick-taylor-management-maximizing-productivity-efficiency.html

Gambrel, J. C. - Cafaro, P. (2010): The Virtue of Simplicity, Journal of Agricultural and Environmental Ethics 23, 85-108.

Gandolfi, F., - Cherrier, H. (szerk.) (2008): Downshifting. A theoretical and practical approach to living a simple life. Hyderabad: Icfai University Press

Gini, C. (1912): Variabilità e mutabilità ('Variability and Mutability')

Gómez-Baggethun, E., D. Barton, L. Braat, H. Saarikoski, E. Kelemen, M. García-Llorente, E., J. van den Bergh, P. Arias, P. Berry, L., M. Potschin, H. Keene, R. Dunford, C. Schröter-Schlaack, P. Harrison) (2014): State-of-the-art report on integrated valuation of ecosystem services. European Commision FP

Gray, R. (2002). Of messiness, systems and sustainability: towards a more social and environmental finance and accounting. The British Accounting Review, 34(4), 357-386.

Gregg, R. (1936): Voluntary Simplicity. Visva-Bharati Quarterly, August, reprinted in The CoEvolution Quarterly, 1977, Summer, 20-7.

Grossman, G. M. (1995). 2 Pollution and growth: what do we know? The Economics of Sustainable Development, 19.

Grossman, G. M., \& Krueger, A. B. (1991). Environmental impacts of a North American free trade agreement. National Bureau of Economic Research. Retrieved from http://www.nber.org/papers/w3914

Grossman, G., \& Krueger, A. (1995). Economic environment and the economic growth. Quarterly Journal of Economics, 110(2), 353-377.

Guha-Sapir, D., Vos, F., Below, R., with Ponserre S. (2011): Annual Disaster Statistical Review 2010: The Numbers and Trends. Brussels: CRED http:// www.cred.be/sites/default/files/ADSR_2010.pdf (accessed on 16/04/2018)

Haines-Young, R., Potschin, M. (2013): Common International Classification of Ecosystem Services (CICES): Consultation on Version 4, August-December 2012. EEA Framework Contract No EEA/IEA/09/003, URL: www.cices.eu

Hankiss E. (1983): Társadalmi csapdák, Diagnózisok, Magvető, Budapest.

Harangozó, G., Csutora, M., Kocsis, T. (2018): How big is big enough? Toward a sustainable future by examining alternatives to the conventional economic growth paradigm. Sustainable Development 26 (2), 172-181.

Harangozó G., Marjainé Szerényi Zs. (2014): Mennyit ér a zajterhelés csökkenése?: Zajvédelmi intézkedések értékelése a haszonértékelések átvitelével, KÖZGAZDASÁGI SZEMLE 61:(1) pp. 68-91. 
Hardin, G. (1968). The tragedy of the commons. Science, 162(3859), 12431248.

Hardin, G. (1998). Extensions of 'The Tragedy of the Commons.' Science, 280(5364), 682-683. http://doi.org/10.1126/science.280.5364.682

Harris, J. R. (1967). The employment of steam power in the eighteenth century. History, 52(175), 133-148.

Hawken, P., Lovins, A., \& Lovins, L. H. (1999). Natural Capitalism, Creating the Next Industrial Revolution. Boston, New York, London: Little, Brown and Company.

Head (1962): Public Goods and Public Policy; Public Finance XVII No.3

Hepburn, C. - Duncan, S. - Papachristodoulou, A. (2010): Behavioural Economics, Hyperbolic Discounting and Environmental Policy; Environmental and Resource Economics 46, 189-206.

Hicks, J. R. (1939). Value and Capital: An Inquiry into Some Fundamental Principles of Economic Theory. Oxford, UK: Clarendon Press.

Hirschmann, A. (n.d.). 0. 1977. The Passions and the Interests: Political Arguments for Capitalism Before Its Triumph. Princeton, NJ: Princeton University Press.

Hoag, D. L., Hughes Popp, J. S., \& Hyatt, D. E. (1998). Sustainability and Resource Assessment A Case Study of Soil Resources in the United States National Center for Environmental Assessment Office of Research and Development U.S. Environmental Protecti. Washington DC.: National Center for Environmental Assessment Office of Research and Development U.S. Environmental Protection Agency.

Hoeppe, P.: Worldwide Natural Disasters - Effects and Trends http:// www.munichre-foundation.org/NR/rdonlyres/E7ED6B1D-2D9F-4E64-9FB35C8A4539AD9B/0/20051116_Hoeppe_Hohenkammer_short_WEB.pdf

Holland, A. (1995): The Assumptions of Cost-Benefit Analysis - A Philosopher's View; In: Willis, K. W., Corkindale, J. K. (1995) (eds.): Environmental Valuation: New Perspectives; CAB International, Wallingford

Holling, C. S. (1973). Resilience and stability of ecological systems. Annual Review of Ecology and Systematics, 1-23.

How Many Energy Slaves Do We Employ? (2012). Source: http://www.earthtoys.com/emagazine.php?issue_number $=06.08 .01$ \&article=slaves

Hubbert, M. K. (1956): Nuclear Energy and the fossil fuels. Spring Meeting of the Southern District Division of Production, American Petroleum Institute, Plaza Hotel, San Antonio, Texas, 1956. március 7-9. http://www.hubbertpeak. com/hubbert/1956/1956.pdf (accessed on 13/04/2018)

Hummels, D. (1999). Have International Transportation Costs Declined? Chicago: University of Chicago, Graduate School of Business

Hummels, D. (2007). Transportation Costs and International Trade in the Second Era of Globalization. The Journal of Economic Perspectives 21 (3), 131-154. 
Husz I. (2001): AZ EMBERI FEJLŐDÉS INDEXE. Szociológiai Szemle 2001/2, pp. 72-83.

Inglehart, R., Klingemann, H.-D. (2000): Subjective Well-being by Level of Economic Development, in. Genes, Culture and Happiness. MIT Press, Cambridge, MA

IPCC Negyedik Értékelő Jelentése, Döntéshozói összefoglaló; letölthető az internetről: http://www.met.hu/pages/ipcc/ipcc_eghajlatvaltozas_2007.pdf

IUCN (1991). Caring for the Earth: A Strategy for Sustainable Living. Gland, Switzerland: IUCN

Jackson, T. (1993): Clean Production Strategies. Lewis Publishers, 1993

Jackson, T. (2008): The Challenge of Sustainable Lifestyles, in. State of the World 2008, The Worldwatch Institute, 45-60.

Jeffrey, K. - Wheatley, H. - Abdallah, S. (2016): The Happy Planet Index 2016 - A global index of sustainable wellbeing. New Economics Foundation (NEF), UK

Jevons, W. S. (1906). The coal question. Рипол Классик. Retrieved from https://www.google.com/books?hl=hu\&lr=\&id=TlcNAwAAQBAJ\&oi=fnd\&pg=P R7\&dq=Jevons + The+Coal+Question\&ots=UmokH8uoV-\&sig=UOjx5yz24Y2P KjbB_1sTIRxAJHM

Juhász-Nagy, P. (1984). Beszélgetések az ökológiáról. Budapest: Mezőgazdasági Könyvkiadó

Jócsik, L. (1971): Az öngyilkos civilizáció. A levegő és víz szennyeződése, a talajerő pusztulása. Közgazdasági és Jogi Könyvkiadó (KJK), Budapest

Kaderják P., Szekeres Sz. (2000): Estimating the Benefits of Cleaning Up Szíkgát Site in Hungary (2000). In: Morris, Glenn: Valuation Studies in Central and Eastern Europe. A Stocktaking Exercise. Final Report, manuscript, 9-11.

Kahneman, D. (2003). Maps of Bounded Rationality: Psychology for Behavioral Economics. The American Economic Review, 93(5) December, 1449-1475.

Kalóczkai Á., Kelemen E., Pataki Gy., Balázs B., Kovács E., Fabók V. (2014): Az ökoszisztéma szolgáltatások szerepe a tájhasználati konfliktusok kialakulásában és feloldásában. In: Kelemen Eszter, Pataki György (szerk.) Ökoszisztéma szolgáltatások: A természet- és társadalomtudományok metszéspontjában. Gödöllő; Budapest: Szent István Egyetem, Környezet- és Tájgazdálkodási Intézet; Environmental Social Science Research Group (ESSRG), 2014. pp. 94-109.

Kalóczkai Á., Pataki Gy., Kelemen E., Kovács E., Fabók V. (2015): A földhasználati konfliktusok tényezői és dinamikája védett természeti területeken, TERMÉSZETVÉDELMI KÖZLEMÉNYEK 21: pp. 97-107.

Kapp, K. W. (1978): The Social Cost of Business Enterprise. Russell Press, Nottingham

Kelemen E., Pataki Gy. (szerk.) (2014): Ökoszisztéma-szolgáltatások: A természet- és társadalomtudományok metszéspontjában. Gödöllő; Budapest: 
Szent István Egyetem, Környezet- és Tájgazdálkodási Intézet; Environmental Social Science Research Group (ESSRG), 2014.

Kelemen E., Pataki Gy., Balázs B., Bela Gy., Fabók V., Kalóczkai Á., Kohlheb N., Kovács E., Kovács Krasznai E., Mertens, C. (2014): A nem pénzbeli értékelési módszerek kontextusfüggő alkalmazásának tapasztalatai In: Kelemen Eszter, Pataki György (szerk.) Ökoszisztéma szolgáltatások: A természet- és társadalomtudományok metszéspontjában. Gödöllő; Budapest: Szent István Egyetem, Környezet- és Tájgazdálkodási Intézet; Environmental Social Science Research Group (ESSRG), 2014. pp. 56-75.

Kelemen, E., Málovics, Gy., Margóczi, K., 2009. Ökoszisztéma szolgáltatások felmérése során feltárt konfliktusok az Alpári-öblözetben. Termvéd. Közl. 15, 119-133.

Kelemen, E., Pataki, Gy. (2014b): Az ökoszisztéma-szolgáltatások értékelésének elméleti megalapozása. In: Kelemen E., Pataki Gy.(szerk.): Ökoszisztémaszolgáltatások: A természet- és társadalomtudományok metszéspontjában. Gödöllő; Budapest: Szent István Egyetem, Környezet- és Tájgazdálkodási Intézet; Environmental Social Science Research Group (ESSRG), 2014. pp. 3555.

Kerekes S. (2002): Méretgazdaságossági és jóléti optimum a környezetvédelmi szolgáltatásokban. Közgazdasági Szemle, 972-985.

Kerekes S. (2003): A magyar gazdaság környezeti teljesítménye az átmenet korában (The performance of the Hungarian economy in the transition period). Akadémiai doktori értekezés (academic doctoral dissertation), Budapest

Kerekes S. (2007): A környezetgazdaságtan alapjai; Aula, Budapest

Kerekes S. (2011): Contradictions Inherent in the Management of Natural and Industrial Disasters. Journal of Environmental Sustainability 1 (1) http://scholarworks.rit.edu/cgi/viewcontent.cgi?article=1006\&context=jes (accessed on 25/04/2018)

Kerekes S. (2018): What I have learned from David Pearce: There is always some good reason for optimism. manuscript

Kerekes S., Szlávik J. (1989): Gazdasági útkeresés - környezetvédelmi stratégiák, KJK, Budapest

Kerekes S., Szlávik, J. (2001): A környezeti menedzsment közgazdasági eszközei. COMPLEX Kiadó

Kerekes, Sándor, Kindler József, Bisztriczky József, Csutora Mária, Kovács Eszter, Kulifai József, Nemcsicsné Zsóka Ágnes, Pál Gabriella, Szabó László, Szerényi Zsuzsanna, (1998): A szigetközi térség természeti tőke értékváltozása. BKE, Környezetgazdaságtani és Technológiai Tanszék, Budapest.

Keynes, J. M. (1963). Essays in Persuasion, Economic Possibilities for our Grandchildren. New York: W.W. Norton \&Co.

Kletz, T. A. (1985): Eliminating Potential Process Hazards. Chemical Engineering, 92. k. April. pp. 48-68. 
Kocsis, T. (2002). Gyökereink - Örömröl és gazdagságról egy világméretü fogyasztói társadalomban. Budapest: Kairosz. 'English version: http://phd.lib. uni-corvinus.hu/737/1/Kocsis_Tamas_den.pdf '

Kocsis T. (2012): Looking through the dataquadrate: characterizing the human-environment relationship through economic, hedonic, ecological and demographic measures. Journal of Cleaner Production 35, 1-15.

Kocsis T. (2014): Is the Netherlands sustainable as a global-scale inner-city? Intenscoping spatial sustainability. Ecological Economics 101, 103-114.

Kocsis T., Kerekes S., Marjainé Szerényi Zs. (2018): The Puzzle of Externalized Costs: a Thought Experiment based on Strong Sustainability. Manuscript

Kocsis T., Marjainé Szerényi Zs. (2018): Pénzáldozat vagy időáldozat? Az értékelés és a költségátháritás problémái a természeti környezetet érintő kérdésekben. Magyar Tudomány 179 (2), 206-221.

Kovács E. (2014): Az ökoszisztéma szolgáltatások megjelenése a biodiverzitás politikában, In: Kelemen Eszter, Pataki György (Szerk.): Ökoszisztéma szolgáltatások: A természet- és társadalomtudományok metszéspontjában. Gödöllő; Budapest: Szent István Egyetem, Környezet- és Tájgazdálkodási Intézet; Environmental Social Science Research Group (ESSRG), 2014. pp. 131-143.

Kovács E., Kelemen E., Kalóczkai Á., Margóczi K., Pataki Gy., Gébert J., Málovics Gy., Balázs B., Roboz Á., Krasznai Kovács E., Mihók B. (2015a): Understanding the links between ecosystem service trade-offs and conflicts in protected areas. ECOSYSTEM SERVICES: SCIENCE, POLICY AND PRACTICE 12: pp. 117-127.

Kovács E., Kelemen E., Pataki Gy.(2011a): Ökoszisztéma szolgáltatások a tudományterületek és a szakpolitikák metszéspontjaiban, Természetvédelmi Közlemények, 17: pp. 1-11.

Kovács E., Pataki Gy., Kelemen E., Kalóczkai Á. (2011b): Az ökoszisztémaszolgáltatások fogalma a társadalomkutató szemszögéből, Magyar Tudomány, 172: (7) pp. 780-787.

Krajnyik Zs. (2008): Környezeti javak pénzbeli értékelése Magyarországon és Szlovákiában a feltételes választás módszerének alkalmazásával, Ph.D. disszertáció, BCE, Budapest

Krejdl, A., Banka, C. N. (2006). Fiscal Sustainability: Definition, Indicators and Assessment of Czech Public Finance Sustainability. Czech National Bank, Economic Research Department. Retrieved from https://www.cnb.cz/miranda2/ export/sites/www.cnb.cz/en/research/research_publications/cnb_wp/download/cnbwp_2006_03.pdf

Kuznets, S. (1971). 'Modern Economic Growth: Findings and Reflections. www.nobelprize.org/nobel_prizes/economics/laureates/, 14.

Kuznets, S. (1934): "National Income, 1929-1932". 73rd US Congress, 2d session, Senate document no. 124, p. 7. 
Kuznets, S. (1973). Modern economic growth: findings and reflections. The American Economic Review, 247-258.

Lancaster, K. J. (1966): A new approach to consumer society, Edward Elgar Publishing Limited.

Langeweg, F., Hilderink, H., Maas, R. (2000). Urbanisation, industrialisation and sustainable development. Retrieved from http://rivm.openrepository.com/ rivm/handle/10029/9461

Láng I. (ed.) (2002): Környezet- és természetvédelmi lexikon. (Encyclopaedia of Environment and Nature Protection). Akadémiai Kiadó, Budapest

Lankia, T., Neuvonen M., Pouta, E., Sievänen, T. (2014): Willingness to contribute to the management of recreational quality on private lands in Finland. Journal of Forest Economics, Volume 20, Issue 2, April 2014, 141-160.

Latouche, S. (2007): Petit traité de la décroissance sereine. Fayard

Layard, R. (2005): Happiness: Lessons from a New Science. Penguin Press, New York

Leonard-Barton, D. (1981): Voluntary simplicity lifestyles and energy conservation, Journal of Consumer Research, vol. 8, 243-252.

Liska, T. (1974). A környezetvédelem közgazdasági problémái. Budapest: MKKE, manuscript

Lloyd, W. F. (1833). Two lectures on the checks to population. Retrieved from https://www.google.com/books?hl=hu\&lr=\&id=kQt9Kg-chXAC\&oi=fnd\&pg=P A1\&dq=Lloyd,+William+Forster+(1833).+Two+lectures+on+the+checks+to+p opulation\&ots $=$ sgD8WzL7I0\&sig=dEo4UhtU-jKc7pVcLNqoyyGCeGA

Lovins, A. B., Lovins, L. H., Hawken, P. (1999). A road map for natural capitalism. Retrieved from https://www.google.com/books?hl=hu\&lr=\&id=nO9MMxT taeMC\&oi=fnd\&pg=PA250\&dq=Hawken,+Lovins, $+\% 26+$ Lovins, $+1999 \&$ ots=K xASv0VYlv\&sig=aLQYZNno2H7pNLS9jTb1DTo0Ozo

MAES (2016): Mapping and Assessment of Ecosystems and their Services. Mapping and assessing the condition of Europe's ecosystems: Progress and challenges. 3rd Report, Final. European Union.

Malthus, T. R. (1803). An Essay on the Principle of Population, or, A View of its Past and Present Effects on Human Happiness, with an Inquiry into our Prospects Respecting the Future Removal or Mitigation of the Evils which it Occasions. London 1803, Second Edition Cambridge, 1989: Cambridge University Press.

Marjainé Szerényi Zs. (2015): Economic valuation of non-market goods in Hungary - The cases of wetlands. Testing the benefit transfer method. Tudományos habilitációs előadás a Budapesti Corvinus Egyetemen. Budapest, 2015. május 6.

Marjainé Szerényi Zs. (2017): Az Ó-Dráva ökoszisztéma-szolgáltatásainak felmérése és az élőhely helyreállitásának várható hatásai az ökoszisztémaszolgáltatásokra. Manuscript. Készült a 'Transboundary cooperation for revi- 
talization of riverine habitat complex in Drava region within Natura 2000 sites' című 'LIFE13 NAT/HU/000388 LIFE Old-Drava' azonosítószámú pályázat keretében végzett projekthez. pp. 74.

Marjainé Szerényi Zs., Csutora M., Harangozó G., Krajnyik Zs., Kontár R., Nagypál N. (2005): A természetvédelemben alkalmazható közgazdasági értékelési módszerek. A Környezetvédelmi és Vízügyi Minisztérium Természetvédelmi Hivatalának Tanulmánykötete.

Marjainé Szerényi Zs., Kerekes S., Flachner Zs., Milton, S. (2011b): The possibility of the economic evaluation of ecosystem services described through a domestic case study. In: Gergő Gábor Nagy, Veronika Kiss (szerk.): Borrowing services from nature: Methodologies to evaluate ecosystem services focusing on Hungarian case studies. 137 p. Budapest: CEEweb for Biodiversity. pp. 6475. (ISBN:978-963-87218-7-7)

Marjainé Szerényi, Zs. (2005): A feltételes értékelés alkalmazhatósága Magyarországon. Akadémiai Kiadó, Budapest. (in Hungarian; The applicability of contingent valuation method in Hungary)

Marjainé Szerényi, Zs. (2011): Az ökoszisztéma-szolgáltatások közgazdaságtudományi megközelítése. Magyar Tudomány 174. évf., 2011/7., 788-794.

Marjainé Szerényi, Zs., Zsóka, Á., Rákosi J. (2011a): Implementation of water framework directive obligations in Hungary: Estimating benefits of development activities in two pilot areas, In: Roger L. Burritt, Stefan Schaltegger, Martin Bennett, Tuula Pohjola, Maria Csutora (szerk.): Environmental management accounting and supply chain management, 376 p., Dordrecht; Heidelberg; London; New York: Springer, 2011. pp. 301-315. (Eco-efficiency in industry and science; 27.) (ISBN:978 940071389 5)

Markandya, A., Haron, P., Bellú, L. G., Cistulle, V. (2002): Environmental Economics for Sustainable Growth. Handbook for Practioners. Edward Elgar, World Bank.

Marshall, A. (1947). Principles of Economics. London: Macmillan and Co 8thEdition (1920).

Marshall, J. D., Toffel, M. W. (2005). Framing the Elusive Concept of Sustainability: A Sustainability Hierarchy. Environmental Science and Technology 39, no. 3, 673-682.

Maslow, A. (1954): Motivation and Personality, Harper and Row, London, New York

Mat Said, A., Ahmadun, F.-R., Hj. Paim, L., \& Masud, J. (2003). Environmental concerns, knowledge and practices gap among Malaysian teachers. International Journal of Sustainability in Higher Education, 4(4), 305-313.

Mattern, C. (2013). Psychologie der Finanzmärkte. In Psychologie der Wirtschaft (pp. 863-882). Springer. Retrieved from http://link.springer.com/chapter/10.1007/978-3-531-18957-4_42 
Matthias and Steger, Ulrich (1998) Managing Outside Pressure, Strategies for Preventing Corporate Disasters John Wiley \& Sons Chichester, New York etc.

McKinsey and Company. 'Re Corporate Response to the Environmental Challenge'

Meadows, D. H., Meadows, D. L., Randers, J., \& Behrens, W. W. (1972). The limits to growth. New York, 102. Retrieved from https://www.google.com/ books?hl=hu\&lr=\&id=vb8_BAAAQBAJ\&oi=fnd\&pg=PA25\&dq=To+the+limits $+\mathrm{t}$ o+growth\&ots=7pozfOxdCh\&sig=2nTIOPMRU98PLZaDwrWnXXMhXIs

Meadows, D. H., Meadows, D., \& Randers, J. (1992). Beyond the Limits. Post Millis, Vermont: Chelsea Green Publishing Co

Meijkamp, R. (1998). Changing consumer behaviour through eco-efficient services: an empirical study of car sharing in the Netherlands Business Strategy and the Environment Volume 7 Issue 4 pages 234-244, September

Mendelsohn, R. (1984): Endogenous technical change and environmental regulation. Journal of Environmental Economics and Management, 11 (3), 202-207.

Milner-Gulland, E.J., Mace, R. (1998): Conservation of biological resources. Wiley-Blackwell

Mishan, E. J. (2007): Cost-Benefit Analysis. 5th Edition, Routledge

Mont, O. (2000). Product-Service Systems, Swedish Environmental Protection Agency. Stockholm: Sweden.

Mont, O., Bleischwitz, R. (2007). Sustainable consumption and resource management in the light of life cycle thinking. European Environment 17(1): 59-76.

Morelli, J. (1999): Voluntary Environmental Management: The Inevitable Future, Crc Press

Moser M., Pálmai Gy. (1999): A környezetvédelem alapjai; Nemzeti Tankönyvkiadó, Budapest

Mourato, S., Csutora M., Marjainé Szerényi Zs., Kerekes S., Pearce, D., Kovács E. (1999): A Balaton vízminőség-javítása értékének becslése a feltételes értékelés módszerével. Gazdaság, Vállalkozás, Vezetés 99/1. p.: 147-170.

Mulder, I. (2007): Biodiversity, the next challenge for financial institutions? Gland, Switzerland: The World Conservation Union (IUCN), Gland, Switzerland in collaboration with Alterra and FSD.

Munasinghe, M. (1993): Environmental Economics and Sustainable Development. Environment Paper No. 3. World Bank, Washington DC

Munasinghe, M. (1999). Is environmental degradation an inevitable consequence of economic growth: tunneling through the environmental Kuznets curve. Ecological Economics, 29(1), 89-109.

Munasinghe, M., O'Ryan, R., da Motta, R. S., de Miguel, C., Young , C., Miller, S., Ferraz, C. (2006): Macroeconomic Policies for Sustainable Growth: 
Analytical Framework and Policy Studies of Brazil and Chile Edward Elgar Cheltenham, UK; Northampton, MA, USA

Munkatermelékenység az EU-27-ben, ágazatonként és vállalati méretkategóriánként (2004-2005). (n.d.). Retrieved March 24, 2016, from http://www. ksh.hu/docs/hun/eurostat_tablak/tabl/tin00054.html

Nádasy, B., Ottman, M. (2010): Kollégiumi fenntarthatósági jelentés. BCE Ipari ökológia évfolyamdolgozat 2010. Manuscript, Budapest: BCE

Neck, R., Sturm, J.-E. (2008): Sustainability of Public Debt., MIT Press.

NÉS (2008): Nemzeti Éghajlatváltozási Stratégia 2008-2025. Forrás: http:// www.kormany.hu/download/9/67/10000/N\%C3\%89S_2008-2025.pdf

Neumann J., M., O. (1944). Theory of Games and Economic Behavior. New York; London; Sydney: John Wiley \& Sons, Inc. New York: Free Press, 1980.

Ng, Y.-K. (2008). Happiness Studies: Ways to Improve Comparability and Some Public Policy Implications. THE ECONOMIC RECORD, VOL. 84, NO. 265, JUNE,253-266.

Ng, S., Ng, Y.-K. (2001): Welfare-reducing Growth despite Individual and Government Optimization, Social Choice and Welfare 18, 497-506.

Ninan, K. N., Jyothis, S., Babu, P., Ramakrishnappa, V. (2007): The Economics of Biodiversity Conservation. Valuation in Tropical Forest Ecosystems. Earthcan

Nithart, Ch., Bossard, Ch. (2010): A vörösiszap katasztrófa (The red-mud catastrophe) Robin des Bois. Magyarország, 2010. december pp. 46.

NYME(2012): Theoretical considerations of evaluating economics of continuous cover forestry. (n.d.). http://www.erdtudkoz.hu/cikk.php?doi=2012.001\&ln=en

Pandeya, B., W. Buytaert, Z. Zulkafli, T. Karpouzoglou, F. Mao, D.M. Hannah (2016): A comparative analysis of ecosystem services valuation approaches for application at the local scale and in data scarce regions, Ecosystem Services, http://dx.doi.org/10.1016/j.ecoser.2016.10.015.

Pasinetti, L. L. (1998): The myth (or folly) of the 3\% deficit/GDP Maastricht 'parameter.' Cambridge Journal of Economics, 22(1), 103-116.

Pataki Gy., Kelemen E., Balázs B., Matolay R., Bela Gy., Fabók V., Kalóczkai Á., Kohlheb N., Kovács E., Kovács Krasznai E., Mertens, C. (2014): Amiről az örségi és vendvidéki erdő mesél... avagy változó értékek a változó tájban In: Kelemen E., Pataki Gy. (eds.) Ökoszisztéma szolgáltatások: A természet- és társadalomtudományok metszéspontjában. Gödöllő; Budapest: Szent István Egyetem, Környezet- és Tájgazdálkodási Intézet; Environmental Social Science Research Group (ESSRG), 2014. pp. 77-93.

Pearce, D. W. - Turner, R. K. (1990): Economics of Natural Resources and the Environment. Johns Hopkins University Press

Pearce, D. W. (1993): A modern közgazdaságtan ismerettára. Közgazdasági és Jogi K. 
Pearce, D., Atkinson, G. (1992): ARE NATIONAL ECONOMIES SUSTAIN$A B L E$ ? Measuring Sustainable Development. CSERGE Working Paper GEC, 92-110.

Pearce, D. W. - Markandya, A. - Barbier, E. B. (1989): Blueprint for a Green Economy. 1st Paperback Edition, Earthscan

Perman R., Yue, M. McGilvray J. (1996): Natural Resource and Environmental Economics. Longman, London and New York

Pickvanke, C. (2002). Local Environmental Regulation in Post-Socoalism: A Hungarian Case Study. Ashgate Publishing.

Pigou, A. C. (2013). The economics of welfare. Palgrave Macmillan. Retrieved from https://www.google.com/books?hl=hu\&lr=\&id=26kAAwAAQBAJ \&oi=fnd\&pg=PT10\&dq=Pigou+1920\&ots=z7s9kLYEid\&sig=Ahk4lzleVrHuZGle isZ5OINKQDc

Pirisi, G. (dátum nélk.). ttk.pte. Letöltés dátuma: 2013. november 24, forrás: http://tamop412a.ttk.pte.hu/files/foldrajz2/ch02s02.html

Plough, A., Krimsky, S. (1987): The emergence of risk communication studies in science and political context. Science Technology and Human Values 12, 4-10.

Pogutz, S., Tyteca, D., \& others. (n.d.). Business organisational response to environmental challenges: innovation. Retrieved from http://www.ucllouvain. be/cps/ucl/doc/iag/documents/WP_58_tyteca.pdf

Princen, T. (1997): The shading and distancing of commerce: When internalization is not enough; Ecological Economics 20, 235-253.

Rai, R. K., Scarborough, H. (2014): Nonmarket valuation in developing countries: incorporating labour contributions in environmental benefit estimates. Australian Journal of Agricultural and Resource Economics, 59, 479-498.

Read, D. (2001): Is time-discounting hyperbolic or subadditive? Journal of Risk and Uncertainty 23 (1), 5-32.

Rockström, J. et al. (2009). A safe operating space for humanity. Nature. Sept. p. $472-475$

Scharer, B. (1984): Wohin führen die „neuen Wege zu guter Luft'? Zur Diskussion der Emissions Zertifikate und Ihrer Abkömmlinge. Zeitschrift für Umweltpolitik, 1984. szeptember. 279-294.

Scholte, S. S., van Teeffelen, A. J. \& Verburg, P. H. (2015): Integrating sociocultural perspectives into ecosystem service valuation: a review of concepts and methods. Ecological Economics, 114, 67-78.

Schreurs, J. (2010): Living with less: Prospects for sustainability. Maastricht: Schrijen-Lippertz

Schumacher, E. F. (1973): Small is Beautiful, London: Blond \& Briggs

Sellen, A. J., Harper, R. H. (2003). The Myth of the Paperless Office. Cambridge: MIT Press Cambridge 
Seonaidh, M., Oates, C. (1999). Sustainability: Consumer Perceptions and Marketing Strategies. Business Strategy and Environmet, 209-217.

Seyfang, G. (2004). Consuming values and contested cultures: a critical analysis of the UK strategy for sustainable consumption and production. Review of Social Economy, 62(3), 323-338.

Shafik, N., Bandyopadhyay, S. (1992). Economic growth and environmental quality: Time series and crosscountry evidence, World Bank Policy Research Working Paper, WPS 904

Shama, A., Wisenblit J. (1984): Values of voluntary simplicity: Lifestyle and motivation, Psychological Reports, vol. 55, pp. 231-240.

Shi, D. (2007): The Simple Life: Plain Living and High Thinking in American Culture, Revised Edition, Athens, University of Georgia Press

Shyamsundar, P, Kramer, R. A. (1996): Tropical Forest Protection: An Empirical Analysis of the Costs Borne by Local People. Journal of Environmental Economics and Management 31, 129-144.

Singer, P. (1995): Animal Liberation; 2nd Edition, Pimlico

Smith, A. (2007 / 1776 ): An Inquiry into the nature and Causes of the Wealth of Nations. Amsterdam, New York: Edited by Sálvio M. Soares. MetaLibri, 2007, v.1.0s.

Somlyódy et al. (1998). Strategies for meeting the requirements of EU water legislation in the water sector (Hungary): The Sajó River case. In. Hungary: Meeting the Requirements of EU Environmental Legislation. Washington DC: World Bank.

Sorci, J. (n.d.). Trust and Investment Professionals: Avoid the Ponzi Trap. Retrieved March 24, 2016, from http://web.premierfinancial.com/blog/trustand-investment-professionals-avoid-the-ponzi-trap

Statisztikai Tükör (2012): A települések infrastrukturális ellátottsága, 2011. Statisztikai Tükör 6 (92), 26/11/2012

Steffen, W., Richardson, K., Rockström, J., Cornell, S. E., Fetzer, I., Bennett, E. M., ... Sörlin, S. (2015). Planetary boundaries: Guiding human development on a changing planet. Science, 347(6223), 1259855. http://doi.org/10.1126/ science. 1259855

Stern, D. I., Common, M. S., Barbier, E. B. (1996): Economic growth and environmental degradation: the environmental Kuznets curve and sustainable development. World Development, 24(7), 1151-1160.

Stern, N., \& others. (2007): The economics of climate change: the Stern report. Cambridge, UK.

Stevenson, B., Wolfers, J. (2008): Economic Growth and Subjective WellBeing: Reassessing the Easterlin Paradox. Brookings Papers on Economic Activity, 1-87. 
Straka, T. J., Bullard, S. H. (1996): Land expectation value calculation in timberland valuation. The Appraisal Journal 64 (4), 399-405.

Swaney, J. A., Evers, M. A. (1989): The Social Cost Concepts of K. William Kapp and Karl Polanyi. Journal of Economic Issues 23 (1), 7-33.

Szlávik, J. (2013). Fenntartható gazdálkodás. Budapest: CompLex

Takács Dániel (2016): Városi szabadterek és szabadtér-fejlesztések ingatlanérték-befolyásoló hatásának elemzése Budapest példáján. Doktori értekezés. SZENT ISTVÁN EGYETEM.

Takács-Sánta A. (2017): Építőkockák egy új világhoz - Ökológia, közösség, boldogulás - helyben! Andron Könyv Kft., Budapest

Thoreau, H. D. (1854/1989): Walden, Princeton University Press (first published in 1854);

Tietenberg, T. (1992): Environmental and Natural Resource Economics. 3rd Edition, HarperCollins

Tilahun, M., L. Vranken, B. Muys, J. Deckers, K. Gebregziabher, K. Gebrehivot, H. Bauer and E. Mathijs (2013): Rural Households' demand for Frankincense forest conservation in Tigray, Ethiopia: a contingent valuation analysis. Land Degradation \& Development. DOI: 10.1002/Idr.2207

Tóth, G., Szigeti, C. (2016): The historical ecological footprint: From overpopulation to over-consumption. Ecological Indicators 60, 283-291.

Treasury, H. M. (2003): The green book. Appraisal and Evaluation in Central Government.

Turner, R. K., Pearce, D., Bateman, I. (1993): Environmental Economics: An Elementary Introduction. Johns Hopkins University Press

U.S. Bureau of Mines/U.S. Geological Survey mineral and coal resource and reserve categories. (From U.S. Department of the Interior news release, 'New Mineral and Coal Resource Terminology Adopted' May 26, 1976

UNDP (1990): Human Development Report 1990. United Nations Development Programme, Oxford University Press, New York, Oxford

US EPA, O. (n.d.). Air Quality Analysis [Data and Tools]. Retrieved March 24, 2016, from https://www.epa.gov/air-quality-analysis

Van Alstine, J., Neumayer, E. (2010): The environmental Kuznets curve. In: Gallagher, K. P., (ed.): Handbook on trade and the environment. Elgar original reference. Edward Elgar, Cheltenham, UK, pp. 49-59.

Vargáné Csobán, K. (2005/16). A turizmus fenntarthatóságának értékelése. Agrártudományi Közlemények, 414-421.

Vastag Gy., Kerekes S., Rondinelli, D. A. (1996): Evaluation of corporate environmental management approaches: A framework and application. International Journal of Production Economics, 43 (2-3). pp. 193-211.

Vastag Gy., Rondinelli, D. A., Kerekes, S. (1996): How Corporate Executives Perceive Environmental Issues: Hungarian and Global Companies. Journal of Euromarketing 5 (3), 5-27. 
Vida G. (2012): Honnan hová Homo? Az Antropocén korszak gondjai; Semmelweis, Budapest

Vorosmarty, C. (ed.) (1991): Beyond Oil: The Threat to Food and Fuel in the Coming Decades 3rd Edition, Univ Pr. of Colorado; 3rd edition

Wackernagel, M., Monfreda, C., Moran, D., Wermer, P., Goldfinger, S., Deumling, D., Murray, M.: National Footprint and Biocapacity Accounts 2005: The underlying calculation method, Global Footprint Network May 25, 2005

Wackernagel, M., Rees, W. E. (2006): Ökológiai lábnyomunk - Hogyan mérsékeljük az ember hatását a Földön?; Föld Napja Alapítvány, Budapest

Walker, B. C. (2004): Resilience, adaptability and transformability in socialecological systems. Ecology and Society, 9(2): 5.

Walker, B. H., Anderies, J. M., Kinzig, A. P., Ryan, P. (2006): Exploring resilience in social-ecological systems through comparative studies and theory development: introduction to the special issue. Ecology and Society, 11(1), 12.

Walker, B., Holling, C. S., Carpenter, S. R., - Kinzig, A. (2004). Resilience, adaptability and transformability in social-ecological systems. Ecology and Society, 9(2), 5 .

Watts, G. (1993) 'A Framework for Environmental Management.' Focus on Physical Distribution and Logistics Management, vol.12, no.2 March 1993, pp. 2-5.

Weitzman, M. L. (1974): Prices vs. Quantities, Rev. Economic Studies. Oct., 41 (49), pp. 102-109.

Weizsäcker, E.U., Lovins, A.B., Lovins, L.H. (1997): Faktor Vier. Doppelter Wohlstand - halbierter Naturverbrauch. Droemer Knaur

Welford, R., Gouldson, A. (1992): Environmental Management and Business Strategy.

Whittington, D. (2010): What have we Learned from 20 Years of Stated Preference Research in Less-Developed Countries? The Annual Review of Resource Economics, 2:209-36.

Wolfbauer, C. A. (1977): Mineral resources for agricultural uses. Agriculture and Energy, 301-314.

World Bank (1992): World Development Report 1992, Development and the Environment. Oxford: Oxford University Press

World Economic Forum (2011): Global Risks 2011. 6th Edition https://www. scribd.com/document/46770255/Riesgos-Globales-Del-2011 (accessed on 25/04/2018)

Wüstenhagen, R., Bilharz, M. (2006): Green Energy Market Development in Germany: Effective Public Policy and Emerging Customer Demand. Energy Policy, 34 Nr 13, S. 1681-1696.

Wynne, B. (1993): 'Uncertainty and Environmental Learning-reconceiving science and policy in the preventive paradigm.' In Clean Production Strategies, edited by T. Jackson, 63-84. Boca Raton, Florida: Lewis Publishers 
Yandle, B., Vijayaraghavan, M., Bhattarai, M. (2008). The Environmental Kuznets Curve: APrimer. The Property and Environment Research Center, Retrieved, 16.

York, R. (2006). Ecological Paradoxes: William Stanley Jevons and the Paperless Office. Human Ecology Review, Vol. 13, No. 2, 143-147.

York, R., Rosa, E. A., Dietz, T. (2003). STIRPAT, IPAT and ImPACT: analytic tools for unpacking the driving forces of environmental impacts. Ecological economics, 46(3), 351-365.

Zamagni, S., Scazzieri, R., Sen, A. (2008): Markets, money and history. Essays in honor of Sir John Hicks. Cambridge (UK): Cambridge University Press 


\section{Sustainability,}

\section{environmental economics,}

welfare

Sustainability, environmental economics, welfare is an advanced, thought-provoking and comprehensive treatise on sustainability, environmental science, environmental economics, and environmental management, visiting and revisiting historical, present and developing theories, policies, practices and understandings regarding natural capital, agriculture, human welfare, population, environment, pollution, wealth, life, happiness, competition, consumption, cooperation, carrying capacity, ecology, ecosystem services, economic valuation, environmental externalities, risk, ecological footprint, economic growth, GDP and voluntary simplicity.

This is an encyclopaedic resource that identifies and examines the environmental aspects of sustainability, the problems with our current measures, the inappropriateness of our assumptions regarding the appropriateness of pollution, the "sin" of dominant paradigms, and continues on to examine key socio-economic models of quality of life and human development, considering many "if" statements regarding the extent and pace of development. It presents visions for possible (sustainable) paths forward, suggesting alternative assessments and principles to follow to keep the economy within the limits of Earth's carrying capacity. It includes an excellent discussion on resilience, limits and ecological footprint and an outstanding description of total economic valuation.

John Morelli, PhD, PE

Professor Emeritus, Environmental Management \& Technology Rochester Institute of Technology 